\title{
Interprofessional collaboration in primary care teams
}

\author{
Citation for published version (APA):
}

van Dongen, J. J. J. (2017). Interprofessional collaboration in primary care teams: development and evaluation of a multifaceted programme to enhance patient-centredness and efficiency. [Doctoral Thesis, Maastricht University]. Maastricht University. https://doi.org/10.26481/dis.20171215jvd

Document status and date:

Published: 01/01/2017

DOI:

10.26481/dis.20171215jvd

Document Version:

Publisher's PDF, also known as Version of record

\section{Please check the document version of this publication:}

- A submitted manuscript is the version of the article upon submission and before peer-review. There can be important differences between the submitted version and the official published version of record.

People interested in the research are advised to contact the author for the final version of the publication, or visit the DOI to the publisher's website.

- The final author version and the galley proof are versions of the publication after peer review.

- The final published version features the final layout of the paper including the volume, issue and page numbers.

Link to publication

\footnotetext{
General rights rights.

- You may freely distribute the URL identifying the publication in the public portal. please follow below link for the End User Agreement:

www.umlib.nl/taverne-license

Take down policy

If you believe that this document breaches copyright please contact us at:

repository@maastrichtuniversity.nl

providing details and we will investigate your claim.
}

Copyright and moral rights for the publications made accessible in the public portal are retained by the authors and/or other copyright owners and it is a condition of accessing publications that users recognise and abide by the legal requirements associated with these

- Users may download and print one copy of any publication from the public portal for the purpose of private study or research.

- You may not further distribute the material or use it for any profit-making activity or commercial gain

If the publication is distributed under the terms of Article $25 \mathrm{fa}$ of the Dutch Copyright Act, indicated by the "Taverne" license above, 


\section{Interprofessional collaboration in primary care teams}

Development and evaluation of a multifaceted programme to enhance patient-centredness and efficiency 
The research presented in this dissertation was conducted at the:

School for Public Health and Primary Care (CAPHRI), Department of Family Medicine, Maastricht University. CAPHRI participates in the Netherlands School of Primary Care Research (CaRe), acknowledged by the Royal Dutch Academy of Science (KNAW). CAPHRI was classified as 'excellent' by the external evaluation committee of leading international experts that reviewed CAPHRI in December 2010.

and

Centre of Research: Autonomy and Participation of people with chronic illness, Faculty of Health, Zuyd University of Applied Sciences, Heerlen, the Netherlands.

The research presented in this dissertation was funded by Stichting Innovatieve Alliantie, RAAKPRO (grant number PRO-3-36).

The printing of this thesis was financially supported by eGPO (Elektronisch Gestructureerd Patiënten Overleg).

All rights are reserved. No part of this book may be reproduced or transmitted in any form or by any means, without the written permission from the author or, where appropriate, the publisher of the article.

C Jerôme van Dongen, Maastricht 2017
Layout: Tiny Wouters
Cover design: Harrie Habets
Illustrations: Harrie Habets
Printed by: $\quad$ Gildeprint - Enschede

ISBN: 978-94-6233-818-0 


\section{Interprofessional collaboration}

\section{in primary care teams}

Development and evaluation of a multifaceted programme to enhance

patient-centredness and efficiency

\section{PROEFSCHRIFT}

ter verkrijging van de graad van doctor aan de Universiteit Maastricht, op gezag van de Rector Magnificus, Prof. dr. Rianne M. Letschert, volgens het besluit van het College van Decanen,

in het openbaar te verdedigen

op vrijdag 15 december 2017 om 10.00 uur

door

Jerôme Jean Jacques van Dongen 


\section{Promotores}

Prof. dr. A.J. Beurskens

Prof. dr. T. van der Weijden

\section{Co-promotores}

Dr. M.A. van Bokhoven

Dr. R. Daniëls (Zuyd Hogeschool, Heerlen)

\section{Beoordelingscommissie}

Prof. dr. J.W.M. Muris (voorzitter)

Prof. dr. D.H.J.M. Dolmans

Prof. dr. P. van Royen (Universiteit Antwerpen)

Prof. dr. D. Ruwaard

Dr. C. Smits (Windesheim, Zwolle) 


\section{Contents}

Chapter 1 General introduction

Chapter 2 Developing interprofessional care plans in chronic care:

a scoping review

BMC Fam Pract 2016;17:137

Chapter 3 Interprofessional collaboration regarding patients' care plans in

primary care: a focus group study into influential factors

BMC Fam Pract 2016;17:58

Chapter 4 Interprofessional primary care team meetings: a qualitative approach comparing observations with personal opinions Fam Pract. 2017;34(1):98-106

Chapter 5 Successful participation of patients in interprofessional team meetings: a qualitative study Health Expect 2016

Chapter 6 "They are talking about me, but not with me". A focus group study 101 to explore the patient perspective on interprofessional team meetings in primary care

Patient 2017

Chapter 7 Development of a customizable programme for improving interprofessional team meetings. An action research approach under review

Chapter 8 Suitability of a programme for improving interprofessional primary care team meetings Submitted

Chapter 9 Sustainable interprofessional teamwork needs a team-friendly healthcare system: Experiences from a collaborative Dutch programme Journal of Interprofessional Care. 2017;33(2):167-169

Chapter 10 General discussion 
Samenvatting

Valorisation

Dankwoord

About the author

255

List of publications 


\section{Chapter 1}

General introduction

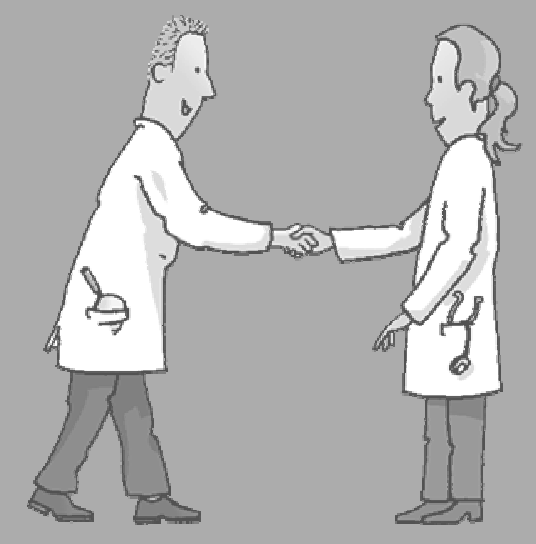





\section{General introduction}

\section{Increasing complexity of chronic care}

Health care systems world-wide are being challenged by an ageing population, and consequently by an increasing prevalence of chronic conditions such as type 2 diabetes, chronic obstructive pulmonary disease or mobility problems. ${ }^{1}$ About $30 \%$ of the European population are suffering from a chronic disease. ${ }^{2}$ Moreover, patients increasingly have to cope with two or more chronic conditions simultaneously, which is referred to as multimorbidity. Multimorbidity is recognized as a major public health challenge, since this category of patients appears to be at greater risk of adverse health outcomes, often resulting in complex care demands. ${ }^{3,4}$ Oostrom et al. showed (based on data from 2002-2008) that multimorbidity of chronic diseases affected $13 \%$ of the Dutch population and $37 \%$ of those older than 55 years. ${ }^{5}$ In addition to physical and mental challenges, patients are increasingly confronted with problems in their social situation, e.g. a limited social network, lack of participation and loneliness. Hence, it is not surprising that professionals are often confronted with patients whose social situation is as much a threat to their health or recovery as the illness itself. ${ }^{6}$ Improved integration of the physical, mental and social aspects of care seems essential for the provision of patient-centred care. ${ }^{6}$ Moreover, the care of patients with complex needs can be delivered more efficiently, and can be tailored to their specific needs, if patients are involved in their own care process. ${ }^{7}$ Determining the degree to which patients are able and willing to control their own daily life, known as self-management, can be considered an essential part of chronic care. ${ }^{8}$ Supporting the self-management abilities of these patients enables them to live independently and participate in society. Support of selfmanagement is also one of the key elements of the chronic care model, which guides towards higher-quality management of chronic conditions within primary care. ${ }^{9}$ According to the chronic care model, optimal chronic care is achieved when a wellprepared proactive practice team interacts with an informed, activated patient. ${ }^{10}$

\section{Primary care setting}

In recent years, the care of people suffering from chronic diseases in the Netherlands has been shifting from secondary to primary care. ${ }^{11}$ Moreover, as a result of improvements in medical care and technology, patients suffering from chronic conditions have a longer life expectancy and often use primary care for longer periods of time. Professionals in primary care will therefore be confronted with a substantial increase in workload, especially regarding patients with complex problems. ${ }^{11}$ In many countries, most of the daily care for people with chronic conditions is delivered in the 
primary care setting by a range of health care professionals from different disciplines. ${ }^{12}$ In Dutch primary care, the family physician can be regarded as a central figure within a network of professionals taking care of one patient. Hospital care in the Netherlands care is only accessible through referral by the family physician. There is evidence that a well-established primary care system is associated with better health outcomes, lower costs and more equity in health. ${ }^{13}$ Features that have been described as defining features of primary care include the provision of generalistic, person-centred care, first contact and open access, and the continuity and coordination of care through collaboration between a variety of disciplines. ${ }^{14}$ Furthermore, primary care implies a stronger focus on the patient in his or her own environment, and on daily functioning, compared to specialist care which is more focused on the treatment of the disease. ${ }^{14}$

\section{Patient-centredness}

Governments and care organisations are increasingly recognizing the need to focus on the patient as a whole, and aim to embrace a patient-centred approach to the provision of health care. ${ }^{15}$. They emphasise the need for health care to be more explicitly aimed at the patients' individual demands. A patient-centred care approach, which is known to be associated with improved health status and efficiency of care, ${ }^{16}$ has been described in different ways. ${ }^{17}$ However, three key elements were distinguished by Kitson and colleagues: patient participation and involvement, the relationship between patient and professional and the context in which care is delivered. ${ }^{15}$ Professionals have a substantial role to play in stimulating patient involvement and self-management and enabling patients to become effective managers of their own lives, tailored to their needs and capabilities. ${ }^{8}$ Programmes directed at self-management support incorporate goal setting as an important feature, as it is associated with enhancing patient autonomy. ${ }^{18}$ Goal setting can be defined as the agreement between (health care) professionals and patients on health-related goals. ${ }^{19}$ In order to set goals for different domains of functioning together with their patients, professionals need to obtain a more complete understanding of a patient's situation, preferences and individual needs. To achieve this, they need to move from a traditional, illness-oriented professional perspective to a broader patient perspective on daily functioning. In such a holistic model of illness and disabilities, supporting people to remain active and able to take part in meaningful activities is of equal importance as managing the disease and preventing deterioration. ${ }^{20}$ The World Health Organization (WHO) translated this development into the International Classification of Functioning, Disability and Health (ICF). ${ }^{21}$ The ICF divides functioning into a number of health and health-related domains. These domains comprise health conditions, body functions, activities and participation, but also include 
environmental and personal factors influencing overall functioning. On the whole, ICF provides a shared language and conceptual framework that transcends traditional disciplinary boundaries. ${ }^{22}$

\section{Interprofessional collaboration}

Facilitating the shift from disease-oriented to more patient-centred care requires collaboration and mutual alignment of care by proactive practice teams. ${ }^{23}$ In this respect, delivering patient-centred care close to the patients' home environment, to ensure that patients can live the life they desire, requires integration of care and collaboration with the patient system, including informal caregivers, partners, children or designated health professionals, and among the different professionals involved. ${ }^{17}$ The collaboration between professionals from a range of disciplines is known as interprofessional collaboration. As early as 1988, the WHO called for more interprofessional collaboration to achieve a less fragmented and more effective approach to complex health problems. Nowadays, health care delivery models clearly envision teams of professionals working together to meet patient needs. ${ }^{24}$ Based on the terminology of the Centre for the Advancement of Interprofessional Education (CAIPE), Morgan and colleagues (2015) defined interprofessional collaboration as:

"An active and ongoing partnership between people from diverse backgrounds with distinctive professional cultures and possibly representing different organisations or sectors who work together to solve problems or provide services" ${ }^{25}$

Alternative terms used by researchers and professionals are 'interdisciplinary collaboration', 'multidisciplinary collaboration', 'interprofessional practice' and 'interprofessional teamwork'. ${ }^{26}$ Compared to the description of the most commonly used term, multidisciplinary collaboration, interprofessional collaboration involves a deeper level of working together, characterised by intensive interactions between participants and the development of a shared care plan. An integrated approach to care through interprofessional collaboration is positively associated with the provision of safe and high-quality health and social care services. ${ }^{27,28}$ It is also widely accepted that a professional from a single discipline is not able to deal with the complexity associated with the care demands of people with goals in various domains. Care standards and guidelines also describe the relevance of patient-centredness and coordination and collaboration among professionals from different disciplines. Conversely, poor interprofessional collaboration can negatively affect the delivery of health services. ${ }^{27}$ By 
jointly developing care plans, professionals are able to merge their perspectives and tailor their care to the patients' needs, preferences and values. A patient-centred care plan is defined as 'a shared document including a patient's current and preferred situation, as well as personal goals and actions'. ${ }^{29,30}$

\section{Interprofessional collaboration in primary care practice}

Within the primary care setting, health care professionals are used to developing their own discipline-specific care plans, and developing shared care plans requires interprofessional collaboration. In primary care practice, interprofessional collaboration occurs at different places and is implemented in several ways. To ensure coordination of care, professionals from various disciplines collaborate through a broad range of consultations, meetings, bilateral discussions, whether ad hoc or in a systematic way. ${ }^{31}$ In many cases, periodic interprofessional team meetings are conducted to discuss patients with complex problems. To illustrate, an average team may comprise family physicians, practice nurses, occupational therapists, physical therapists and district nurses. It is becoming clear that interprofessional collaboration by means of team meetings can be considered a meaningful strategy for coordinating care, developing patient-centred care plans and consequently dealing with the increasing complexity of chronic care. However, providing patient-centred care for the increasing number of people with complex care demands remains a major challenge to primary care. ${ }^{32,33}$ Unfortunately, current practice rarely promotes a patient's active engagement in his or her health through self-management. ${ }^{33}$ Professionals find it difficult to support selfmanagement by their chronically ill patients, especially as regards the process of interprofessional collaboration. ${ }^{34,35}$ Moreover, conducting efficient interprofessional collaboration in practice is perceived as rather complex, since it is influenced by interrelated factors regarding structure, organisation, interaction and context. ${ }^{36-40}$ Consequently, the current approach to the care for people with complex care demands lacks patient-centredness and is often poorly coordinated, fragmented and inefficient. $^{33,41}$

Enhancing interprofessional collaboration is clearly perceived as a useful strategy for the development of patient-centred care plans, but it appears difficult to achieve properly in practice. ${ }^{36}$ Before current practice can be improved, more information is needed on the way efficient and patient-centred interprofessional care should be achieved in practice. 


\section{Aim of this thesis}

The aim of the research reported on in this thesis was to explore the key factors for improving primary care professionals' interprofessional collaboration for the development of patient-centred care plans. This thesis reports on three phases, including eight studies, as outlined in Figure 1.1, starting by exploring the field of interprofessional collaboration and an in-depth problem analysis of current practice (phase 1), followed by a programme development process characterised by co-creation with intended users (phase 2), and finally evaluation of the resulting programme (phase 3). The research questions for each phase are:

\section{Phase 1}

1. What is known in the scientific literature about developing interprofessional shared care plans?

2. What factors influence the development of interprofessional shared care plans?

3. How are interprofessional team meetings currently conducted in Dutch primary care, and what are the participants' experiences?

4. How do patients and professionals experience patient participation in interprofessional team meetings?

5. What is the patients' perspective on interprofessional team meetings in primary care?

\section{Phase 2}

6. What are the key elements of a programme to improve interprofessional team meetings in primary care?

\section{Phase 3}

7. What are the critical factors determining the suitability and potential impact of a programme to improve the functioning of interprofessional team meetings?

8. What are the contextual facilitators of and barriers to a sustainable implementation of interprofessional teamwork in a primary care setting? 


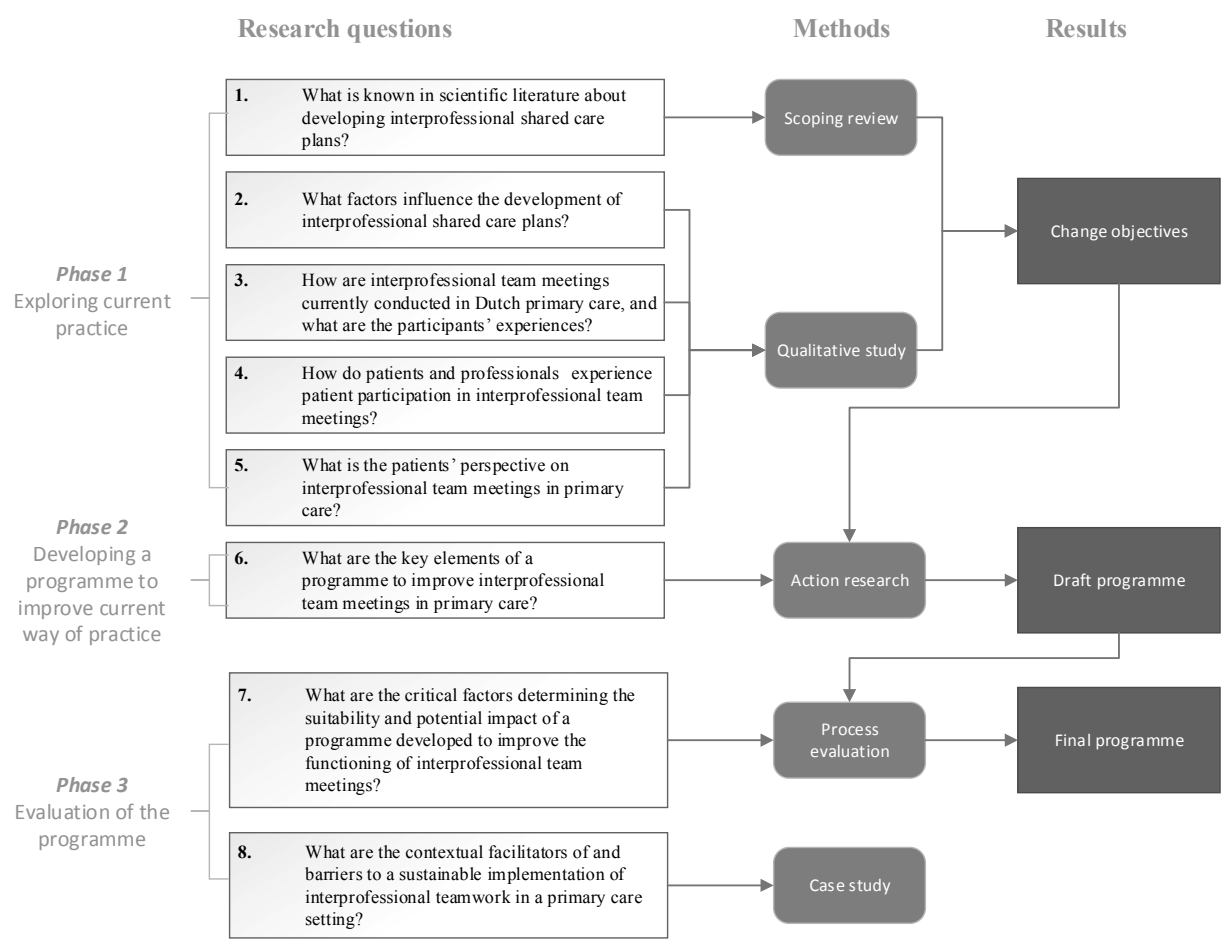

Figure 1.1 The systematic approach of the entire thesis project.

The development of the methodologies of the various studies reported on in this thesis was based on the basic assumptions and theoretical background of the social constructivist paradigm. Social constructivism explains reality as an ongoing dynamic process, reproduced by individuals acting on the basis of their interpretation and knowledge. ${ }^{42}$ The social constructivist approach often relies on naturalistic methods. Therefore, and based on the principles of naturalistic inquiry, ${ }^{43}$ we applied a primarily qualitative research design using observations and interviews in natural practice settings for data collection. In the light of social constructivism, the methodology of some studies was based on social constructionism, ${ }^{44}$ in which social interaction between people leads to the development of knowledge. The findings of the scoping review and qualitative studies have been translated into a programme, developed through action research and characterised by co-creation with different stakeholders. Finally, the programme was evaluated by means of a process evaluation in six primary care practices. Furthermore, contextual facilitators of and barriers to a sustainable implementation of interprofessional teamwork were explored by means of a case study. 


\section{Thesis outline}

Chapter 2 describes the scoping review used to identify currently available scientific literature on developing interprofessional shared care plans. Chapter 3 addresses several factors influencing interprofessional collaboration for care plan development. A qualitative study was performed including four focus group meetings with health care professionals, patient representatives and experts in the field of interprofessional collaboration. Chapter 4 presents a qualitative study on the current working methods within interprofessional primary care team meetings and the experiences of team members. Current practice was observed and compared with team members' personal opinions as explored by interviewing them individually immediately afterwards Chapter 5 discusses patient participation in interprofessional team meetings in various settings. A qualitative study including observations and interviews was conducted to examine the current professional practices and experiences of both professionals and patients. Chapter 6 specifically addresses the patients' perspective on interprofessional team meetings in primary care, based on a qualitative study with a focus group design. Chronically ill patients who had been involved in interprofessional collaboration were asked for their viewpoints, expectations and concerns regarding team meetings, after having watched video vignettes of different meetings.

The results of the studies in Chapters 2, 3, 4, 5 and 6 were used as input for the next study, reported on in Chapter 7. This chapter describes the development and final content of the programme to improve professional collaboration. As part of the development process, different teams took part in an action research approach. This iterative process involved testing and evaluating the draft version of the programme in three primary care teams. Chapter 8 describes the process evaluation and potential impact of the programme after implementation in six primary care teams. Chapter 9 addresses external factors influencing the implementation of sustainable interprofessional teamwork in a case study.

Chapter 10 discusses the main findings and methodological considerations in the light of existing literature, and defines lessons learnt and recommendations for future research. 


\section{References}

1. WHO. Global Status Report on noncumminicable diseases 2014. World Health Organization, 2014.

2. Robustill S, Corsini V, Marcu M, Vasileva K, Marchetti E. EU employment and social situation, quarterly review. In: Union E, editor. Luxembourg: Publications Office of the European Union; 2013.

3. Wallace E, Salisbury C, Guthrie B, Lewis C, Fahey T, Smith SM. Managing patients with multimorbidity in primary care. BMJ. 2015;350:h176.

4. Mercer SW, Smith SM, Wyke S, O'Dowd T, Watt GC. Multimorbidity in primary care: developing the research agenda. Fam Pract. 2009;26(2):79-80.

5. van Oostrom SH, Picavet HS, van Gelder BM, Lemmens LC, Hoeymans N, van Dijk CE, et al. Multimorbidity and comorbidity in the Dutch population - data from general practices. BMC Public Health. 2012;12:715.

6. Peek CJ. Integrating care for persons, not only diseases. J Clin Psychol Med Settings. 2009;16(1):13-20.

7. Holman H, Lorig K. Patients as partners in managing chronic disease. BMJ. 2000;320:526-7.

8. Wagner EH, Bennett SM, Austin BT, Greene SM, Schaefer JK, Vonkorff M. Finding common ground: patient-centeredness and evidence-based chronic illness care. J Altern Complement Med. 2005;11 Suppl 1:S7-15.

9. Bodenheimer T, Wagner EH, Grumbach K. Improving primary care for patients with chronic illness: the chronic care model, Part 2. JAMA. 2002;288(15):1909-14.

10. Bodenheimer T, Wagner EH, Grumbach K. Improving primary care for patients with chronic illness. JAMA. 2002;288(14):1775-9.

11. Jansen D, Spreeuwenberg P, Heijmans M. Developments in the care for people with chronic conditions Report 2012. Utrecht: NIVEL, 2012.

12. Grumbach K, Bodenheimer T. A primary care home for Americans: putting the house in order. JAMA. 2002;288(7):889-93.

13. Rawaf S, De Maeseneer J, Starfield B. From Alma-Ata to Almaty: a new start for primary health care. Lancet. 2008;372(9647):1365-7.

14. Wiegers T, Hopman P, Kringos D, de Bakker D. Nivel Overzichtstudies: de eerste lijn. Utrecht: NIVEL, 2011.

15. Kitson A, Marshall A, Bassett K, Zeitz K. What are the core elements of patient-centred care? A narrative review and synthesis of the literature from health policy, medicine and nursing. J Adv Nurs. 2013;69(1):4-15.

16. Stewart M, Brown JB, Donner A, McWhinney IR, Oates J, Weston WW, et al. The impact of patientcentered care on outcomes. J Fam Pract. 2000;49(9):796-804.

17. Mead N, Bower P. Patient-centred consultations and outcomes in primary care: a review of the literature. Patient Educ Couns. 2002;48(1):51-61.

18. Lorig KR, Holman H. Self-management education: history, definition, outcomes, and mechanisms. Ann Behav Med. 2003;26(1):1-7.

19. Bodenheimer T, Handley MA. Goal-setting for behavior change in primary care: an exploration and status report. Patient Educ Couns. 2009;76(2):174-80.

20. Goering S. Rethinking disability: the social model of disability and chronic disease. Curr Rev Musculoskelet Med. 2015;8(2):134-8.

21. WHO. International Classification of Functioning, Disability and Health: ICF. Geneva: World Health Organization; 2001.

22. Allan CM, Campbell WN, Guptill CA, Stephenson FF, Campbell KE. A conceptual model for interprofessional education: The international classification of functioning, disability and health (ICF). J Interprof Care. 2006;20(3):235-45.

23. Van Royen $\mathrm{P}$, Rees CE, Groenewegen P. Patient-centred interprofessional collaboration in primary care: challenges for clinical, educational and health services research. An EGPRN keynote paper. Eur J Gen Pract. 2014;20(4):327-32.

24. Decter M. Health care renewal in Canada: accelerating change. Healthc Q. 2005;8(2):34-5. 
25. Morgan S, Pullon S, McKinlay E. Observation of interprofessional collaborative practice in primary care teams: An integrative literature review. Int J Nurs Stud. 2015;52(7):1217-30.

26. Bookey-Bassett S, Markle-Reid M, McKey CA, Akhtar-Danesh N. Understanding interprofessional collaboration in the context of chronic disease management for older adults living in communities: a concept analysis. J Adv Nurs. 2017;73(1):71-84.

27. Zwarenstein M, Goldman J, Reeves S. Interprofessional collaboration: effects of practice-based interventions on professional practice and healthcare outcomes. The Cochrane database of systematic reviews. 2009(3):CD000072.

28. Ouwens M, Wollersheim H, Hermens R, Hulscher M, Grol R. Integrated care programmes for chronically ill patients: a review of systematic reviews. Int J Qual Health Care. 2005;17(2):141-6.

29. Newbould J, Burt J, Bower P, Blakeman T, Kennedy A, Rogers A, et al. Experiences of care planning in England: interviews with patients with long term conditions. BMC Fam Pract. 2012;13:71.

30. Trivedi D, Goodman C, Gage H, Baron N, Scheibl F, lliffe S, et al. The effectiveness of inter-professional working for older people living in the community: a systematic review. Health Soc Care Ccommunity. 2013;21(2):113-28.

31. Hansen J, van Greuningen M, Batenburg RS. Monitor multidisciplinaire samenwerking binnen de eerste lijn (Monitoring system for multidisciplinary collaboration in primary care). Utrecht: NIVEL, 2010.

32. Bleijenberg N, Drubbel I, Schuurmans MJ, Dam HT, Zuithoff NP, Numans ME, et al. Effectiveness of a Proactive Primary Care Program on Preserving Daily Functioning of Older People: A Cluster Randomized Controlled Trial. J Am Geriatr Soc. 2016;64(9):1779-88.

33. Boult C, Wieland GD. Comprehensive primary care for older patients with multiple chronic conditions: "Nobody rushes you through". JAMA. 2010;304(17):1936-43.

34. van Dijk-de Vries A. Towards integrated nurse-led self-management support in routine diabetes care. Maastricht: Maastricht University; 2015. Available from: https://cris.maastrichtuniversity.nl/portal/ files/573394/guid-48083a29-ac17-4f7c-8f1a-2b6ae680715b-ASSET2.0.

35. Metzelthin SF. An interdisciplinary primary care approach for frail older people. Maastricht: Maastricht University; 2014. Available from: http://digitalarchive.maastrichtuniversity.nl/fedora/get/guid:bae7aba12b03-43dc-b3aa-87aa60642586/ASSET1.

36. Xyrichis A, Lowton K. What fosters or prevents interprofessional teamworking in primary and community care? A literature review. Int J Nurs Stud. 2008;45(1):140-53.

37. Kennedy N, Armstrong C, Woodward O, Cullen W. Primary care team working in Ireland: a qualitative exploration of team members' experiences in a new primary care service. Health Soc Care Community. 2015;23(4):362-70.

38. Jaruseviciene L, Liseckiene I, Valius L, Kontrimiene A, Jarusevicius G, Lapao LV. Teamwork in primary care: perspectives of general practitioners and community nurses in Lithuania. BMC Fam Pract. 2013;14:118.

39. Smith-Carrier T, Neysmith S. Analyzing the interprofessional working of a home-based primary care team. Can J Aging. 2014;33(3):271-84.

40. Martin-Rodriguez LS, Beaulieu M-D, D'amour D, Ferrada-Videla M. The determinants of succesful collaboration: A review of theoretical and empirical studies. J Interprof Care. 2005;1:132-47.

41. Schoen C, Osborn R, Squires D, Doty M, Pierson R, Applebaum S. New 2011 survey of patients with complex care needs in eleven countries finds that care is often poorly coordinated. Health Aff (Millwood). 2011;30(12):2437-48.

42. Thomas, A., et al., Applications of social constructivist learning theories in knowledge translation for healthcare professionals: a scoping review. Implement Sci, 2014;9:54.

43. Lincoln YS, Guba EG. Naturalistic Inquiry. Newburry Park: SAGE; 1985.

44. Berger L, Luckmann T. The social construction of reality. 1966, USA: Penguin Books. 


\section{Chapter}

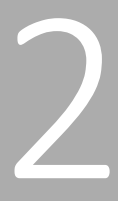

Developing interprofessional care plans in chronic care:

a scoping review

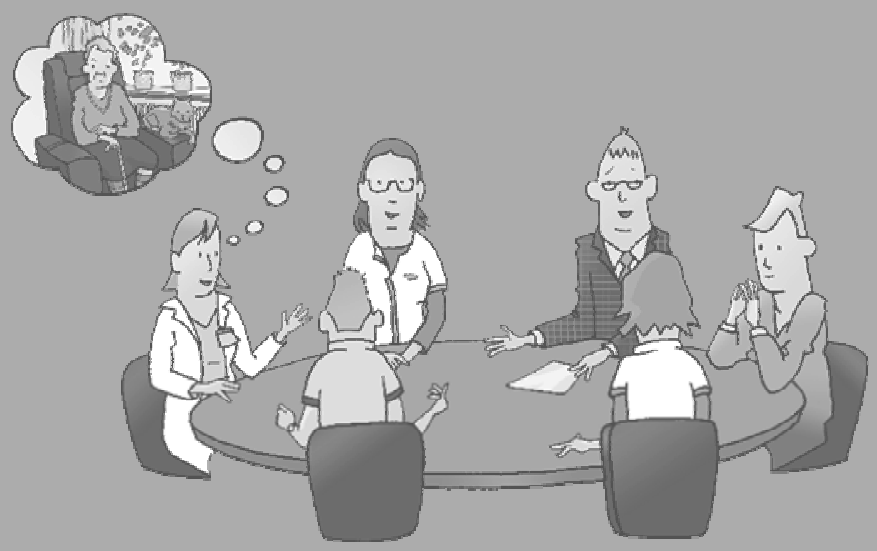

Jerôme van Dongen Loes van Bokhoven Ramon Daniëls Trudy van der Weijden Wencke Emonts Sandra Beurskens 


\section{Abstract}

\section{Background}

The number of people suffering from one or more chronic conditions is rising, resulting in an increase in patients with complex health care demands. Interprofessional collaboration and the use of shared care plans support the management of complex health care demands of patients with chronic illnesses. This study aims to get an overview of the scientific literature on developing interprofessional shared care plans.

\section{Methods}

We conducted a scoping review of the scientific literature regarding the development of interprofessional shared care plans. A systematic database search resulted in 45 articles being included, five of which were empirical studies concentrating purely on the care plan. Findings were synthesised using directed content analysis.

\section{Results}

This review revealed three themes. The first theme was the format of the shared care plan, with the following elements: patient's current state; goals and concerns; actions and interventions; and evaluation. The second theme concerned the development of shared care plans, and can be categorised as interpersonal, organisational and patient-related factors. The third theme covered tools, whose main function is to support professionals in sharing patient information without personal contact. Such tools relate to documentation of and communication about patient information.

\section{Conclusion}

Care plan development is not a free-standing concept, but should be seen as the result of an underlying process of interprofessional collaboration between team members, including the patient. To integrate the patients' perspectives into the care plans, their needs and values need careful consideration. This review indicates a need for new empirical studies examining the development and use of shared care plans and evaluating their effects. 


\section{Introduction}

As the average age in European countries rises, so does the number of people suffering from chronic diseases such as diabetes. ${ }^{1}$ Depending on their age, $30-80 \%$ of these patients with a chronic disease are confronted with multiple chronic conditions. ${ }^{2,3}$

Suffering from chronic conditions leads to considerable deterioration of functioning and increased care demands. ${ }^{4}$ Chronically ill patients visit 4-9 different health care professionals regularly. ${ }^{5}$ In order to keep rising health care costs under control, governments aim to shift the treatment of chronic patients from hospital care to primary care. ${ }^{6,7}$ The primary care setting will therefore be confronted with a substantial increase in workload, especially regarding patients with complex problems. ${ }^{5}$

Accordingly, there is a need for effective and efficient interprofessional collaboration in chronic care, especially in the primary care setting. ${ }^{8}$ Interprofessional collaboration can have positive effects on health care processes and outcomes. ${ }^{9}$ In addition, interprofessional collaboration seems to be a prerequisite to facilitate a shift from disease-oriented to patient-oriented care. ${ }^{10}$

Health care professionals are used to developing their own discipline-specific care plans. However, given the increasing complexity of care for people with multiple chronic conditions, it seems meaningful to synchronise these discipline-specific care plans into one interprofessional shared care plan. Interprofessional collaboration appears to be positively affected by the use of shared care plans. ${ }^{11-13}$ Based on the literature, we define a shared care plan as a collaborative and shared document that involves a joint input from an interprofessional team of professionals, ${ }^{14}$ summarising the patient's current and preferred situation, as well as personal goals and actions. ${ }^{15}$ Developing shared care plans can be perceived as a means to improve the communication, coordination and synchronisation of care across health care professionals from a diversity of disciplines, resulting in more complete care plans. ${ }^{16}$ In addition, the shared care plan should highlight the process of care, rather than being solely a chronically arranged list of interventions or tasks. ${ }^{17}$

Although the use of shared care plans is recommended in various guidelines for chronic diseases, they have not been implemented on a large scale. ${ }^{15,18}$ Furthermore, there seem to be differences in both the content and structure of these care plans, and to date, they have rarely been patient-centred. ${ }^{18}$ Various interrelated factors (both barriers and facilitators) influence the development of these care plans. Factors that have been mentioned as possible causes obstructing the development of such plans include poor coordination of care and lack of time in consultations. ${ }^{15}$ San Martin-Rodriguez and colleagues. ${ }^{19}$ divided these factors into interactional determinants (processes related to interpersonal relationships), organisational determinants (aspects of the organisation), 
and systemic determinants (external factors). ${ }^{19}$ The development of tools and the use of health information technology have been acknowledged as possible strategies supporting the development of shared care plans.

Supporting implementation in practice would benefit from an overview of the scientific knowledge regarding the development process of interprofessional shared care plans. However, to our knowledge no overviews are available for this specific area. We therefore conducted a scoping review to explore the scientific literature on developing interprofessional shared care plans.

\section{Methods}

\section{Study design}

We explored the literature using a scoping review. We chose this approach, described by Arksey and O'Malley, because the area is complex and has not yet been reviewed comprehensively. ${ }^{20,21}$ In a scoping review, the inclusion of articles is merely based on the relevance of the studies, rather than on methodological quality, in order to accumulate as much information as possible and to map the key concepts and research gaps. Within this approach, five stages, similar to those in systematic reviews, have been described. ${ }^{21}$

\section{Identifying the research question}

Based on preliminary research and the expertise of the research team, the following research question was formulated: 'What is known in the scientific literature about developing interprofessional shared care plans in chronic care?' We were particularly interested in the interprofessional issues related to the development of shared care plans.

\section{Identifying relevant studies}

The search strategy included three different concepts: 'chronic disease', 'interprofessional collaboration' and 'care plan' (Figure 2.1). Both free-text search terms and MESH headings were used to search the following electronic databases: Pubmed, CINAHL, Cochrane and PsycINFO. The search was updated until April 2014 and limited to human adults and the English, Dutch, French or German language. In addition to searching electronic databases, the reference lists of relevant articles were checked. Subsequently, we contacted 10 experts in the field, who were asked by e-mail what they regarded as key publications on the topic. 


\section{Search string}

1) "chronic disease OR aged OR elder* OR multimorbid*";

AND

2) "interprofessional relations OR cooperative behaviour OR patient care team OR interdisciplinary communication OR interprofessional OR collaborat* OR team* OR interdisciplin* OR shared OR multidisciplin* OR shared decision making";

AND

3) "patient care planning OR electronic health records OR personal health records OR goals OR care plan OR treatment plan OR shared care plan OR nursing plan OR goal setting OR action planning OR action plan".

Figure 2.1 Search string.

\section{Study selection}

The selection was made by two reviewers (JVD and WE) independently in three rounds: first titles were screened, then titles with abstracts, and the remaining set of studies were screened on full text. Any differences and uncertainties were discussed until consensus was reached. Studies fulfilling the following criteria were included: (1) dealing with interprofessional collaboration (two or more health care professionals from different professional backgrounds) in chronic care for adults; and (2) describing the development of care plans, goals or actions. No methodological criteria were applied, so a broad range of papers, varying from discussion papers to papers based on empirical data, were included. Since the search was sensitive, we also included papers describing interventions in which the development of shared care plans was only a minor element.

\section{Charting the data}

A descriptive summary of each study was made in a spreadsheet to map the article's general citation information, methodology and key findings (can be retrieved from online publication). Two reviewers (JVD and WE) charted the data independently and discussed the results.

\section{Collating, summarising and reporting the results}

Initial reading and preliminary content analysis by two reviewers (JVD and WE) revealed three themes, which were used to structure the findings: the main elements of a care plan, factors influencing the interprofessional development of a shared care plan, and tools to support the building and use of shared care plans. Directed content analysis, using deductive reasoning, was used to validate or conceptually extend the existing 
preliminary thematic framework described above. ${ }^{22}$ Subsequently, the two reviewers iteratively extracted the data independently and discussed the results related to these themes until consensus was reached. In cases where no consensus was reached or questions remained, a third researcher (MvB) was consulted.

\section{Results}

The search resulted in 5011 hits, and after reading the titles, abstracts and full texts and correcting for duplicates, we found 45 articles fulfilling the inclusion criteria (Figure 2.2). Of these, 22 had been published in 2008 or later and most originated from the USA $(n=15)$. Eight articles (seven discussion papers and one study protocol) reported no new empirical data. In 26 of the other 37, a care plan was the intervention being studied (or part of it), with either quantitative or qualitative evaluations. In addition, eight reviews were included. ${ }^{14,23-29}$ Most of the reviews aimed to identify models of multidisciplinary collaboration, exploring factors that influence interprofessional teamwork, or assessing the effectiveness of multidisciplinary or collaborative programmes. The review by Dellefield ${ }^{24}$ concerned interdisciplinary care planning in nursing facilities, and a written plan of care. ${ }^{24}$ Ring and colleagues ${ }^{28}$ conducted a systematic review on the use of the asthma action plan. ${ }^{28}$

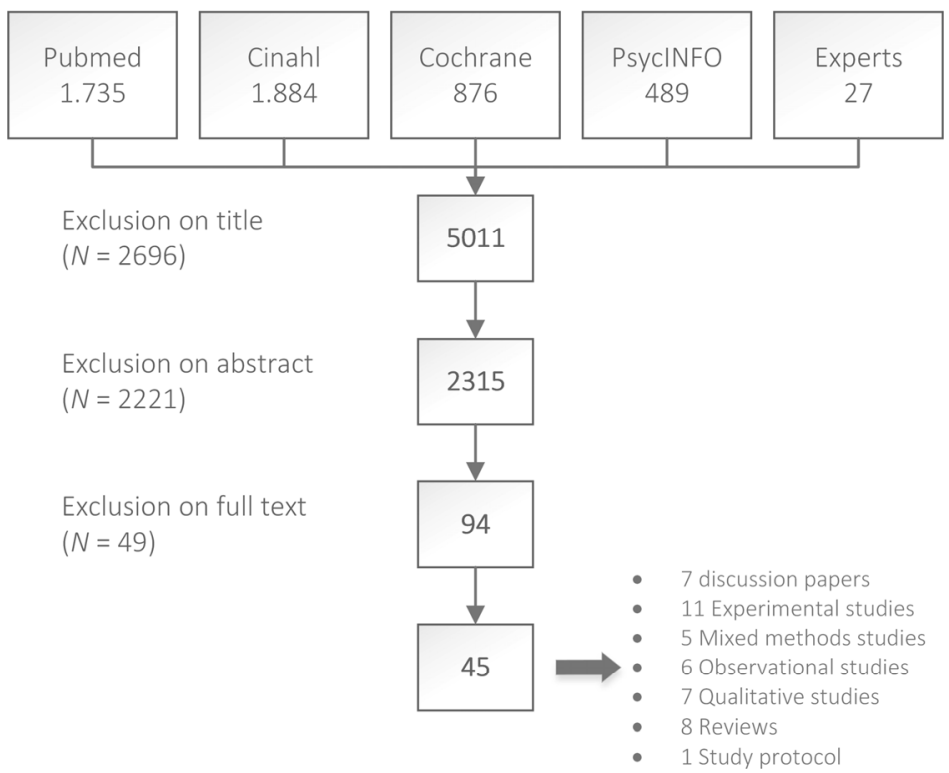

Figure 2.2 Study selection process. 
Most of the care plans in the included studies were disease-specific and e.g. related to cancer, pulmonary or diabetes care. Studies used various designs and embraced a wide range of professions and settings, including primary care, rehabilitation, nursing home care, hospital care and home care. Most of the included articles concerned broad topics, including interprofessional collaboration, care planning process, integrated care and teamwork. Only five of the empirical studies solely concerned the development and use of shared care plans. ${ }^{17,24,28,30,31}$ Initial reading revealed three themes: (1) elements of care plans, (2) factors influencing the development of care plans, and (3) tools to support the building and use of care plans.

\section{Main elements of a shared care plan}

In 18 of the included studies (11 empirical), various elements of a shared care plan were described. However, none of the studies explored 'elements' as the main outcome measure. The elements derived from these studies can be divided into four categories: information about the current state of the patient; goals and concerns; actions and interventions, and an evaluation of the care delivered and the plan (Figure 2.3).

\section{Elements of the shared care plan}

\section{Current state}

Patients' individual situation/ background/ demographics/

functioning/ medication use/ usual treatment/ list of professionals involved

\section{Goals and concerns}

Patients' preferences/values/ needs/ expectations/meaningful activities/ preferred outcomes

\section{Actions and interventions}

Individualised interventions/ actions/strategies

Evaluation

Evaluation of patients' progress/successes/struggles/ level of participation

Figure 2.3 Main elements of a shared care plan.

The first element, current state, relates to the patients' individual situation, and covers information about their background, demographics, functioning, medication use and usual treatment. ${ }^{17,32}$ Besides patient information, the presence of a list of professionals 
involved was mentioned, with a clarification of their roles and responsibilities. ${ }^{17,33,34}$ In addition, Chunchu described the current state as 'about me', and provided the health care team with essential background information. ${ }^{13}$ This current state can be seen as an element of the care plan which is composed and continuously adjusted by the interprofessional team. ${ }^{17}$

The second element includes patients' goals and concerns and contains information related to the care requirements and goals formulated by the patient and the professionals. The goals can cover patient's preferences, values, needs and expectations and can be seen as the central focus of the shared care plan, according to several authors. ${ }^{35-38}$ Since setting goals is a complex process and often difficult to understand for patients, Gage ${ }^{39}$ preferred to talk about patients' 'concerns' instead of goals. ${ }^{39}$ Goals can be explored and described as specific, measurable, assignable, realistic and timerelated (SMART). ${ }^{37,40,41}$ Furthermore, different levels of goals and behaviour change elements can be distinguished: (1) general goals (e.g. weight loss), (2) ongoing activity (e.g. exercising), (3) specific activity (e.g. walking, swimming), (4) frequency of activity (e.g. 3 times a week), (5) when the activity would occur (e.g. before work), (6) barriers to success, (7) assessment of confidence (1 low-10 high), and (8) ways to improve confidence. ${ }^{13}$ In order to explore personal goals, patients are asked to formulate their own preferred outcomes in the care plan. ${ }^{39}$ Patients are also asked to mention activities they enjoy or need to do, also known as meaningful activities. ${ }^{42}$ Berger $^{35}$ specifically focused on the patients' own personal stories instead of the illness and used the patients' own words to describe their goals. ${ }^{35}$ According to Berger, ${ }^{35}$ the care process begins and ends with health care professionals helping patients to explore and tell their own story, including their experience with illness and health. ${ }^{35}$ Since the patients' situation is not static, the shared care plan evolves continuously. ${ }^{17}$

The third element concerns the actions and interventions that result from the goals and concerns as mentioned in the previous category. Wright ${ }^{31}$ stated that a plan of actions is needed, and that the starting point for these actions is the patient's personal perspective. ${ }^{31}$ Dellefield ${ }^{24}$ and Metzelthin et al. ${ }^{42}$ recommended including individualised interventions (including strategies and actions), tailored to the individual patient, in the care plan, rather than standardised interventions. ${ }^{24,42}$ This will enable the patients' personal goals to be reached. ${ }^{42}$ Redundancy will be minimised when the actions and interventions are specified, time- and date-based and relate to one of the health care professionals involved. Specifying interventions and actions facilitates monitoring and follow-up. ${ }^{23,42}$

The fourth element of the care plan concerns evaluation, including the professional documenting the patient's evaluation of progress, including successes, struggles, the level of participation in goal setting, and capacity to revise the care plan. ${ }^{13,17,41}$ Gage 
used the patient's own outcomes and evaluated these with a format called the 'tracking and evaluation form' on three dimensions: importance, personal performance and satisfaction. $^{39}$

In addition to the elements of a care plan, several authors mentioned preconditions to developing these plans. They stated that the plan should be kept up to date, tailored to the individual patient, and expressed in lay language, balancing the patient's emotional, social and physical needs. Furthermore, the care plan should be easily accessible to all health care professionals involved. ${ }^{17,23,28,41,43}$ The care plan should also be able to be updated as it travels with the patient, so that the patient does not have to re-explain the situation all over again. ${ }^{17}$

\section{Factors influencing the interprofessional development of a shared care plan}

Factors that influence the process of interprofessional collaboration in developing care plans were mentioned in 35 of the included studies (29 empirical). Often, however, authors did not describe these factors specifically in relation to a shared care plan, but to the underlying process of interprofessional collaboration. We divided these factors into interpersonal factors, organisational factors and patient-related factors.

Interpersonal factors are related to individual professionals and interactions between the team members, and concern issues such as knowing each other, the competencies of individual team members ${ }^{17}$ and mutual communication. ${ }^{16}$ One study identified the need to develop collaboration skills between social and health care professionals in order to better serve the needs of patients with complex health care demands. ${ }^{44}$ Professionals in health care teams have various backgrounds and education, resulting in different professional languages and lack of a common vocabulary. ${ }^{45}$ These differences have been described as barriers to the negotiation process about a shared care plan. ${ }^{16,17,28,31}$ Other factors mentioned in the studies are clarity about and appreciation of each other's roles and collaboration based on trust and respect. ${ }^{16,37,44}$ To create a situation of mutual trust and respect, individuals could, according to Lewis et al., ${ }^{16}$ focus on reaching team goals instead of individual goals, listen to other team members without attacking each other, convey criticism in a positive way, provide positive feedback and respect, and understand the norms and rules of the team. ${ }^{16}$

Most of the factors can be assigned to the category of organisational factors. Organisational factors are conditions related to the structure and logistics of team meetings ${ }^{16,17,29}$ and a shared team vision. ${ }^{37}$ Elements related to structure are team composition, division of roles, organisational support and leadership. ${ }^{16,29,39}$ Preferably, organisational roles and responsibilities should be defined, team members should work towards a common goal, and there should be shared responsibility for optimal patient 
outcomes. ${ }^{39}$ Leadership and coordination were addressed frequently in the studies, and authors often expressed their preference for one person taking the lead in the process. ${ }^{26,29,34,43}$ The success of an interprofessional team working according to a structured protocol strongly depends on the person who coordinates the meetings. ${ }^{42}$ For both patients and health care professionals, it is often unclear which of the professionals involved has the overall responsibility for coordinating the interprofessional collaboration. ${ }^{44}$ Despite the fact that this coordinator could be from any professional background, it is often a nurse (or nurse practitioner) who adopts this coordinating role. $^{13,14,24,29,34,42,46-50}$ Elements related to logistics are accommodation, time and place. Time is mentioned several times as a common barrier across different settings and organisations. ${ }^{45}$ Pressure of time can be associated with both attendance to meetings and the coordination and development of care plans. ${ }^{16,26,32,36,44,45,51}$

Patient-related factors regarding the integration of the patient's perspective during the care plan development process were discussed in 15 studies. These studies described patients' unique knowledge (experiential knowledge) about their conditions and lives, which complements the knowledge of the professionals. Several authors emphasised that before a team can discuss a patient's goal, it is essential to know their wishes, expectations and needs. ${ }^{30,40,52}$ Nine studies highlighted the role of the patient as an active participant in the team, and stressed the importance of patients being empowered by, e.g. providing information, setting goals and developing an action plan. ${ }^{15,25,27,39,44,52-55}$ However, four studies reported difficulties with involving patients in the care process, because of time pressure, unrealistic goal setting, patients' lack of understanding of the process, leading professional perspective, and difficulties in translating patients' needs into agreed goals. ${ }^{15,51,56,57}$

\section{Tools to support the building and use of shared care plans}

Fourteen of the selected studies (13 empirical) described tools to support the interprofessional formulation and use of care plans, or tools to support patient involvement. One of the main functions of the tools is to support the exchange of information and bring new information to the team members' attention through emailing or by using an alert system. ${ }^{58-60}$ An alert system may be an element of the electronic health record (EHR), sending professionals a reminder to contact colleagues for information and assistance. ${ }^{61}$ Likewise, Casas et al. ${ }^{48}$ described the use of an ICT platform including a web-based call centre facilitating access by patients, carers and primary care professionals to a specialist nurse who acts as case manager. The use of an EHR, which is associated with greater care coordination among health care professionals and agreement about treatment goals, can be a tool to provide comprehensive patient 
information. ${ }^{62}$ Some of the tools are only used by professionals from one discipline, while others are used by all stakeholders involved. ${ }^{47,58}$ Several professionals use electronic systems before and during the process of developing a care plan, ${ }^{47,58}$ while others make use of these systems just to document the care plan. ${ }^{61}$

In addition to tools mainly directed at care plan development, several studies discussed ways to empower patients to become involved in the care plan development. The aims of these tools can be divided into developing communication and decision-making skills, training patients and caregivers in mutual communication and decision-making and selfmanagement skills, and training professionals in motivational interviewing. ${ }^{30,44,47}$ In addition, a user-friendly and patient-centred use of the EHR, in which patients can actively participate, can promote patient self-management. ${ }^{13}$

In some cases, patients are able to enter the system and contribute to modifications and adaptations. ${ }^{13,17}$ The option of modifying information can provide the patient with a more active role. ${ }^{13}$ Boyd described a tool to enhance this active role of the patient, which merges data from the individual assessments with evidence-based best-practice recommendations to support discussion between professional and patient. ${ }^{47}$ Measurement instruments such as the Goal Attainment Scaling (GAS) can be used to evaluate a patient's progress in terms of attaining personal goals. It is used for patients with multiple complex problems, and monitored during team meetings. 39,56

\section{Discussion}

This scoping review explored the scientific literature on developing interprofessional shared care plans. This research domain seems to be relatively new as most of the included articles were published in 2008 or later. It is surprising that, despite the fact that the use of shared care plans is recommended in guidelines, the empirical evidence about their value in practice is limited. In most of the included studies, the care plan was part of a larger intervention study. Only five empirical studies exclusively concentrated on the development and use of care plans. Most of the care plans in the included studies were disease-specific and focused on, e.g. cancer, pulmonary or diabetes care. Only a small number of studies have addressed the development of shared care plans for patients with multimorbidity. ${ }^{15}$ The results of our review identify the different elements of the care plan, the factors that influence the care plan development, including the key role of the patient, and an overview of supporting tools.

Four separate elements of shared care plans could be distinguished from the results: (1) patient's current state; (2) goals and concerns; (3) actions and interventions and (4) evaluation. Despite the limited empirical evidence, there seems to be consensus 
among authors about the different elements of a care plan. Patients' current state includes an overview of the various health care professionals who are involved in the care plan development. However, no studies were found that highlighted the process of decision making as to which professionals should be involved. The exploration of patients' goals and concerns is essential in the development of a care plan, and can be seen as the central point. The process of patients and professionals collaborating to set goals is regarded as complex and challenging. ${ }^{57}$ Lenzen et al. found that this process is influenced especially by attitude, skills and the use of supporting tools. ${ }^{63}$ How professionals deal with this complexity in the context of shared care plan development has not been addressed in the included articles, which may either indicate that this is obvious, or can be seen as a blind spot in the research.

We found that the development of the plans can be influenced by factors regarding the interaction between team members, the organisation and facilitation of the care plan development and patient-related factors. This implies that care plan development cannot be seen as a free-standing concept, but more as a result of an underlying process of interprofessional collaboration. In a general reflection on successful collaboration, San Martin-Rodriguez and colleagues studied its determinants and divided them into interactional, organisational, and systemic. ${ }^{19}$ Besides the factors we examined, they added systemic determinants, relating to the external environment of an organisation e.g. funding, education and legal and privacy issues. Of the studies included in our review, only the study by Bell et al. mentioned the lack of remuneration for allied care professionals as a barrier to collaboration. ${ }^{46}$ Conversely, our study added a category of patient-related factors, highlighting the importance of integrating the patient's perspective in the care plan. This includes supporting patients' participation in care plan development, and access to their EHR. Despite the importance of integrating the patient's perspective in the care plan development process, Dykes et al. stated that to date, care plans have rarely been patient-centred. ${ }^{18}$

Some tools are already available to support both professionals and patients in sharing the care plan. Possibilities for and availability of these tools are expanding, partly due to developments in technology, making it possible to share information without personal contact. However, implementation of these tools is often hampered, e.g. by privacy regulations, lack of funding, and the diversity of tools that cannot communicate with each other. ${ }^{18,64}$

The underlying process of interprofessional collaboration seems to be an important aspect in developing shared care plans. Interprofessional collaboration and providing care that focuses on the individual patient's needs require certain competencies of the professionals involved. ${ }^{65}$ Based on a review of different interprofessional competency frameworks, Reeves et al. distinguished core competencies regarding communication, 
collaboration, patient-centred care, teamwork and the role of a coordinator or leader. ${ }^{66,67}$ Information about crucial skills and competencies could not be extracted from the findings of our review, although we found information about the crucial role of the coordinator.

Some limitations of this scoping review need to be taken into account when interpreting the results. Our search was restricted to a combination of key words based on a preliminary but broad literature exploration. It is possible that this broad topic has caused us to miss key words in our search string, resulting in missing articles. However, by using the input of experts and reference checking, we expect to have minimised this potential shortcoming. Another possible limitation of our study is that we limited our search to databases of peer-reviewed, scientific articles. Books and grey literature were not included. As a result we may have missed relevant publications describing care plans and practical tools. However, among these publications, we do not expect empirical studies with methodologically sound evaluations.

\section{Conclusions}

Research into developing interprofessional shared care plans is rather new. The exploration of the scientific literature identified four topics for further research and implementation in practice. First, more empirical studies of good quality are needed. These studies should focus on the development, use and evaluation of the effects of shared care plans. Second, interventions could be developed to ensure the role of the patient and his/her perspective in developing shared care plans. Interesting interventions to explore include training professionals, enabling patients to access their electronic health records, and translating patients' goals and concerns into concrete actions and interventions in the care plan. Third, teams considering the use of shared care plans should pay attention to the underlying process of interprofessional collaboration. This includes both interpersonal (e.g. language, interaction, competencies, trust and respect) and organisational aspects (e.g. structure, logistics and the role of a central coordinator / leader). Finally, an increasing number of tools that can be used to facilitate the care plan development process are becoming available for implementation. It is especially linking them to each other which seems to be a challenge. 


\section{References}

1. Busse R, Blumel M, Scheller-Kreinsen D, Zentner A. Tackling Chronic Disease in Europe: Strategies, interventions and challenges. Europen Observatory on Health Systems and Policies. 2010;20:1-18.

2. Salive ME. Multimorbidity in Older Adults. Epidemiol Rev. 2013;35(1):75-83.

3. Salisbury C, Johnson L, Purdy S, Valderas JM, Montgomery AA. Epidemiology and impact of multimorbidity in primary care: a retrospective cohort study. Br J Gen Pract. 2011;61(582):e12-21.

4. Wijlhuizen GJ. Impact of multimorbidity on functioning: Evaluating the ICF core set approach in an empirical study of people with rheumatic diseases. J Rehabil Med. 2012;44:664-8.

5. Jansen D, Spreeuwenberg P, Heijmans M. Developments in the care for people with chronic conditions report 2012. Utrecht: NIVEL; 2012.

6. Singh D. Making the shift: Key Success Factors: A rapid review of best practice in shifting hospital care into the community. Birmingham: University of Birmingham; 2006.

7. Oldman C. Moving care to the community: an international perspective. In., vol. Policy briefing 12/13: Royal College of Nursing; 2013.

8. Bodenheimer T, Chen E, Bennett HD. Confronting the growing burden of chronic disease: can the U.S. health care workforce do the job? Health Aff (Millwood). 2009;28(1):64-74.

9. Zwarenstein M, Goldman J, Reeves S. Interprofessional collaboration: effects of practice-based interventions on professional practice and healthcare outcomes (Review). Cochrane Collaboration. 2009;8(3):CD000072.

10. Van Royen P, Rees CE, Groenewegen P. Patient-centred interprofessional collaboration in primary care: challenges for clinical, educational and health services research. An EGPRN keynote paper. Eur J Gen Pract. 2014;20(4):327-32.

11. Vyt A. Interprofessional and transdisciplinary teamwork in healthcare. Diabetes Metab Res Rev. 2008;24(1):S106-9.

12. Rocco N, Scher K, Basberg B, Yalamanchi S, Baker-Genaw K. Patient-centered plan-of-care tool for improving clinical outcomes. Qual Manag Health Care. 2011;20(2):89-97.

13. Chunchu K, Mauksch L, Charles C, Ross V, Pauwels J. A patient centered care plan in the EHR: Improving collaboration and engagement. Fam Syst Health. 2012;30(3):199-209.

14. Trivedi D, Goodman C, Gage H, Baron N, Scheibl F, lliffe S, Manthorpe J, Bunn F, Drennan V. The effectiveness of inter-professional working for older people living in the community: a systematic review. Health Soc Care Community. 2013;21(2):113-28.

15. Newbould J, Burt J, Bower P, Blakeman T, Kennedy A, Rogers A, Roland M. Experiences of care planning in England: interviews with patients with long term conditions. BMC Fam Pract. 2012;13:71.

16. Lewis RE, Tucker R, Tsao H, Canaan E, Bryant J, Talbot P, King D, Flythe M. Improving interdisciplinary team process: a practical approach to team development. J Allied Health. 1998;27(2):89-95.

17. Clausen C, Strohschein FJ, Faremo S, Bateman D, Posel N, Fleiszer DM. Developing an Interprofessional Care Plan for an Older Adult Woman With Breast Cancer: From Multiple Voices to a Shared Vision. Clin J Oncol Nurs. 2012;16(1):E18-25.

18. Dykes PC, Samal L, Donahue M, Greenberg JO, Hurley AC, Hasan O, O'Malley TA, Venkatesh AK, Volk LA, Bates DW. A patient-centered longitudinal care plan: vision versus reality. J Am Med Inform Assoc. 2014;21(6):1082-90.

19. San Martin-Rodriguez L, Beaulieux M-D, D’Amour D, Ferrada-Videla M. The determinants of succesful collaboration: A review of theoretical and emperical studies. J Interprof Care. 2005;5(1):132-47.

20. Poth C, Ross C. Meta-analysis, systematic review, or scoping review? Comparing methodologies in educational research. In: Annual Conference of the Canadian Society for the Study of Education. Ottawa, ON, Canada; 2009

21. Arksey H, O'Malley L. Scoping studies: towards a methodological framework. Int J Soc Res Methodol. 2005;8(1):19-32.

22. Hsieh HF, Shannon SE. Three approaches to qualitative content analysis. Qual Health Res. 2005;15(9):1277-88. 
23. Benetos A, Novella JL, Guerci B, Blickle JF, Boivin JM, Cuny P, Delemer B, Gabreau T, Jan P, Louis J, et al. Pragmatic diabetes management in nursing homes: individual care plan. J Am Med Dir Assoc. 2013;14(11):791-800.

24. Dellefield ME. Interdisciplinary care planning and the written care plan in nursing homes: A critical review. Gerontol. 2006;46(1):128-33.

25. Duff J. Team assessment in stroke rehabilitation. Top Stroke Rehabil. 2009;16(6):411-9.

26. Martin JS, Ummenhofer W, Manser T, Spirig R. Interprofessional collaboration among nurses and physicians: making a difference in patient outcome. Swiss Med Wkly. 2010;140:w13062.

27. Ospina M, Harstall C. Multidisciplinary pain programs for chronic pain: evidence from systematic reviews (Structured abstract). Health Technology Assessment Database. 2003;53(2):1-48.

28. Ring N, Jepson R, Hoskins G, Wilson C, Pinnock H, Sheikh A, Wyke S. Understanding what helps or hinders asthma action plan use: a systematic review and synthesis of the qualitative literature. Patient Educ Couns. 2011;85(2):e131-43.

29. Xyrichis A, Lowton K. What fosters or prevents interprofessional teamworking in primary and community care? A literature review. Int J Nurs Stud. 2008;45(1):140-53.

30. Crossen-Sills J, Bilton W, Bickford M, Rosebach J, Simms L. Home care today: showcasing interdisciplinary management in home care. Home Healthc Nurse. 2007;25(4):245-52.

31. Wright BA. Behavior diagnoses by a multidisciplinary team. To create a plan of care for an elderly patient in a nursing home, members of multidisciplinary teams must find a common language. Geriatr Nurs. 1993;14(1):30-5.

32. Oeseburg B, Jansen D, De Keyser J. Reducing discrepancies between MS patients' needs and use of healthcare services by applying a transmural care model. J Neurosci Nurs. 2004;36(4):214.

33. Duner A. Care planning and decision-making in teams in Swedish elderly care: A study of interprofessional collaboration and professional boundaries. J Interprof Care. 2013;27(3):246-53.

34. Keks NA, Altson BM, Sacks TL, Hustig HH, Tanaghow A. Collaboration between general practice and community psychiatric services for people with chronic mental illness. Med J Aust. 1997;167(5):266-71.

35. Berger JL. Incorporation of the Tidal Model into the interdisciplinary plan of care-a program quality improvement project. J Psychiatr Ment Health Nurs. 2006;13(4):464-7.

36. Norburn JEK, Nettles-Carlson B, Soltys FG, Read CD, Pickard CG. Long-term care organizational challenges and strategies: art vs. regulation. J Gerontol Nurs. 1995;21(8):37.

37. Clay M, Wade S. Continuing professional development. Rehabilitation and older people. Nurs Older People. 2003;15(7):25-30.

38. Zawadski RT, Eng C. Case management in capitated long-term care. Health Care Financing Review. Spec. 1988;No:75-81:26-35.

39. Gage M. The patient-driven interdisciplinary care plan. J Nurs Adm. 1994;24(4):26-35.

40. Bovend'eerdt TJH, Botell RE, Wade DT. Writing SMART rehabilitation goals and achieving goal attainment scaling: a practical guide. Clin Rehabil. 2009;23(4):352-61.

41. Weklar MA. Patient care of the elderly: application of the team approach. Nurs Homes. 1982;31(2):12-7.

42. Metzelthin SF, Daniels R, van Rossum E, Cox K, Habets H, de Witte LP, Kempen Gl. A nurse-led interdisciplinary primary care approach to prevent disability among community-dwelling frail older people: a large-scale process evaluation. Int J Nurs Stud. 2013;50(9):1184-96.

43. Johansson BC. Care coordination: Key to providing timely treatment, rehabilitation for elderly, at-risk patients. Caring. 2012;31(1):40-4.

44. Eloranta S, Arve S, Routasalo P. Multiprofessional collaboration promoting home care clients' personal resources: Perspectives of older clients. Int J Older People Nurs. 2008;3(2):88-95.

45. L égaré F, Stacy D, Briere N, Fraser K, Desroches S, Dumont S, Sales A, Puma C, Aubé D. Healthcare providers' intentions to engage in an interprofessional approach to shared decision-making in home care programs: A mixed methods study. J Interprof Care. 2013;1-9:214-22.

46. Bell JS, Aslani P, McLachlan AJ, Whitehead P, Chen TF. Mental health case conferences in primary care: Content and treatment decision making. Res Social Adm Pharm. 2007;3(1):86-103.

47. Boyd CM, Boult C, Shadmi E, Leff B, Brager R, Dunbar L, Wolff JL, Wegener S. Guided care for multimorbid older adults. Gerontol. 2007;47(5):697-704. 
48. Casas A, Troosters T, Garcia-Aymerich J, Roca J, Hernández C, Alonso A, Pozo F, Toledo P, Antó JM, Rodríguez-Roisín R, et al. Integrated care prevents hospitalisations for exacerbations in COPD patients. Eur Respir J. 2006;1:123-30.

49. Boorsma M, Frijters DH, Knol DL, Ribbe ME, Nijpels G, Hout HP. Effects of multidisciplinary integrated care on quality of care in residential care facilities for elderly people: a cluster randomized trial. Can Med Assoc J. 2011;11:E724-32.

50. Johnson JA, Al Sayah F, Wozniak L, Rees S, Soprovich A, Chik CL, Chue P, Florence P, Jacquier J, Lysak P, et al. Controlled trial of a collaborative primary care team model for patients with diabetes and depression: rationale and design for a comprehensive evaluation. BMC Health Serv Res. 2012;258.

51. Russell G, Thille P, Hogg W, Lemelin J. Beyond fighting fires and chasing tails? Chronic illness care plans in Ontario, Canada. Ann Fam Med. 2008;6(2):146-53.

52. Aberg-Wistedt A, Cressell T, Lidberg Y, Liljenberg B, Osby U. Two-year outcome of team-based intensive case management for patients with schizophrenia. Psychiatr Serv. 1995;46(12):1263-6.

53. Preston KM. A team approach to rehabilitation. Home Healthcare Nurse. 1990;8(1):17-23.

54. Orchard CA, King GA, Khalili H, Bezzina MB. Assessment of interprofessional team collaboration scale (AITCS): Development and testing of the instrument. J Contin Educ Health Prof. 2012;32(1):58-67.

55. Eleazer GP, Baskins JP, Egbert J, Johnson CD, Wilson L. Managed care for the frail elderly: the PACE Project. J S C Med Assoc. 1994;90(12):586-91.

56. Stolee P, Zaza C, Pedlar A, Myers AM. Clinical experience with Goal Attainment Scaling in geriatric care. J Aging Health. 1999;11(1):96-124.

57. Barnard RA, Cruice MN, Playford ED. Strategies used in the pursuit of achievability during goal setting in rehabilitation. Qual Health Res. 2010;20(2):239-50.

58. Emery EE, Lapidos S, Eisenstein AR, Ivan II, Golden RL. The BRIGHTEN program: implementation and evaluation of a program to bridge resources of an interdisciplinary geriatric health team via electronic networking. Gerontologist. 2012;52(6):857-65.

59. Mitton C, O’Neil D, Simpson L, Hoppins Y, Harcus S. Nurse-physician collaborative partnership: a rural model for the chronically ill. Can J Rural Med. 2007;12(4):208-16.

60. Hedrick SC, Chaney EF, Felker B, Liu CF, Hasenberg N, Heagerty P, Buchanan J, Bagala R, Greenberg D, Paden $\mathrm{G}$, et al. Effectiveness of collaborative care depression treatment in Veterans' Affairs primary care. J Gen Intern Med. 2003;1:9-16.

61. Counsell SR, Callahan CM, Buttar AB, Clark DO, Frank KI. Geriatric resources for assessment and care of elders (GRACE): a new model of primary care for low-income seniors. J Am Geriatr Soc. 2006;54(7):113641.

62. Graetz I, Reed M, Shortell SM, Rundall TG, Bellows J, Hsu J. The association between EHRs and care coordination varies by team cohesion. Health Serv Res. 2014;49(1 Pt 2):438-52.

63. Lenzen SA, Daniels R, van Bokhoven MA, van der Weijden T, Beurskens A. Setting goals in chronic care: Shared decision making as self-management support by the family physician. Eur J Gen Pract. 2015;21(2):138-44.

64. Ajami S, Arab-Chadegani R. Barriers to implement Electronic Health Records (EHRs). Mater Sociomed. 2013;25(3):213-5.

65. Chan AK, Wood V. Preparing tomorrow's healthcare providers for interprofessional collaborative patientcentrered practice today. UBCMJ. 2010;1(2):22-4.

66. Reeves S. The rise and rise of interprofessional competence. J Interprof Care. 2012;26(4):253-5.

67. Chatalalsingh $\mathrm{C}$, Reeves $\mathrm{S}$. Leading team learning: what makes interprofessional teams learn to work well? J Interprof Care. 2014;28(6):513-8. 


\section{Chapter}

Interprofessional collaboration regarding patients' care plans in primary care: a focus group study into influential factors

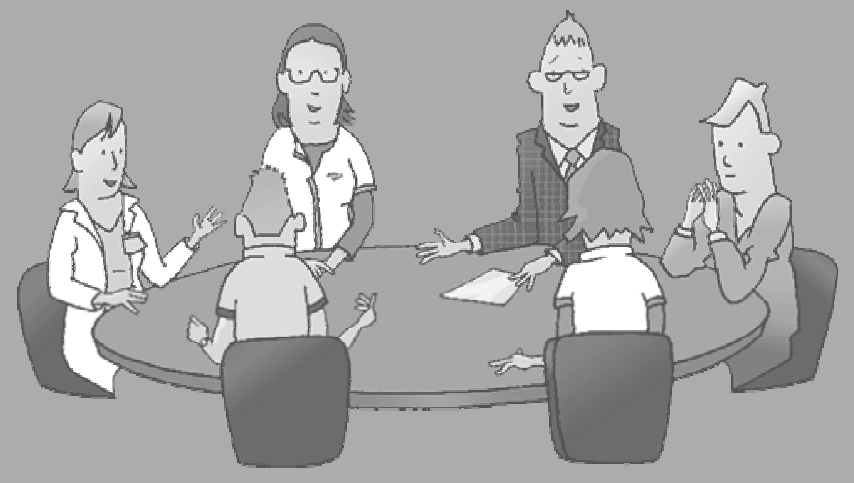

Jerôme van Dongen Stephanie Lenzen Loes van Bokhoven Ramon Daniëls Trudy van der Weijden Sandra Beurskens BMC Fam Pract 2016;17:58 


\section{Abstract}

\section{Introduction}

The number of people with multiple chronic conditions demanding primary care services is increasing. To deal with the complex health care demands of these people, professionals from different disciplines collaborate. This study aims to explore influential factors regarding interprofessional collaboration related to care plan development in primary care.

\section{Methods}

A qualitative study, including four semi-structured focus group interviews $(n=4)$. In total, a heterogeneous group of experts $(n=16)$ and health care professionals $(n=15)$ participated. Participants discussed viewpoints, barriers, and facilitators regarding interprofessional collaboration related to care plan development. The data were analysed by means of inductive content analysis.

\section{Results}

The findings show a variety of factors influencing the interprofessional collaboration in developing a care plan. Factors can be divided into 5 key categories: (1) patient-related factors: active role, self-management, goals and wishes, membership of the team; (2) professional-related factors: individual competences, domain thinking, motivation; (3) interpersonal factors: language differences, knowing each other, trust and respect, and motivation; (4) organisational factors: structure, composition, time, shared vision, leadership and administrative support; and (5) external factors: education, culture, hierarchy, domain thinking, law and regulations, finance, technology and ICT.

\section{Conclusions}

Improving interprofessional collaboration regarding care plan development calls for an integral approach including patient- and professional related factors, interpersonal, organisational, and external factors. Further, the leader of the team seems to play a key role in watching the patient perspective, organising and coordinating interprofessional collaborations, and guiding the team through developments. The results of this study can be used as input for developing tools and interventions targeted at executing and improving interprofessional collaboration related to care plan development. 


\section{Introduction}

The number of people with multiple, chronic diseases is increasing. ${ }^{1,2}$ These chronic diseases lead to considerable functional, social, and emotional impairment and an increased health care demand, especially in primary care. ${ }^{3-5}$ In addition, moving patient care out of the hospitals into the primary care setting also influences this increase. Further, it can be assumed that the needs of patients with complex health care demands often are beyond the expertise of any single profession. ${ }^{6,7}$

To deal with the complex health care demands and to deliver efficient, safe, and high quality care, different health care professionals need to collaborate. ${ }^{8-10}$. This process of interprofessional collaboration (IPC) is defined by the World Health Organization as: "Multiple health workers from different professional backgrounds work together with patients, families, caregivers, and communities to deliver the highest quality of care". 8 Instead of a fragmented health care supply of single health care professionals, IPC aims to attain more tailored and synchronized health care delivery from a diversity of disciplines. ${ }^{9,11}$ Within this process, the patient's perspective plays a central role. In patient-centred care, the individual patient's goals are at the centre of care. ${ }^{12}$

Shared talking about (patient) goals, formulating action plans, and developing a patientcentred care plan can be considered useful strategies to integrate the patient perspective in the decision-making process. Ideally, within shared goal setting, the patient discusses and sets health-related goals together with a health care professional. ${ }^{13,14}$ After setting goals with the patient, the health care professional discusses these goals in the interprofessional team meeting. The team subsequently flows into action planning and negotiation on who best carries out each action. ${ }^{13}$ Based on the patient's goals and formulated actions, the team develops a patient-centred care plan, which can be seen as a collaborative and dynamic document. ${ }^{15}$

In the care for chronically ill, however, collaborative goal setting and action planning have not been implemented on a large scale, and there seems to be a lack of evidence on how to integrate the patient's perspective. ${ }^{15,16}$ Furthermore, the situation of a variety of single health care professionals working for their own practice makes IPC a challenge. ${ }^{7}$ In addition, different interrelating factors can serve as barriers to or facilitators of the process of IPC. Several factors that influence IPC in primary care have been mentioned in the literature. ${ }^{11,17-19}$ San Martin-Rodriguez and colleagues (2005) divide these factors into issues related to interpersonal relationships (interactional determinants), conditions within the organisation (organisational determinants), and the organisation's environment (systemic determinants). ${ }^{18}$ Dinh (2012) makes an approximately equal categorisation and distinguishes barriers into three levels: individual, practice, and system level. ${ }^{17}$ From a review by Xyrichis and Lowton (2008) two main themes emerge: 
team structure and team processes. Team structure includes the team premises, size, and organisational support. Team processes include the team meetings, clear goals, and objectives. ${ }^{11}$ In the literature all evidence concentrates on factors related to IPC in general. However, in the context of team talk about (patient) goals, formulating action plans, and developing a patient-centred care plan, IPC might be influenced by other dynamics and factors.

Mapping the viewpoints, barriers, and facilitators of IPC concerning patients' goals and action plans seems to be a prerequisite for developing interventions to improve shared goal setting and action planning by IPC in primary care. Therefore, the aim of this qualitative study is to explore influential factors of IPC regarding patient goals and the patient-centred care plan.

\section{Methods}

\section{Study design}

We conducted a qualitative focus group study. Four focus group meetings were organized in March 2013 with experts and health care professionals from different disciplines in primary care $(n=31)$. We chose to conduct focus groups because we assumed that the interaction between the different participants could lead to more indepth insights. ${ }^{20,21}$ Relevant aspects of this study are reported following the Consolidated Criteria for Reporting Qualitative Research (COREQ). ${ }^{22}$

\section{Setting}

The focus group meetings took place in a quiet meeting room at Zuyd University of Applied Sciences (Heerlen, the Netherlands) and lasted approximately 90 minutes each.

\section{Participants}

Participants were selected by means of purposive sampling to achieve a diverse range of health care professionals and experts from different disciplines. We aimed to include a variety in expertise in the following areas: interprofessional collaboration, selfmanagement support, shared decision making, communication, and interprofessional education. We invited primary health care professionals from disciplines representing family physicians, practice nurses, occupational therapists, physical therapists, psychologists, and social workers. We only included health care professionals working within interprofessional teams and dealing with chronically ill patients in primary care. In 
sampling the participants we assured that they were appointed at a diversity of practices. We conducted two types of focus groups: groups with experts $(n=2)$ and groups with health care professionals $(n=2)$. Recruitment took place in the Netherlands, and potential participants were selected from a list either composed by the research team or named by key persons. During recruitment, we purposefully invited 27 health care professionals and 22 experts. Candidates who were interested in participating received written background information without disclosure of the exact purpose of the focus groups in order to avoid bias. Eventually, 16 experts and 15 health care professionals participated (Table 3.1). As presented in Table 3.1, 11 men and 20 women participated; the mean age was 47. Participants signed a written informed consent form and filled out an additional questionnaire with socio-demographic variables. The informed consent form was used to confirm the participants' voluntary participation and the right to end participation in the study at any moment, if desired. Appendix 3.1 provides a detailed overview of the participants.

Table 3.1 Characteristics of the participants.

\begin{tabular}{lccccc}
\hline Source & Code & $N$ & Mean age & Men & Women \\
\hline Focus Group 1 (Experts) & E1 & 8 & 40 & 2 & 6 \\
Focus Group 2 (Experts) & E2 & 8 & 54 & 2 & 6 \\
Focus Group 3 (Health care professionals) & H1 & 9 & 44 & 4 & 5 \\
Focus group 4 (Health care professionals) & H2 & 6 & 52 & 3 & 3 \\
Total & & 31 & 48 & 11 & 20 \\
\hline
\end{tabular}

\section{Data collection}

A semi-structured interview guide with open-ended questions was prepared for all focus group meetings (see Appendix 3.2). ${ }^{20}$ The interview guide started with an open question to capture participants' first thoughts about IPC. Subsequent questions were related to experiences with IPC in developing patient-centred care plans, to factors that influence the process of interprofessional collaboration, and to experienced barriers and facilitators. Before actual use, the interview guide was tested in a pilot interview and adapted where needed. An experienced and independent researcher acted as moderator, guiding the interviews and starting each focus group with a short introduction. Subsequently, he asked participants about experiences, barriers, and facilitators to the process of interprofessional collaboration on patient-centred care plan development in the primary care setting. Follow-up questions were used to gain more in-depth information. Two focus groups started discussions from the patient perspective and ended with the team perspective, and two focus groups used the opposite order. 
Besides the moderator, a second researcher (JvD) facilitated the meeting and took field notes.

\section{Analysis}

To analyse the data, we applied an inductive content analysis approach. ${ }^{23}$ The focus group meetings were audio-taped and transcribed verbatim. NVivo 9 software was used to structure the transcripts and code the data. ${ }^{24}$ The analysis was carried out by two researchers (JVD) and (SL), both experienced in qualitative research. JVD and SL independently analysed all transcripts and carried out open coding of all quotes relevant to the aim of the study. Different concepts were identified and grouped into subcategories, (axial coding). ${ }^{25}$ In the next step, the two researchers compared and discussed their codes until they reached consensus and subsequently categorized the different subcategories. In case of disagreement, the research team was asked for advice. In the last step, the researchers identified different key categories into which the subcategories could be divided.

\section{Trustworthiness}

The researchers' field notes and written comments were used in the analysis process to enhance the trustworthiness of the study. Furthermore, two researchers coded data independently and then discussed and compared categories and subcategories. An independent senior researcher with experience in conducting and guiding focus group interviews moderated the interviews to reduce the researchers' influence. To increase accuracy, validity, and credibility, a member check was done. Main findings were sent to all participants, giving them the opportunity to comment on the key findings. To enhance the results' transferability, purposive sampling was used to include the perspectives of various disciplines.

\section{Results}

Content analysis of the four focus group meetings revealed 5 key categories of factors:

(1) patient-related factors, (2) professional-related factors, (3) interpersonal factors, (4) organisational factors, and (5) external factors (Figure 3.1). The categorisation of determinants of IPC as presented by San Martin-Rodriguez (2005) appeared to be useful in structuring the key findings of this study. ${ }^{18}$ In addition to this categorisation, two categories of factors were added, related to both patients' and professionals' perspectives. 


\section{Professional-related factors}

- Individual competences

- Domain thinking

- Motivation

\section{Patient-related factors}

- Active role of the patient

- Formulation/language of patients' goals and wishes

- Member of the team
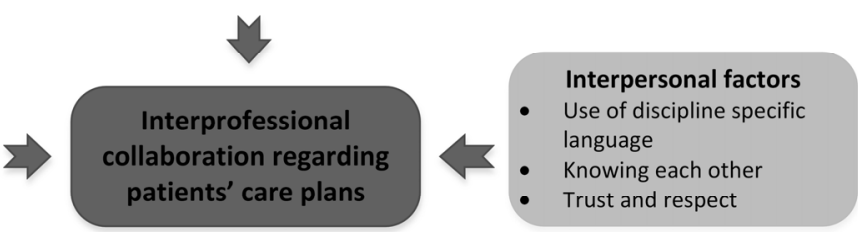

External factors
- Education
- Lulture
- Law and regulations
- Information and
communications technology

\section{Organisational factors}

- Format and composition of the team

- Time and efficiency

- Shared vision and mission

- Leadership

- Administrative support

Figure 3.1 Key categories of factors.

\section{Patient-related factors}

\section{Active role of the patient}

Many participants described the importance of a central and proactive role of the patient. Patients, for example, could participate in team meetings. Prior to this, one of the participants used the term active citizenship in which the role of an assertive and responsible patient is highlighted. To support patient involvement and stimulate this active citizenship, one participant mentioned self-management support. According to the participants, an increasing number of courses seem available for training patients to get more in control of their own lives and stimulate communication with health care professionals.

"The patient has to change and become more proactive as a member of the team". (Researcher, E1.2)

\section{Formulation/language of patients' goals and wishes}

Further, a difference between patients' and professionals' goals was distinguished, in which participants mentioned professionals' tendency to set goals solely from the professional perspective. Some participants stated that the wishes, needs, and problems 
of the patient should be translated into patient-directed goals, and they highlighted the importance of a goal-setting process. According to the participants, these goals need to be explored together with the patient before the interprofessional team meeting. Participants also stated that goals should be formulated in the patient's experience language. After this, the patient's goals can be introduced during the interprofessional team meeting.

\section{Member of the team}

Further, participants mentioned that, occasionally, the patient or a relative or informal caregiver are invited to attend interprofessional team meetings. They mentioned both benefits and barriers regarding the presence of a patient during a team meeting. Some participants experienced a participating patient as a benefit because in this way the patient's goals can be synchronized with the goals of the different health care professionals. Furthermore, by participating, patients get the feeling of being taken seriously as members of the team, and health care professionals no longer talk about the patient, but with the patient. Other patients experience barriers, e.g., the overwhelming professional perspective of the health care providers in comparison with the patients' perspective. As a response, one of the participants introduced safe climate as a factor that influences the input of the patient during team meetings.

\section{Professional-related factors}

\section{Individual competences}

Participants perceived professionals' individual competences as a factor influencing the process of collaboration. The ability of professionals to discover patients' goals and introduce these during team meetings was discussed during one of the focus group sessions as such a competence of professionals.

"In dialogue with the patient, professionals should discover the patients' goals, wishes and expectations as good as possible and bring these to the interprofessional team meeting". (Occupational therapist, H1.7)

Other competences were related to open communication and the ability to collaborate with colleagues from other disciplines as facilitators of interprofessional collaboration. 


\section{Domain thinking}

A professional-related barrier was domain thinking, or professionals only focusing on their own domains and showing a lack of interest for aspects outside these domains. One of the participants mentioned that professionals need to look beyond their own profession to share goals with colleagues from other disciplines.

"Dare to cross the own borders". (Occupational therapist, H1.7)

\section{Motivation}

Another critical factor for successful collaboration and sustaining success for the future is related to the professionals' continuing motivation. Participants mentioned both intrinsic and extrinsic aspects of motivation. Intrinsic motivation was described as the professionals' personal ideological drive, need, and willingness to collaborate. Financial incentives were mentioned as an aspect of extrinsic motivation.

"In starting up something new, everyone is motivated and willing to invest time and resources, but after a while, this willingness and motivation decrease". (Physical therapist, H1.5)

\section{Interpersonal factors}

\section{Use of discipline specific language}

The majority of the participants mentioned one or more factors related to the interaction between team members. According to the participants, professionals from different disciplines compile an interprofessional team with a diversity of perspectives and discipline specific language. These differences in languages are expressed by some of the participants as possible barriers to collaboration and a cause for confusion.

"Be able to define a shared language (also for the patient), and create a successful base for developing a shared care plan". (Consultant, E1.1)

Participants stated the importance of defining a shared language. One of the participants mentioned the World Health Organization's International Classification of Functioning (ICF), a model used to classify patients' functioning with standardized terminology, as a possible tool to support defining patients' functioning from various perspectives using a mutual language. ${ }^{26}$ In addition, participants recommended approaching patients from a broader perspective and formulating goals per discipline or domain. In addition to 
adopting a shared language, participants also stressed the importance of a shared interpretation of care, for instance, the concept of patient-centred care.

\section{Knowing each other}

According to the participants there is a difference between recently started teams and more self-regulating teams working together for a longer period. Participants were consistent about the importance of professionals (especially in beginning teams) paying attention to knowing each other as persons and knowing each other's professional backgrounds. Participants believed that professionals knowing each other well are better able to take advantage of each other's discipline-specific competences.

"Collaboration contributes to the mutual respect and supports in knowing each other's core business, strengths, and points in which professionals can reinforce each other, in the patients' benefits". (Social worker, H1.6)

Also for recently started teams, participants stressed the importance of in-person meetings to learn to know each other, create an atmosphere of mutual trust, and learn about the others' added value.

\section{Trust and respect}

In addition to the foregoing, trust and respect are two related terms that were mentioned multiple times during the focus groups as underlying preconditions of successful collaboration. A relation of trust and respect can grow by creating an open and safe environment in which the professionals dare to think and act broader than their own discipline. Within a safe environment, reflection and intervision were considered by participants as useful tools to talk about both individual and team functioning, roles and pitfalls, and improving the IPC. One of the participants stated the importance of periodic reflection by emphasizing that teams should regularly look at their status quo and possible pitfalls. As an example, one of the participants mentioned a technique called mirroring, a form of self-reflection that can be used as a method of intervision to look at both individual and team functioning.

"Mirroring, how do I perform in comparison with my colleagues, or how does our team function, compared with other teams"? (Manager, E1.7) 


\section{Organisational factors}

This category contains factors related to the organisation and execution of IPC regarding care plan development. Organisation-related factors were introduced by most of the participants and were associated with the format and composition of the team, time and efficiency, shared vision and mission, leadership, and administrative support.

\section{Format and composition}

Participants discussed a large variety of formats of a team meeting. Team meetings differed in composition, group size (3-14 members), frequency, duration, objective and mission, location and setting, and the number of patients discussed. Despite the fact that participants prefer smaller teams because of efficiency, they also stated the importance of the presence of all health care professionals involved. It seems to be hard to define who should be part of the core team. In practice, some professionals are present only on demand, based on the specific expertise needed at that moment. Further, some professionals do not take the oath of secrecy (e.g., welfare workers from municipalities), which has been mentioned as a barrier to sharing patient-related information and participation in a team meeting. Occasionally, the patient also is a member of the team.

\section{Time and efficiency}

Lack of time, both travelling time and the time that the health care professionals need to invest in participating in a team meeting, was considered to be a serious barrier. Due to different and busy schedules among team members, it sometimes is hard to find an appropriate meeting date.

"I think it's a mission impossible to assemble six health care professionals from different disciplines, meeting at the same time on a structural basis". (Researcher, E1.3)

Participants preferred the maintenance of short communication lines between colleagues from different disciplines. Different methods of communication concerning complex patients, both formal and informal, were introduced, e.g., emailing, phone calls, in person meetings, and virtual meetings. In addition, participants mentioned that by collaborating through virtual meetings and asynchronous communication, the time issue could be tackled. 


\section{Shared vision and mission}

Further, participants stated the relevance of general agreement on the team's goals and objectives, vision and mission, and how to talk as a team about patients' goals. Participants thought that clear rules and collaboration agreements support the progress and transparency within team meetings.

\section{Leadership}

All agreed that one of the team members should take the role of a leader or coordinator who monitors the shared goals and objectives, and guarantees the organisational requirements. This role, comprising the planning, agenda setting, structuring, and chairing of the team meetings, is a crucial task in attaining efficient and successful team meetings, as perceived by the participants. They saw the practice nurse as an appropriate person for this leading role.

"When the organisational task, containing the preparation and facilitation, is not arranged, the progress of the team meeting will be a disaster. In addition, the follow up of agreements needs to be agreed on". (Occupational therapist, E1.7)

Besides the role of a leader who carries out organisational tasks, participants also mentioned the role of a case manager being the contact person for the patient and overseeing all agreements and actions. Per patient, the team members need to consider who the appropriate case manager would be. According to the participants, this case manager explores goals and needs with the patient, and brings the patient's goals and wishes as a patient advocate to the interprofessional team meeting.

"Good to have a contact person for both patient and caregivers, someone who knows about the patient's situation". (Researcher, E1.3)

\section{Administrative support}

In addition, administrative support for documenting the meetings and adjusting the patient file, was acknowledged by the participants as a supporting factor for the practical organisation of the team meeting. 


\section{External factors}

\section{Education}

Participants explained the importance of paying attention to interprofessional education and suggested collaboratively discussing patient cases among students from various disciplines. At present professional education is seen as discipline specific, as a result of which individual expertise varies.

\section{Culture}

In addition to education, cultural aspects were highlighted during the focus group meetings. The cultural aspects include, for example, the traditional dominant role of the general practitioner (GP) as a leader. Several participants experienced the traditional role of the GP as a barrier to the unrestrained contribution of team members from other disciplines.

\section{Law and regulations}

Participants experienced the presence of laws, rules, and regulations as a barrier to the process of collaboration. The law regarding client privacy was mentioned multiple times. Strictly, the patient must give permission for the sharing of (patient) information between health care providers. In practice, this seems unworkable and is experienced by the participants as bureaucracy.

\section{Finance}

Another barrier introduced by several participants was financial remuneration. For most of the professionals, except for the GP and the practice nurse, participation in an interprofessional team meeting is not being rewarded financially. Participants argue that financial compensation for all team members would motivate and facilitate collaboration. As an example, one of the participants stated that collaborative projects and initiatives often come to an end when initial funding runs out. Integral financing for the interprofessional team as a whole was mentioned by the participants as possible answer to this financial issue.

\section{Information and communications technology (ICT)}

Participants also discussed the availability of ICT-related tools to support the interprofessional collaboration. These tools could be divided into two groups: tools for communication and tools for documentation of patient information. Participants 
mentioned the growing supply of possibilities for health care professionals to communicate with each other from a distance via, e.g., a Skype or Adobe connection, and the rising possibilities of asynchronous communication.

"One part of the key to successful interprofessional collaboration can be found in the implementation of ICT, and shared patient files". (Manager, H1.8)

Furthermore, participants introduced the use of shared information systems to document patient information and the benefit of sharing patient information. Some participants mentioned the example of the patient taking along a memory stick with personal information and the care plan to the different health care providers. In doing so, the patient is owner of his patient file and secures who will get access to the information.

\section{Discussion}

The aim of this qualitative focus group study was to map influential factors of interprofessional collaboration (IPC) concerning patient-centred care planning in primary care, as experienced by health care professionals and experts from various backgrounds. Our findings show a variety of factors that influence the process of interprofessional care plan development. The results can be divided into 5 categories: (1) patient-related factors: active role of the patient, formulation/language of patients' goals and wishes, member of the team; (2) professional-related factors: individual competences, domain thinking, motivation; (3) interpersonal factors related to the interaction between team members: use of discipline-specific language, knowing each other, trust, and respect; (4) organisational factors: format and composition of the team, time and efficiency, shared vision and mission, leadership, and administrative support; and (5) external factors: education, culture, law and regulations, finance, information and communications technology. Not surprisingly, most of the factors described correspond to the general theory of IPC and findings from previous published studies. This study, however, adds patient- and professional-related factors and issues directly related to interprofessional development of the patient-centred care plans. We will discuss some of these factors in more depth. 


\section{Point of departure}

Participants mentioned "knowing each other" and "motivation" as starting points and preconditions of successful care plan development. In practice, however, professionals seem to have a lack of awareness of each other's roles, which may lead to uncertainty and breakdowns in communication. ${ }^{27}$ Besides knowing each other, the results show the importance of building trust and respect among team members. Moreover, it becomes clear that professionals need certain competences in order to collaborate effectively. However, Frenk et al. (2010) state that professionals are falling short on appropriate competences for effective teamwork. ${ }^{28}$ In addition, participants emphasize the importance of interprofessional education and developing competencies that will enable students to work collaboratively throughout their professional careers. There seems to be a need for health professional education programmes that are committed to integrating interprofessional education into the curricula. ${ }^{29,30}$

\section{Leadership}

Our study indicates the importance of having a leader (one of the organisational factors) who prepares, structures, and organizes the interprofessional team meeting. In practice, the practice nurse or GP often fulfils the role of this chairperson. Cheater and colleagues (2005) recommend a trained, external chairperson or facilitator to structure and guide the interprofessional team meeting. ${ }^{31}$ Their study reveals a positive effect of an external chairperson, who used strategies to encourage collaborative working, associated with improvements to care. ${ }^{31}$ However, hiring an external leader may lead to considerable costs, and it's unknown if the benefits of such an external leader outweigh the additional costs.

\section{Professional related factors}

Another interesting finding is that participants experience domain thinking as a barrier to the process of shared care plan development. Baldwin (2007) sees this phenomenon of territoriality as a major challenge to IPC, in which the members of the group protect the scope and practice of their particular profession in regard to identity autonomy and accountability. ${ }^{32}$

\section{Patient related factors}

Our results also show the importance of involving the patients' perspective during care plan development. Empirical evidence emerging from qualitative studies indicates that patients value an approach to care that is focused on their individual needs and 
facilitates their involvement in care. ${ }^{33}$ Based on their review, D'amour et al. (2005) concluded that the patient is one of the main actors of a professional team. ${ }^{16}$ Patient participation takes different forms, tends to vary in application, and often is not explicitly stated. There is a growing advocacy for including patients as members of the teams collaboratively managing their chronic illnesses. ${ }^{34}$ A systematic review shows that patients with chronic diseases who participate in the decision-making process are better able to reach treatment agreement. ${ }^{35}$ However, Safran (2003) found that for most patients in primary care, the team remains invisible. Becoming more visible as a team seems to be a challenge. ${ }^{36}$

\section{Team development}

Finally, our study shows that IPC related to care plan development is about teamwork and is not associated to one given moment in time but more in line with a longitudinal developing process. Depending on the level of team development, different factors have an impact on care plan development. Periodic evaluation and reflection were mentioned by participants as a method of paying attention to team development and functioning. A review of Widmer and colleagues (2009) on recent developments in reflexivity also demonstrates that reflexivity can be important to guarantee and foster team functioning. ${ }^{37}$ Besides, periodic evaluation and reflection, they emphasize the role of leadership during team development and highlight the leader's key role in guiding reflection and discussing processes. ${ }^{37}$

\section{Strengths and limitations}

The description of the results of this study should be interpreted taking into consideration the strengths and limitations of this study. One of the strengths of this study is the mixture of participants involved in the focus groups. We included health care professionals form different disciplines and experts with a variety of experiential expertise working at different facilities, which enlarged the variety of view. Furthermore, the use of an experienced and independent moderator avoided bias. In their answers, the participants seemed to stick on theory instead of personal experiences, which could be seen as a possible limitation. Moreover, the patient perspective appears to be underexposed because the patient-experts seemed to have adopted a rather professional perspective. We recognize the importance of further research on this patient perspective. Moreover, we acknowledge that we cannot ignore the possibility that conducting an extra focus group meeting could bring in additional information. However, by purposive sampling a diverse range of professionals and experts, we think this possible shortcoming has been overcome. 


\section{Conclusion}

When targeting interventions aimed at improving IPC related to care plan development in primary care, a variety of influencing factors have to be taken into account. We recommend the development of interventions or tools that are multifaceted and focus on the patient perspective as a starting point, the professional's competences and attitudes, the interaction and communication between team members, the organisation and structuring of interprofessional team meetings, and the influence of external factors (e.g., law and regulation). The leader of the team seems to play a key role in the development and guidance of IPC. To conclude, it appears to be desirable to develop interventions with an integrated approach including these aspects. Furthermore, awareness needs to be raised for the importance of the patient perspective during care plan development. Further research on the patient perspective during care plan development seems to be desirable. 


\section{References}

1. Busse R, Blumel M, Scheller-Kreinsen D, Zentner A. Tackling Chronic Disease in Europe: Strategies, interventions and challenges. Europen Observatory on Health Systems and Policies 2010, 20.

2. Campbell-Scherer D. Multimorbidity: a challenge for evidence-based medicine. Evid Based Med. 2010; 15(6):165-6.

3. Wijlhuizen GJ. Impact of multimorbidity on functioning: Evaluating the ICF core set approach in an empirical study of people with rheumatic diseases. J Rehabil Med. 2012;44:664-8.

4. van Oostrom SH, Picavet HS, de Bruin SR, Stirbu I, Korevaar JC, Schellevis FG, Baan CA. Multimorbidity of chronic diseases and health care utilization in general practice. BMC Fam Pract. 2014;15:61.

5. Schafer W, Kroneman M, Boerma W, van den Berg M, Westert G, Deville W, van Ginneken E. The Netherlands: health system review. Health Syst Transit. 2010;12(1):v-xxvii, 1-228.

6. Freeth D: Sustaining interprofessional collaboration. J Interprof Care. 2001;15(1):37-46.

7. Samuelson M, Tedeschi P, Aarendonk D, de la Cuesta C, Groenewegen P. Improving interprofessional collaboration in primary care: position paper of the European Forum for Primary Care. Qual Prim Care. 2012;20(4):303-12.

8. Gilbert JHV, Yan J. Framework for action on interprofessional eduction and collaborative practice. In.: WHO Study Group on Interprofessional Education and Collaborative Practice; 2010.

9. Bodenheimer T, Chen E, Bennett HD. Confronting the growing burden of chronic disease: can the U.S. health care workforce do the job? Health Aff (Millwood). 2009;28(1):64-74.

10. Jansen D, Spreeuwenberg P, Heijmans M. Developments in the care for people with chronic conditions Report 2012. In. Utrecht: NIVEL; 2012.

11. Xyrichis A, Lowton K. What fosters or prevents interprofessional teamworking in primary and community care? A literature review. Int J Nurs Stud. 2008;45(1):140-53.

12. Sidani S, Fox M. Patient-centered care: clarification of its specific elements to facilitate interprofessional care. J Interprof Care. 2014;28(2):134-41.

13. Bodenheimer T, Handley MA. Goal-setting for behavior change in primary care: an exploration and status report. Patient Educ Couns. 2009;76(2):174-80.

14. Scobbie L, Dixon D, Wyke S. Goal setting and action planning in the rehabilitation setting: development of a theoretically informed practice framework. Clin Rehabil. 2011;25(5):468-82.

15. Newbould J, Burt J, Bower P, Blakeman T, Kennedy A, Rogers A, Roland M. Experiences of care planning in England: interviews with patients with long term conditions. BMC Fam Pract. 2012;13:71.

16. D'Amour D, Ferrada-Videla M, San Martin Rodriguez L, Beaulieu MD. The conceptual basis for interprofessional collaboration: core concepts and theoretical frameworks. J Interprof Care. 2005;19 Suppl 1:116-31.

17. Dinh T. Improving Primary Health Care Through Collaboration. Briefing 2: Barriers to Succesfull Interprofessional Teams. In. Ottawa: The Conference Board of Canada. 2012:2 e.v.

18. San Martin-Rodriguez L, Beaulieux M-D, D'Amour D, Ferrada-Videla M. The determinants of succesful collaboration: A review of theoretical and emperical studies. J Interprof Care. 2005;5(1):132-47.

19. Goldman J, Meuser J, Rogers J, Lawrie L, Reeves S. Interprofessional collaboration in family health teams: An Ontario-based study. Can Fam Physician. 2010;56(10):e368-74.

20. Krueger R, Casey M, Focus Groups. A Practical Guide for Applied Research, vol. 4. Los Angeles; 2009.

21. Wong LP. Focus group discussion: a tool for health and medical research. Singapore Med J. 2008; 49(3):256-60.

22. Tong A, Sainsbury P, Craig J. Consolidated criteria for reporting qualitative research (COREQ): a 32-item checklist for interviews and focus groups. Int J Qual Health Care. 2007;19(6):349-57.

23. Hsieh HF, Shannon SE. Three approaches to qualitative content analysis. Qual Health Res. 2005;15(9): 1277-88.

24. Mortelmans D. Kwalitatieve analyse met Nvivo. Leeuwen: Acco Uitgeverij; 2011.

25. Holloway L, Wheeler S. Qualitative Research in Nursing and Healthcare: John Wiley \& Sons. 2010.

26. Constand MK, MacDermid JC. Applications of the International Classification of Functioning, Disability and Health in goal-setting practices in healthcare. Disabil Rehabil. 2014;36(15):1305-14. 
27. Jenkins VA, Fallowfield LJ, Poole K. Are members of multidisciplinary teams in breast cancer aware of each other's informational roles? Qual Health Care. 2001; 10(2):70-5.

28. Frenk J, Chen L, Bhutta ZA, Cohen J, Crisp N, Evans T, Fineberg H, Garcia P, Ke Y, Kelley P et al. Health professionals for a new century: transforming education to strengthen health systems in an interdependent world. Lancet. 2010;376(9756):1923-58.

29. Chan AK, BPharm, Wood V. Preparing Tomorrow's Healthcare Providers for Interprofessional Collaborative Patient-Centrered Practice Today. UBCMJ. 2010;1(2).

30. Tsakitzidis G, Timmermans O, Callewaert N, Truijen S, Meulemans H, Van Royen P. Participant evaluation of an education module on interprofessional collaboration for students in healthcare studies. BMC Med Educ. 2015;15(1):188.

31. Cheater FM, Hearnshaw H, Baker R, Keane M. Can a facilitated programme promote effective multidisciplinary audit in secondary care teams? An exploratory trial. Int J Nurs Stud. 2005;42(7):779-91.

32. Baldwin DC, Jr.: Territoriality and power in the health professions. J Interprof Care. 2007;21 Suppl 1: 97107.

33. Sumsion T, Lencucha R: Balancing challenges and facilitating factors when implementing client-centred collaboration in a mental health setting. Br J Occupational Ther. 2007, 70(12):513-20.

34. Coulter A. Partnerships with patients: the pros and cons of shared clinical decision-making. J Health Serv Res Policy. 1997;2(2):112-21.

35. Joosten EA, DeFuentes-Merillas L, de Weert GH, Sensky T, van der Staak CP, de Jong CA. Systematic review of the effects of shared decision-making on patient satisfaction, treatment adherence and health status. Psychother Psychosom. 2008;77(4):219-26.

36. Safran DG. Defining the future of primary care: what can we learn from patients? Ann Intern Med. 2003; 138(3):248-55.

37. Widmer PS, Schippers MC, West MA. Recent developments in reflexivity research: a review. J Psychol Everyday Activity 2009, 2(2). 
Appendix 3.1

\section{Background information of participants}

\begin{tabular}{|c|c|c|c|}
\hline N & $\begin{array}{l}\text { Identification } \\
\text { number }\end{array}$ & Occupation & Expertise \\
\hline 1 & E1.1 & Consultant & Process management / organisational science \\
\hline 2 & $\mathrm{E} 1.2$ & Researcher & Self-management \\
\hline 3 & $\mathrm{E} 1.3$ & Researcher & Implementation science \\
\hline 4 & E1.4 & Teacher general practice & Patient communication \\
\hline 5 & E1.5 & Teacher/researcher & Interprofessional education, patient centred care \\
\hline 6 & E1.6 & Teacher/researcher & Interprofessional teamwork, technology in care \\
\hline 7 & E1.7 & Manager & Health care processes and logistics \\
\hline 8 & E1.8 & Teacher/researcher & Communication and multimedia design \\
\hline 9 & H1.1 & Practice nurse & Geriatrics \\
\hline 10 & $\mathrm{H} 1.2$ & Psychologist/researcher & Neuropsychology \\
\hline 11 & $\mathrm{H} 1.3$ & Manager & Patient organisation, patient perspective \\
\hline 12 & $\mathrm{H} 1.4$ & Family physician & Chronic care, polypharmacy \\
\hline 13 & $\mathrm{H} 1.5$ & Physical therapist & Geriatrics \\
\hline 14 & H1.6 & Social worker & Manager social work \\
\hline 15 & $\mathrm{H} 1.7$ & Occupational therapist & Practice holder, interprofessional collaboration \\
\hline 16 & $\mathrm{H} 1.8$ & Manager & Manager home care, nurse \\
\hline 17 & $\mathrm{H} 1.9$ & Nurse/teacher & Geriatric clinical nurse specialist \\
\hline 18 & E2.1 & Researcher & Self-management, patient perspective \\
\hline 19 & E2.2 & Manager & Patient organisation, informal care giving \\
\hline 20 & E2.3 & Teacher/researcher & $\begin{array}{l}\text { Communication trainer, patient professional } \\
\text { communication }\end{array}$ \\
\hline 21 & E2.4 & Teacher/researcher & Patient-centred care \\
\hline 22 & E2.5 & Teacher & Patient - professional communication \\
\hline 23 & E2.6 & Researcher & Patient communication \\
\hline 24 & E2.7 & Researcher & Professor family practice, shared decision making \\
\hline 25 & E2.8 & Researcher & Patient communication \\
\hline 26 & $\mathrm{H} 2.1$ & Practice nurse & Geriatrics \\
\hline 27 & $\mathrm{H} 2.2$ & Social worker & Youth care \\
\hline 28 & $\mathrm{H} 2.3$ & Physical therapist & Geriatrics, teacher \\
\hline 29 & $\mathrm{H} 2.4$ & Practice nurse & Geriatrics \\
\hline 30 & $\mathrm{H} 2.5$ & Physical therapist & Psychosomatic, geriatrics, teacher \\
\hline 31 & $\mathrm{H} 2.6$ & Occupational therapist & Geriatrics, psychology \\
\hline
\end{tabular}




\section{Appendix 3.2}

\section{Semi structured interview guide}

Interview guide focus groups

- Introduction

o Introduction of the discussion leader/moderator

o Consent for audio recording

- Explanation of participants' rights

o Aim of the focus group: The aim is to explore your experience with interprofessional collaboration in the context of self-management in primary care, to explore your viewpoint about relevant factors and about facilitators and barriers.

o Procedure, duration etc.

o Definition self-management: Self-management is defined as "the degree to which a patient with a chronic condition is able and willing to control his or her daily life by effective management of symptoms, treatment of physical, social and psychological disease consequences, and lifestyle adjustments".

o Definition interprofessional collaboration: We define interprofessional collaboration as "Multiple health workers from different professional backgrounds work together with patients, families, caregivers, and communities to deliver the highest quality of care".

o Clarification that all information is relevant

\section{Main questions}

1. What is the first thing that comes into your mind when you think about interprofessional collaboration in primary care?

2. What are your experiences with interprofessional collaboration (related to the development of patient-centred care plans) in primary care?

3. According to you, what are relevant factors that influence the process of interprofessional collaboration (related to the development of patient-centred care plans) in primary care?

4. What do you experiences as a barrier/facilitator with regard to the process of interprofessional collaboration (related to the development of patient-centred care plans) in primary care?

5. Did you miss a relevant question/factor in this discussion? 


\section{Subquestions}

- Can you give an example?

- Can you explain in detail what you mean by...?

- Why do you experience...as a relevant factor/barrier/facilitator?

\section{Summary}

Moderator gives a summary.

- Did I forget relevant information in this summary? 


\section{Chapter 4}

Interprofessional primary care team meetings: a qualitative approach comparing observations with personal opinions

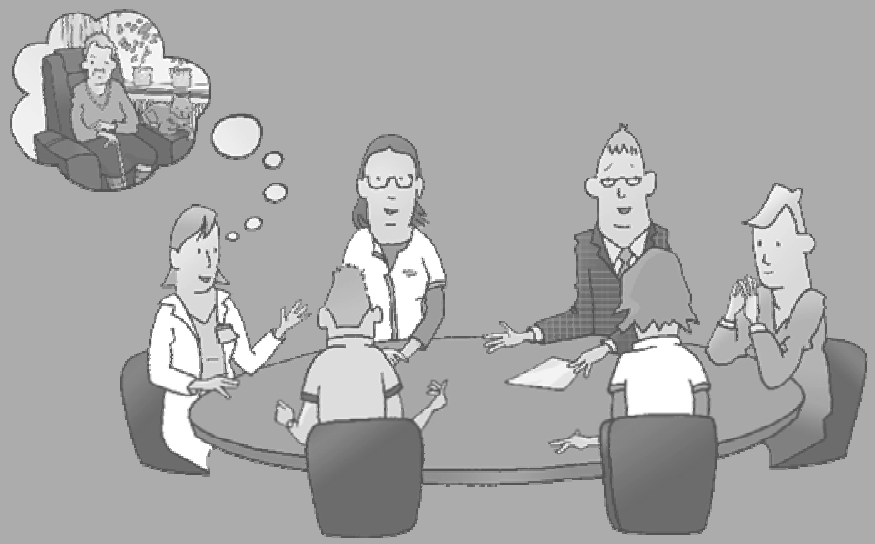

Jerôme van Dongen Loes van Bokhoven Ramon Daniëls Stephanie Lenzen Trudy van der Weijden Sandra Beurskens Fam Pract. 2017;34(1):98-106 


\section{Abstract}

\section{Introduction}

The number of people with multiple chronic conditions requiring primary care services increases. Professionals from different disciplines collaborate and coordinate care to deal with the complex health care needs. There is lack of information on current practices regarding interprofessional team (IPT) meetings.

\section{Objectives}

This study aimed to improve our understanding of the process of interprofessional collaboration in primary care team meetings in the Netherlands by observing the current practice and exploring personal opinions.

\section{Methods}

Qualitative study involving observations of team meetings and interviews with participants. Eight different IPT meetings $(n=8)$ in different primary care practices were observed by means of video recordings. Experiences were explored by conducting individual semi-structured interviews ( $n=60$ ) with participants (i.e. health care professionals from different disciplines) of the observed team meetings. The data were analysed by means of content analysis.

\section{Results}

Most participants expressed favourable opinions about their team meetings. However, observations showed that team meetings were more or less hectic, and lacked a clear structure and team coordinator or leader. There appears to be a discrepancy between findings from observations and interviews. From the interviews, four main themes were extracted: (1) Team structure and composition, (2) Patient-centredness, (3) Interaction and (4) Attitude and motivation.

\section{Conclusion}

IPT meetings could benefit from improvements in structure, patient-centredness and leadership by the chairpersons. Given the discrepancy between observations and interviews, it would appear useful to improve team members' awareness of aspects that could be improved before training them in dealing with specific challenges. 


\section{Introduction}

The number of patients with multiple chronic conditions requiring primary care services is increasing in European countries. ${ }^{1-3}$ Nowadays, care delivery for these chronically ill people is moving towards patient-centred care, highlighting the need for health care to be more explicitly focused on individual patients' personal needs and wishes. ${ }^{4}$ Dealing with this complex care demand and the patient-centred care approach involves efforts over a long time period, comprising coordinated inputs from a wide range of health care professionals. ${ }^{5}$ It appears valuable to encourage and achieve interprofessional collaboration (IPC) by working in partnership with patients and health care professionals from different disciplines to enhance the quality of care. ${ }^{6}$ A cohesive and cooperative team of professionals seems to be an important element of patient-centred care, ${ }^{7}$ as quality of care is influenced by effective interaction between patients and health care professionals, as well as by successful cooperation among the team of professionals (8). This interprofessional team (IPT) identifies the best options and facilitates the patient's involvement in decision-making using those options, also known as interprofessional shared decision-making. ${ }^{9}$

In Dutch primary care practice, IPC is often implemented in periodic IPT meetings, in which health care professionals from a diversity of disciplines collaborate, discuss and work towards a shared patient-centred care plan. This shared care plan can be seen as a collaborative and shared document, ${ }^{10}$ summarizing the patient's current and preferred situation, and personal goals and actions. ${ }^{11}$ IPC appears to be a promising approach to the development of shared care plans. Working in teams enables health care professionals to communicate and address the complex and challenging needs of the chronically ill. ${ }^{12}$ In addition, working together enables health care professionals to share their expertise and perspectives to set common goals, in order to improve or maintain patients' quality of life. Furthermore, IPT meetings can be seen as learning opportunities, as health care professionals learn from each other's expertise. ${ }^{13}$

Conducting IPT meetings is regarded as complex and influenced by many interrelated factors. ${ }^{12,14-17}$ Frequently mentioned favourable factors are: shared vision, common goals, respect and trust among team members, communication, effective leadership, shared reflection ${ }^{12,14,15}$ and a clear description of roles and responsibilities. ${ }^{17} \mathrm{~A}$ review by Xyrichis and Lowton (2008) revealed that team processes as well as team structure impact on successful IPT meetings in a primary care setting. ${ }^{14} \mathrm{~A}$ study by Jaruseviciene and colleagues (2013) found that both formal and individual behavioural factors should be targeted in efforts to strengthen IPT meetings. ${ }^{17}$

Although various influencing factors are known, it is unclear how effective team meetings can be accomplished, and there seems to be no consensus about the key 
features of successful interprofessional teamwork in primary care. ${ }^{18}$ In addition, since IPC is gaining in popularity, it seems important to explore the experiences of team members participating in primary care team meetings, to allow the voices of the health care professionals themselves to be heard. ${ }^{12}$ There also seems to be a lack of information on current practices regarding interprofessional teamwork and developing shared care plans in primary care in the Netherlands. In order to examine the current practices in greater depth, and to answer the 'how' question, it is important to use multiple data collection methods. According to Morgan (2015), direct observations of collaborative practice in everyday work settings are a promising approach to exploring the complex phenomena of IPC. Interviews can be used to examine professionals' personal experiences. However, there seems to be a lack of studies attempting to directly observe such practices, ${ }^{19}$ and most of the existing studies have applied a survey approach or only included a small number of different professions. Overall, there seems to be a lack of studies based on observations of interprofessional teamwork combined with interviews. ${ }^{20}$ The aim of the present study was therefore to examine current practices in IPT meetings in primary care, as well as 'how' they are conducted, as well as to explore health care professionals' personal opinions regarding the current practice.

\section{Methods}

\section{Study design}

We conducted a qualitative study involving both observations of team meetings and individual semi-structured interviews with participating health care professionals. Relevant aspects of this study are reported here following the Consolidated Criteria for Reporting Qualitative Research (COREQ).

\section{Setting and participants}

Both observations and interviews took place in various health care centres and primary care practices in the Province of Limburg, the Netherlands. Data were collected between 2012 and 2013. Primary care teams were recruited and selected by pragmatic sampling, using the researchers' network. Teams meeting the following criteria were included: (1) the IPT had to consist of three or more health care professionals from different professional backgrounds and (2) primary care team meetings had to focus on discussing complex health care demands of individual (adult) patients (embracing conditions related to physical, mental and social aspects) and developing shared care plans. Practices were approached by e-mail or, in case of non-response, by telephone. The 
teams' contact persons received a letter with background information about the nature of the study and the confidentiality of the data. After a team had been selected, the other team members received oral background information from the researcher. Before the observations and interviews took place, oral informed consent was obtained from all participating health care professionals. Further, we obtained written informed consent from the patient and informal caregiver participating in team 7. In total, eight primary care teams $(n=8)$ were included. From those eight teams, only a few members were unable to attend an interview due to lack of available time, so eventually 60 team members took part in an interview $(n=60)$. The 60 team members we interviewed included family physicians, nurse practitioners, occupational therapists, physical therapists, psychologists, nurses, social workers, pharmacists, case managers for dementia, a human resource consultant, patient advisors, and one patient and his informal caregiver. Table 4.1 gives an overview of the interviewees in each team.

\section{Observations}

Access to the meetings was arranged by the teams' contact person or coordinator. Team meetings were audio and video recorded. During the observations, field notes were taken by one of the researchers (JVD or SL). In addition, regular features of the meeting (e.g. presence of a chairperson, agenda, shared reporting and number of participants) were recorded, using an observation list (Appendix 4.1). In order to better understand the communication and behaviour in the teams we observed meetings at three different levels of communication (procedural level, content level and interaction level) as described by Remmerswaal. ${ }^{21}$ The procedural level refers to the way a team works on a task, such as the methods and procedures used to achieve the goal. The content level concerns the topic of the conversations, their content and the information discussed. The interaction level refers to the team process and to what happens between the team members. In observing the content, we specifically focussed on the patients' background and health condition, the professionals' questions to the team, whether or not the patients' goals were mentioned, the exchange of information, clarification of patients' values/preferences, concrete actions and decisions, and evaluation of the care plan, based on the structure of the 'interprofessional shared decision-making model' ${ }^{22}$.

\section{Interviews}

Immediately after a team meeting took place, the team members were interviewed individually but simultaneously by a team of trained interviewers (under supervision of JVD and SL) from the Faculty of Health (Zuyd University). This method ensured that the team members did not have to wait to be interviewed and they could immediately 
reflect on the team meeting. The individual interviews lasted an average of 15 minutes and were recorded using voice recorders. A semi-structured interview guide with openended questions guided the individual interviews (Appendix 4.2). All interviews started with an open-ended question to explore respondents' experiences with the IPT meetings that had just taken place. Subsequently, respondents were asked about their experiences, barriers and facilitators for effective IPT meetings, and possible improvements to their IPT meetings, in relation to the development of patient-centred care plans. Follow-up questions were used to gain more in-depth information and elicit rich information. Before being actually used, the interview guide was tested in a pilot interview and adjusted where needed.

\section{Analysis}

Observations as well as interviews were transcribed verbatim. The primary transcription was made from the audio recordings, while the video recordings were used during transcription to clarify who was speaking. NVivo 9 software was used to store and structure the transcripts and code the data from both observations and interviews. Observations were analysed by means of directed content analysis. ${ }^{23} \mathrm{~A}$ detailed description of each observation was made, concentrating on the focal points mentioned in Appendix 4.1. The interview data were analysed using thematic content analysis. ${ }^{24}$ Two researchers, JVD and SB (an external and experienced coder), analysed all the transcripts independently and carried out the open coding of all quotes relevant to the aim of the study. Concepts were identified and grouped into subcategories. In the next step, the two researchers compared and discussed their codes until they reached consensus and subsequently categorized into the different subcategories. In case of disagreement, a third researcher (LVB) was asked for advice. In the final step, the researchers identified key theme categories into which the subcategories could be divided.

\section{Trustworthiness}

The researchers' field notes and written comments were used in the analysis process to enhance the trustworthiness of the study. Furthermore, two researchers coded the data independently and then discussed and compared categories and subcategories, consulting a third researcher in case of disagreement. Moreover, combining data from both observations and interviews, also known as data triangulation, provided additional perspectives and a more complete picture, and enhanced internal validity. ${ }^{25}$ 


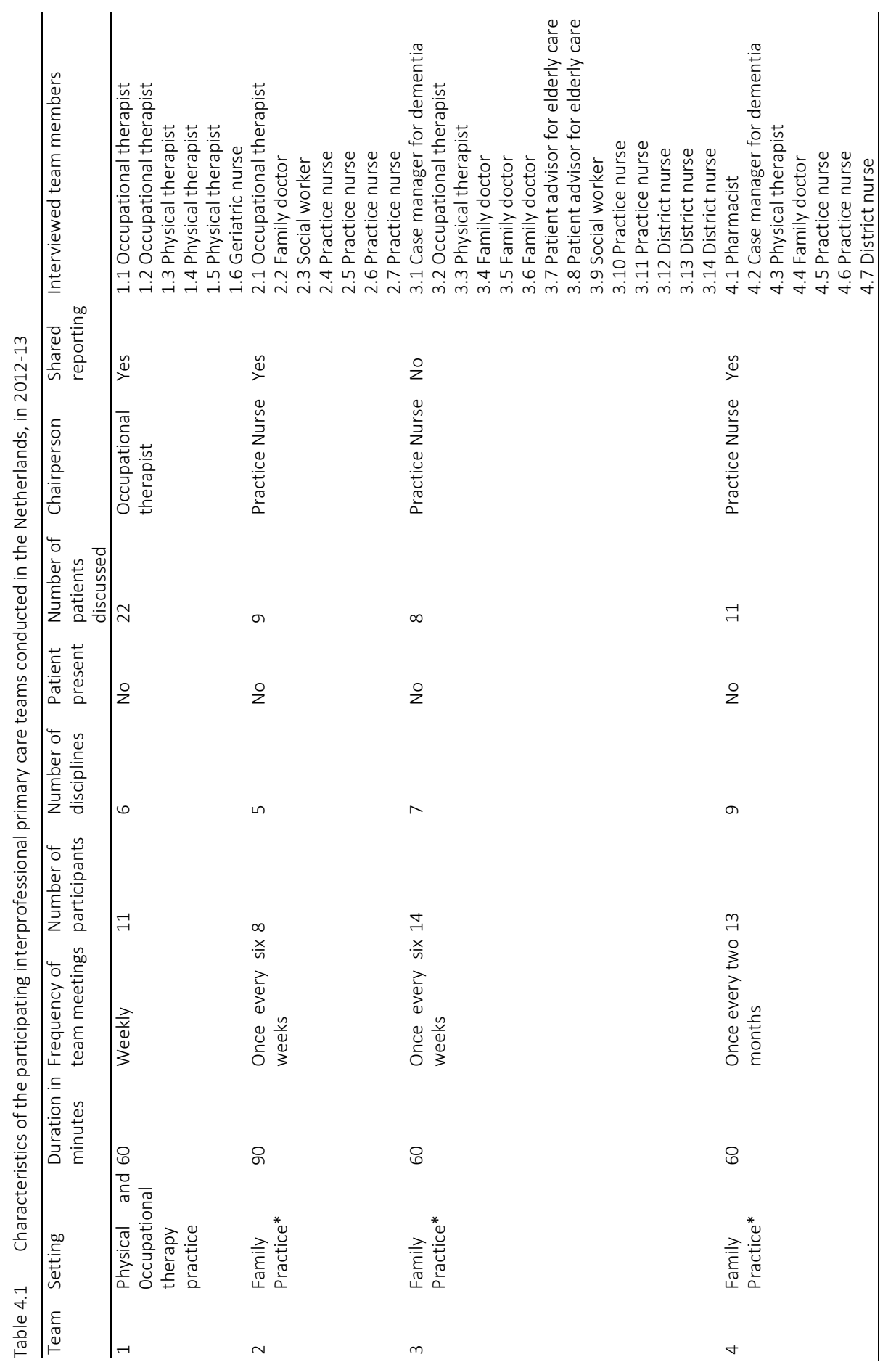




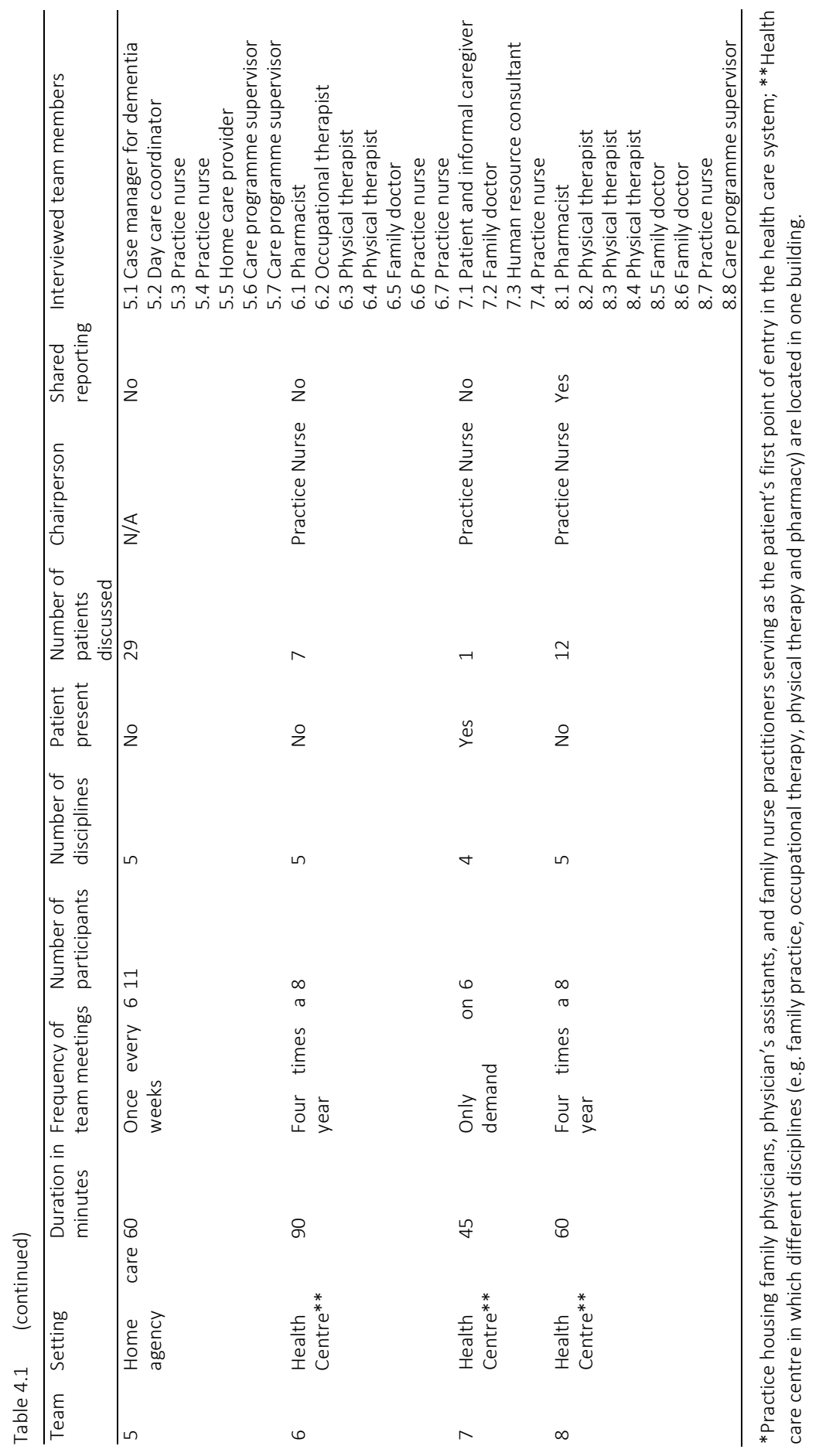




\section{Results}

We observed eight interprofessional primary care team meetings in different practices and interviewed 60 participants individually. After having analysed 5 observations of different IPT meetings and 40 individual interviews, we found that analysing additional observations and interviews did not bring new insights, so data saturation had been achieved. Table 4.1 gives an overview of the teams' characteristics.

\section{Observations}

\section{Procedural level}

As described in Table 4.1, the IPT meetings were conducted in various ways. They varied in terms of setting, duration, frequency, numbers of participants, disciplines and numbers of patients discussed. In some practices, an agenda was used to prepare for the meeting, indicating which patients were to be discussed. The number of participants of the team meetings ranged from 6 to 14, and included 4 to 9 different disciplines. It should be noted, however, that not all participants were present for the entire meeting. The number of patients discussed during a meeting also differed between the teams. One team meeting discussed 29 patients, while the team meeting that was attended by the patient only discussed this particular patient's case. Half of the teams applied shared reporting, capturing the teams' main agreements. Most of the observed team meetings did not have a clear structure, though in a minority of practices the chairperson actively structured the meeting, introduced patient cases, summarized agreements and kept track of the time. In all but one team was the role of chairperson fulfilled by the practice nurse, who guided the meeting. However, the interpretation of this role differed per team, ranging from active and directive to more or less passive.

\section{Content level}

All teams observed discussed patients with complex health care demands requiring an interprofessional approach. These patients suffered from multiple chronic conditions and experienced problems related to the physical, mental and social domain. Almost all case discussions during the meetings started with a description of the patients' history and background. In most of the observed meetings, a lot of time was spent on this history and background. In the majority of the team meetings, no clear question was put before to the team and the attendees did not ask for such a question. As a result, most of the meetings did not result in concrete agreements and adjustments to the care plan but remained descriptive and noncommittal, lacking actual decision-making. 
During some of the discussions, however, it became clear from the context what problem or question the health care professional wanted to be dealt with.

We observed that in most cases, the professionals' perspective on a patient's case appeared to be superior to the patient's individual perspective and personal goals, since patients' goals and concerns were not introduced and problems were discussed as perceived by the professionals. Even during the meeting where the patient was present, no clear patient goals were formulated. Only in one case did a health care professional ask about the patient's goals during the meeting.

Throughout most of the cases discussed, team members pro- posed specific ideas, interventions or possible actions to deal with the patients' health care demand and support the patients in managing their situation. Suggestions and ideas differed in nature and covered various domains, including practical adjustments to the home situation, informal care, day care, adjusting medication or transfer to a nursing home. Suggested actions rarely concerned contributions by the patients themselves. Based on the suggested actions and interventions, most of the teams prioritized and decided on actions which could be presented to the patient. Only for a minority of the suggested actions did the team agree on who would be responsible and at what moment feedback would be given to the team.

\section{Interaction level}

We observed a pleasant atmosphere during all of the meetings and did not detect any visible conflicts or irritations. During some of the meetings, we observed a dominant role of the family doctors. When it came to making decisions, most of the team members looked towards the family doctor. We further observed a close relationship and 'short lines of communication' between health care professionals. Professionals were able to find and consult each other easily. Moreover, we did not observe any negative or fractious participants. Most of the team members seem to have an open attitude in which they asked each other questions and reacted positively towards other people's insights. We further observed that not all team members played an active role during the meeting. For most of the meetings, only a small proportion of the members participated actively. The patients' family doctors and practice nurses were talking most of the time, while the professionals from other disciplines talked less frequently.

\section{Interviews}

Four main themes emerged from the interviews, describing current practices and personal experiences of health care professionals regarding IPT meetings: (1) Team 
structure and composition, (2) Patient-centredness, (3) Interaction and (4) Attitude and motivation. The main themes with their subthemes are presented in Figure 4.1.

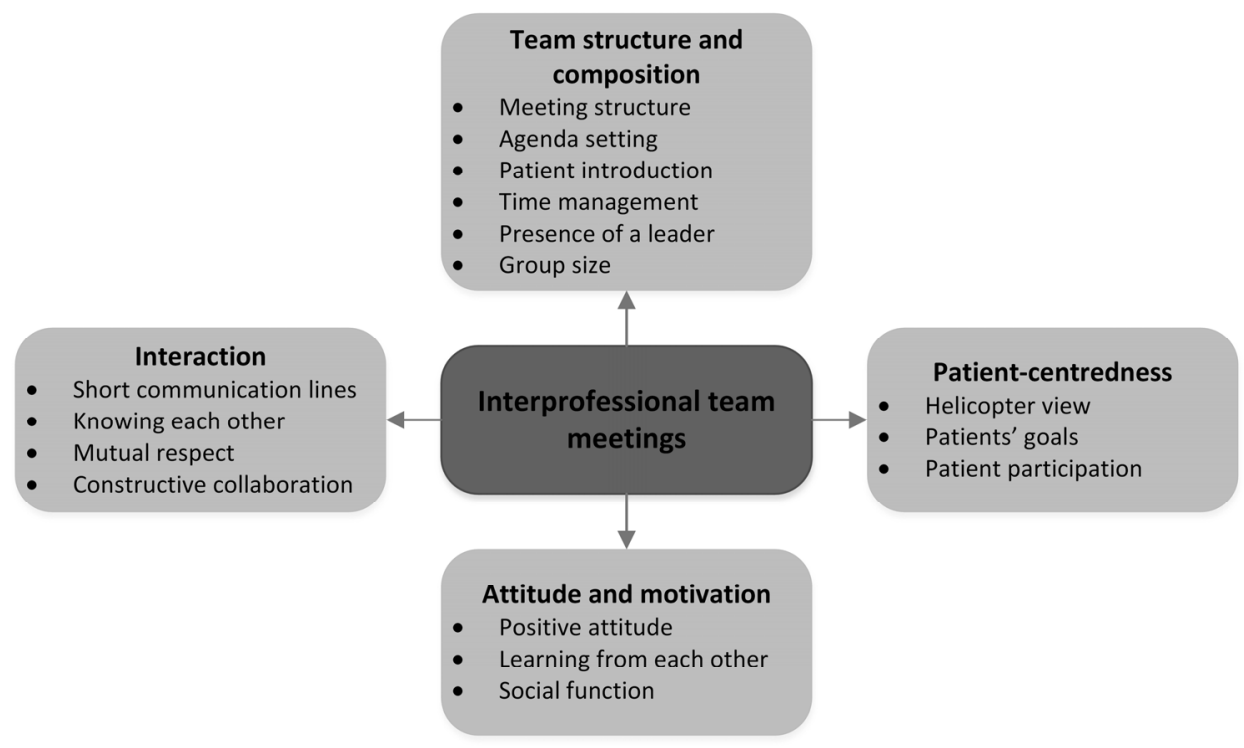

Figure 4.1 Key themes regarding interprofessional team meetings derived from observations and interviews in the Netherlands, conducted in 2012-13.

\section{Team structure and composition}

Most of the respondents reported having perceived a structured team meeting. Nevertheless, some of the respondents did recognize structure as a target for improvement. Some of the respondents mentioned that the team does not usually discuss patients according to a fixed structure. They acknowledged that elements like the patient's care demand and goals, a summary of agreements, conclusions, suggestions or action points were mixed or missing.

"Sometimes the purpose of the topic discussed is unclear; is it a matter of informing? Or coordinating? Or a question for the group to answer?" (Social worker, team 2)

Some of the respondents thought that the introduction and description of the patients could be improved, so that all participants quickly get a good picture of each patient. 
"The person who introduces the patient should present a clear case and a question" (Social worker, team 2)

Working on the basis of an agenda, keeping minutes, time management and working in a problem-oriented fashion were mentioned as possible strategies to structure the meetings. Some of the respondents suggested disclosing the patients' name and date of birth and stating a specific question on the agenda, allowing the attendees to know in advance which patient is involved so they suitably prepare the meeting. Another factor mentioned as a precondition for a structured meeting was an active and directive role of the person chairing the meeting. Respondents argued that it is not easy to find an appropriate chairperson because of a lack of expertise and time.

"I'm a family doctor, not a chairperson. I did not go to chairpersons college, but studied medicine. Those are two very different things" (Family doctor, team 3)

Some respondents mentioned that the large number of team members sometimes meant it was not clear who was who. They also stated that a group which is too large has a negative effect on group processes, efficiency and time, and confuses team members, resulting in chaotic meetings. As a solution, they recommended working with nametags and spending time introducing themselves to the others.

"The meeting is chaotic because there are many people present and everyone wants to have their say" (Physical therapist, team 1)

\section{Patient-centredness}

Some of the respondents mentioned that they had developed an overall picture and helicopter view of the patient during the team meeting, since each team member knew the patient from the perspective of his or her own discipline and experience.

"By joining such a meeting you get a complete picture of the patient" (Physical therapist, team 6)

Some respondents said they appreciated team meetings more when the patients' goals were addressed. During one of the meetings, a patient and his partner were present. Both the patient and the health care professionals attending this specific meeting mentioned that the personal goals of the patient had been introduced. During this meeting, the patient was given the opportunity to tell and explain his personal story. 
However, due to the emotionally charged nature of the story, this meeting was perceived as being very stressful for the patient and his partner.

"The conversation was very stressful for the patient, in an emotional sense as well. It makes you wonder if this is the right thing to do?" (Practice nurse, team 7)

\section{Interaction}

Some of the interviewees appreciated the short lines of communication between health care professionals. They mentioned that these led to greater efficiency, more accessibility and thus faster decision-making. In addition, it allows tasks to be divided, which supports care coordination.

"If you have any questions, you can immediately contact the appropriate colleague" (Occupational therapist, team 1)

Getting to know the other professionals personally was also perceived as positive by the respondents. They stated that it enhanced trust.

"As you get to know each other better, you get a better idea what to expect from a person" (Case manager for dementia, team 4)

Respondents also appreciated the fact that everyone could have their say and that team members did not interrupt each other. Team members listened carefully to each other in a constructive way. Another respondent mentioned the importance of mutual respect.

\section{Attitude and motivation}

In general, the respondents had a favourable impression of the team meetings, and had enjoyed attending the meeting. Respondents said they appreciated the possibility to ask questions and express their opinions. They further mentioned the social value of meeting people face to face, and enjoyed seeing each other regularly. In addition, the informal approach during the team meetings and the positive team climate made respondents enjoy their work more. A number of participants indicated that they actively learned from each other's input and expertise. Some respondents valued the fact that interesting topics, like care reforms and practical applications of laws and regulations, were sometimes discussed. 


\section{Discussion}

Both the observations and interviews showed that IPT meetings took place in a pleasant atmosphere, and that they varied in both form and content. However, the ultimate goal of such meetings, to jointly develop a shared care plan, summarizing the patient's current and preferred situation, and personal goals and actions, was frequently not reached. This was, however, often not recognized by the professionals themselves, who perceived the meetings as more or less structured and patient-centred.

Certain targets for improvement can be identified, especially regarding structure and patient-centredness, both of which have been recommended in the literature to strengthen IPT meetings. ${ }^{14,26,27}$ Similar to the findings of our study, Xyrichis identified group size and composition, as well as clear goals and objectives as important indicators of successful teamwork. ${ }^{14}$ Xyrichis also identified organizational support and support for innovation as factors influencing teamwork, which were indeed also mentioned by the participants of our study. As regards structure, we observed a lack of clarity regarding the purpose of the meetings and the topics discussed, resulting in rather superficial discussions. This was confirmed by the interviews, in which respondents suggested that the person who introduces the patient, should also pose a clear question to the team. The chairperson appears to play a significant role in structuring and guiding the team meeting, as has also been emphasized in the literature. ${ }^{12,28,29}$ In addition to their 'technical' role, it has also been claimed that the chairperson should adopt the role of a leader who is responsible for the team's performance, and guides the team through its development over time. ${ }^{12}$ This role might require sufficient authority and sometimes a directive leadership style. ${ }^{27}$ The 2015 CanMEDS medical competency framework recognizes the importance of leadership competencies in the increasingly complex health care. ${ }^{30}$

Prior to the IPT meeting, professionals need to explore goals and meaningful activities of the patients they would like to discuss. ${ }^{31}$ As regards patient-centredness, the professionals we interviewed stated that they did introduce the personal goals of the patients during the IPT meetings. However, our observations showed that it was the professionals' perspective which dominated, and that patients' personal goals were only mentioned in exceptional cases. The literature reveals that professionals appear to have difficulties regarding the implementation of goal setting in their routine practice, ${ }^{32,33}$ which can be explained by the fact that guidelines rarely offer information on how the goal setting should be realized. ${ }^{34}$ Another possible explanation could be that professionals have 'blind spots' with regard to patient-centredness and are in need of support to increase their awareness and self-reflective power as a first step towards improving current practice and the patients' health. An alternative to exploring patients' 
goals prior to the IPT meeting, is that patients participate themselves and introduce their own goals. However, our observations demonstrate that patients seldom participate during team meetings. Due to patient participation, the decision-making process and care of chronic illness improves, ${ }^{35}$ therefore it seems to be interesting to explore possibilities to increase patient participation during team meetings.

Scientific literature shows that improved IPC is positively related to the care and health outcomes of patients. ${ }^{36,37}$ Further, from oncology setting, we know that conducting IPT meetings can lead to significant changes in the way patients are assessed and managed. ${ }^{36}$ This study offers insight into current practices of the process of IPC in IPT meetings and enlightens opportunities to improve.

\section{Strengths and limitations}

The qualitative approach of this study provides an in-depth under- standing of 'how' IPT meetings in primary care are actually conducted and the health care professionals' opinions. By conducting the interviews immediately after the IPT meetings took place, we gave the team members an opportunity to reflect on their experiences with the meetings. Furthermore, this approach provided us with an opportunity to detect blind spots that team members were often not aware of. We were not able to interview all participating team members. Therefore, we have to take into account the potential influence of selective participation impacting our findings. However, we were able to interview $76 \%$ of all participating team members, (range $55 \%$ to $100 \%, n=60$ ) from 15 different disciplines (range 3 to 7). Therefore, we assume the sample representative of health care professionals participating in IPT meetings. Data saturation was reached after observations of five different IPT meetings and 40 individual interviews had been analysed. A possible limitation to his study could be the fact that we hired a team of students to conduct some of the interviews. Given the inexperience of these students, this might have resulted in underreporting of findings. However, we trained these students in qualitative interviewing and therefore assume they were able to conduct individual interviews appropriately.

\section{Conclusion}

The current practice of IPT meetings leaves room for improvement in terms of structure and patient-centredness. The chairperson of the team, when appropriately trained, may play the role of a change agent. Given the discrepancy between our observations and the interviews, it would seem to be useful to improve team members' awareness of the 
aspects that need to be improved before training them in dealing with the specific challenges of these meetings. Further research is needed to identify opportunities to increase professionals' self-reflective power. 


\section{References}

1. Blokstra A, Verschuren WMM, Baan CA, Boshuizen HC, Feenstra TL, Hoogenveen RT, et al. Impact of ageing population on burden of disease. Projections of chronic disease prevalence for 2005-2025. Eindhoven: National Institute for Public Health and the Environment (RIVM), 2007.

2. Campbell-Scherer D. Multimorbidity: a challenge for evidence-based medicine. Evid Based Med. 2010; 15(6):165-6.

3. Busse R, Blumel M, Scheller-Kreinsen D, Zentner A. Tackling chronic disease in Europe: Strategies, interventions and challenges. European Observatory on Health Systems and Policies, 2010.

4. Sidani S, Fox M. Patient-centered care: clarification of its specific elements to facilitate interprofessional care. J Interprof Care. 2014;28(2):134-41.

5. Nolte E, McKee M. Caring for people with chronic conditions: a health system perspective. Berkshire: Open University press; 2008.

6. Van Houdt S, De Lepeleire J, Driessche KV, Thijs G, Buntinx F. Multidisciplinary team meetings about a patient in primary care: an explorative study. J Prim Care Community Health. 2011;2(2):72-6.

7. Kitson A, Marshall A, Bassett K, Zeitz K. What are the core elements of patient-centred care? A narrative review and synthesis of the literature from health policy, medicine and nursing. J Adv Nurs. 2013;69(1): 4-15.

8. Schaefer J, Davis C. Case management and the chronic care model: a multidisciplinary role. Lippincotts Case Manag. 2004;9(2):96-103.

9. Legare F, Stacey D, Graham ID, Elwyn G, Pluye P, Gagnon MP, et al. Advancing theories, models and measurement for an interprofessional approach to shared decision making in primary care: a study protocol. BMC Health Serv Res. 2008;8:2.

10. Trivedi D, Goodman C, Gage H, Baron N, Scheibl F, lliffe S, et al. The effectiveness of inter-professional working for older people living in the community: a systematic review. Health Soc Care Community. 2013;21(2):113-28.

11. Newbould J, Burt J, Bower P, Blakeman T, Kennedy A, Rogers A, et al. Experiences of care planning in England: interviews with patients with long term conditions. BMC Fam Pract. 2012;13:71.

12. Kennedy N, Armstrong C, Woodward O, Cullen W. Primary care team working in Ireland: a qualitative exploration of team members' experiences in a new primary care service. Health Soc Care Community. 2015;23(4):362-70.

13. Nisbet G, Dunn S, Lincoln M. Interprofessional team meetings: Opportunities for informal interprofessional learning. J Interprof Care. 2015;29(5):426-32.

14. Xyrichis A, Lowton K. What fosters or prevents interprofessional teamworking in primary and community care? A literature review. Int J Nurs Stud. 2008;45(1):140-53.

15. Smith-Carrier T, Neysmith S. Analyzing the Interprofessional Working of a Home-Based Primary Care Team. Can J Aging. 2014;33(3):271-84.

16. Martin-Rodriguez LS, Beaulieu M-D, D'amour D, Ferrada-Videla M. The determinants of succesful collaboration: A review of theoretical and empirical studies. Journal of Interprofessional Care. 2005;1:132-47.

17. Jaruseviciene L, Liseckiene I, Valius L, Kontrimiene A, Jarusevicius G, Lapao LV. Teamwork in primary care: perspectives of general practitioners and community nurses in Lithuania. BMC Fam Pract. 2013;14:118.

18. Korner M, Butof S, Muller C, Zimmermann L, Becker S, Bengel J. Interprofessional teamwork and team interventions in chronic care: A systematic review. J Interprof Care. 2015:15-28.

19. Morgan S, Pullon S, McKinlay E. Observation of interprofessional collaborative practice in primary care teams: An integrative literature review. Int J Nurs Stud. 2015;52(7):1217-30.

20. Duner A. Care planning and decision-making in teams in Swedish elderly care: a study of interprofessional collaboration and professional boundaries. J Interprof Care. 2013;27(3):246-53.

21. Remmerswaal J. Group Dynamics: an introduction. Amsterdam: Uitgeverij boom/nelissen; 2015.

22. Legare F, Stacey D, Pouliot S, Gauvin FP, Desroches S, Kryworuchko J, et al. Interprofessionalism and shared decision-making in primary care: a stepwise approach towards a new model. J Interprof Care. 2011;25(1):18-25. 
23. Hsieh HF, Shannon SE. Three approaches to qualitative content analysis. Qual Health Res. 2005;15(9): 1277-88.

24. Braun V, Clarke V. Using thematic analysis in psychology. Qualitative Research in Psychology. 2006;3(2): 77-101.

25. O'Cathain A, Murphy E, Nicholl J. Three techniques for integrating data in mixed methods studies. BMJ. 2010;341:c4587.

26. Raine R, Wallace I, Nic a' Bhaird C, Xanthopoulou P, Lanceley A, Clarke A, et al. Improving the effectiveness of multidisciplinary team meetings for patients with chronic diseases: a prospective observational study. Health Services and Delivery Research. 2014.

27. Tyson SF, Burton L, McGovern A. Multi-disciplinary team meetings in stroke rehabilitation: an observation study and conceptual framework. Clin Rehabil. 2014;28(12):1237-47.

28. van Drielen E, de Vries AW, Ottevanger PB, Hermens RP. [Better multidisciplinary team meetings are linked to better care]. Ned Tijdschr Geneeskd. 2012;156(45):A4856.

29. Harris MF, Advocat J, Crabtree BF, Levesque JF, Miller WL, Gunn JM, et al. Interprofessional teamwork innovations for primary health care practices and practitioners: evidence from a comparison of reform in three countries. J Multidiscip Healthc. 2016;9:35-46.

30. Dath D, Chan M-K. The CanMEDS 2015 Manager Working Group Report. Ottawa: Royal College of Physicians and Surgeons of Canada, 2015.

31. Metzelthin SF, Daniels R, van Rossum E, Cox K, Habets H, de Witte LP, et al. A nurse-led interdisciplinary primary care approach to prevent disability among community-dwelling frail older people: a large-scale process evaluation. Int J Nurs Stud. 2013;50(9):1184-96.

32. Kruse RL, Olsberg JE, Oliver DP, Shigaki CL, Vetter-Smith MJ, LeMaster JW. Patient-provider communication about diabetes self-care activities. Fam Med. 2013;45(5):319-22.

33. Lenzen SA, van Dongen JJ, Daniels R, van Bokhoven MA, van der Weijden T, Beurskens A. What does it take to set goals for self-management in primary care? A qualitative study. Fam Pract. 2016;33(6): 698-703.

34. Lenzen SA, Daniels R, van Bokhoven MA, van der Weijden T, Beurskens A. Setting goals in chronic care: Shared decision making as self-management support by the family physician. Eur J Gen Pract. 2015; 21(2):138-44.

35. Longtin Y, Sax H, Leape LL, Sheridan SE, Donaldson L, Pittet D. Patient participation: current knowledge and applicability to patient safety. Mayo Clin Proc. 2010;85(1):53-62.

36. Pillay B, Wootten AC, Crowe H, Corcoran N, Tran B, Bowden P, et al. The impact of multidisciplinary team meetings on patient assessment, management and outcomes in oncology settings: A systematic review of the literature. Cancer Treat Rev. 2016;42:56-72.

37. Zwarenstein M, Goldman J, Reeves S. Interprofessional collaboration: effects of practice-based interventions on professional practice and healthcare outcomes. Cochrane Database Syst Rev. 2009(3):CD000072. 


\section{Appendix 4.1}

\section{Observation list to examine current practices in IPT meetings in primary} care

Setting

Team:

Date:

\begin{tabular}{|l|l|}
\hline Background variables \\
\hline Setting \\
\hline Duration in minutes & \\
\hline Frequency of team meetings & \\
\hline Number of participants & \\
\hline Different disciplines & \\
\hline Patient present? & \\
\hline Number of patients discussed & \\
\hline Chairperson & \\
\hline Shared reporting & \\
\hline
\end{tabular}

Observation: Levels of communication (Remmerswaal)

Procedural level refers to how the team works on the task, such as the methods and procedures used to achieve the goal, and the structure and organization of the meeting.

$>$ Content level concerns the topic and content of the meeting and what happens in the team; which information is exchanged by the team members.

Interaction level refers to the team process and to what happens between the team members 


\section{Appendix 4.2}

\section{Semi-structured interview guide to explore team member's experiences} with IPT meetings

\section{Interview guide}

- Introduction

- Introduction by the interwiewer

- Consent for audio recording

- Explanation of participants' rights

- Aim of the interview: The aim is to explore your experience, viewpoints, and facilitators and barriers for IPC

- Procedure, duration etc.

- Definition of IPC: We define interprofessional collaboration as "Multiple health care workers from different professional backgrounds working together with patients, families, caregivers and communities to deliver the highest quality of care".

- Clarification that all information is relevant

\section{Main questions}

1. How did you experience the IPT meeting which has just taken place?

2. According to you, what are relevant factors that influence the process of IPC (relating to the development of patient-centred care plans) in primary care?

3. What do you experience as barriers/facilitators with regard to the process of IPC (regarding the development of patient-centred care plans) in primary care?

\section{Subquestions}

- Can you give an example?

- Can you explain in detail what you mean by...?

- Why do you experience... as a relevant factor/barrier/facilitator?

\section{Summary}

Interviewer provides a summary.

- Did I forget any relevant information in this summary? 


\section{Chapter 5}

Successful participation of patients in interprofessional team meetings: a qualitative study

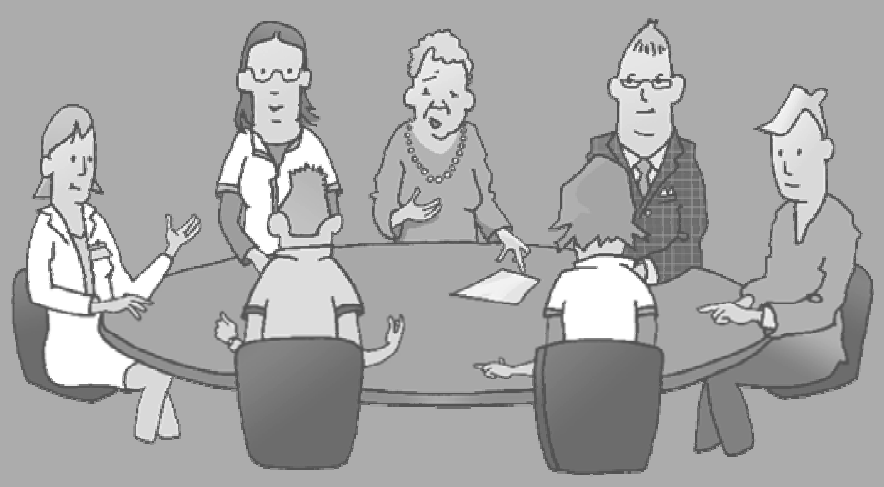

Jerôme van Dongen Iris Habets Sandra Beurskens Loes van Bokhoven Health Expect 2016 


\section{Abstract}

\section{Introduction}

The number of people with multiple chronic conditions increases as a result of aging. To deal with the complex health care needs of these patients, it is important that health care professionals collaborate in interprofessional teams. To deliver patient-centred care, it is often recommended to include the patient as a member of the team.

\section{Objectives}

To gain more insight into how health care professionals and patients, who are used to participate in interprofessional team meetings, experience and organise patient participation in the team meetings.

\section{Methods}

A qualitative study including observations of meetings $(n=8)$, followed by semi-structured interviews with participating health care professionals $(n=8)$, patients and/or relatives $(n=11)$. Professionals and patients were asked about their experiences of patient participation immediately after the team meetings. Results from both observations and interviews were analysed using content analysis.

\section{Results}

The findings show a variety of influencing factors related to patient participation that can be divided into five categories: (1) structure and task distribution, (2) group composition, (3) relationship between professionals and patients or relatives, (4) patients' characteristics, and (5) purpose of the meeting.

\section{Conclusion}

Patient participation during team meetings was appreciated by professionals and patients. A tailored approach to patient involvement during team meetings is preferable. When considering the presence of patients in team meetings, it is recommended to pay attention to patients' willingness and ability to participate, and the necessary information shared before the meeting. Participating patients seem to appreciate support and preparation for the meeting. 


\section{Introduction}

Nowadays, chronic diseases are responsible for $60 \%$ of the global disease burden. Due to increased life expectancy, it can be expected that by the year 2020 80\% of the disease burden will be related to chronic diseases. ${ }^{1}$ Patients often suffer from multiple chronic conditions at the same time, which makes them particularly vulnerable to suboptimal quality of care. They tend to use health services more often and use a greater array of services compared to other consumers of care. ${ }^{2}$ Consequently, good coordination of care appears important.

The Institute of Medicine, Committee on Quality of Health Care in America suggested that professionals working in interprofessional teams are able to communicate and address the complex and challenging needs of a chronic patient. ${ }^{3}$ An interprofessional team is a collaborative partnership between at least three health care professionals from a diversity of disciplines that work together to meet the multiple care needs of a targeted population. ${ }^{4,5}$ By working together, professionals can share their expertise and perspectives to formulate common goals in order to restore or maintain an individual's health. ${ }^{6,7}$ Several systematic reviews about interprofessional team working in chronic diseases have reported improved health outcomes, and enhanced patient satisfaction and acceptance of treatment. ${ }^{8-11}$

However, besides collaboration among professionals, collaboration between professionals and patients also seems to be valuable to coordinate care and in formulating goals, thereby ensuring patient-centred care. ${ }^{12}$ Health care services and organisations stimulate involvement of patients in their own care process. ${ }^{13,14}$ Patients suffering from one or more chronic diseases have a unique expertise related to their personal situation, disease, treatment and recovery. ${ }^{15}$ Patient participation, defined by the US National Library of Medicine as 'the involvement of the patient in the decision-making process regarding health issues', is increasingly recognised as a key component in the redesign of health care processes. Including the patient or relatives as core members of a health care team can be seen as a way to stimulate patient participation. ${ }^{16,17}$ Apparently, most teams only consist of professionals, who have the tendency to discuss care plans and set goals, solely from their professional perspective. ${ }^{18}$ In order to actively integrate the patients' perspective, and stimulate patient participation, the patient and/or relative can be invited to join team meetings. During team meetings they have the opportunity to express their individual preferences, needs and values and get involved in decision making about treatment options. Several positive effects of involvement of patients in team meetings have been described. Wittenberg-Lyles and colleagues found that teams formulated more patient-centred goals when relatives participated in team meetings by videophone technology. ${ }^{19}$ In other studies, relatives expressed high levels of satisfaction 
by being involved in team meetings, ${ }^{20}$ and experienced increased involvement in decision making. ${ }^{21}$ Also professionals thought that family involvement could have added value, because it provides more understanding, openness, recognition and trust between professionals and relatives. ${ }^{22}$

However, professionals also mention barriers. They state that they are more careful choosing their words in discussions and answers when patients or relatives are present at the meetings. ${ }^{22,23}$ In addition, professionals sometimes experience patient participation as stressful, especially in situations of disagreement with relatives. ${ }^{20}$ Furthermore, they find patient participation time consuming both due to offering participation to the patients and to the time needed for answering patients' questions. In addition, most professionals felt the need to modify their linguistic usage, resulting in adverse consequences to the accurate reporting of case specifics. ${ }^{23}$ Patients and relatives also experienced excessive use of jargon by professionals. ${ }^{22,24}$ In spite of these barriers, in several settings patients do participate as members of interprofessional teams.

Previously mentioned studies are primarily directed at family or caregiver participation during team meetings, ${ }^{20-22}$ or executed in hospice setting. ${ }^{19,21}$ There seems to be a lack of literature on experiences of both professionals and patients regarding patient participation in interprofessional team meetings within other health care settings.

Therefore, the aim of this study is to gain more insight into how professionals and patients, used to participation in such teams, experience and organise patient participation in team meetings. Outcomes are useful for teams who consider inviting patients to their meetings, but do not know how to organise this in a feasible, efficient and successful manner.

\section{Methods}

\section{Study design}

The methodology of this study was developed based on the basic assumptions of naturalistic inquiry. ${ }^{25}$ We applied a qualitative research design using observations and interviews for data collection. To explore the current way of practice, we observed team meetings in different settings. Further, to map the experiences related to patient participation, we conducted semi-structured interviews with a number of the participants, including professionals, patients and relatives. 


\section{Setting and participants}

The observations and interviews took place in various health care settings in the Southern part of the Netherlands. Data were collected between July and September 2015. Interprofessional team meetings from a diversity of settings were recruited by means of pragmatic sampling, using the researchers' network. Team meetings were included in the study if there was an interprofessional composition, including three or more professionals from different disciplines. In addition, patients had to have chronic problems or complex health care questions and they (or their relatives) had to be present at the team meeting. Per health care setting, several institutions were approached by email or, in case of non-response, by telephone. A total of eight institutions $(n=8)$ were included: five intramural care settings and three extramural care settings.

\section{Observations}

The observed team meetings were not especially initiated for this study, but were part of the regular care process and took place in the natural setting of the teams' practice. Meetings were arranged by one of the team members or support staff of the facility. All patients and relatives received oral information, and a letter with information about the content of the study and confidentiality of the data. Professionals received oral or written information about the study. During the team meeting, audio-recordings and field notes were made by the researchers. Field notes were made by using an observation list including regular features of the meeting (e.g. time, location, duration, and number of attendees), complemented with relevant themes derived from the literature. ${ }^{6,8,11-17,19-24}$ The observation list was structured based on three different levels of communication (content level, procedural level, and interaction level), as described by Remmerswaal. ${ }^{26}$ Within these levels of communication, attention was paid to: content of the discussed topics (e.g. goal setting), patient and relative involvement in decision making and goal setting, organisational and structural aspects of the meeting and interaction between professionals, patients and relatives (see Appendix 5.1).

\section{Interviews}

After the team meeting, the patients or relatives, and one or two professionals from different disciplines were interviewed individually. The individual interviews lasted on average 15 minutes. The interview guide (see Appendices 5.2 and 5.3) started with an open-ended question to discover respondents' experiences with the meeting that took place. Other questions were related to the barriers and facilitators regarding 
involvement of patients or relatives, the added value and possible improvements of this team meeting. Professionals were also asked about possible differences between participation and non-participation of patients. The interview guide had been previously tested among three fellow researchers and one elderly person and adjusted according to their feedback. All interviews were recorded by using a voice recorder.

\section{Analysis}

Directed content analysis was used to analyse the data. ${ }^{27} \mathrm{~A}$ detailed description of each observation was made, based on the points of attention mentioned in Appendix 5.1. This description was completed with field notes about notable events and non-verbal communication. The audio-recorded interviews were transcribed verbatim. Data were analysed by two researchers (IH, JVD). Both read all descriptions of the observations and transcripts of the interviews independently and repeatedly in order to become familiar with the data. Hereafter, all the data was coded using Nvivo 10 software and compared and discussed until consensus was reached. ${ }^{28}$ Analysis was conducted following an iterative approach, enabling the researchers to easily switch between analysed codes and themes, and discuss interpretations of results collaboratively. For both observations and interviews, the same initial coding scheme, based on themes derived in the literature was used (Appendix 5.4). If necessary, new codes were added. In the next step codes of the interviews and observations were grouped into themes. Finally, connections between the themes were explored. While analysing the last interviews and observations it became clear that the main themes that emerged from the different settings were comparable, we therefore assume that data saturation has occurred.

\section{Trustworthiness}

Field notes and written comments were used in the analysis process to enhance the trustworthiness of the study. To increase the studies credibility, two researchers analysed the data independently and discussed and compared results, consulting a third researcher in case of disagreement. Further, combining data from both observation and interviews, known as methodological triangulation, provided additional perspectives and enhanced credibility. ${ }^{29}$

\section{Ethical considerations}

The ethical committee of Zuyderland, The Netherlands, Heerlen judged the proposal and confirmed that given the non-invasive nature of the study, no ethical approval was needed according to the law. Further, before observations and interviews took place, 
oral informed consent was obtained from all professionals, and written informed consent from all patients and relatives.

\section{Results}

In total eight observations $(n=8)$ in different institutions, and nineteen $(n=19)$ interviews were performed. Characteristics of the participating teams are presented in Table 5.1. Content analysis revealed five key themes: (1) structure and task distribution, (2) group composition, (3) relationship between professionals and patients or relatives, (4) patients' characteristics, and (5) purpose of the meeting. Within each theme, experiences and both facilitators of and barriers to patient participation during interprofessional team meetings could be identified (Figure 5.1). The results from the observations and interviews reinforce each other and are presented together.

Table 5.1 Characteristics of the team meetings

\begin{tabular}{|c|c|c|c|c|}
\hline Team & Institution & Patient description & $\begin{array}{l}\text { Number of } \\
\text { attendees }\end{array}$ & Participants \\
\hline 1 & $\begin{array}{l}\text { Residential care for } \\
\text { patients with } \\
\text { mental disabilities }\end{array}$ & $\begin{array}{l}\text { Young man with mental } \\
\text { and physical disabilities }\end{array}$ & 4 & $\begin{array}{l}\text { Personal mentor, behavioural scientist, } \\
\text { team manager, legal representative }\end{array}$ \\
\hline 2 & $\begin{array}{l}\text { Nursing home } \\
\text { (somatic } \\
\text { department) }\end{array}$ & Elderly woman & 7 & $\begin{array}{l}\text { Geriatrician, speech therapist, care } \\
\text { coordinator, physiotherapist, nurse, } \\
\text { patient }\end{array}$ \\
\hline 3 & Hospital & Middle-aged woman & 5 & $\begin{array}{l}\text { Clinical geneticist, medical student, } \\
\text { dermatologist, patient and one relative }\end{array}$ \\
\hline 4 & $\begin{array}{l}\text { Social team } \\
\text { (municipality) }\end{array}$ & Middle-aged man & 10 & $\begin{array}{l}\text { Specialised home care, two family } \\
\text { guardians, activation coach, community } \\
\text { consultant, school counselor, paediatrician } \\
\text { and colleague, social worker, patient }\end{array}$ \\
\hline 5 & $\begin{array}{l}\text { Nursing home } \\
\text { (somatic } \\
\text { department) }\end{array}$ & Elderly married couple & 8 & $\begin{array}{l}\text { Family physician, nurse, care coordinator, } \\
\text { two patients (a couple) and three relatives }\end{array}$ \\
\hline 6 & Family practice & $\begin{array}{l}\text { Elderly man with } \\
\text { mental and physical } \\
\text { disabilities }\end{array}$ & 9 & $\begin{array}{l}\text { Family physician, family physician in } \\
\text { training, home care, care coordinator, } \\
\text { physiotherapist, authorised family } \\
\text { representative, patient and two relatives }\end{array}$ \\
\hline 7 & $\begin{array}{l}\text { Nursing home } \\
\text { (psychogeriatric } \\
\text { department) }\end{array}$ & Elderly woman & 5 & $\begin{array}{l}\text { Geriatrician, nurse, care coordinator, } \\
\text { psychologist, relative }\end{array}$ \\
\hline 8 & $\begin{array}{l}\text { Nursing home } \\
\text { (somatic } \\
\text { department) }\end{array}$ & Elderly woman & 7 & $\begin{array}{l}\text { Geriatrician, nurse, care coordinator, } \\
\text { psychologist, social worker, patient and } \\
\text { relative }\end{array}$ \\
\hline
\end{tabular}




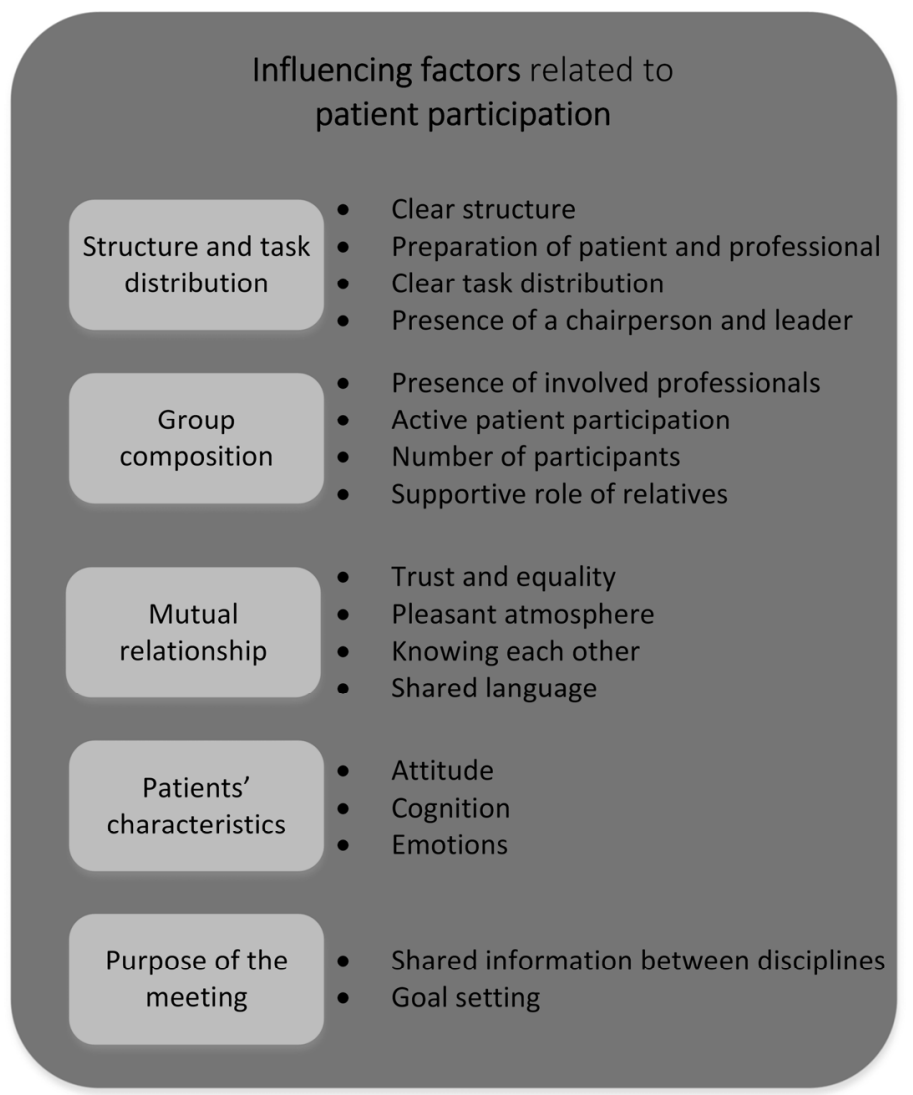

Figure 5.1 Key themes.

\section{Structure and task distribution}

During interviews several professionals mentioned the importance of a clear structure and task distribution as facilitating factors of interprofessional team meetings in general. According to them, there are a few important tasks that should be divided between professionals: arrangement of the meeting, preparation of the participating patient or relatives before the meeting, distribution of the agenda or health care plan, leadership and time management during the meeting. Observations showed that in most teams these tasks were divided and appeared to be clear for each team member. In some teams, agreements about leadership and time management were made just before the patient entered the room. One of the professionals stated the crucial role of a 
chairperson summarising information, leading discussions and closing the meeting in the right way, within the planned time span:

A chairperson who at the end takes decisions and will summarise and says: 'Well then, we have this now agreed' (Community consultant, team 4)

Observations showed that in most meetings a team leader or care coordinator was present. This role was assigned to a professional (not necessarily the chairperson) who was actively involved in the patients' care process, like a doctor or a nurse. In those meetings the team leader played a role in preparing and involving the patient in the discussions by actively asking the patient to respond to the statements which were made, and if there were any questions or additions. In one of the observed teams the care coordinator provided day to day care management services, as determined by individualised plans of care. She informed the patient before the meeting, about the purpose of the meeting, the available time and the number of disciplines present at the meeting. In addition, she recommended the patient and relative to make a list of subjects they wanted to discuss during the meeting. Observations revealed more discussion between professionals and relatives, when relatives were visibly prepared by using a paper with notes or questions during the meeting. The observations and interviews revealed that in most team meetings, patients and relatives received the agenda or the patients' care plan a few weeks before the meeting takes place.

Participants further explained that all professionals present at the meeting should be well informed about the patients' care process before the meeting starts. In particular, the main problems and (health care) demands of the patient and relatives should be known by all team members. According to professionals, sending patients' care plans to all team members (including the patient or relatives), is one of the possibilities to inform everyone in preparation of the meeting. In one observed team meeting, health care professionals briefly discussed the main issues five minutes before the patient was called into the room.

\section{Group composition}

Professionals and patients are not like-minded about the groups' composition. However, according to the majority of professionals and patients, it is crucial that all professionals who are directly involved in the patient's care process, are present at the meeting. One professional stated that this is a prerequisite to answer questions related to a specific discipline immediately. However, another professional did not see added value in the involvement of all committed disciplines, if the patient's condition is stable for a long 
period and there are no new developments. In most of the observed meetings professionals who were most intensively involved in the patient's care process, were present at the meeting.

According to relatives, it is essential that everyone involved in the patient's care process is present and aware of the patient's current situation and new developments. They were especially positive about sharing information between professionals from different disciplines and the patient. In addition, one health care professional noticed that it is also clearer to relatives which health care professional provides what kind of care service. Patients and relatives mentioned to appreciate active participation and expression of their perspectives on the goals formulated by health care professionals, and the input of personal preferences in creating new goals.

Observations showed that in most meetings the patient or relative was actively involved in these processes. When goals were evaluated during the meeting, a lot of attention was paid to the patients' feedback. The patients were often asked about how they thought the goals should be achieved or which problems needed more attention.

Field note: The professionals actively invite and ask the patient to express his personal goals and wishes and also stimulate relatives to think along. Eventually appointments correspond to the patient's personal goals (team 6)

Also in formulating new goals, professionals asked patients and relatives, about their preferences and wishes. In addition, professionals were open to comments and suggestions made by relatives or patients. Another positive point was phrased by patients who appreciated being involved in the meeting, because the idea of professionals speaking behind their backs was perceived as unpleasant.

I really appreciate having the opportunity to give a reply (Relative, team 6)

On the other hand, for some patients participation felt more like an obligation. They stated that they did not see a need to be present at the meeting and relied on the judgment of the professionals. Further, some professionals experienced taking more responsibility in setting and reaching goals if the patients or relatives are involved in the meeting. A few professionals argued that they feel a higher pressure to achieve goals when a patient or relative is present at the meeting. However, one professional mentioned that fulfilment of agreements has nothing to do with pressure of the family as it belongs to your job as a professional. 
The number of team members present at the meeting was frequently mentioned as important by both professionals and patients during the interviews. Professionals noticed that patients and relatives seem to be more comfortable in smaller group meetings. They indicated that in smaller groups, patients tend to tell more personal things. In interviews, patients and relatives agree that they are deterred when there are many team members sitting around the table:

.. there are so many people staring at me (Patient, team 2)

Professionals mentioned that next to the number of professionals being present at the meeting, too many relatives can also have a negative influence on the meeting. Observation showed that a team meeting involving two patients (a couple) and three relatives was more chaotic than meetings with only one patient or relative present. This was also caused by disagreements between relatives and the input of each relative on each topic. During the interviews the professionals stated that they experienced the meeting as chaotic and unstructured as well. To avoid these situations, one professional suggested to only invite one representative of the family to the meeting.

Nevertheless, according to professionals and patients, relatives can have a supportive role during team meetings. One older patient mentioned that she was happy to bring someone of the family to the meeting. In addition to this supportive role, professionals describe relatives as a source of additional and essential patient information. One professional mentioned as an example information about certain characteristics of the patient or his behaviour in the past that was only known by the relative. Professionals indicated use of this information in explaining the behaviour of the patient and possible related interventions.

\section{Relationship between professionals and patients (mutual relationship)}

We found that the majority of professionals, patients and relatives mentioned one or more factors related to the relationship between professionals and patients. According to both professionals and patients, a relationship based on trust and equality, and a pleasant atmosphere are important. In order to create such a relationship, they stated that it is essential to know each other well. This was confirmed by the observations. Observations also showed that a pleasant atmosphere was encouraged by making jokes. In particular, patients and relatives seem to be comfortable in team meetings where the patient has a good relationship with the professionals present. During interviews patients and relatives mentioned the professionals' approachable attitude as important in this respect. The importance of this attitude was confirmed by several professionals. 
One of the professionals declared that you have to continuously invest in your relationship with the patient and relatives:

We approach each other by first names, also the patients. If patients find it difficult, then it's doctor [X] instead of [X]. I'm just [Y], my manager is Ms. [Z] or [Z], just how they want it. We want patients to approach health care professionals easily and I invest a lot of energy in that (Care coordinator, team 2)

According to some professionals and relatives, participation of patients in team meetings can also be a possibility to get to know each other better. In particular, relatives mentioned that by meeting the professional in real life, it is easier to approach professionals in case of problems, worries or questions.

It is quite difficult to make contact with the family physician, to actually speak to him, and through such meetings lines get shorter (Relative, team 6)

Professionals mentioned that negative events or complaints in the past, can have a negative effect on the relationship between them and the patient or relative. They stated that a difficult relationship can be perceived as a barrier to the team meeting because patients do not want or dare to share information, resulting in the omission of significant information. Furthermore, one professional declared during the interview that in case of a difficult relationship with the patient or relatives, she has a restrained attitude during the team meeting:

To some patients you feel more attracted than to others, and in the team meetings I sometimes take a little distance (Nurse, team 5)

Further, most of the professionals mentioned that jargon should naturally not be used during team meetings when patients and/or relatives participate. They also indicate that care professionals are being trained to use simple language and not use difficult medical terms in normal conversations with either patients or relatives:

As a family physician you continuously switch between jargon and simple language, no that's not a barrier (Family physician, team 5)

Patients, too mentioned that they do not experience jargon and using difficult words during the team meetings as a barrier. In cases where words are used that they do not understand, they will ask for clarification or search for the meaning of the words on the 
internet. During none of the meetings observed, neither patients nor relatives seemed to be bothered by difficult words used by professionals. In addition, no clarifying questions were asked during meetings concerning the language. One professional stated the importance for the patient to know the medical name of his chronic condition because it could be useful in contact with different health care professionals.

Field note: Professionals do not use any technical jargon. They frequently ask the patient's husband if there are any questions or uncertainties (team 1)

\section{Patients' characteristics}

One patient characteristic mentioned is 'assertiveness'. A few relatives mentioned that they actively monitor if goals and appointments, set during the meeting, are actually fulfilled. According to some professionals and relatives, patients' or relatives' assertiveness during the team meeting can be seen as both facilitator and barrier. Observations showed that in most meetings an active attitude of the patient or relative has a positive effect on formulating goals and agreements. During interviews, professionals agreed that an active attitude of the patient resulted in more information, making it easier to formulate goals. One health professional felt that such a critical attitude stimulates professionals to be more focused on reaching goals:

.. there he goes to check on me, he is going to ask me questions, what have you done? That's a positive thing (Team manager, team 1)

On the other hand, both patients and professionals mentioned during the interview that an offensive attitude of the patient can be perceived as a barrier to the meeting, because this attitude can provoke negative discussions between team members and patients.

Field note: There is a friendly atmosphere, however, the contribution of the patient is sometimes provocative, nevertheless, most professionals do not seem to be disturbed (team 4)

Another barrier, mentioned by professionals and relatives, is cognitive impairment of the patient. The professionals stated that involvement of patients with cognitive impairment in a team meeting creates unrest within the patient. They declared that it is necessary to give more or other ways of information about things that are said or done. Furthermore, it takes time to reassure the patient in case they get confused. In one observed meeting, 
an older person with early dementia was present at the meeting. The patient was visibly agitated because he missed or misinterpreted a lot of information. Professionals and relatives tried to calm down the patient, which resulted in a disordered and unstructured meeting:

You noticed very strongly that the patient turned to a resistance attitude, and tried to defend herself, it takes time to calm her down, but sometimes that is counterproductive (Family physician, team 5)

One professional explained that in patients with cognitive impairment, processing all new things which are happening takes longer. Also the slow speaking, which is associated with some conditions or cognitively impaired patients can be perceived as a barrier to the team meeting.

A few professionals mentioned the influence of emotions of patients or relatives on the team meeting, and stressed both positive and negative effects. According to professionals, emotions make the meeting more difficult, hectic and less constructive. On the other hand, they think it is good that patients and relatives show their feelings because it makes professionals more focused.

\section{Purpose of the meeting}

Almost all professionals mentioned that the patients' presence during team meetings should depend on the purpose of the meeting. During interviews, they mentioned that if the purpose of the meeting is gathering information from different disciplines or sharing immature information which maybe provokes discussion between team members, patient or relatives' participation is not desirable. The majority of the professionals mentioned hesitation in being completely honest in sharing all information when patients or relatives are present at the meeting. They stated that they receive more information from the different disciplines in a meeting without the patient in the room. Besides, they stressed the importance of the absence of patients or relatives when they have relational problems that first have to be clarified between professionals only.

You should be able to brainstorm on the patient and you should actually discuss well-observed things without constantly, let me say, feeling the censorship of the presence of a relative (Psychologist, team 7)

However, if the purpose of the meeting is to evaluate the patients' goals or setting new goals, the added value of the patient or family being present was really appreciated. 


\section{Discussion}

The goal of this study was to gain more insight into how health care professionals and patients, who are used to participate in interprofessional team meetings, experience and organise patient participation in interprofessional team meetings. Factors can be summarised into five categories: (1) structure and task distribution, (2) group composition, (3) relationship between professionals and patients or relatives, (4) patients' characteristics, and (5) purpose of the meeting.

According to participants, good preparation is an essential part in organising a successful meeting. This includes informing the patient about the purpose of the meeting. Griffith and colleagues discovered that patients identified a diversity of aims for a team meeting, like resolving inconsistencies, educating and informing, updating and reviewing care options. ${ }^{20}$ In addition, Donnelly and colleagues showed that sharing expectations with patients or relatives prior to the meeting is critical to establishing opportunities for participation. ${ }^{24}$ In our study, the observations showed that well prepared relatives, introducing their own questions, seem to stimulate discussion between them and the professionals. In a study by Dijkstra (2007) the quality of the discussion improved by informing relatives about the meeting in advance. ${ }^{22}$ Our study showed that the care coordinator may play a central role in informing the patient and his or her relatives. Griffith and colleagues suggested a written patient information booklet, as a tool to explain the purpose of the meeting and to orientate patients and families in preparation for the meeting. ${ }^{20}$

Another interesting finding is that in the literature, difficult language used by professionals seems to be a barrier to patients and relatives. ${ }^{22,}{ }^{24}$ Dijkstra discovered that professionals often use words that are difficult for relatives to understand, and that not all relatives have the courage to ask for an explanation. However, in our study both patients and relatives mentioned that they are not bothered by jargon used by professionals. In addition, they stated that they will ask for clarification if discussed topics or words are unclear. Unlike Choy and colleagues, who discovered that the majority of the professionals felt they had to modify their medical language, ${ }^{23}$ our study showed that for the meetings we observed, professionals do not need to make extra efforts to adapt their language, because it is natural to avoid difficult jargon when patients or relatives are involved. However, we observed a small number of meetings and we did not include a team meeting in which complex technological procedures were the focus of the discussion (e.g. oncology setting in which diagnostic and therapeutic value is discussed). Therefore we can not exclude the possibility that jargon would be an issue in such settings. Further research in these settings is necessary. 
Finally, one can question if patient involvement in team meetings is always desirable. Our results show that this depends on the topic of the meeting, the preferences of the patient or relatives and the characteristics of the patient. In the literature, different studies recognise that patients vary substantially in their preferences for participation and decision making. ${ }^{30-32}$ Sainio and colleagues showed that a good relationship and interaction of the patient with professionals promoted involvement of patients. ${ }^{33}$ Another factor that emerged from the literature is the age of the patient. Say and colleagues found that younger patients preferred a more active role in decision making than older patients. However, older patients want to be involved in their care but their definition is more focused on a 'caring relationship' and 'person-centred care' than on 'active participation in decision-making'. ${ }^{34}$ Nonetheless, among patients who do prefer an active or collaborative role, some do not have the ability to participate as much as they desire. Some patients suffer from cognitive impairment, which is associated with exclusion from decision-making. ${ }^{35}$ According to Say and colleagues, it is important that professionals identify the factors that might influence patients' involvement, so that they may be more sensitive to individual patients' preferences and provide better patientcentred care. ${ }^{36}$ Further research into factors that might influence patients' involvement would be interesting.

\section{Strengths and limitations}

Combining observations and interviews with both professionals and patients is a methodological strength of this study, a phenomenon also known as data triangulation. Observations took place in various institutions and settings, and interviews were conducted with health care providers from different disciplines. As a consequence, it was possible to create a broad view on patient participation in interprofessional team meetings. However, our findings are probably not transferable to other settings outside our scope, like settings in which complex diagnostic and therapeutic discussions take place, for example in oncology setting, a setting which is known for its complex therapeutic protocols and high level of technology. The low number of observations and interviews per setting can be seen as a limitation. However, after analysing all interviews and observations it became clear that the main themes that emerged from the different settings were comparable, so we assume that data saturation has occurred. To prevent uncomfortable situations for participants, observations were conducted by one researcher. This may have restricted the detection of relevant cues. However, the observations were recorded with a voice recorder and replayed various times, so it is unlikely that substantial information is missing. In addition, the data were coded independently by two researchers and consensus was reached. 


\section{Conclusion}

Patient participation during team meetings is appreciated by both professionals and patients. Guiding the patient in both the preparation of the meeting and during the meeting itself seems important. Further, both professionals and patients prefer a pleasant atmosphere and a mutual relationship based on trust and equality, which, according to them has positive effects on the team meeting. In contrast to the literature, this study indicates that difficult language or jargon was not perceived as a barrier. Further, not every patient is the same, and therefore, it seems to be promising to explore to what extent patients are actually willing to and capable of participating during team meetings. In this perspective, it would be interesting to enlighten what active participation requires from a patient, which information the patient needs in order to be prepared for a meeting and to be well informed to make an informed choice about participation. It can be concluded that more insight into differences between patients, care settings, and topics discussed during team meetings, enables a tailored approach to patient participation. 


\section{References}

1. WHO. Innovative care for chronic conditions: Building blocks for action: global report. Geneva: World Health Organization. 2002.

2. Vogeli C, Shields A, Lee T, Gibson T, Marder W, Weiss K, et al. Multiple chronic conditions: prevalence, health consequences, and implications for quality, care management, and costs. J Gen Intern Med. 2007;22(3):391-5.

3. Institute of Medicine. Crossing the quality chasm: A new health system for the 21st century2001.

4. Mulvale G, Embrett M, Razavi SD. 'Gearing Up' to improve interprofessional collaboration in primary care: a systematic review and conceptual framework. BMC Fam Pract. 2016;17(1):83.

5. Canadian Interprofessional Health Collaborative. A National Interprofessional Competency Framework. Canada: Canadian Interprofessional Health Collaborative, 2010.

6. Barker KK, Oandasan I. Interprofessional care review with medical residents: lessons learned, tensions aired--a pilot study. J Interprof Care. 2005;19(3):207-14.

7. Lumague M, Morgan A, Mak D, Hanna M, Kwong J, Cameron C, et al. Interprofessional education: the student perspective. J Interprof Care. 2006;20(3):246-53.

8. Cameron ID, Finnegan TP, Madhok R, Langhorne P, Handoll HH. Co-ordinated multidisciplinary approaches for inpatient rehabilitation of older patients with proximal femoral fractures. Cochrane Database Syst Rev. 2000(2):CD000106.

9. Hearn J, Higginson IJ. Do specialist palliative care teams improve outcomes for cancer patients? A systematic literature review. Palliat Med. 1998;12(5):317-32.

10. Hughes SL, Cummings J, Weaver F, Manheim L, Braun B, Conrad K. A randomized trial of the cost effectiveness of VA hospital-based home care for the terminally ill. Health Serv Res. 1992;26(6):801-17.

11. Tyrer P, Coid J, Simmonds S, Joseph P, Marriott S. Community mental health teams (CMHTs) for people with severe mental illnesses and disordered personality. Cochrane Database Syst Rev. 2000(2):CD000270.

12. Sidani S, Fox M. Patient-centered care: clarification of its specific elements to facilitate interprofessional care. J Interprof Care. 2014;28(2):134-41.

13. Patients and Information Directorate NE. Transforming participation in health and care. 2013.

14. Raad voor de Volksgezondheid en Samenleving. De participerende patient (The participating patient). Den Haag: Raad voor de Volksgezondheid en Samenleving, 2013.

15. Clayton MF, Latimer S, Dunn TW, Haas L. Assessing patient-centered communication in a family practice setting: how do we measure it, and whose opinion matters? Patient Educ Couns. 2011;84(3):294-302.

16. Vahdat S, Hamzehgardeshi L, Hessam S, Hamzehgardeshi Z. Patient involvement in health care decision making: a review. Iran Red Crescent Med J. 2014;16(1):e12454.

17. Saltz CC, Schaefer T. Interdisciplinary teams in health care: integration of family caregivers. Soc Work Health Care. 1996;22(3):59-70.

18. van Dongen JJ, Lenzen SA, van Bokhoven MA, Daniels R, van der Weijden T, Beurskens A. Interprofessional collaboration regarding patients' care plans in primary care: a focus group study into influential factors. BMC Fam Pract. 2016;17(1):58.

19. Wittenberg-Lyles E, Oliver DP, Demiris G, Burt S, Regehr K. Inviting the absent members: examining how caregivers' participation affects hospice team communication. Palliat Med. 2010;24(2):192-5.

20. Griffith JC, Brosnan M, Lacey K, Keeling S, Wilkinson TJ. Family meetings--a qualitative exploration of improving care planning with older people and their families. Age Ageing. 2004;33(6):577-81.

21. Oliver DP, Albright DL, Kruse RL, Wittenberg-Lyles E, Washington K, Demiris G. Caregiver evaluation of the ACTIVE intervention: "it was like we were sitting at the table with everyone". Am J Hosp Palliat Care. 2014;31(4):444-53.

22. Dijkstra A. Family participation in care plan meetings: promoting a collaborative organizational culture in nursing homes. J Gerontol Nurs. 2007;33(4):22-9; quiz 30-1.

23. Choy ET, Chiu A, Butow P, Young J, Spillane A. A pilot study to evaluate the impact of involving breast cancer patients in the multidisciplinary discussion of their disease and treatment plan. Breast. 2007;16(2):178-89. 
24. Donnelly SM, Carter-Anand J, Cahill S, Gilligan R, Mehigan B, O'Neill D. Multiprofessional Views on Older Patients' Participation in Care Planning Meetings in a Hospital Context. Practice. 2013;25(2):121-38.

25. Lincoln YS, Guba EG. Naturalistic Inquiry. Newburry Park: SAGE; 1985.

26. Remmerswaal J. Group Dynamics: an introduction. Amsterdam: Uitgeverij boom/nelissen; 2015.

27. Hsieh HF, Shannon SE. Three approaches to qualitative content analysis. Qual Health Res. 2005;15(9):1277-88.

28. Mortelmans D. Kwalitatieve analyse met Nvivo. Den Haag: Acco uitgeverij; 2011.

29. O'Cathain A, Murphy E, Nicholl J. Three techniques for integrating data in mixed methods studies. BMJ. 2010;341:c4587.

30. Rosenbaum L. The Paternalism Preference--Choosing Unshared Decision Making. N Engl J Med. 2015; 373(7):589-92.

31. Vos de M. Wanneer samen beslissen niet vanzelf spreekt: Reflecties van patienten en artsen over gezamenlijke besluitvorming (When shared decisionmaking is not self-evident). Den Haag: Centrum voor Ethiek en Gezondheid, 2014.

32. Ellis O. The agony of choice. BMJ. 2013;347:f5344.

33. Sainio C, Lauri S, Eriksson E. Cancer patients' views and experiences of participation in care and decision making. Nurs Ethics. 2001;8(2):97-113.

34. Bastiaens H, Van Royen P, Pavlic DR, Raposo V, Baker R. Older people's preferences for involvement in their own care: a qualitative study in primary health care in 11 European countries. Patient Educ Couns. 2007;68(1):33-42.

35. Miller LM, Whitlatch CJ, Lyons KS. Shared decision-making in dementia: A review of patient and family carer involvement. Dementia. 2016;15(5):1141-57.

36. Say R, Murtagh M, Thomson R. Patients' preference for involvement in medical decision making: A narrative review. Patient Educ Couns. 2006;60(2):102-14. 


\section{Appendix 5.1}

Observation List

\begin{tabular}{|c|c|}
\hline $\begin{array}{l}\text { Date: } \\
\text { Time: } \\
\text { Location: } \\
\text { Number of attendees: } \\
\text { Present disciplines: } \\
\text { Duration: }\end{array}$ & \\
\hline Content & $\begin{array}{l}\text { What kind of information is exchanged during the meeting? } \\
\text { What is the content of the goals being discussed? } \\
\text { How are the needs and goals of the patient taken into account? } \\
\text { Do the appointments match with the set goals? }\end{array}$ \\
\hline Procedure & $\begin{array}{l}\text { Structure of the meeting } \\
\text { Agenda } \\
\text { Chairman } \\
\text { Task distribution } \\
\text { Patient and relatives } \\
\text { Health care professionals }\end{array}$ \\
\hline Interaction & $\begin{array}{l}\text { Do the team members and patient or relatives know each other? } \\
\text { Group climate and atmosphere? } \\
\text { How is the patient involved in creating goals? } \\
\text { Are power and status of influence? } \\
\text { Communication aspects (language/jargon, interruptions, questions) }\end{array}$ \\
\hline
\end{tabular}




\section{Appendix 5.2}

\section{Interview Guide - Patients/relatives}

\section{Questions}

- How did you experience the team meeting where you were involved?

- Pleasent/unpleasent, important/unimportant, examples

- What factors have a positive influence on the team meeting?

\section{Themes}

- Preparation

- Task distribution/chairman

- Presence of relatives

- Relationship between patient and health care professional

- What factors have a negative influence on the team meeting?

\section{Themes}

- Jargon

- Emotions

- Kind of problems

- Disruptions/social conversations

- Duration

- Location

- Authoritarian attitude

- Does involvement in the team meeting change the way you handle your disease or chronic condition? If yes, in what way?

- What is for you the added value of being involved in an interprofessional team meeting?

\section{Themes}

- Clearer goals

- How do you think patients' involvement in interprofessional team meetings can be improved? 


\section{Appendix 5.3}

\section{Interview Guide - Health care professionals}

\section{Questions}

- How did you experience the team meeting where you were involved?

- Pleasent/unpleasent, important/unimportant, examples

- What factors have a positive influence on the team meeting?

\section{Themes}

- Preparation

- Task distribution/chairman

- Presence of relatives

- Relationship between patient and health care professional

- What factors have a negative influence on the team meeting?
Themes
o Jargon
- Emotions
- Kind of problems
- Disruptions/social conversations
- Duration
- Location
- Authoritarian attitude

- What can you say about the task distribution and responsibilities of health care professionals and patients, when patients are involved in the meeting?

- What kind of influence does participation of the patient or relative have, on the relationship between you and the patient?

- Are there differences between team meetings where patients are involved and team meetings where patients are not involved?

\section{Themes}

- Psychosocial factors

- Patient-centred goals

- How do you think patients' involvement in interprofessional team meetings can be improved? 


\section{Appendix 5.4}

Initial coding scheme based on literature

\section{Theme}

Meeting structure

Patient's competences

Professionals' competences

Client's influence on the meeting

Role of the families' contact person

Mutual relationship patient - professional

Language and jargon

Preconditions

Preparation of the meeting 


\section{Chapter 6}

"They are talking about me, but not with me": a focus group study to explore the patient perspective on interprofessional team meetings in primary care

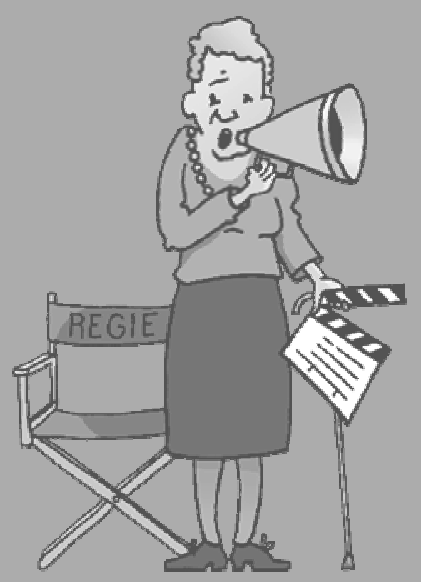

Jerôme van Dongen Maarten de Wit Hester Smeets Esther Stoffers Loes van Bokhoven Ramon Daniëls 


\section{Abstract}

\section{Introduction}

The number of people with multiple chronic conditions receiving primary care services is growing. To deal with their increasingly complex health care demands, professionals from different disciplines need to collaborate. Interprofessional team (IPT) meetings are becoming more popular. Several studies describe important factors related to conducting IPT meetings, mostly from a professional perspective. However in the light of patient-centeredness it is valuable to also explore the patients' perspective.

\section{Objectives}

The aim was to explore the patients' perspectives regarding IPT meetings in primary care.

\section{Methods}

A qualitative study with a focus group design was conducted in the Netherlands. Two focus group meetings took place, for which the same patients were invited. The participants, chronically ill patients with experience on interprofessional collaboration were recruited through the regional patient association. Participants discussed viewpoints, expectations, and concerns regarding IPT meetings in two rounds, using a focus group protocol and selected video-taped vignettes of team meetings. The first meeting focused on conceptualization and identification of themes related to IPT meetings that are important to patients. The second meeting aimed to gain more in-depth knowledge and understanding of the priorities. Discussions were audio-taped and transcribed verbatim, and analyzed by means of content analysis.

\section{Results}

The focus group meetings included seven patients. Findings were divided into six key categories, capturing the factors that patients found important regarding IPT meetings: (1) Putting the patient at the center, (2) Opportunities for patients to participate, (3) Appropriate team composition, (4) Structured approach, (5) Respectful communication, and (6) Informing the patient about meeting outcomes.

\section{Conclusion}

Patients identified different elements regarding IPT meetings that are important from their perspective. They emphasized the right of patients or their representatives to take part in IPT meetings. Results of this study can be used to develop tools and programs to improve interprofessional collaboration. 


\section{Introduction}

Demographic change is characterized by the rise of the ageing population and its concomitant growing number of people with chronic and often complex conditions. ${ }^{1}$ Chronic conditions commonly refer to noninfectious diseases such as type 2 diabetes, chronic obstructive pulmonary disease, or chronic heart failure. To illustrate, thirty percent of the population of the European Union is suffering from a chronic disease whereby the number of people suffering from more than one condition, known as multimorbidity is increasing. ${ }^{2}$ Most of the care for these patients is delivered in the primary care setting, where health care professionals from different disciplines have to deal with increasingly complex and multidimensional health care demands. ${ }^{3,4}$ To comply with this increasing complexity, health care professionals need to work in partnership with each other and the patient system, known as interprofessional collaboration. ${ }^{5}$ In a review by Morgan et al., interprofessional collaboration was defined as: "An active and ongoing partnership often between people from diverse backgrounds with distinctive professional cultures and possibly representing different organizations or sectors who work together to solve problems or provide services". ${ }^{\prime}$ Morgan et al. further explain interprofessional collaboration as a deeper level of working together, emphasizing the interaction between team members. ${ }^{6}$

Health care professionals increasingly collaborate in interprofessional team (IPT) meetings to ensure communication among and coordination of all professionals involved in patient care. In the Dutch primary care setting, an average IPT consists of family physicians, practice nurses, occupational therapists, physical therapists, district nurses, and in some cases pharmacists. ${ }^{7}$ Conducting IPT meetings has been endorsed by the Department of Health in the UK as the core model for managing chronic diseases. ${ }^{8}$ IPT meetings may ensure higher quality decision-making and are associated with improved outcomes. $^{3,9,10}$ During IPT meetings, patients' care plans are the central topic of discussion. Such care plans can be seen as collaborative and dynamic documents including patients' goals and actions. ${ }^{11}$ However, within current practice, effective, and patient-centered teamwork is often lacking. ${ }^{7,12}$

Several studies to explore and improve IPT meetings described key features and influencing factors from the professional perspective ${ }^{10,13,14}$; the patients' perspective on these primary care team meetings seems to be underrepresented in the literature, although we found some data from the field of patient-centered care. Patients seem to value this approach to care, in which they are put at the center as a person, ${ }^{15}$ and care is focused on their individual needs, facilitating their involvement in care. ${ }^{16}$ This last condition is becoming more and more important in the western world, where patient associations are starting to formulate their own quality indicators for chronic health 
care. These criteria from a patient perspective comprise aspects like effective care, accessible care, safe care, being in charge of one's own care process, continuity of care, sufficient information, and transparency about the quality and costs of care. ${ }^{17}$ Despite the literature that suggests that the patient's care plan and need for help should be central during IPT meetings, and that the patient's role and perspectives are of significant value in refining care processes, there seems to be a lack of literature on patients' perspective on these IPT meetings. ${ }^{18}$ As confirmed by a recent observational study on the effectiveness of multidisciplinary team care, ${ }^{8}$ exploring the patients' perspective regarding IPT meetings appears to be a promising approach.

The purpose of this study was to collect qualitative data from patients concerning their views, expectations and concerns regarding IPT meetings in primary care. These findings are valuable for health care professionals, patient organizations and policy makers who are responsible for the development of programmes and tools to optimize IPT meetings.

\section{Methods}

\section{Study design}

We used a qualitative study design and conducted two focus group meetings in December 2015. Our theoretical orientation was based on social constructionism, ${ }^{19}$ in which social interaction between people leads to the development of knowledge. In this perspective, the main rationale for using focus groups is the production of knowledge through social interaction between all participants, patients as well as members of the research team. The dynamic interaction stimulates the thoughts of participants and reminds them of their own feelings. ${ }^{20}$ We assumed that the patient participants were not fully aware of the complexity of the concept of interprofessional collaboration. Therefore, we decided to have two focus groups with the same participants. The first meeting focused on conceptualization by introducing the concept and exploring the views and priorities of the participating patients. The second meeting focused on judgement and included reflexive discussions about the preliminary findings and interpretations. We also assumed that repeated interaction between the same participants leads to more in-depth information. ${ }^{21,22}$ In addition we expected that repeated interaction would increase the sense of belonging to a group and participants' sense of cohesiveness, ${ }^{23}$ which creates a safe climate to share information. ${ }^{24}$ Relevant aspects of this study are reported according to the Consolidated Criteria for Reporting Qualitative Research. ${ }^{25}$ 


\section{Research team}

The research team consisted of a range of experts, and comprised five researchers and one patient advocate. JVD is specialized in qualitative research on interprofessional collaboration. MdW is an experienced qualitative researcher and expert on participatory research. He is also an active patient research partner, and moderated both meetings. HS is a qualitative researcher. ES is a patient advocate and staff member at Huis voor de Zorg, a regional umbrella organization of patient organizations in the south of the Netherlands. MvB is a practicing family doctor and senior researcher. RD is a senior researcher (educated as occupational therapist), and mentored the research team.

\section{Study participants and recruitment}

Participants were selected by means of purposive sampling based on a profile comprising a set of selection criteria (Box 6.1). Besides the selection criteria, we aimed to obtain a diverse range of patients in terms of sex, age, and health condition. Recruitment was coordinated by patient organization Huis voor de Zorg. From their network and database, Huis voor de Zorg invited ten people who met our selection criteria (Box 6.1).

Box 6.1 Participant selection criteria

- $\quad$ Experience as a chronically ill patient

- Experience with interprofessional collaboration

- Sufficient understanding of the Dutch language

- Ability to prepare the focus group meeting at home and attend both meetings

The potential participants received written background information without disclosure of the exact purpose of the focus groups, in order to avoid bias and discourage participants from studying the literature on this topic in advance. Potential participants were invited for both meetings.

\section{Data collection}

Two focus group meetings were conducted in December 2015, and took place in a quiet room at Zuyd University of Applied Sciences (Heerlen, The Netherlands). Each meeting lasted approximately 120 minutes. During both meetings the moderator (MdW) used a semi-structured interview guide to structure the meeting (Appendix 6.1). The discussions were audiotaped and transcribed verbatim. After the transcripts had been analyzed by means of content analysis, one focus group participant ( $E d B)$ joined the research team to complement the teams' interpretation of the results. 


\section{Meeting 1}

The first focus group meeting was meant to familiarize the participants with the concept of IPT meetings, and focused on the identification of relevant themes related to IPT meetings that were perceived as valuable from the patients' perspective. In order to stimulate the participants' understanding and picture of IPT meetings, and provoke discussion, several video fragments of actual IPT meetings in primary care setting were presented. We assumed that showing video fragments would better enable the participants to reflect on issues that matter to them in IPT meetings.

\section{Meeting 2}

The second meeting aimed to gain more in-depth knowledge and understanding of the priorities that are important from the perspective of the participants. The meeting started with a member check on the findings of the first meeting: to what extent did they recognize and support the list of elements and categories (or subcategories) that the team had derived from the first meeting? The second part of the meeting comprised a reflexive discussion on relevant facets of IPT meetings, supported by showing several video fragments.

\section{Data analysis}

We applied conventional content analysis to analyze the transcripts. ${ }^{26}$ Immediately after the first meeting, an interim analysis was carried out by MdW and HS, who independently analyzed the transcripts and used open coding to abstract meaningful quotes and concepts. Nvivo 10 software was used to organize the data. ${ }^{27}$ The two researchers then compared and discussed their codes until consensus was reached, and subsequently grouped the concepts identified into subcategories and broader categories. Disagreements or doubtful codes were discussed by the research team in a face-to-face meeting. Results of the preliminary analysis of the first meeting were used as input for the second meeting. The transcript of the second meeting was analyzed following the same procedure as described above. In the last step, the team came together in another face-to-face meeting, and concluded that the second meeting had provided more in-depth data on the items identified during the first meeting, but had not resulted in new items. The in-depth findings as derived from the second meeting supported a better understanding and simplification of the initial coding as derived from the open coding, and enabled categorization (Appendix 6.2). Eventually, the team agreed on a final set of key categories and subcategories. 


\section{Trustworthiness}

In order to avoid selection bias, Huis voor de Zorg coordinated the recruitment of patients. The researchers' field notes and written comments were used in the analysis process to enhance the trustworthiness of the study. Furthermore, two researchers coded the data independently and then discussed and compared categories and subcategories. During the preliminary analysis, one of the participants of the study joined and helped interpreting the research findings by conducting a preliminary member check. An independent qualitative researcher, experienced in moderating focus groups (MdW), and with personal experience with a chronic disease, moderated the focus groups to reduce the researchers' influence. To increase accuracy, validity and credibility, we completed a member check. ${ }^{28}$ Main findings were sent to all participants, giving them the opportunity to comment on the key findings. To enhance the transferability of the results we aimed to include the perspectives of patients with a variety of backgrounds and experiences

\section{Results}

Huis voor de Zorg recruited ten patients who fulfilled the inclusion criteria. Eventually, seven of them were able to take part. The remaining three were not able to take part since they were not available at both meeting dates. All participants had personal experience as a patient with a chronic condition, and four participants were taking or had taken care of people with a complex illness. Their characteristics are presented in Table 6.1. All participants attended both sessions and were involved in the member check.

\begin{tabular}{|c|c|c|c|c|c|}
\hline $\mathrm{N}$ & Gender & Age & Condition & Current occupation & Professional background \\
\hline Respondent A & $F$ & 65 & $\begin{array}{l}\text { Breast cancer / care- } \\
\text { taker }\end{array}$ & Volunteer / retired & Psychologist \\
\hline Respondent B & $\mathrm{F}$ & 55 & Multiple sclerosis & On social benefit & Education \\
\hline Respondent C & $\mathrm{F}$ & 62 & $\begin{array}{l}\text { Spinal cord injury / } \\
\text { osteoarthritis }\end{array}$ & $\begin{array}{l}\text { Volunteer / On social } \\
\text { benefit }\end{array}$ & Child physiotherapist \\
\hline Respondent D & $\mathrm{F}$ & 59 & Multiple sclerosis & Volunteer & Caregiver \\
\hline Respondent E & $\mathrm{F}$ & 47 & $\begin{array}{l}\text { Breast cancer / } \\
\text { cardiovascular }\end{array}$ & $\begin{array}{l}\text { Volunteer / On social } \\
\text { benefit }\end{array}$ & Secretary \\
\hline Respondent F & $\mathrm{F}$ & 73 & Asthma & Volunteer & Nurse \\
\hline Respondent G & M & 54 & Blind since childhood & Disability pension & Financial specialist \\
\hline
\end{tabular}


Analysis of the focus groups resulted in a set of six key features regarding IPT meetings that were important to patients, as presented in Figure 6.1.

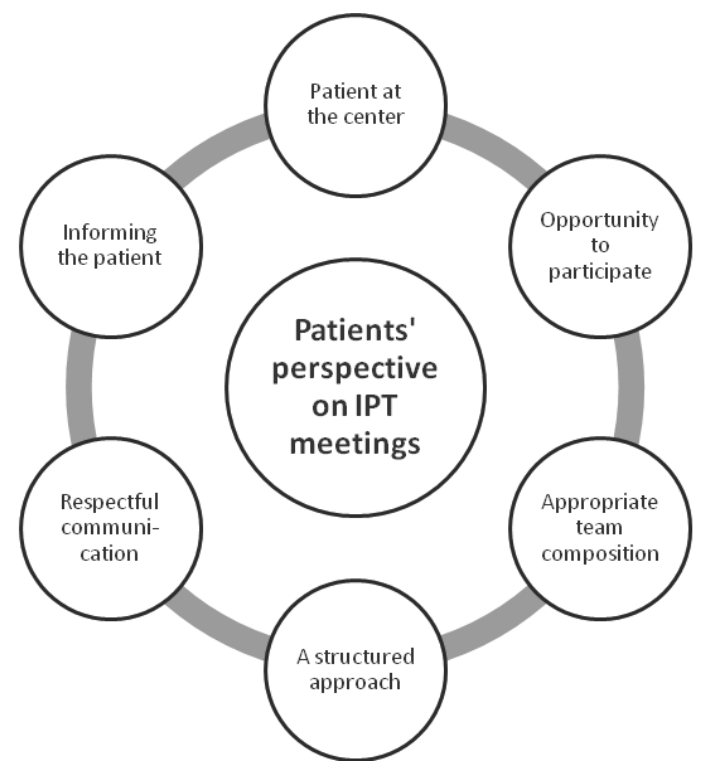

Figure 6.1 Key features of IPT meetings that are important to patients.

\section{The patient at the center}

\section{Holistic approach}

Participants emphasized the importance of patient-centered care. During IPT meetings, the health care professionals should focus on the needs of the patient and ensure that the patient's autonomy is respected as much as possible. There was a broad understanding of the concept of patients' needs. For patients, this concept refers to the notion of well-being and a patient's role in society, and not merely to physical symptoms and disease-related aspects of care. In response to a video fragment, participants noticed that emotions, cognitive and social problems were often neglected by health care professionals.

"They did ask me how I was dealing with the chemo, how do you deal with it. But when they told us the bad outcomes, then we were told 'we will discuss what to do with this at such and such a date. Nothing more, while our world had just fallen apart. Nothing about that." [A] 
For this reason, the participants pleaded for a more holistic approach to health care, highlighting their desire for team members to realize that their patients are more than their diseases or limitations. In addition, more attention should be paid to the psychosocial impact of chronic diseases; patients should be seen in their social context during team meetings, for example as being part of a family that provides support or, in contrast, is hampering effective solutions. Rather than only the individual patient, the IPT should not forget to assess the entire patient system, including the roles of caregivers, partners, children or other people representing the patient.

"The IPT takes individual things into account, insulin has to be injected, food and drinks have to be brought, a pacemaker has to be inserted. But comprehensive care for the patient is lacking. And at the end of the day, that's what patients and their environment need." [G]

\section{Need for support}

The participants noted that in several video vignettes, no clear definition was presented of the patient's problem. In some cases, participants saw no need for bringing up the patient's problem for discussion during the IPT meeting, as the problem could be solved easily by one health care professional or because the issue was too personal and should not be discussed with the entire team. According to participants, an IPT meeting should aim to address the needs for support, preferably formulated or agreed by the patient or his or her representative.

"If you have a clearly formulated request for support from the patient, it is easier to find the right persons who you need in the IPT." [E]

According to the participants, the real nature of the patients' need for support is often unclear, so the IPT meeting does not always result in an appropriate solution for the patient. Participants suggested using a template form or checklist to formulate the request for support to ensure that the meeting remains focused on the patient's personal interests.

\section{Opportunity for patients to participate}

In Dutch primary care it is not routine practice for patients to take part in IPT meetings. Most participants, however, were strongly in favor of giving patients the opportunity to be part of it: 
"As a principle, patients have the right to be present when others talk about them." [C]

They mentioned several benefits. It gives patients the opportunity of free choice and it enhances their own responsibility, as "People will not be speaking about me, but with me". They mentioned that taking part ensures that the patient's personal interest will be taken into account, and they expected that IPT members would make clearer decisions about task allocations (who will be doing what) and inform the patient. Although there was consensus on the assumption that patients should be given the opportunity to take part, participants differed in their desire to attend such a meeting. Two participants who did not want to attend such a meeting explained that they trusted the competences of the health care providers and were convinced that they would act in the patients' best interest. Furthermore, they did not want to put an additional burden on the patient's shoulders: "Not all patients are able to fulfil this new partnership role". Patients might not be able to follow the discussion or might not want to hear unpleasant information. As one of the participants said:

"When thrown to the wolves, they can completely clam up." [B]

The participants identified conditions for participation, in particular the competences of both patient and health care provider. The patient must be willing to attend the meeting and able to contribute to the discussion. Participants expressed that professionals should prepare patients for their role in the meeting, to clarify mutual expectations. They could introduce the professionals the patient is going to meet and guarantee that all information shared will remain confidential. If the patient is not able to participate in the meeting, a representative could attend instead. If a patient is unwilling or unable to participate, participants found it important that the patient is informed in advance of the meeting and consulted about expectations or preferences. Afterwards, the results and decisions should be appropriately reported to the patient or their representative.

\section{Appropriate team composition}

Based on several video fragments, participants questioned the efficiency of having many health care professionals around the table, some of whom do not know the patient. They were concerned about the patient's privacy when intimate information was shared with everyone. Other participants assumed there would be advantages to having unprejudiced experts in the meeting who may represent a different perspective or professional expertise. 
"Beforehand, you don't know what will be discussed. As a psychologist, for example, you may not have a lot of specific input in advance. However, you can think along during the meeting. I think within the multidisciplinary approach it works well to think together, each from his own discipline." [A]

The participants agreed that all health care professionals around the table should share an interest in the patient's request for support, should be willing to listen to the patient and should focus on identifying solutions relevant to the patient's problem(s). This requires empathy, a competence which is not possessed by all professionals, according to the participants.

The patient participants recognized that implementing integrated care requires professionals to be additionally trained in dealing with patients and their families during IPT meetings. They also agreed that time is an important barrier to improving communication. However, from the perspective of patients, they argued that lack of time may never be a reason for not providing the care that a patient needs.

\section{A structured approach to IPT meetings}

Watching the video vignettes, the participants observed that sometimes discussions were very chaotic and lacked a clear structure and coordination. The participants wondered whether the members of the IPT followed a validated approach or methodology:

"I cannot see a common thread, a lot of information was exchanged and an overall picture of the patient was outlined, but in the end, what's going to actually happen?" [G]

They expected health care professionals to prepare the meeting carefully, to read all information about the patient in advance (including a clear and patient-focused problem definition) and to adhere to an agenda, supervised by a competent chairperson. Participants mentioned the importance of the role of a chairperson who structures the meeting, summarizes, invites others to participate and guides the team. In the participants' opinion, the discussions and decisions should be reported in writing and shared with all involved, including deadlines and persons responsible for taking action. According to the respondents, in some of the video vignettes, the team did not make any decisions, nor were tasks or responsibilities assigned to persons. It was not clear to the focus group participants what would be reported to the patient and what problem 
had actually been solved. They suggested that an IPT meeting should result in a care plan.

\section{Respectful communication}

When watching the video vignettes, some participants observed a lack of respect towards the patient under discussion. They commented that especially in the presence of the patient, it is important for team members to communicate respectfully. For the focus group participants, trust and respectful communication between team members, as well as about the patient, were important requirements in IPT meetings:

"Respect?...the patient is present, but is treated as a case, but not as a human being." [G]

The participants observed that professionals interrupted each other regularly, avoided eye contact, and did not really listen to each other. According to them, members hardly raised any questions and were sometimes doing other things during meetings, not related to the discussion. According to participants, the professionals should adjust their terminology and explain concepts or procedures if the patient has questions:

"They are speaking in jargon to each other, and I as a patient don't know all the medical terminology." [A]

\section{Informing the patient about meeting outcomes}

Based on participants' own experience, they commented that informing the patient after an IPT meeting is often forgotten. Though, participants perceived direct contact before, as well as after the meeting as being important, especially in situations when patients or their representatives are not taking part in the IPT. Participants confirmed that being informed about the outcomes of the meeting is crucial to patients:

"In my opinion the patient has to be informed before the meeting about what the team is going to discuss, and afterwards informed about the outcomes of the meeting" [C]

At the end of the IPT meeting, those taking part should agree what decisions or agreements need to be shared with the patient. Participants mentioned that some teams have appointed a designated contact person for the patient who ensures that the patients' needs and preferences are not lost along the way and who is responsible for 
telling the patients what has been agreed upon. Participants argued that in many cases professionals are still working from the narrow perspective of their own discipline or department. Some participants mentioned the position of a case manager, and indicate that it is his or her task to follow up on decisions made and to inform the patient, not only orally, but also in writing.

\section{Discussion}

The aim of this study was to collect qualitative data from patients regarding their perspective on IPT meetings. Findings were extracted through social interaction between the participants, and can be summarized into six categories: (1) Putting the patient at the center, (2) Opportunities for patients to participate, (3) Appropriate team composition, (4) Structured approach, (5) Respectful communication, and (6) Informing the patient about the outcomes of the meeting.

Many health care professionals subscribe to the value of patient-centeredness, although they give different meanings to the concept in everyday practice. ${ }^{29,30}$ The focus group participants noticed that despite this intention, health care professionals often act within the narrow boundaries of their own specific discipline and often fail to integrate the real-life experiences of patients in their health care. The focus group participants mentioned that the current health care system is still medically oriented, and would like to see those taking part in IPT meetings move towards a more holistic model of illness and disabilities also including social and emotional aspects. In such a model, supporting people to remain active and able to participate in activities that are meaningful to them, including their own care, is just as important as managing the disease and prevent deterioration. ${ }^{31}$ A possible strategy to assure patient-centered-ness in team meetings is exploring patients' functioning from a biopsychosocial perspective and supporting patients to formulate personal values, needs and goals before the meeting, and to focus during the team meeting on how to support patients in achieving those goals. ${ }^{32}$ Participation of patients or their representatives in IPT meetings is another way to enhance patient-centered and holistic care. ${ }^{33}$ According to the participants all patients or their representatives should be given the opportunity to participate in IPT meetings if they prefer to do so. The value of taking part in IPT meetings lay in the desire to have a voice in their own care process and thereby preserve one's autonomy. However, the focus group participants expressed understanding for the fact that not all patients are able or confident enough to raise their voice during an IPT meeting. Children or people with mental or cognitive limitations might be represented by their relatives or 
caregivers. According to the literature, including the patient or their relatives in a health care team is appreciated by professionals and patients, ${ }^{34}$ and can be considered a way to stimulate engagement and patient participation. ${ }^{35,36}$ Various studies have shown positive effects of patient participation during IPT meetings and reported that this provided added value in terms of interdependency, communication, and mutual trust, ${ }^{37-39}$ and increased involvement in decision making. ${ }^{40}$ Wittenberg-Lyles et al. reported that hospice teams formulated more patient-centered goals when relatives participated in team meetings. ${ }^{39}$ Other studies mentioned barriers to participation like the excessive use of jargon ${ }^{41,42}$ and the potential risk of overburdening the patient. ${ }^{43} \mathrm{~A}$ tailored approach to patient involvement during IPT meetings appears preferable. ${ }^{34}$ It seems interesting to explore what it takes to include patients as team members in IPT meetings. According to the participants, the patient should be given the opportunity to have a representative as a stand in for the patient's interest during IPT meetings, if the patient is not able or willing to attend him- or herself. An alternative option may be to appoint a case manager, i.e., a professional with overall responsibility for the patient's care. ${ }^{44}$ When the case manager's function includes preparing the meeting by consulting the patient, introducing the patient's goals and perspective during the meeting, and informing the patient about the outcomes of the meeting, such a case manager could provide added value. $^{44}$

Other themes derived from this study are the importance of a structured approach to IPT meetings and respectful communication within the team, in which the chairperson plays a significant role, structuring the meeting and guiding the team. Structured meetings, division of roles (especially the role of a chairperson) and mutual communication are factors that have been found in several studies on influencing factors to the process of interprofessional collaboration. ${ }^{10,14,45,46}$ Further, participants also discussed the attendance of professionals and team composition. According to Okun et al. effective health care teams include a mix of people, talents, and capabilities that perform interdependent functions to fulfil the needs of the patients with whom they collaborate. ${ }^{47}$ Participants agreed on this, but remarked that this should not lead to an oversized team, since they questioned the effectiveness of having a large team of professionals. Moreover, they emphasized the importance of confidentiality of patient related information in which professionals should work in accordance with prevailing laws and regulations. Mutual agreements on organization, working procedures, team composition, roles and responsibilities, and communication strategy, can be considered a useful approach for stimulating cohesion during IPT meetings. ${ }^{48}$

The findings of this study were derived in the context of the Dutch health care system, and although we have tried to ensure diversity in the perspectives of the focus group participants, we did not completely succeed in this. We included only one man, no 
young people, no ethnic minority, and no patient with a mental health problem. Further, most of the participants were active volunteers of various patient organizations, leaving the perspective of vulnerable groups probably underrepresented. However, we did have a mixed group of patients representing a diversity of disease experiences, and we obtained a range of perspectives on the value of IPT meetings. Since IPT meetings are a rather new phenomenon for patients, participants had to master a certain degree of reflectivity and imagination to be included. Hereby we assume a majority of the group (not all) was higher educated, which eventually resulted in a diversity of opinions. As a possible strength, we assume that using video vignettes to illustrate the current IPT meeting practice supported participants in remaining focused on the aim of their discussion.

To our knowledge, this study is the first of its kind to explore the patient perspective regarding IPT meetings in primary care among patients themselves. Professionals and experts recognize the added value of patient participation as well. ${ }^{45}$ However, they add external factors relating to professionals' education, culture, hierarchy and finance. ${ }^{45}$ Since every team has its specific features, reflexivity, the extent to which teams reflect upon their functioning, can be considered the base for all teams to improve. ${ }^{49}$ The findings of this study might function as an eye-opener for interprofessional teams, inviting them to self-reflect on patient-centered and holistic care before, during and after IPT meetings. Within the field of interprofessional care, findings can be used to support further development and implementation of quality improvement programmes. Further, education developers can use findings to develop or adapt interprofessional modules.

\section{Conclusion}

Patients participating in this study stated that they value the opportunity to be part of IPT meetings, and emphasized the right of the patients or their representatives to attend IPT meetings. More knowledge might be needed about conditions and skills for including patients as team members in IPT meetings. To improve IPT meetings and increase patient-centeredness, promising directions appear to be making someone responsible for respectful communication with the patient system before, during and after IPT meetings; putting the patient at the center and follow a holistic approach in which the patient's functioning is discussed from a biopsychosocial perspective; and working according to a structured approach. Additional research to explore the effectiveness of these promising directions is needed. 


\section{Key points for Decision Makers}

- Chronically ill patients appreciate having a voice in their own care process, and feeling part of the team.

- Following the previous key point, patients value the opportunity to participate, or be represented in interprofessional team (IPT) meetings.

- Patients expect health care professionals to put the patient at the center and to follow a structured as well as holistic approach to address their needs.

- Patients want health care professionals to work in a professional manner and communicate respectfully with the 'patient system' (comprises the patient and the people representing the patient, such as caregivers, partners, children or designated health professionals) before, during and after IPT meetings. 


\section{References}

1. Robustill S, et al. EU employment and social situation, quarterly review, E. Union, Editor. 2013, Publications Office of the European Union: Luxembourg.

2. Hopman $P$, et al. Health care utilization of patients with multiple chronic diseases in the Netherlands: Differences and underlying factors. Eur J Intern Med. 2016;35:44-50.

3. Vyt A. Interprofessional and transdisciplinary teamwork in health care. Diabetes Metab Res Rev. 2008;24 Suppl 1:S106-9.

4. Pullon $\mathrm{S}$, et al. Observation of interprofessional collaboration in primary care practice: a multiple case study. J Interprof Care. 2016;30(6):787-94.

5. Bodenheimer T, Chen E, Bennett HD. Confronting the growing burden of chronic disease: can the U.S. health care workforce do the job? Health Aff (Millwood). 2009;28(1):64-74.

6. Morgan S, Pullon S, McKinlay E. Observation of interprofessional collaborative practice in primary care teams: An integrative literature review. Int J Nurs Stud. 2015;52(7):1217-30.

7. van Dongen JJJ, et al. Interprofessional primary care team meetings: a qualitative approach comparing observations with personal opinions. Family Practice. 2017;34(1):98-106.

8. Raine R, et al. Improving the effectiveness of multidisciplinary team meetings for patients with chronic diseases: a prospective observational study, in Health Services And Delivery Research. 2014: Southampton (UK).

9. Mickan SM. Evaluating the effectiveness of health care teams. Aust Health Rev, 2005. 29(2): p. 211-7.

10. van Drielen, E., et al., Beter multidisciplinair overleg past bij betere zorg [Better multidisciplinary team meetings are linked to better care]. Ned Tijdschr Geneeskd. 2012;156(45):A4856.

11. Newbould J, et al. Experiences of care planning in England: interviews with patients with long term conditions. BMC Fam Pract. 2012;13:71.

12. Dimas ID, Renato Lourenco P, Rebelo $T$. The effects on team emotions and team effectiveness of coaching in interprofessional health and social care teams. J Interprof Care. 2016;30(4):416-22.

13. Korner $\mathrm{M}$, et al. Interprofessional teamwork and team interventions in chronic care: A systematic review. J Interprof Care. 2016;30(1):15-28.

14. Nancarrow SA, et al. Ten principles of good interdisciplinary team work. Hum Resour Health. 2013;11:19.

15. Moore M. What does patient-centred communication mean in Nepal? Med Educ. 2008;42(1):18-26.

16. Sumsion T, Lencucha R. Balancing challenges and facilitating factors when implementing client-centered collaboration in a mental health setting. Br J Occupational Ther. 2007;70:513-20.

17. Kwaliteit in Zicht, Basisset kwaliteitscriteria: Het patientenperspectief op de zorg voor chronisch zieken (Basic set of quality criteria: The patients' perspective towards chronic care). 2010, Kwaliteit in Zicht.

18. Cheong $\mathrm{LH}$, Armour CL, Bosnic-Anticevich SZ. Multidisciplinary collaboration in primary care: through the eyes of patients. Aust J Prim Health. 2013;19(3):190-7.

19. Berger L, Luckmann T. The social construction of reality. 1966, USA: Penguin Books.

20. Holloway I, Wheeler S. Qualitative research in nursing and healthcare. 2010, UK: Wiley-Blackwell. 351.

21. Wong LP. Focus group discussion: a tool for health and medical research. Singapore Med J. 2008;49(3): 256-60; quiz 261.

22. Krueger R, CaseyM. Focus Groups: A Practical Guide for Applied Research. Vol. 4. 2009, Los Angeles.

23. Peters DA. Improving quality requires consumer input: using focus groups. J Nurs Care Qual. 1993;7(2): 34-41.

24. Vaughn S, Schumm JS, Sinagub J. Focus group interviews in education and psychology. 1996, Thousand Oaks: SAGE Publications.

25. Tong A, Sainsbury P, Craig J. Consolidated criteria for reporting qualitative research (COREQ): a 32-item checklist for interviews and focus groups. Int J Qual Health Care. 2007;19(6):349-57.

26. Hsieh HF, Shannon SE. Three approaches to qualitative content analysis. Qual Health Res. 2005;15(9): 1277-88.

27. Mortelmans D. Kwalitatieve analyse met Nvivo. 2011, Leeuwen: Acco Uitgeverij.

28. Lincoln M, Guba EG. Naturalistic inquiry. 1985, Beverly Hills: Sage.

29. Epstein RM, Street RL Jr. The values and value of patient-centered care. Ann Fam Med 2011;9(2):100-3. 
30. Sidani S, Fox M. Patient-centered care: clarification of its specific elements to facilitate interprofessional care. J Interprof Care. 2014;28(2):134-41.

31. Goering S. Rethinking disability: the social model of disability and chronic disease. Curr Rev Musculoskelet Med. 2015;8(2):134-8.

32. van Dongen JJ, et al. Developing interprofessional care plans in chronic care: a scoping review. BMC Fam Pract. 2016;17(1):137.

33. Locatelli SM, et al. Provider perspectives on and experiences with engagement of patients and families in implementing patient-centered care. Healthc (Amst). 2015;3(4):209-14.

34. van Dongen JJ, et al. Successful participation of patients in interprofessional team meetings: a qualitative study. Health Expect. 2016.

35. Vahdat $\mathrm{S}$, et al. Patient involvement in health care decision making: a review. Iran Red Crescent Med J. 2014;16(1):e12454.

36. Saltz CC, Schaefer T. Interdisciplinary teams in health care: integration of family caregivers. Soc Work Health Care. 1996;22(3):59-70.

37. Griffith JC, et al. Family meetings--a qualitative exploration of improving care planning with older people and their families. Age Ageing. 2004;33(6):577-81.

38. Dijkstra A. Family participation in care plan meetings: promoting a collaborative organizational culture in nursing homes. J Gerontol Nurs. 2007;33(4):22-9; quiz 30-1.

39. Wittenberg-Lyles $\mathrm{E}$, et al. Inviting the absent members: examining how caregivers' participation affects hospice team communication. Palliat Med. 2010;24(2):192-5.

40. Oliver DP, et al. Caregiver evaluation of the ACTIVE intervention: "it was like we were sitting at the table with everyone". Am J Hosp Palliat Care. 2014;31(4):444-53.

41. Choy ET, et al. A pilot study to evaluate the impact of involving breast cancer patients in the multidisciplinary discussion of their disease and treatment plan. Breast. 2007;16(2):178-89.

42. Donnelly SM, et al. Multiprofessional views on older patients' participation in care planning meetings in a hospital context. Practice 2013;25(2):121-38.

43. van de Bovenkamp HM, Trappenburg MJ, Grit KJ. Patient participation in collective healthcare decision making: the Dutch model. Health Expect. 2010;13(1):73-85.

44. Bakker $\mathrm{M}$, et al. Need and value of case management in multidisciplinary ALS care: A qualitative study on the perspectives of patients, spousal caregivers and professionals. Amyotroph Lateral Scler Frontotemporal Degener. 2015;16(3-4):180-6.

45. van Dongen JJ, et al. Interprofessional collaboration regarding patients' care plans in primary care: a focus group study into influential factors. BMC Fam Pract. 2016;17(1):58.

46. Xyrichis A, Lowton K. What fosters or prevents interprofessional teamworking in primary and community care? A literature review. Int J Nurs Stud. 2008;45(1):140-53.

47. Okun S, et al. Patients and Health Care Teams Forging Effective Partnerships, I.o. Medicine, Editor. 2014: Washington.

48. Mickan SM, Rodger SA. Effective health care teams: a model of six characteristics developed from shared perceptions. J Interprof Care. 2005;19(4):358-70.

49. Widmer PS, Schippers MS, West MA. Recent Developments in Reflexivity Research: A Review. Psychology of Everyday Activity. 2009;2(2):2-11. 


\section{Appendix 6.1}

\section{Semi-structured interview guide}

Interview guide for meeting 1: "Conceptualization and identifying relevant themes"

\section{Introduction}

- Introduction of the discussion leader/moderator

- Consent for audio recording

- Explanation of participants' rights

- Aim of the focus group:

- We want to collect qualitative data from patients regarding their priorities and opinions on the potential benefits and limitations of IPT meetings. Within IPT meetings, health workers from different professional backgrounds work together to deliver the highest quality of care

- Duration and procedure

- Explaining that all information is relevant

\section{Round of introductions}

Most of you have personal experience with a chronic health care demand. In order to deal with this demand you have contacts with health care professionals from a diversity of disciplines. These professionals meet on a regular basis to discuss complex health care demands.

- Do you have a clear image of an IPT meeting?

- $\quad$ Some specific terms in this field are used interchangeably. Which terms do you prefer: health care provider or professional, patient or client?

\section{Questions for part 1}

1. Did you ever attend a meeting? At your work, an organisation, society or somewhere else? What are your positive and negative experiences?

2. Have you ever been in a situation with multiple health care professionals? How did you experience this?

3. When thinking about a meeting with multiple health care professionals discussing a patient's care, what do you perceive to be important?

a. Could you explain this?

b. Why do you perceive this as an important aspect? 


\section{Summary of the factors mentioned}

Questions for part 2: (questions related to three video vignettes)

Now we will watch three video vignettes showing an interprofessional team meeting. At the end of each video vignette, we will ask you to respond / react to it.

4. What do you notice when watching the fragments?

a. Why do you notice this?

b. Why is this important to you?

5. [after all fragments have been viewed]. At the beginning of this focus group meeting you mentioned some important features regarding IPT meetings. After watching these video vignettes, are there any other (additional) features? Did anything change regarding your perception of the previously mentioned features?

\section{Summary of the factors mentioned}

- Give a summary of the main findings and factors mentioned.

- Did I forget any relevant information in this summary?

\section{Completion and rounding off}

In the next focus group meeting we will present a summary of the features that have been mentioned and discussed today. We will ask you to check whether this overview is complete and recognizable, and if you have any additions. Then we will again watch some video vignettes and ask you to react to what you see.

Interview guide for meeting 2: "Judgements"

\section{Introduction}

- Introduction of the discussion leader/moderator

- Consent for audio recording

- Explanation of participants' rights

- Aim of the focus group:

- We want to collect qualitative data from patients regarding their priorities and opinions on the potential benefits and limitations of IPT meetings. Within IPT meetings, health workers from different professional backgrounds work together to deliver the highest quality of care

- Duration and procedure

- Explaining that all information is relevant 


\section{Questions part 1: (questions related to conceptualization)}

At the previous focus group meeting we talked about features you perceive to be important regarding IPT meetings. We have summarized these features and want to ask you to read them again.

1. We want to ask you whether you recognize these features. Are there any features you want to add? Features that have to be rephrased?

In a moment we will again watch some video vignettes. At the end of each video vignette we will ask you to respond / react to it

2. What do you notice when watching the fragments?

a. Why do you notice this?

b. What does it mean for you?

\section{Summary of the factors mentioned}

\section{Questions for part 2: (questions related to judgment)}

3. What could be done to improve the IPT meeting? What's your opinion about patients attending IPT meetings? In what sense would this change the IPT meeting?

\section{Completion and rounding off}

Explaining the follow-up process. 


\section{Appendix 6.2}

\section{Coding scheme}

\begin{tabular}{|c|c|}
\hline \multicolumn{2}{|l|}{ Coding scheme } \\
\hline $\begin{array}{l}\text { Results initial coding scheme } \\
\text { (Preliminary analysis after meeting 1) }\end{array}$ & $\begin{array}{l}\text { Results categorization: Key features } \\
\text { (Final analysis after meeting 2) }\end{array}$ \\
\hline $\begin{array}{l}\text { Patient at the center } \\
\text { Working demand oriented } \\
\text { Holistic approach } \\
\text { Integrated care }\end{array}$ & Patient at the center \\
\hline Patient as participant & Opportunity to participate \\
\hline $\begin{array}{l}\text { Diversity of professionals involved } \\
\text { Privacy }\end{array}$ & Appropriate team composition \\
\hline $\begin{array}{l}\text { Preparation of the meeting } \\
\text { Meeting structure } \\
\text { Organisational conditions }\end{array}$ & A structured approach \\
\hline $\begin{array}{l}\text { Sharing infomation } \\
\text { Mutual respect } \\
\text { Social skills }\end{array}$ & Respectful communication \\
\hline $\begin{array}{l}\text { Informing the patient } \\
\text { Feedback to the patient } \\
\text { Case manager }\end{array}$ & Informing the patient \\
\hline
\end{tabular}




\section{Chapter}

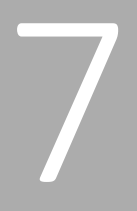

Development of a customizable programme for improving interprofessional team meetings. An action research approach

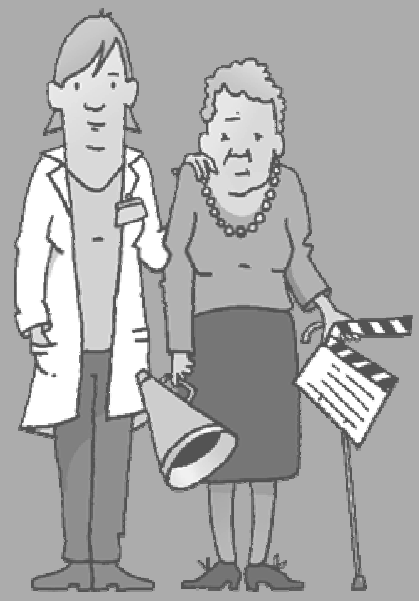

Jerôme van Dongen Loes van Bokhoven Wim Goossens

Ramon Daniëls Trudy van der Weijden Sandra Beurskens 


\section{Abstract}

\section{Introduction}

Interprofessional teamwork is increasingly necessary in primary care to meet the needs of people with complex care demands. Needs assessment shows that this requires efficient interprofessional team meetings, focusing on patients' personal goals. The aim of this study was to develop a programme to improve the efficiency and patient-centredness of such meetings.

\section{Methods}

Action research approach: a first draft of the programme was developed, and iteratively used and evaluated by three primary care teams. Data were collected using observations, interviews and a focus group, and analysed using directed content analysis.

\section{Results}

The final programme comprises a framework to reflect on team functioning, and training activities supplemented by a toolbox. Training is intended for the chairperson and a co-chair, and aims at organizing and structuring meetings, and enhancing patient-centredness. Our findings emphasize the essential role of the team's chairperson, who, in addition to technically structuring meetings, should act as a change agent guiding team development.

\section{Conclusion}

Findings show that the programme should be customizable to each individual team's context and participants' learning objectives. Becoming acquainted with new structures can be considered a growth process, in which teams have to find their way, with the chairperson as change agent. 


\section{Introduction}

Today, chronic diseases are responsible for $60 \%$ of the global disease burden. Due to increased life expectancy, it is expected to rise to, $80 \%$ by the year $2020 .{ }^{1}$ Chronically ill patients often suffer from multiple chronic conditions, and use health services more often than other patients. ${ }^{2}$ The key to a better understanding of these patients' individual needs appears to be patient-centred care, which is associated with improved health status and efficiency of care. ${ }^{3}$ In patient-centred care, the patient is considered as a whole person with biological, psychological and social needs. ${ }^{4}$

To provide patient-centred care for patients with multiple chronic conditions, contributions of professionals from different disciplines need to be integrated into joint care plans. ${ }^{4-8}$ Effective communication and teamwork within those teams is promoted to ensure integrated care. ${ }^{9}$ This requires effective collaboration by the professionals and the patient. ${ }^{5}$ In the Dutch primary care setting, interprofessional collaboration is often implemented through periodic interprofessional team (IPT) meetings. Such meetings appear to vary considerably in format and content. An average team may comprise family physicians, practice nurses, occupational therapists, physical therapists, and district nurses. ${ }^{10}$

Conducting successful IPT meetings is complex as it is influenced by many factors. ${ }^{7,10-12} \mathrm{~A}$ structure for team meetings, preparation of the meetings, division of roles and shared values have been reported to be important aspects of successful and efficient team meetings. ${ }^{10}$ In practice, teamwork is often inefficient and time consuming, due to lack of a clear structure, depth of discussion and lack clear agreements. ${ }^{10,13}$ Professionals consider lack of time to be a serious barrier to team functioning. ${ }^{11}$ Moreover, observations have shown that IPT meetings are still dominated by the professional instead of the individual patients' perspective and often lack a leader who can guide team development through stimulating team reflection. ${ }^{10}$

Consequently, there is a need for effective interventions to improve IPT meetings. ${ }^{13} \mathrm{~A}$ needs assessment encompassing various qualitative studies and a scoping review ${ }^{10-12,14}$ showed that current practice could benefit from improvements in structure, patientcentredness and leadership. The aim of the present study is to systematically develop the format and content of a programme for improving interprofessional team meetings focusing on these prioritized topics. 


\section{Methods}

\section{Design}

An action research design was used to develop the programme. The rationale for using action research was to develop a programme in an iterative approach by learning through action, and ensuring the involvement of intended users (health care professionals). Action research is usually conducted in four phases (Box 7.1). ${ }^{15}$

Box 7.1 Phases of action research.

1. Plan (development of the draft programme)

2. Act and observe (testing the draft programme)

3. Reflect (evaluation of the usability in context)

4. Revised plan (final programme)

In the first phase a development team devised the draft programme. Figure 7.1 shows the programme's development process. The input for the development team consisted of a list of topics for improvement (compiled during a needs assessment ${ }^{10-12,14}$ ), which were prioritized during a consensus meeting by an expert panel including experts and professionals. Subsequently, five main change objectives were derived: (1) knowing each other personally, (2) clear structure and organization, (3) patient-centredness, (4) feedback and team reflexivity, and 5) chairing meetings and guiding team development. The development team gathered five times during the period May - June 2014. Firstly, the team studied the change objectives as derived from the needs assessment (Figure 7.2). Secondly, the team defined the preconditions of the programme (Figure 7.2). They then started a preliminary exploration of ideas, in which thinking outside the box was encouraged. During the subsequent meetings, preliminary ideas were converted into actual drafts.

The second and third phases involved evaluating the programmes usability in context through four iterative action research cycles. Each cycle comprised a period of acting and observing, reflecting and revising (Figure 7.2). In between the cycles, participants had the opportunity to adjust the materials. In the fourth phase, the draft programme was revised and adjusted based on the findings of the previous phases, resulting in a set of criteria and the final programme. The programme was developed over a 6-month period (Jan - Jun 2015). 


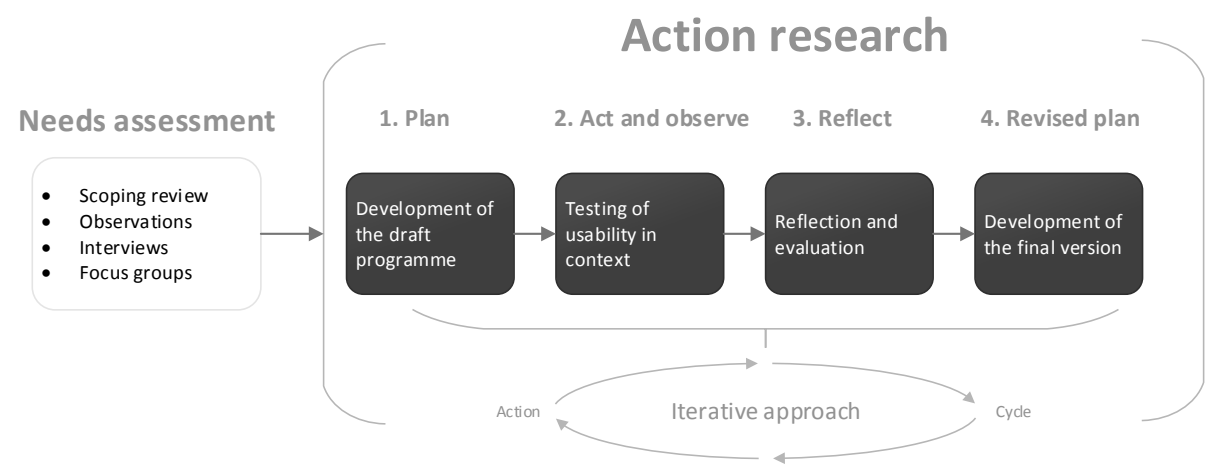

Figure 7.1 Programme development process.

\section{Participants}

All participants were recruited by means of purposive sampling using the researchers' network. The expert panel and development team included experts and professionals comprising at least one researcher, one health care professional, one expert in group dynamics, and one creative designer. Nine experts and professionals (including one patient representative) participated in the expert panel, five in the development team (three researchers, a practice nurse, and an expert in group dynamics).

Further, three interprofessional primary care teams were included in the study if they periodically conducted IPT meetings including three or more health care professionals from different disciplines. In addition, the teams' chairpersons should be willing to participate in a training programme. The meetings were part of the regular care process, and not initiated specifically for this study. Team members received oral information, and a letter with information about the content of the study and confidentiality of the data. The characteristics of the three participating teams are presented in Table 7.1.

Table 7.1 Characteristics of the participating interprofessional primary care team meetings.

\begin{tabular}{lllll}
\hline Team & $\begin{array}{l}\text { Duration } \\
\text { in } \\
\text { minutes }\end{array}$ & $\begin{array}{l}\text { Frequency of } \\
\text { team } \\
\text { meetings }\end{array}$ & $\begin{array}{l}\text { Average } \\
\text { number of } \\
\text { participants }\end{array}$ & Disciplines \\
\hline 1 & 90 & $\begin{array}{l}\text { Once every } \\
\text { two months } \\
\text { Once a } \\
\text { month }\end{array}$ & 7 & $\begin{array}{l}\text { Family physician, practice nurse, physical therapist, } \\
\text { occupational therapist, pharmacist }\end{array}$ \\
3 & 60 & $\begin{array}{l}\text { Family physician, practice nurse, physical therapist, } \\
\text { occupational therapist, psychotherapist, dietician, district } \\
\text { nurse, psychologist, social worker, nurse } \\
\text { Once every } \\
\text { six weeks }\end{array}$ & 8 & $\begin{array}{l}\text { Family physician, practice nurse, physical therapist, } \\
\text { occupational therapist, social worker, district nurse, } \\
\text { neighbourhood care }\end{array}$ \\
\hline
\end{tabular}




\section{Prioritized points for} improvement

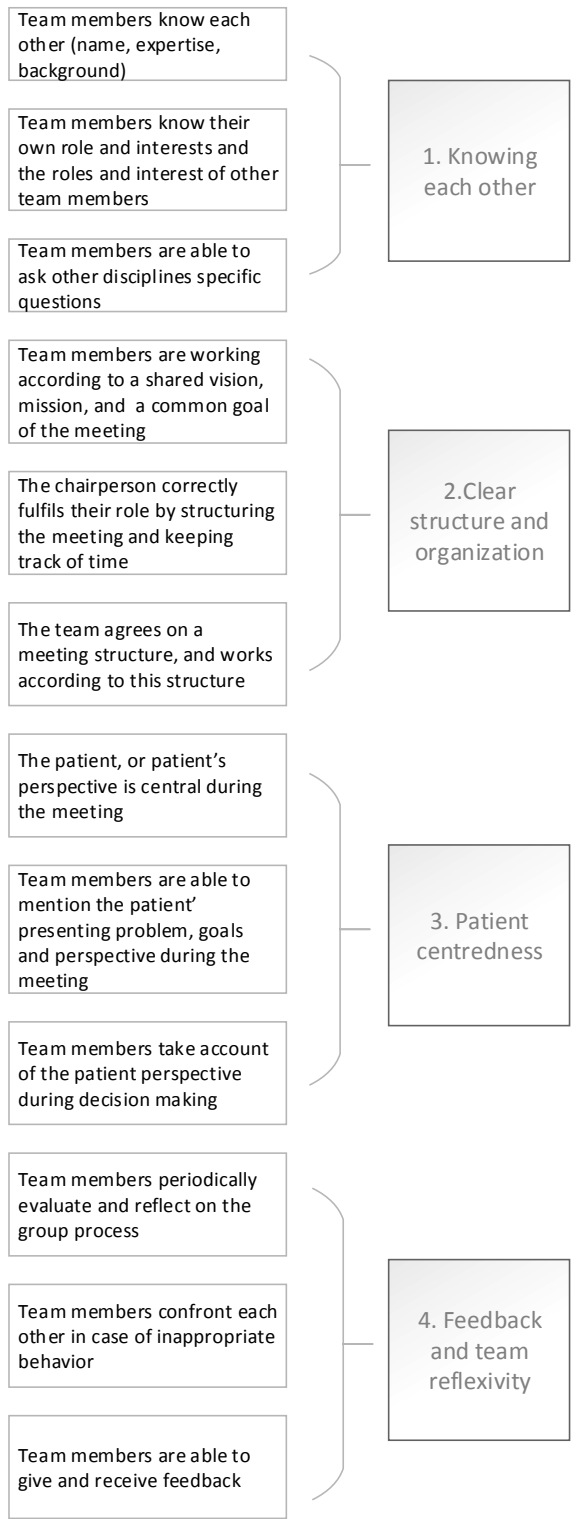

Draft programme

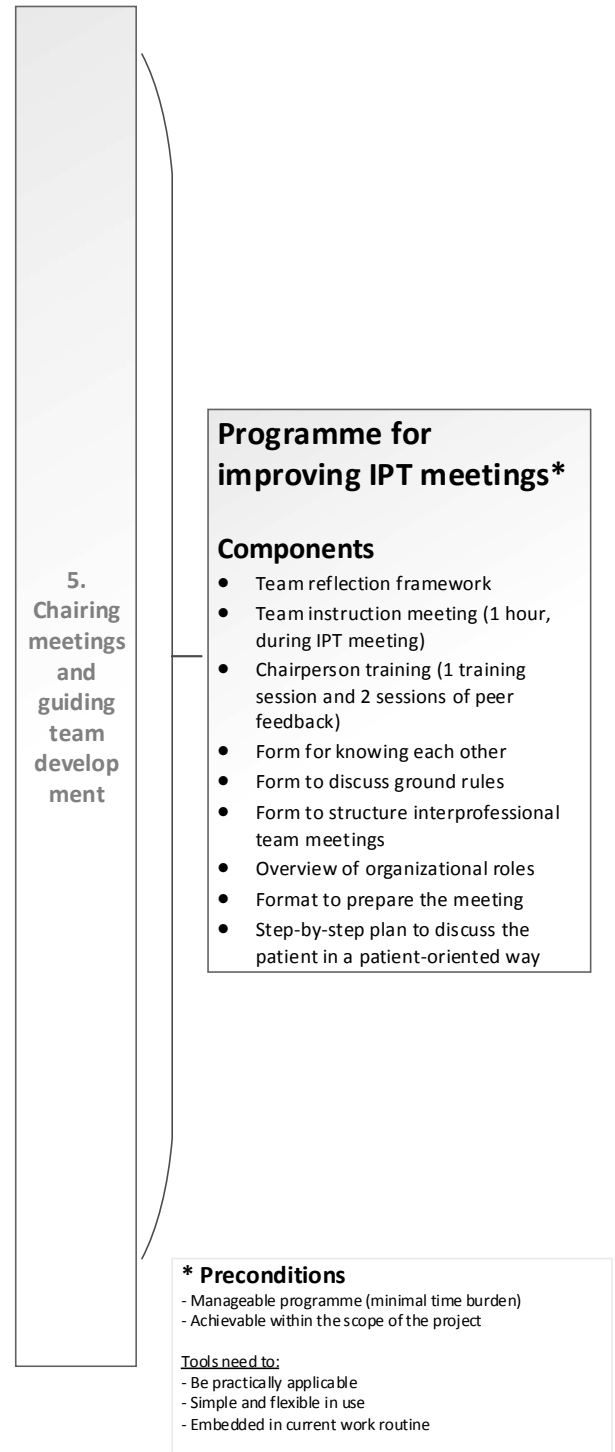

Figure 7.2 Development of the draft programme. 


\section{Data collection}

During phases 2 and 3, we used an iterative approach with ongoing data collection from observations, interviews with participants and a focus group meeting. Table 7.2 offers an overview of the qualitative data collection.

Table 7.2 Qualitative data collection.

\begin{tabular}{|c|c|c|c|c|}
\hline Team & $\begin{array}{l}\text { Team } \\
\text { observations } \\
(n=12)\end{array}$ & $\begin{array}{l}\text { Individual } \\
\text { interviews } \\
(n=25)\end{array}$ & Disciplines interviewed & $\begin{array}{l}\text { Focus group meeting } \\
(n=6)\end{array}$ \\
\hline \multirow[t]{4}{*}{1} & Round 1 & $N=3$ & $\begin{array}{l}\text { Family physician, physical therapist, practice } \\
\text { nurse }\end{array}$ & \multirow[t]{4}{*}{$\begin{array}{l}\text { Practice nurse \& physical } \\
\text { therapist }\end{array}$} \\
\hline & Round 2 & $N=2$ & Practice nurse, occupational therapist & \\
\hline & Round 3 & $N=2$ & Family physician, practice nurse & \\
\hline & Round 4 & $N=3$ & Practice nurse $(\times 2)$, family physician & \\
\hline \multirow[t]{4}{*}{2} & Round 1 & $N=3$ & Psychologist, practice nurse, family physician & \multirow[t]{4}{*}{ Dietician \& district nurse } \\
\hline & Round 2 & $N=2$ & Physical therapist, district nurse & \\
\hline & Round 3 & $N=2$ & Practice nurse, district nurse & \\
\hline & Round 4 & $N=2$ & Occupational therapist, district nurse & \\
\hline \multirow[t]{4}{*}{3} & Round 1 & $N=2$ & Social worker, physical therapist & \multirow{4}{*}{$\begin{array}{l}\text { Social worker \& district } \\
\text { nurse }\end{array}$} \\
\hline & Round 2 & $N=2$ & Practice nurse, district nurse & \\
\hline & Round 3 & $N=0$ & No team member was available & \\
\hline & Round 4 & $N=2$ & Occupational therapist, district nurse & \\
\hline
\end{tabular}

\section{Observations}

Access to the meetings was arranged by the teams' contact persons. Meetings were audio-recorded. A non-participant observer (JvD) took field notes and collected background data using an observation list (Appendix 7.1). In total 12 meetings were observed (4 per team).

\section{Interviews}

Participants were selected by means of pragmatic sampling. After each observation, we intended to individually interview at least two other team members. This resulted in 25 interviews. The interview guide (Appendix 7.2) started with an open question to explore how respondents felt about the meeting that had just taken place. Other questions were related to barriers and facilitators regarding the applicability of the programme, added value and possible improvements of the programme. The interview guide was previously pilot-tested on two members of an IPT, to see how questions were interpreted, and subsequently improved. Interviews lasted on average 15 minutes and were conducted by JVD and a fellow researcher experienced in interviewing. Moreover, at the end of 
each training activity, participating chairpersons briefly evaluated the value and content of the course as a group.

\section{Focus group meeting}

We organized a focus group meeting (two hours) with representatives from the three participating teams. Teams were asked to delegate two members from different disciplines (other than the chairperson) to represent their team. In total six team members participated. The purpose of this meeting was to share experiences regarding the use of the tools and components of the programme among the three teams, with the aim of providing improvements to the programme. An experienced researcher (MvB) moderated the meeting, while a second researcher (JvD) was responsible for facilitating the meeting and taking notes. During the first hour participants introduced their own work problems and questions. The second hour consisted of sharing experiences regarding the application and added value of the different components of the programme.

\section{Analysis}

Directed content analysis was used to analyse all data collected in phases 2 and $3{ }^{16} \mathrm{~A}$ detailed description of each observation was made, based on the focal points presented in Appendix 7.1, and completed with field notes about significant events and non-verbal communication. The audio-recorded interviews were transcribed verbatim. Analysis was completed by two researchers (JVD and SB). Both read all transcripts independently and repeatedly in order to familiarize themselves with the data. They then coded all the data with the assistance of Nvivo 10 software, and compared and discussed their findings until consensus was reached. ${ }^{17}$ Field notes and the written comments of the researcher were kept and used in the analysis process to enhance the trustworthiness of the study. The same initial coding scheme was used for both observations and interviews. Data that could not be coded using the existing codes were identified and analysed later to determine whether they represented a new category or subcategory of an existing code.

\section{Results}

Results are described per phase of action research. First, the development and subsequent content of the draft programme are described (phase 1 of action research), followed by findings from the testing and evaluation phases (phases 2 and 3 of action 
research). Lastly, the main results of the evaluation and the final version of the programme are presented (phase 4 of action research).

\section{Developing the draft programme}

In addition to the preconditions (Figure 7.2), the development team had to take into account the dynamic interprofessional team setting. From a theoretical perspective, the Total Process Coaching of Groups (TPCG) model, developed by Goossens, appeared to be a useful framework to obtain a better understanding of group development and team dynamics. ${ }^{18}$ The development team agreed to use the TPCG model as a supporting framework, since the model fitted the findings from our needs assessment. The model offers an understanding of complex group processes, from the perspective of their interrelationships, and focuses on the links between four core elements (1) group development; (2) communication levels; (3) leadership; (4) the context of the group. Based on the findings of our needs assessment and the theoretical insights derived from the TPCG model, we assumed that an appropriately trained chairperson might play a significant role in chairing meetings and guiding team development (Figure 7.2). Based on programmes preconditions (Figure 7.2), the development team developed a multifaceted programme mainly intended to improve the functioning of IPTs by facilitating and training chairpersons. Table 7.3 offers background information on the components of the draft programme.

\section{Testing and evaluating the draft programme}

Three teams used the draft programme. They started with the team instruction meeting, and experimented with the tools. The teams' chairpersons attended the training activities. In order to analyse the results, we describe the findings per change objective. For each programme component, the facilitators, barriers and suggested adjustments in terms of format and content are described and presented in Table 7.3. 


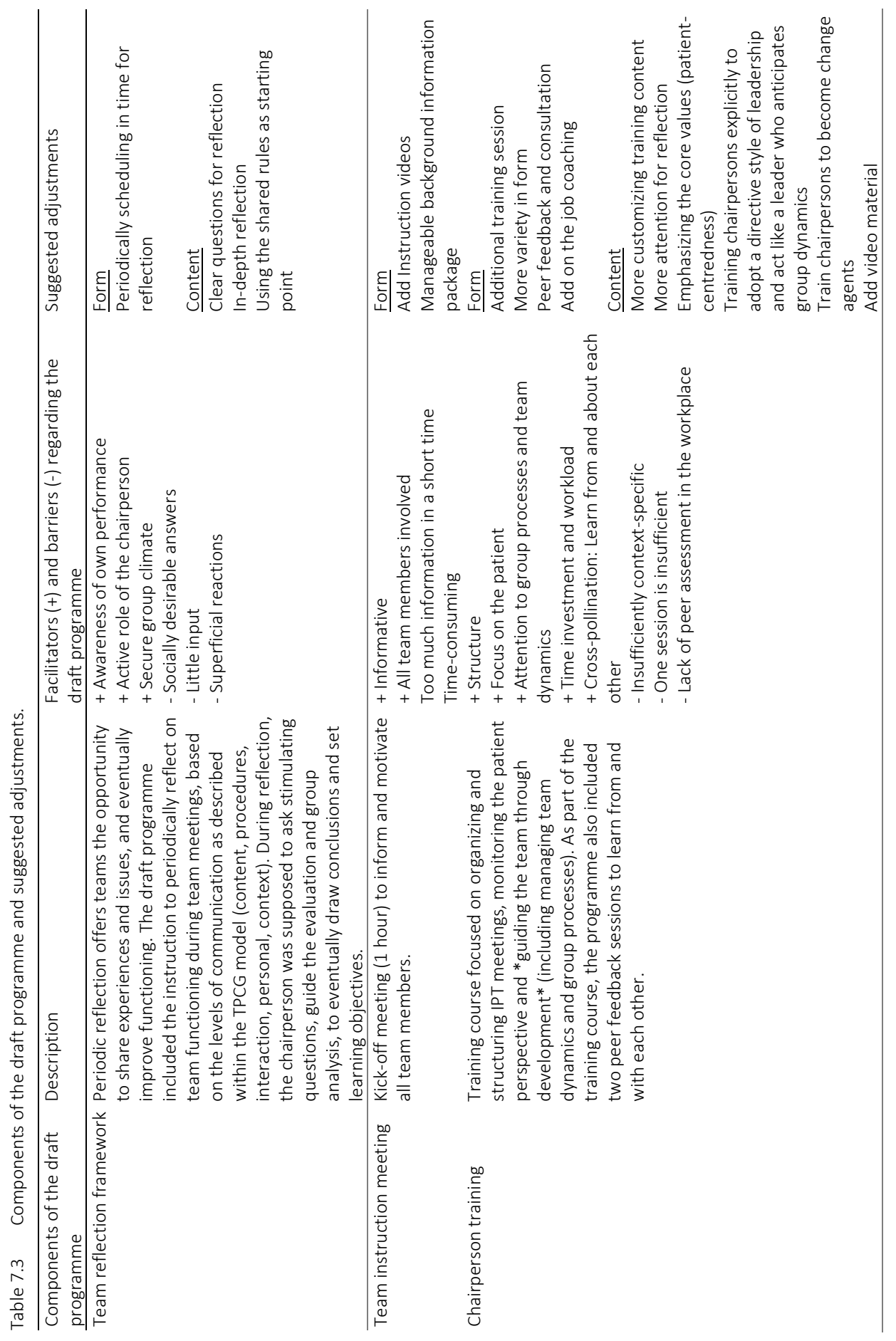




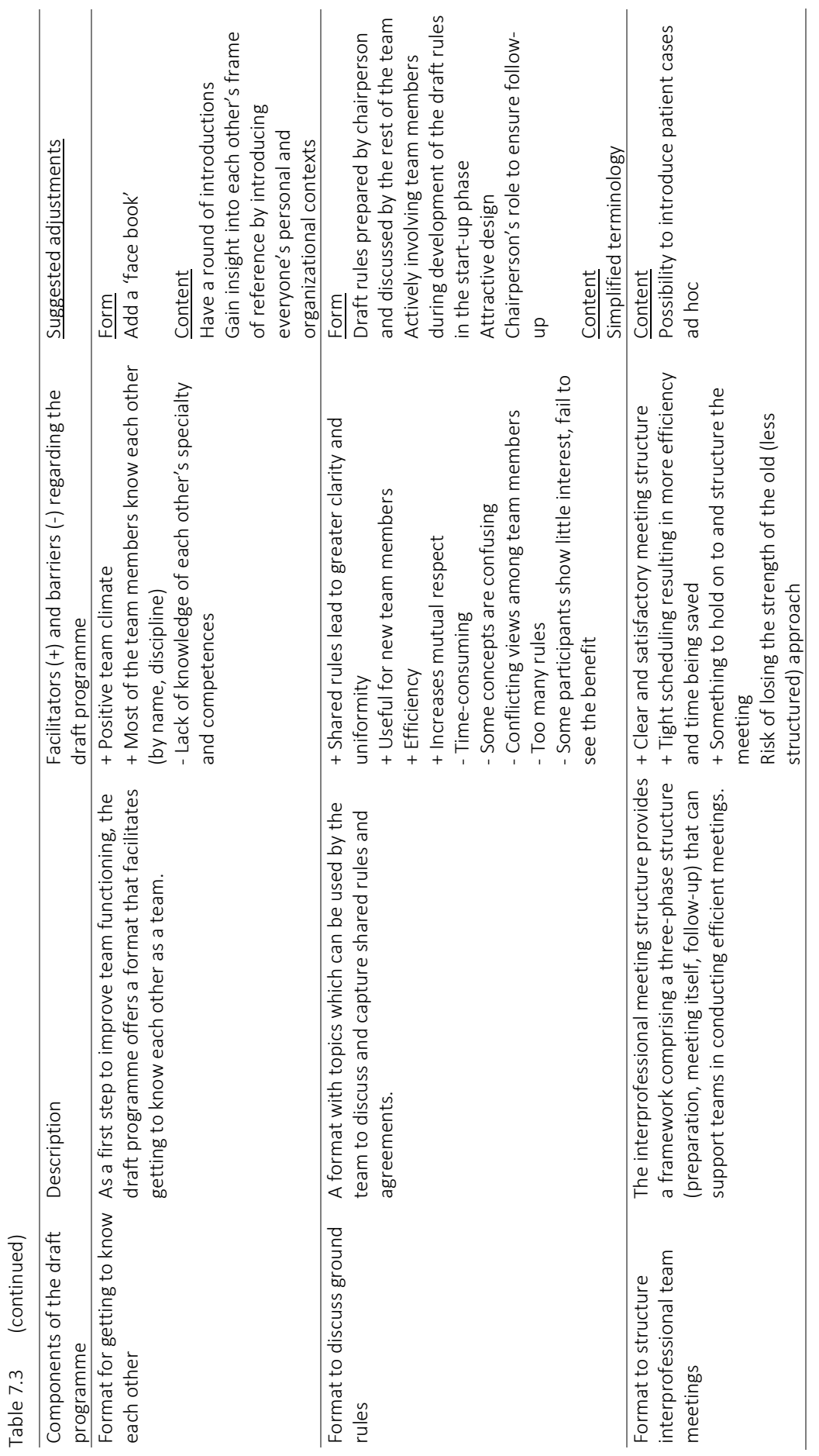




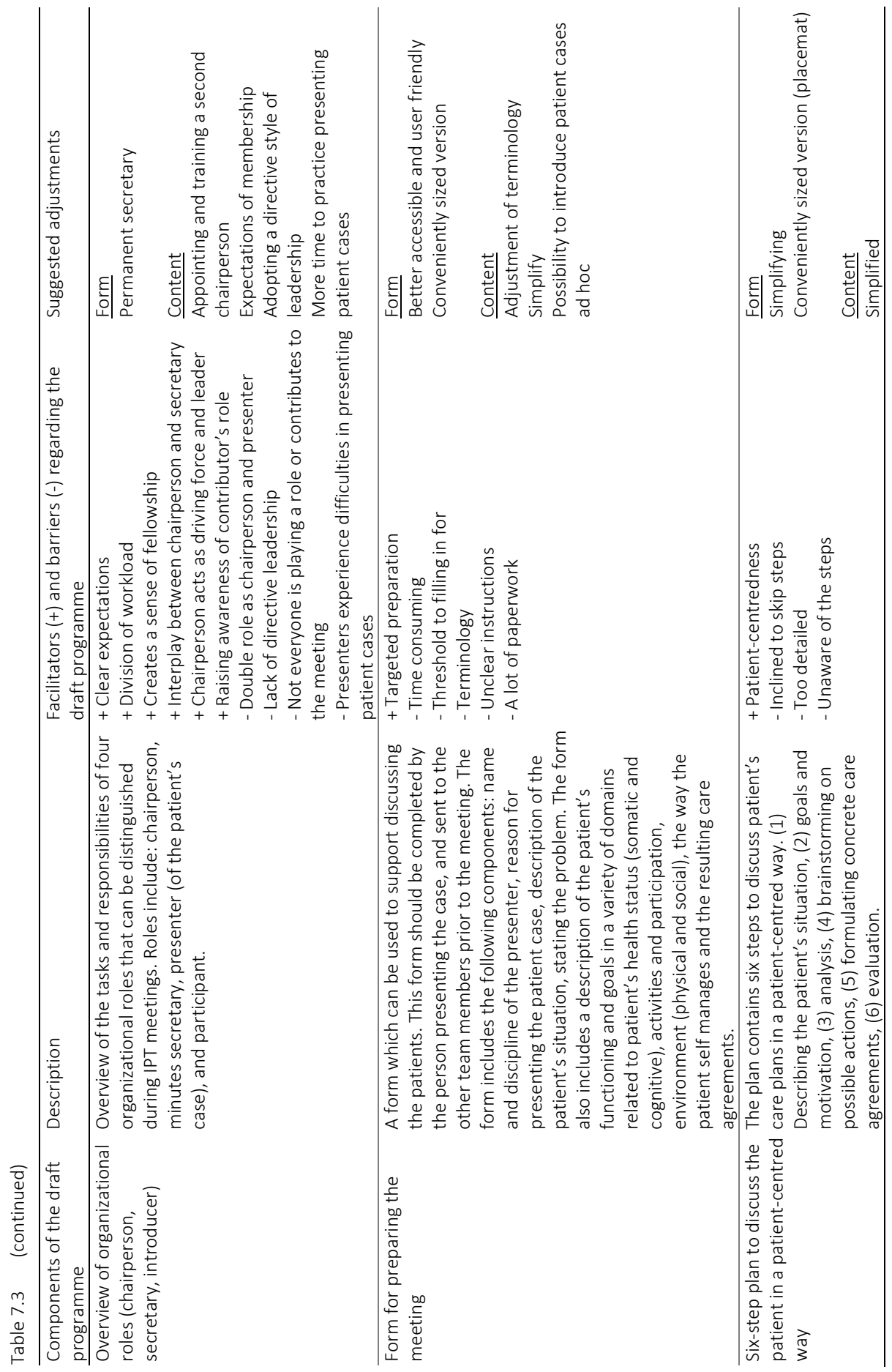




\section{Knowing each other}

Both observations and interviews showed that most of the team members knew their colleagues by name or face. However, due to changes in team composition over time, and the fact that some members were only occasionally present, teams frequently had to deal with new team members. This caused situations in which team members were not familiar with each other's expertise, impeding collaboration. As a possible strategy, participants suggested to add a proposal round each time a new team member joins. Others recommended the use of a "face book" with some professional and personal details of all team members plus a photo.

"There are some people whom you don't know as well as others, and contacts with those people are less smooth." (Physical therapist, practice 1).

\section{Clear structure and organization}

Participants recommended that teams should agree on the goal of the meeting, the language used, content of the meeting, organization (frequency, time span, location), structure of the meeting, division of roles, exchange of information, presentation of cases, and reflection on and evaluation of meetings. Participants explicitly mentioned that for them, division and specification of organizational roles created clarity. Participants recommended documenting the agreements made, so they can be easily handed to new team members. According to participants, the drafting of and adherence to these rules and arrangements can be considered a shared investment. Some mentioned that the rules were not properly applied in practice due to the strong and deviant views of some of their colleagues, confusing concepts, or the fact that some members had not read the rules. As a solution, participants emphasized the importance of discussing and formulating the rules jointly with the team.

"It's good that there is now a concrete agreement. That puts pressure on people. You have to stick to this now. Before, ... if it was different each time, then it didn't matter ... this offers more guidelines. Everyone now comes prepared, which wasn't always the case before." (Practice nurse, practice 1)

Observations showed that the three-phase IPT meeting structure (Table 7.3) as introduced by the chairperson was adopted by the teams in a natural way. The follow-up part, including feedback to the patient, was evaluated particularly favourably by participants. Summarizing the action points at the end of the meeting yielded clearly 
defined results. Participants also valued that the meetings were tightly scheduled, resulting in more efficiency.

"In my view, the main advantage is that everything is more tightly planned. You can now schedule in your next patient appointment precisely. It used to be that you had to schedule out another hour, as you never knew whether it was going to end at 2 or at 3. So it's better from a practical point of view." (Physical therapist, practice 3)

However, some participants questioned the potential risk of working in a too structured manner, which might mean losing some of the advantages of an informal approach. They mentioned the necessity of maintaining the possibility to discuss acute situations ad hoc. Lastly, participants believed that becoming acquainted with the meeting structure can be considered a growth process, in which the team has yet to find its way, which takes time.

\section{Patient-centredness}

The form used to prepare and present patients supported participants in making up a complete picture of the patient (Table 7.3). Some participants filled in the complete form, while others used key words or only used parts of it. Most mentioned that using the form stimulated them to prepare the meeting in a targeted way, which resulted in time gain during the meeting and increasing patient-centredness. However, some reported to struggle with formulating and presenting realistic and achievable patient goals and concerns, which was visible during the observations. They argued that filling in the form is a labour-intensive activity that could take too much time. This could hamper just quickly discussing an acute patient, and be a barrier to presenting new patients. Observations showed that the number of patients discussed had decreased since the form was introduced.

"It definitely takes a lot of work. And that prevents you from just quickly presenting a patient's case. You have to write down a whole history. Just spontaneously presenting a case on the spot is out of the question." (District nurse, practice 2)

As a result, participants contended that the possibility to discuss patients with unexpected and urgent problems ad hoc, without using the form should be maintained. They further agreed on a flexible way of completing the form, in which the different 
parts should be described succinctly. Despite the suggestion of simplifying the way the form has to be completed, participants also suggested various topics to be added: feedback to the patient, informed consent from the patient, case manager or ultimately responsible person, question of the presenter, and current care and currently involved disciplines. Moreover, participants appreciated the possibility to tailor the form to their own specific needs. To safeguard patients' privacy, one of the practices experimented with discussing patients anonymously. However, this was perceived by some of the team members as unsatisfactory, making them feel unfamiliar and disconnected with the patients discussed.

Further, participants appreciated following the six-step approach since it was clearly defined and provided the necessary structure to appropriately discuss patients. The form used to prepare the meeting and the six-step plan were seen as mutually strengthening aspects. However, observations showed that teams struggled to stick to the six steps in the suggested way, resulting in care agreements that were not always specific. Interviewees acknowledged that the steps were not yet fully integrated into their work routine. They were not used to talking about patients' personal goals, and tended to define these goals themselves, from their professional perspective.

"It's not part our routine, I think, to think on the basis of the patient's goals. You do discuss it with them, but to explicitly define them... I guess that wasn't part of our education." (Practice nurse, practice 1)

Other participants mentioned that detailed completion of all six steps took too much time, making people skip some of the steps. Others indicated that the draft plan was too detailed, and should be simplified into a conveniently sized format like a "place-mat". Participants also considered that keeping track of all the steps and ensuring that the other team members are included in the discussion were primary tasks of the chairperson. In meetings where the steps were followed systematically, the chairperson was visibly monitoring the steps by naming them and summarizing the results after each step.

"It's the chair's task to ensure that the six-step plan is followed. It's not up to me to keep track of that and check what I have to do now and what is the next step. I'm very willing to follow the chair's lead in that. He's the one who has to ensure that we stick to the plan." (Family physician, practice 1) 


\section{Feedback and team reflectiveness}

Most participants considered team reflection as valuable for progress. They perceived the reflection framework to be useful in guiding team reflection. However, observations showed that reflection was frequently conducted in general terms. An opening sentence often used by the chairperson was:

... "What did we all think of the team meeting? And what about using the new guidelines ... How did you experience that?" (Practice nurse, practice 3)

Some mentioned lack of time for reflection or reported negative experiences with reflection. They stated that it was difficult to talk openly in front of the team, as it made them feel vulnerable. Others regarded reflection as superficial, yielding socially desirable answers, or were critical about compulsory reflection. Observations indicated that only a minority of the team members were actively participating. Further, some participants believed that reflection was not always needed, and expected that if the team is functioning well, there will be no need to reflect regularly. Participants mentioned that the use of reflection was still in its early stages, and teams were still searching for a way to include reflection in their current routines. One of the challenges of reflection is to get everyone to express their opinions and to avoid ending up with superficial reactions. As a possible point for improvement, participants mentioned the importance of involving all team members, especially the unmotivated.

"I don't think anybody is feeling, like, I'm afraid to say what I feel. There's always room for reflection." (Psychologist, practice 2)

In addition, participants stated that a secure group climate, characterized by security and trust is needed to reflect freely about group atmosphere. Getting to know each other and team building were mentioned as relevant for creating a secure climate. In order to enable reflection, participants proposed to schedule it as integral part on the agenda. Further, to avoid superficial reactions, participants suggested that reflection should be more specific and proposed using video recordings of own meetings.

"If you just ask is everything OK, they'll just say fine. But if you say 'What about this specific issue, does anybody have any comments on that?" ... then they'll say Oh yes, actually. You have to have a starting point for reflection." (Family physician, practice 1) 


\section{Chairing meetings and guiding team development}

Findings emphasize the essential role of the team's chairperson in organizing and structuring IPT meetings, and guiding the team development. Most participants preferred a chairperson who was not afraid to take the lead by activating and motivating team members. Given the continuously changing composition of teams, participants recommended to train chairpersons specifically to adopt principles of a directive style of leadership, and to correctly anticipate group dynamics. The chairperson should play an active role by intervening on content, procedure and interactional level. During reflection, the chairperson ought to ask stimulating questions, guide the evaluation and group analysis, to eventually draw conclusions and set learning objectives. Regardless of the participants' preference for a more directive chairperson, they mentioned that involving the team in the decision-making process, and letting team members think along is crucial in creating a sense of belonging.

"The chairperson is really the leader. We're a kind of fellow-travellers who tag along. At least that's how I perceive it. She really takes up that role wholeheartedly. And it works very well." (Occupational therapist, practice 3)

Participating chairpersons experienced both the training course and the peer feedback as valuable and learned a lot from each other. However, they regarded a 4-hour training as too short, and recommended expansion with a second session. In addition, participants expressed a desire for direct feedback and on-the-job coaching. Some chairpersons perceived their role as leader to be complex, especially when they had to fulfil the double role of chairperson and presenter of a patient case. As possible solution for support and peer feedback they recommended to appoint and train a second chairperson in each team as a co-chair. Lastly, the participating chairpersons highlighted the importance of tailoring the content of the training to the specific team context and chairpersons' learning objectives.

\section{Final programme}

Based on the findings of phases 2 and 3, we adjusted both the form and content of the draft programme (Table 7.3). The training course was expanded by an additional session, and on-the-job coaching (comprises observing the chairperson during a meeting and providing direct feedback and feedforward immediately afterwards). A second team member is also to be trained as a co-chair and sparring partner. Tools were adjusted based on the participants' suggestions (Table 7.3), and expanded with supplementary video materials and brochures. The programme's core content now comprises a 
multifaceted framework (based on the TPCG model) that can be used by interprofessional primary care teams to reflect on the various dimensions and functioning of their meetings (Figure 7.3). Team reflection enables the programme to be customized and tailored to a team's specific context and learning objectives. In the final programme, the training course includes two sessions to develop leadership skills, and skills needed to organize and structure meetings, ensure patient-centredness and guide the team development.

\section{Discussion}

This article describes the lessons learnt from the systematic, iterative development process of a programme to improve structure, patient-centredness and leadership of interprofessional team (IPT) meetings, using an action research approach. The final programme comprises a reflection framework for interprofessional primary care teams, a team instruction meeting, training for the persons chairing such meetings, as well as a toolbox.

Knowing the team members personally and building up a relationship of trust and respect can be regarded as a precondition for achieving a sustainable collaboration. ${ }^{10}$ Knowing each other personally enables professionals to take advantage of each other's discipline-specific competences. Our findings show that getting to know each other remains an ongoing concern, in view of the continuously changing team composition in primary care.

Further, the process of jointly coming to agreements and setting group rules for the content, procedure, and the interaction of meetings was appreciated by participants, contributing to a positive team spirit. Our findings show that after general agreement has been reached on the structure of the meetings, the team offers support and the chairperson is able to initiate the new structure easily. Similarly, other studies have shown that roles and responsibilities in such meetings need to be clearly articulated and negotiated. ${ }^{19,20}$ Although most participants supported a structured approach, they also appreciated the positive effect of viewing the meetings as a social gathering with an informal approach. 


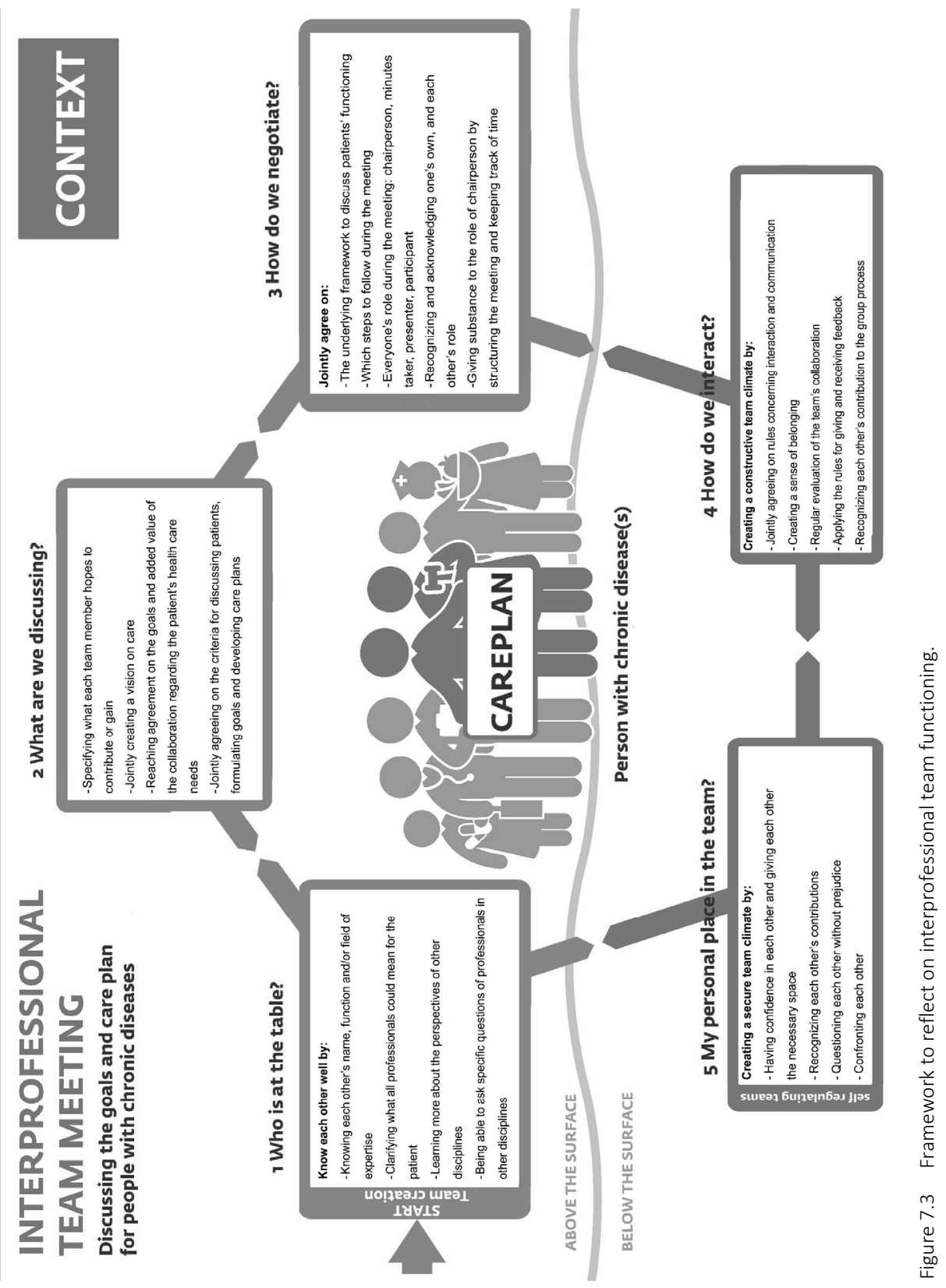


For achieving patient-centredness, the draft programme included a form that can be used to put a patient's case on the agenda of the meeting, and present it at the meeting. Most participants valued the form, although some experienced its use as timeconsuming and a possible barrier to presenting patients, preventing them from discussing patients ad hoc. In addition, a six-step approach was developed to structure the way the patients are discussed. Observations showed that professionals tended to quickly move from describing the patient's situation to proposing possible solutions, reflecting their apparent eagerness to carry out interventions and provide care. The professionals reported skipping the step of defining patients' goals because this is not part of their culture and work routine. However, a qualitative study of patients' perspectives of IPT meetings has shown that patients do expect health care professionals to put them at the centre and follow a structured as well as holistic approach to address their needs. ${ }^{21}$ Patients also appreciate having a voice in their own care process and having the opportunity to attend or be represented during team meetings. ${ }^{14,21}$ Inviting them or their representatives to take part could be considered a possible way to ensure patient-centredness.

Moreover, participants regarded improving their teams' functioning by adopting new structures as a growth process. They considered periodic team reflection as a possible approach to improvement. However, team reflection is not self-evident. During the time set aside for reflection, the chairperson ought to ask stimulating questions, guide the evaluation and joint analysis, and eventually draw conclusions and set learning objectives. Our reflection framework (Figure 7.3) appeared a useful aid for participants to reflect on their functioning.

Lastly, the role of the chairperson as a "change agent" appeared even more important than anticipated. In addition to the technical aspects of structuring meetings and monitoring the agreed rules, leadership appeared crucial. It is known that active participation by leaders increases the chances of successful implementation of quality improvement projects. ${ }^{22}$ From a theoretical point of view, and according to the TPCG model, it appears preferable to think of leadership in terms of situational leadership. In this approach, originally developed by Hersey and Blanchard, the style of leadership depends on the group's current circumstances and specific situation. ${ }^{18}$ However, given the continuously changing composition of interprofessional primary care teams, a directive style of leadership appeared to be preferable. This leadership style is characterized by a leader who initiates ideas and tasks, and sets out a clear course, ${ }^{18}$ and who is able to make decisions and to empower the other team members to collaborate. ${ }^{19,23}$ Research directed at IPT meetings in stroke rehabilitation, also found that this directive leadership style is associated with effective meetings. ${ }^{24}$ In addition to the directive style, participants of our study recommended to also adopt principles of 
the coaching style. Coaching is known to be positively associated with the level of team members' satisfaction with the team, team climate and positive emotions. ${ }^{25}$ Our participants recommended supporting the chairperson by appointing and training a second person who should function as co-chair and sparring partner. The interplay between the two chairpersons, characterized by sharing responsibilities and complementing each other's area of expertise, can be regarded as co-leadership, contributing to the provision of sustainable integrated care. ${ }^{26}$ In addition to the training course they had been provided with, our chairpersons expressed a need for direct feedback and coaching, and accordingly suggested to add on-the-job coaching as a component to the training course.

During the development process, we became more aware of the influence of contextual preconditions on the way IPT meetings are conducted. Such contextual preconditions include the nature, size and composition of the team, how the team has existed, the location, but also external conditions like financial systems and laws. It becomes clear that effective development of interprofessional teams requires support from the wider organizational context. ${ }^{27}$ Contextual issues were also highlighted in another study which concluded that impacts of interventions designed to enhance interprofessional teamwork vary under the influence of professional and organizational contexts. ${ }^{19}$ Flexibility in terms of local adaptation and customizing appears desirable. Ideally, the content of the training course and the application of both framework and toolbox should be tailored to the context and specific setting of a participating team. A study on coaching interprofessional teams confirms this finding and concluded that since there is no "one size fits all" solution, it is essential to explore and adjust to the team's specific context. $^{28}$

\section{Strengths and limitations}

The strengths of this study are the cyclic process in which research, action and evaluation were interlinked and intended users were continuously involved. This was achieved by leaving the decision making to the development team in collaboration with the three participating interprofessional teams, making the findings more likely to be incorporated into practice. ${ }^{29}$ The trainers (JD and WG) served as coaches to the teams, rather than trying to persuade them with their own insights. This increased the team members' receptivity to change, and encouraged them to take action themselves. Another strength was the practice of discussing issues in the team, rather than between individuals outside the team. ${ }^{30}$ The empirical evidence for the TPCG model, used as underlying theoretical framework is limited. Although this can be considered a potential weakness, the model fits in with existing theories and proved to be useful and practically 
feasible for the participants. The participating teams volunteered, were intrinsically motivated, and recognized the importance of efficient and patient-centred team meetings. In this respect, however, they may not be representative of average primary care teams, which could be a potential source of bias. For practical reasons, the individual interviews were rather short (15 minutes). This might have caused us to miss some in-depth findings. However, by interviewing a range of professionals from different professional backgrounds, we included many perspectives. Another strength was the use of data triangulation by using different sources to check for inconsistencies and divergent perspectives across the data set. Initial analyses were undertaken by one researcher and checked by a second researcher to ensure consistency of coding and safeguard against selective use of data. After four cycles of action research we concluded to have reached data saturation, since we did not extract any new insights from the last cycle.

\section{Conclusion}

This article reports on the systematic development of a programme to improve IPT meetings in primary care. The programme comprises a multifaceted framework that can be used by interprofessional primary care teams to reflect on the various dimensions and functioning of their IPT meetings. Findings revealed the important role of the chairperson as change agent initiating reflection and guiding the team through development. We developed a training course for two members per team, focussing on the effective organization and structuring of IPT meetings and safeguarding the patient's perspective. The programme also included a toolbox to assist teams in improving their effectiveness and efficiency. Getting acquainted with new structures can be considered a growth process, in which teams have to find their way. To be effective, the programme should be customizable and adapted to the teams' specific contexts and dynamics. Further research is needed to determine the actual value and manageability of the programme. 


\section{References}

1. WHO. Innovative care for chronic conditions: Building blocks for action, in Global report. 2002, World Health Organization: Geneva.

2. Vogeli C, Shields AE, Lee TA, Gibson TB, Marder WD, Weiss KB, Blumenthal D. Multiple chronic conditions: prevalence, health consequences, and implications for quality, care management, and costs. J Gen Intern Med. 2007;22 Suppl 3:391-5.

3. Stewart M, Brown JB, Donner A, McWhinney IR, Oates J, Weston WW, Jordan J. The impact of patientcentered care on outcomes. J Fam Pract. 2000;49(9):796-804.

4. Pelzang R. Time to learn: understanding patient-centred care. Br J Nurs. 2010;19(14):912-7.

5. Van Houdt S, De Lepeleire J, Driessche KV, Thijs G, Buntinx F. Multidisciplinary team meetings about a patient in primary care: an explorative study. J Prim Care Community Health. 2011;2(2):72-6.

6. Kitson A, Marshall A, Bassett K, Zeitz K. What are the core elements of patient-centred care? A narrative review and synthesis of the literature from health policy, medicine and nursing. J Adv Nurs. 2013;69(1): 4-15.

7. Xyrichis A, Lowton K. What fosters or prevents interprofessional teamworking in primary and community care? A literature review. Int J Nurs Stud. 2008;45(1):140-53.

8. Wodchis WP, Dixon A, Anderson GM, Goodwin N. Integrating care for older people with complex needs: key insights and lessons from a seven-country cross-case analysis. Int J Integr Care. 2015;15:e021.

9. Atwal A, Caldwell K. Do multidisciplinary integrated care pathways improve interprofessional collaboration? Scand J Caring Sci. 2002;16(4):360-7.

10. van Dongen JJJ, van Bokhoven MA, Daniëls R, Lenzen SA, van der Weijden T, Beurskens A. Interprofessional primary care team meetings: a qualitative approach comparing observations with personal opinions. Family Practice. 2017;34(1):98-106.

11. van Dongen JJ, Lenzen SA, van Bokhoven MA, Daniels R, van der Weijden T, Beurskens A. Interprofessional collaboration regarding patients' care plans in primary care: a focus group study into influential factors. BMC Fam Pract. 2016;17(1):58.

12. van Dongen JJ, van Bokhoven MA, Daniels R, van der Weijden T, Emonts WW, Beurskens A. Developing interprofessional care plans in chronic care: a scoping review. BMC Fam Pract. 2016;17(1):137.

13. Korner M, Butof S, Muller C, Zimmermann L, Becker S, Bengel J. Interprofessional teamwork and team interventions in chronic care: A systematic review. J Interprof Care. 2016;30(1):15-28.

14. van Dongen JJ, Habets IG, Beurskens A, van Bokhoven MA. Successful participation of patients in interprofessional team meetings: A qualitative study. Health Expect. 2016.

15. Koshy E, Koshy V, Waterman H. Action Research in Healthcare. 2011: SAGE publications Ltd. 200.

16. Hsieh HF, Shannon SE. Three approaches to qualitative content analysis. Qual Health Res. 2005;15(9): 1277-88.

17. Mortelmans D. Kwalitatieve analyse met Nvivo. 2011, Den Haag: Acco uitgeverij.

18. Remmerswaal J, Group Dynamics: an introduction. 2015, Amsterdam: Uitgeverij boom/nelissen.

19. Harris MF, Advocat J, Crabtree BF, Levesque JF, Miller WL, Gunn JM, Hogg W, Scott CM, Chase SM, Halma L, Russell GM. Interprofessional teamwork innovations for primary health care practices and practitioners: evidence from a comparison of reform in three countries. J Multidiscip Healthc. 2016;9: 35-46.

20. Jaruseviciene L, Liseckiene I, Valius L, Kontrimiene A, Jarusevicius G, Lapao LV. Teamwork in primary care: perspectives of general practitioners and community nurses in Lithuania. BMC Fam Pract. 2013;14:118.

21. van Dongen JJ, de Wit M, Smeets HW, Stoffers E, van Bokhoven MA, Daniels R. "They are talking about me, but not with me": a focus group study to explore the patient perspective on interprofessional team meetings in primary care. Patient. 2017.

22. Rantz MJ, Zwygart-Stauffacher M, Flesner M, Hicks L, Mehr D, Russell T, Minner D. The influence of teams to sustain quality improvement in nursing homes that "need improvement". J Am Med Dir Assoc. 2013;14(1):48-52.

23. Bodenheimer T, Ghorob A, Willard-Grace R, Grumbach K. The 10 building blocks of high-performing primary care. Ann Fam Med. 2014;12(2):166-71. 
24. Tyson SF, Burton L, McGovern A. Multi-disciplinary team meetings in stroke rehabilitation: an observation study and conceptual framework. Clin Rehabil. 2014;28(12):1237-47.

25. Dimas ID, Renato Lourenco P, Rebelo T. The effects on team emotions and team effectiveness of coaching in interprofessional health and social care teams. J Interprof Care. 2016. 30(4): p. 416-22.

26. Klinga $\mathrm{C}$, Hansson J, Hasson $\mathrm{H}$, Sachs MA. Co-leadership - a management solution for integrated health and social care. Int J Integr Care. 2016;16(2):7.

27. van Dijk-de Vries A, van Dongen JJ, van Bokhoven MA. Sustainable interprofessional teamwork needs a team-friendly healthcare system: Experiences from a collaborative Dutch programme. J Interprof Care. 2017;31(2):167-9.

28. Godfrey MM, Andersson-Gare B, Nelson EC, Nilsson M, Ahlstrom G. Coaching interprofessional health care improvement teams: the coachee, the coach and the leader perspectives. J Nurs Manag. 2014; 22(4):452-64.

29. Karim K. Assessing the strengths and weaknesses of action research. Nurs Stand. 2001. 15(26): p. 33-5.

30. Lewis RE, Tucker R, Tsao H, Canaan E, Bryant J, Talbot P, King D, Flythe M. Improving interdisciplinary team process: a practical approach to team development. J Allied Health. 1998;27(2):89-95. 


\section{Appendix 7.1}

\section{Observation guide}

\begin{tabular}{|c|c|c|}
\hline $\begin{array}{l}\text { Observation } \\
\text { list } \\
\text { Overall }\end{array}$ & $\begin{array}{l}\text { Is the programme (core component / tool) being } \\
\text { applied, and if so, which parts? } \\
\text { How (and to what extent) are the different } \\
\text { components and tools of the programme being } \\
\text { applied? }\end{array}$ & $\begin{array}{l}\text { Manageability and feasibility } \\
\text { What do you notice about the feasibility of } \\
\text { the programme? } \\
\text { Bottlenecks } \\
\text { What are the evident bottlenecks? } \\
\text { Contextual factors } \\
\text { Which visible contextual factors are } \\
\text { influencing the application of the } \\
\text { programme? } \\
\text { Added value } \\
\text { What can you say about the added value } \\
\text { provided by the programme? }\end{array}$ \\
\hline $\begin{array}{l}\text { Knowing } \\
\text { each other }\end{array}$ & $\begin{array}{l}\text { O Team members know each other (No one has } \\
\text { to be introduced, no new faces) }\end{array}$ & \\
\hline $\begin{array}{l}\text { Rules for the } \\
\text { meeting }\end{array}$ & $\begin{array}{ll}\circ & \begin{array}{l}\text { Everyone visibly adheres to the agreements } \\
\text { and rules for the meeting }\end{array} \\
\circ & \begin{array}{l}\text { Team members stick to the organizational } \\
\text { agreements }\end{array}\end{array}$ & \\
\hline Roles & \begin{tabular}{|ll} 
Chairperson \\
0 & Has prepared the meeting \\
0 & Structures the meeting \\
0 & Ensures adherence to the rules of the \\
& meeting \\
0 & Follows the six-step plan \\
0 & Summarizes \\
0 & Keeps track of time \\
0 & Guides reflection \\
0 & Points out tensions \\
0 & Clearly announces closing the meeting and \\
Secretary & plans next meeting \\
0 & Takes care of the reporting (preparing \\
minutes) & Checks regularly whether minutes correspond \\
to what has been agreed on during discussion \\
Where appropriate, refers to previous minutes
\end{tabular} & \\
\hline $\begin{array}{l}\text { Interprofessi } \\
\text { onal meeting } \\
\text { structure }\end{array}$ & \begin{tabular}{|ll} 
Preparation \\
0 & Clear agenda \\
0 & Information about patients is provided before \\
& the meeting \\
Meeting \\
0 & Opening \\
0 & Discussion of each patient \\
0 & Closing \\
Aftercare & \\
0 & Reporting \\
0 & Agreements regarding feedback to patient \\
0 & Agenda and agreements for next meeting
\end{tabular} & \\
\hline
\end{tabular}




\begin{tabular}{|c|c|c|}
\hline $\begin{array}{l}\text { Interaction } \\
\text { and team } \\
\text { climate }\end{array}$ & $\begin{array}{l}\text { Team members give each other feedback } \\
0 \quad \text { On content } \\
0 \quad \text { On procedure } \\
0 \quad \text { On interaction } \\
\text { Any comments about the team climate and } \\
\text { atmosphere? } \\
\text { Are there any visible irritations? } \\
\text { Any comments about the way the team talks about } \\
\text { patients? }\end{array}$ & \\
\hline $\begin{array}{l}\text { Reflection } \\
\text { tool }\end{array}$ & $\begin{array}{l}\text { At which level does the team reflect? } \\
0 \quad \text { Is there any input from participants? } \\
0 \quad \text { Are specific learning objectives defined? } \\
0 \quad \text { Does the team refer back to previous } \\
\text { agreements and learning objectives? }\end{array}$ & \\
\hline
\end{tabular}




\section{Appendix 7.2}

\section{Semi-structured interview guide}

Interview guide

- Introduction

- Introduction of the interviewer

- Consent for audio recording

- Explanation of participants' rights

- Aim of the interview: The aim is to explore personal experiences (both barriers and facilitators) regarding the new way of working and the use of the new tools and methods.

- Procedure, duration etc.

- Emphasizing that all information is relevant

\section{Introduction question}

What did you think of the interprofessional team meeting which has just taken place?

\section{Subquestions}

- Can you give an example?

- Can you explain in detail what you mean by...?

- Why do you perceive ... as a relevant factor/barrier/facilitator?

\section{Main questions}

Questions concern the use, experience, handling, added value and suggestions for improvement of the different components of the programme.

1. To what extent do the team members know each other?
a. What do you think of this?
b. How would you suggest to improve this?

2. To what extent did the meeting go according to the agreed rules for the meetings?
a. How were the rules applied according to you?
b. How did you personally feel about handling these rules?
c. What are barriers and facilitators regarding the application of these rules?
d. What do you need to apply these rules?
e. In your view, did working according to these rules provide added value?
f. Did you miss any topics on which agreements and rules have to be made?
g. Do you have any suggestions for improvement?

3. Which roles were fulfilled during the team meeting? What was your role?

(Chairperson, secretary, presenter, participant)
a. How did feel about fulfilling your role?
b. What do you need in order to fulfil your role properly? (What factors influence the fulfilment of roles?)
c. In your view, did the division of roles offer added value? And why?
d. Do you have any suggestions to improve the way roles are fulfilled? 
4. What can you tell us about working according to the new meeting structure?

a. What did you think about working according to the new meeting structure?

b. What parts of the structure did or didn't you adhere to? And why?

c. What did you perceive as barriers to working according to the new meeting structure? What factors influence this?

d. In your view, did working according to this new meeting structure offer added value? And why?

e. Do you have any suggestions for adjustment and improvement of the meeting structure?

5. How did you prepare for the discussion of a patient?
a. What did you think of preparing the meeting?
b. To what extent did you use the form to prepare your presentation of a patient?
c. What can you tell us about the way you used the form?
d. Were there parts of this form that you found difficult to fill in? If yes, why?
e. What helped you to prepare the meeting properly? (What factors influence this?)
f. In your view, did preparing your presentation of the patient case using this form offer added value? And why?
g. How would you suggest the preparation of the meeting could be further improved?

6. How did you discuss patients?
a. What did you think of the use of the six-step plan to discuss patients?
b. What steps did you go through? (And if you skipped certain steps, why did you do so?)
c. What factors influence the process of following the different steps?
d. In your view, did the use of this six-step plan to discuss patients offer added value?
e. Do you have any suggestions to improve the six-step plan?

7. Did you evaluate and reflect together? If yes, what did you think of this and what can you tell us about it?
a. On which topics did you reflect/ evaluate? (content, procedure, interaction)
b. What does a team need in order to make reflection possible?
c. In your view, did periodic reflection and evaluation offer added value?
d. Do you have any suggestions to improve the team reflection effort?

8. How was it to feed back the suggested agreements to the patient?
a. What bottlenecks did you experience?
b. How did the patient react?

9. To what extent was the patient's perspective (goals and wishes) focused on during the meeting? Could you give an example?
a. Do you have any suggestions to improve the patient-centredness of interprofessional team meetings?

\section{Summary}

Interviewer gives a summary.

- $\quad$ Did I forget any relevant information in this summary? 


\title{
Chapter 8
}

\section{Suitability of a programme for improving interprofessional primary care team meetings}

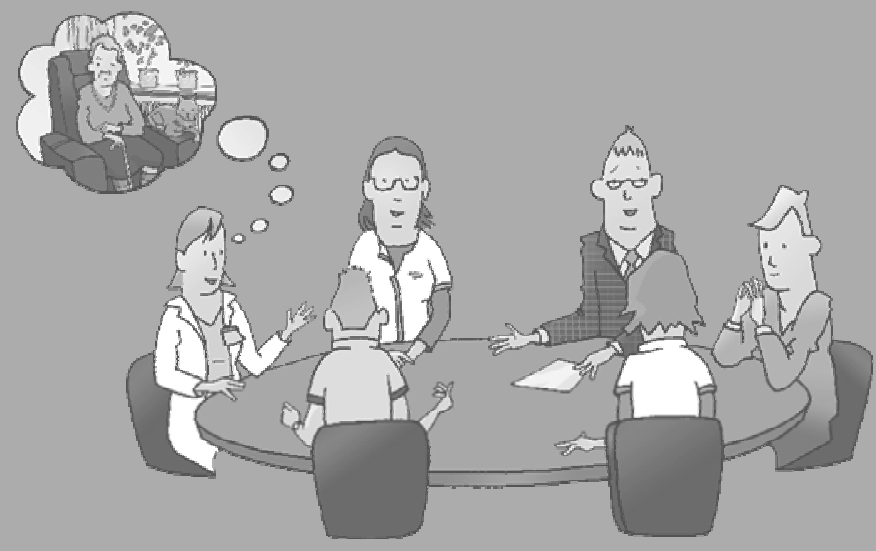

\author{
Jerôme van Dongen \\ Loes van Bokhoven \\ Wim Goossens \\ Ramon Daniëls \\ Trudy van der Weijden \\ Sandra Beurskens \\ Submitted
}




\section{Abstract}

\section{Introduction}

Primary care is increasingly being confronted with complex health care demands stemming from both biomedical and psychosocial problems of people with chronic diseases. Interprofessional collaboration is needed to enhance patient-centredness and coordinate care provision in an efficient manner. In primary care, collaboration often occurs through periodic interprofessional team (IPT) meetings. We have developed a multifaceted programme to enhance team functioning in terms of improved patient-centredness and efficiency of meetings. The aim of this study was to evaluate the perceived suitability and potential impact of this programme. Eventually, findings of this evaluation should contribute to understanding the suitability of the programme and optimizing its design.

\section{Methods}

A prospective process evaluation was conducted, using a mixed-methods approach. Six primary care IPTs participated. Data collection included observations of team meetings, semi-structured interviews with team chairpersons, a focus group meeting, and a questionnaire for all team members. Qualitative data were analysed using directed content analysis and quantitative data using descriptive statistics.

\section{Results}

The results show that, on the whole, the programme was appreciated. Most progress was perceived regarding structure and organization. Chairs perceived increased awareness of patientcentredness and team processes. They perceived the training activities as useful and instructive, and valued peer feedback and on-the-job coaching as the most effective strategies. Findings from the questionnaire showed a tendency in the desired direction for all variables.

\section{Conclusion}

To conclude, the programme can be considered as a suitable approach for improving team functioning. However, enhancing patient-centredness requires additional training/practice and onthe-job coaching. Lastly, the programme should be context-specific, flexible in use, and preferably delivered and mediated by an external facilitator at the workplace. 


\section{Introduction}

Primary health care is being confronted with an increasing number of people with multiple chronic diseases, requiring complex health and social care services. A key element in delivering high-quality care is interprofessional collaboration (IPC). ${ }^{1}$ In their review, Zwarenstein and colleagues describe IPC as a process in which different professional groups work together to positively impact on health care. ${ }^{2}$ IPC is perceived as an ongoing interpersonal process of shared goal setting and decision making, which occurs among professionals from a diversity of disciplines, and a patient system to optimize the management of chronic disease. ${ }^{3}$ In the Dutch primary care setting, IPC often takes place through periodic interprofessional team (IPT) meetings. These meetings vary in terms of setting, duration, frequency, number of participants, disciplines and numbers of patients discussed. By way of illustration, an average team may comprise family physicians, practice nurses, occupational therapists, physical therapists and district nurses. ${ }^{4}$ Based on a needs assessment encompassing various qualitative studies $^{4-7}$ and a scoping review, ${ }^{8}$ we concluded that there is room to improve the functioning of these IPT meetings. Often, meetings appeared to be unstructured and lacked clear coordination and leadership, and therefore seemed to lack efficiency. Moreover, observations showed that patient-centredness was often lacking in team meetings. ${ }^{4}$ Findings also emphasized the essential role of the teams' chairpersons, who, in addition to structuring the meetings, should also act as change agents in guiding team development over time. ${ }^{9}$

Practice-based IPC interventions appear to be able to improve healthcare processes and outcomes. ${ }^{2}$ In addition, there is evidence that teamwork innovations can promote better communication, better relationships and greater satisfaction among the workforce. ${ }^{10}$ Other studies have also demonstrated that multifaceted intervention programmes, tailored to the needs of the teams, are most effective. ${ }^{11}$ Despite the lack of high-quality evidence, some studies show that interventions including training activities have positive effects on the effectiveness of interprofessional teams. ${ }^{12}$ With this knowledge, we systematically (by means of action research) developed a multifaceted programme to improve the functioning of IPT meetings. The programme comprises aspects of all three main types of interprofessional interventions as described in Reeves' interprofessional framework: interprofessional education; interprofessional practice; and interprofessional organization. ${ }^{13}$ The multifaceted programme primarily focuses on organizing and structuring IPT meetings, enhancing patient-centredness and guiding team development over time. As part of the programme, a team reflection framework, training activities and a toolbox with supporting materials were developed. Findings from the action research study confirm the important role of the chairperson being a 
change agent who guides team reflection and development. To be effective, the programme should also be customizable and tailored to the teams' specific contexts and dynamics. ${ }^{9}$

The aim of the process evaluation reported on here was to examine the way the programme is implemented, how it works in practice, and which factors contribute to its success or failure. Eventually, findings of this process evaluation should contribute to understanding the suitability of the programme and optimizing its design. In addition to suitability, we examined the potential impact of the programme on team climate, efficiency and patient-centredness. We used principles of the Medical Research Council Process Evaluation Framework to guide the process, ${ }^{14}$ and formulated the following research questions:

1. To what extent was the programme implemented?

2. How did participants experience the programme?

3. What was the programme's potential impact on team climate, efficiency and patient centredness?

\section{Methods}

\section{Methodology}

We conducted a process evaluation ${ }^{14}$ using a mixed-methods approach, including both qualitative and quantitative data.

\section{Setting and participants}

Six interprofessional teams working in primary care were recruited by means of convenience sampling, using the researchers' network and contacts of a regional care group (Huisartsen Oostelijk Zuid-Limburg). Teams were included if they periodically conducted IPT meetings, including three or more health care professionals from different disciplines. In each team, a chairperson and a co-chair should be willing to take part in the training activities. The team meetings, arranged by one of the team members, were part of the regular care process and not specifically initiated for this study. Team members received oral and written information about the content of the study and confidentiality of the data collection and analysis. 


\section{Content and scope of the programme}

The programme was developed through action research ${ }^{9}$ and aims to improve IPT functioning by focusing on five main objectives for improvement: (1) knowing each other personally, (2) clear structure and organization, (3) patient-centredness, (4) feedback and team reflexivity, and (5) chairing meetings and guiding team development. A logic model of the programme is presented in Figure 8.1.

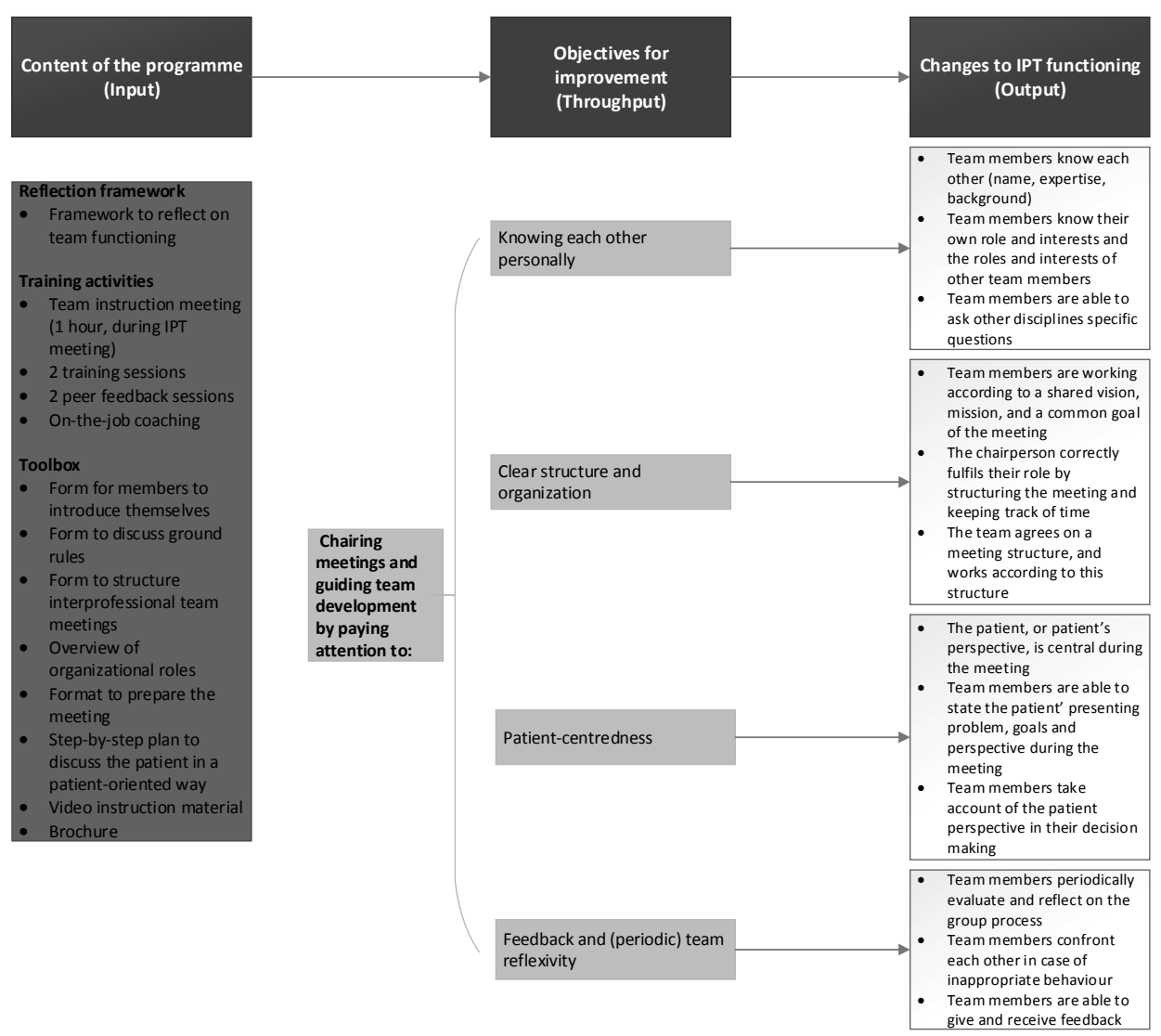

Figure 8.1 Logic model for the programme to improve IPT functioning

The programme's backbone is formed by a framework that can be used by interprofessional primary care teams to reflect on the functioning of their IPT meetings (Appendix 8.1). Team reflection should enable the programme to be customized and adapted to a team's specific context and learning objectives. The programme also includes a team instruction meeting and multifaceted training for the chairperson and 
co-chair. The training course comprises two sessions, one focusing on organizing and structuring meetings, and the second primarily focusing on safeguarding patientcentredness. Both sessions involve training leadership competences and use of the tools. The training course also includes two peer feedback sessions and on-the-job coaching. On-the-job coaching comprises observation of an IPT meeting and provision of feedback and feedforward immediately afterwards. In addition, a toolbox including instructive video materials and a brochure with information about the supporting tools is part of the programme. Teams are free to adjust the tools to their specific needs and apply them as appropriate. Chairpersons were asked to instruct and encourage the other team members. By focusing on the chairpersons as change agents, we intended to improve team functioning.

\section{Data collection}

Data were collected at baseline (pretest), and at the end of the programme (posttest), see Figure 8.2. Table 8.1 offers an overview of the three research questions and data collection methods. Over a one-year period, participating teams used the programme and had the opportunity to gain experience with the new approach, and to experiment with the different supplementary tools in practice.

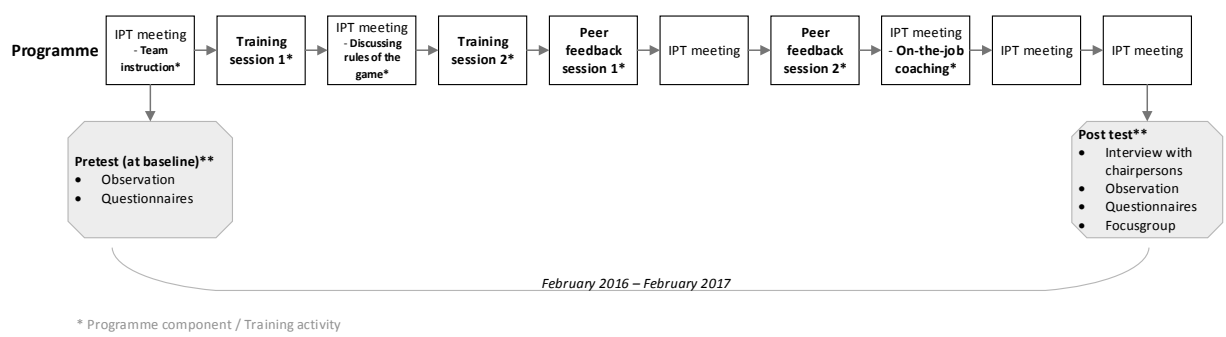

Figure 8.2 Timing of data collection.

Table 8.1 Research questions and data collection methods.

\begin{tabular}{|c|c|c|c|c|}
\hline & $\begin{array}{c}\text { Interviews } \\
\text { with } \\
\text { chairpersons }\end{array}$ & $\begin{array}{c}\text { Observations } \\
\text { of IPT } \\
\text { meetings } \\
\end{array}$ & Questionnaire & $\begin{array}{c}\text { Focus group meeting } \\
\begin{array}{c}\text { (+ additional } \\
\text { interviews })\end{array} \\
\end{array}$ \\
\hline $\begin{array}{l}\text { 1. To what extent was the programme } \\
\text { implemented? }\end{array}$ & & $x$ & & \\
\hline $\begin{array}{l}\text { 2. How did participants experience the } \\
\text { programme? }\end{array}$ & $x$ & & & $x$ \\
\hline $\begin{array}{l}\text { 3. What was the programme's } \\
\text { potential impact on team climate, } \\
\text { efficiency and patient-centredness? }\end{array}$ & & & $x$ & \\
\hline
\end{tabular}




\section{To what extent was the programme implemented?}

\section{Observations}

Observations of team meetings were conducted before and after the training course to ascertain the extent to which the programme was implemented. Access to the meetings was arranged for the researchers by the teams' chairpersons. Two researchers observed the meetings, took field notes and collected background data using an observation guide focusing on the presence and implementation of the different components of the programme (Appendix 8.2).

\section{How did participants experience the programme?}

\section{Interviews}

To explore the experiences of the participating chairpersons and co-chairs about *following/using* the programme, we conducted individual interviews. We intended to interview at least one of the two chairpersons for each participating team at posttest. The interview guide (Appendix 8.3) started with an open-ended question to discover respondents' experiences with taking part in the programme. Other questions related to the barriers and facilitators regarding the suitability, added value and possible improvements of the programme, the chairpersons' role and perceived personal growth. The interviews were conducted by JVD, lasted between 30 and 45 minutes, and were recorded using a voice recorder.

\section{Focus group meeting}

In order to explore experiences regarding the suitability and added value of the programme among team members, we organized a focus group meeting (two hours) with representatives from each of the six teams. By way of purposive sampling, we asked each team to delegate one or two team members (other than the chairpersons who had taken part in the training course) to represent their teams. An experienced researcher $(\mathrm{MvB})$ moderated the meeting and guided the discussion, while a second researcher (JVD) was responsible for facilitating the meeting and taking notes. The moderator guided the meeting using an interview guide based on Appendix 8.3. 


\section{What was the programme's potential impact on team climate, efficiency and patient-centredness?}

\section{Questionnaire}

To examine the programme's potential impact on team climate and patient-centredness, we presented a questionnaire including 48 questions at pretest and posttest (Appendix 8.4). The first part of the questionnaire (Q1-38) focused on team climate. Since team climate appears to be an important characteristic of successful teams, ${ }^{15,16}$ we opted for the Dutch Team Climate Inventory ( $\mathrm{TCl}$ ), which is known to be a reliable and valid instrument. ${ }^{17}$ The Dutch TCl contains 38 questions covering three domains, and has a 5 point response scale ranging from 'strongly disagree' to 'strongly agree', with higher scores indicating a better or more desirable team climate. The second part of the questionnaire (Q39-48) contains five questions regarding patient-centredness and four regarding team efficiency. For these questions we used a 7-point response scale ranging from 'strongly disagree' to 'strongly agree'. To assess patient-centredness, we included the 'patient involvement' domain of the Collaborative Practice Assessment Tool (CPAT), which can be regarded as a reliable tool for assessing levels of collaborative practice. $^{18}$ This domain comprises five questions. The remaining four questions focused on perceived team efficiency, ending with the question to rate team functioning on a scale from 1 (very bad) to 10 (very good).

\section{Data analysis}

Qualitative data were analysed by means of directed content analysis. ${ }^{19}$ The audiorecorded interviews were transcribed verbatim. A detailed description of each observation was made, based on the focal points presented in Appendix 8.1. The summary was supplemented with field notes about significant events and non-verbal communication. Data analysis was completed by two researchers (SB and JvD). Both analysed and coded all transcripts independently and repeatedly in order to familiarize themselves with the data. They coded with the assistance of Nvivo 10 software, and compared and discussed their findings until consensus was reached. ${ }^{20}$ The same initial coding scheme was used for both observations and interviews, based on themes derived from the literature. If necessary, new codes were added. In the next step, codes assigned to the interviews and observations were grouped into themes. Finally, connections between the themes were explored. Findings derived from the focus group were analysed similarly. Quantitative data from the questionnaire were analysed by descriptive statistics (frequencies, means per domain analysed, both per team and as 
mean overall scores) using Statistical Software package for Social Sciences (SPSS) version 23. Given the clustering of data per team, we calculated means per team.

\section{Trustworthiness}

Field notes and written comments were used in the analysis process to enhance the trustworthiness of the study. To increase credibility, JVD and SB analysed the data independently and discussed and compared results, consulting $\mathrm{MvB}$ in case of disagreement. Furthermore, combining data from both observations and interviews, known as methodological triangulation, provided additional perspectives and enhanced credibility. ${ }^{21}$ All observations were conducted by two researchers in order to ensure independence and avoid blind spots. To increase accuracy, validity and credibility, we conducted a member check of the focus group meeting: a summary of the main findings was sent to the participants, giving them the opportunity to reflect.

\section{Ethical considerations}

The ethical committee of the Zuyderland hospital (Heerlen, The Netherlands) assessed the study protocol and confirmed that given the non-invasive nature of the study, no ethical approval was needed according to Dutch law.

\section{Results}

The programme was implemented between February 2016 and February 2017. Data were collected until March 2017. Characteristics of the six participating teams are presented in Table 8.2. Table 8.3 offers an overview of the data collection and response rates. Regardless our selection criteria of selecting teams that already conduct IPT meetings, we also included a beginning team (team 6). This team was set up at baseline, and offered us additional perspectives. Consequently this team could not be observed at pretest. A total of five observations at pretest and six observations at posttest took place. Additionally, the chairpersons of all six teams were interviewed at posttest, and in five cases the co-chair participated in these interviews as well. At pretest, 29 questionnaires were completed, at posttest 49. In addition, a focus group meeting was conducted with four participating team members, other than the chairpersons. Additionally, three team members who were not able to attend the focus group meeting were interviewed individually within two weeks after the meeting. 
Table 8.2 Characteristics of the participating interprofessional primary care team meetings.

\begin{tabular}{|c|c|c|c|c|}
\hline Team & $\begin{array}{l}\text { Duration of } \\
\text { meetings in } \\
\text { minutes }\end{array}$ & $\begin{array}{l}\text { Frequency of } \\
\text { team } \\
\text { meetings }\end{array}$ & $\begin{array}{l}\text { Number of } \\
\text { participants } \\
\text { attending } \\
\text { posttest } \\
\text { observation }\end{array}$ & Disciplines \\
\hline 1 & 60 & $\begin{array}{l}\text { Once every } \\
\text { two weeks }\end{array}$ & 10 & $\begin{array}{l}\text { Case manager for dementia (1), remedial educationalist (1), } \\
\text { district nurse (1), family physician ( } 2 \text { ), occupational } \\
\text { therapist (1), psychologist (1), social worker (1), practice } \\
\text { nurse (1), nurse specialist (1) }\end{array}$ \\
\hline 2 & 60 & $\begin{array}{l}\text { Once a } \\
\text { month }\end{array}$ & 9 & $\begin{array}{l}\text { Family physician (4), trainee family physician (1), practice } \\
\text { nurse (1), physical therapist (1), district nurse (2) }\end{array}$ \\
\hline 3 & 60 & $\begin{array}{l}\text { Once every } \\
\text { six weeks }\end{array}$ & 12 & $\begin{array}{l}\text { Family physician (2), physical therapist (1), occupational } \\
\text { therapist (1), district nurse (1), location manager (1), } \\
\text { practice nurse (3), case manager for dementia (2), care } \\
\text { process supervisor (1) }\end{array}$ \\
\hline 4 & 60 & $\begin{array}{l}\text { Once every } \\
\text { two months }\end{array}$ & 14 & $\begin{array}{l}\text { Family physician (1), case manager for dementia (1), } \\
\text { practice nurse (2), physical therapist ( } 2 \text { ), occupational } \\
\text { therapist (2), trainee occupational therapist (1), pharmacist } \\
\text { (1), customer adviser (1), district nurse (3) }\end{array}$ \\
\hline 5 & 60 & $\begin{array}{l}\text { Once every } \\
\text { two months }\end{array}$ & 7 & $\begin{array}{l}\text { Family physician (2), practice nurse (1), physical therapist } \\
\text { (1), doctor's assistant (1), case manager for dementia (1), } \\
\text { nurse (1) }\end{array}$ \\
\hline 6 & 60 & $\begin{array}{l}\text { Once every } \\
\text { six weeks }\end{array}$ & 8 & $\begin{array}{l}\text { Physical therapist (3), occupational therapist (1), district } \\
\text { nurse (3), case manager for dementia (1) }\end{array}$ \\
\hline
\end{tabular}

Table 8.3 Data collection.

\begin{tabular}{|c|c|c|c|c|c|c|}
\hline \multirow[t]{2}{*}{ Team } & \multicolumn{2}{|c|}{$\begin{array}{l}\text { Team meeting } \\
\text { observations } \\
(n=11)\end{array}$} & \multirow{2}{*}{$\begin{array}{l}\text { Interviews with } \\
\text { chairpersons and co- } \\
\text { chairs } \\
(n=6) \\
\text { Post-test } \\
(n=6)\end{array}$} & \multicolumn{2}{|c|}{$\begin{array}{l}\text { Completed } \\
\text { questionnaires and } \\
\text { response rate } \\
(n=78)\end{array}$} & \multirow[t]{2}{*}{ Focus group meeting } \\
\hline & $\begin{array}{l}\text { Pretest } \\
(n=5)\end{array}$ & $\begin{array}{l}\text { Posttest } \\
(n=6)\end{array}$ & & $\begin{array}{l}\text { Pretest } \\
(n=29)\end{array}$ & $\begin{array}{l}\text { Post-test } \\
(n=49)\end{array}$ & \\
\hline 1 & $\mathrm{x}$ & $\mathrm{X}$ & Family physician & $4(57 \%)$ & $6(86 \%)$ & Practice nurse \\
\hline 2 & $x$ & $x$ & Family physician (2)** & $4(40 \%)$ & $9(90 \%)$ & District nurse ${ }^{* * *}$ \\
\hline 3 & $x$ & $x$ & $\begin{array}{l}\text { Family physician and } \\
\text { practice nurse** }\end{array}$ & $6(67 \%)$ & $8(89 \%)$ & $\begin{array}{l}\text { Care process supervisor and } \\
\text { district nurse }\end{array}$ \\
\hline 4 & $x$ & $x$ & $\begin{array}{l}\text { Practice nurse and family } \\
\text { physician** }\end{array}$ & $7(50 \%)$ & $9(64 \%)$ & Practice nurse $* * *$ \\
\hline 5 & $x$ & $x$ & $\begin{array}{l}\text { Practice nurse and family } \\
\text { physician** }\end{array}$ & $8(67 \%)$ & $10(83 \%)$ & Practice nurse \\
\hline 6 & $N / A^{*}$ & $x$ & $\begin{array}{l}\text { Physical therapist and } \\
\text { district nurse** }\end{array}$ & $N / A^{*}$ & $7(88 \%)$ & Physical therapist*** \\
\hline
\end{tabular}

This description of the results starts with the evaluation of the training activities. The results are presented below for each objective for improvement: knowing each other personally, clear structure and organization, patient-centredness, feedback and team reflexivity, chairing meetings and guiding team development. Lastly, we present the 
findings of the questionnaire regarding the programme's potential impact on team climate and patient-centredness.

\section{Participation of chairs and co-chairs in training activities}

\section{Level of implementation}

A team instruction meeting was arranged for each team. All 12 chairpersons (chairs and co-chairs) participated actively in two training sessions, two peer feedback sessions and an on-the-job coaching session. During the training sessions, the chairpersons received instructions on, and experimented with, using the reflection framework and supporting tools as intended.

\section{Participants' experiences?}

Overall, chairpersons expressed positive experiences regarding both content and form of the training course and did not feel crucial elements had been missing. They considered the variety of exercises, practice and theory in the training course to be effective. They especially regarded the theory concerning group processes (levels of communication, group development) as helpful when guiding teams. They mentioned that they had become more aware of group processes, more alert to specific behaviours of team members and better able to observe team functioning. Others perceived the training activities as a format supporting awareness of the patients' perspective, by offering insights into theory and best practices.

I think you should see the training course as a format or framework giving you some awareness of group processes and of the way this could work in an ideal situation' (Family physician, chair of team 1)

Some argued that the content of the training course should be more tailored to the specific team context (including setting, composition and organization). They mentioned that time efficiency could be improved by focusing on the efficiency-related learning objectives expressed by the team. For example, one chairperson, who was struggling with chairing a large group, suggested that more attention should have been paid to this specific theme during the training sessions.

The chairpersons especially valued the on-the-job coaching by the independent observers after the meetings, detecting blind spots and providing feedback. The chairs suggested expanding this element of the training course and would value feedback to the team during the meetings. 
Participating in the training course with a colleague and co-chair was considered by the chairpersons as not only useful but also pleasant, since they were able to support each other. Chairs valued feedback from their own colleague, as well as from the participants of other teams, as being both constructive and instructive. Chairpersons suggested making more use of team activities, like refresher courses, which might inspire team members to get involved in team development.

'Well, I just like it that she, err, has the same information as I, so there's always someone to fall back on, who knows how it works (District Nurse, chair of team 6)

In contrast to the request for more training activities, some chairpersons stated that participation had been time-consuming, and suggested reducing the duration of the training course. They suggested that time could be saved by shortening the theoretical part of the training course and providing additional video materials instead.

\section{Knowing each other personally}

\section{Level of implementation}

On average, 10 professionals from different disciplines participated during each of the IPT meetings we observed. Observations showed that most participating teams took some time to get to know each other. There were no major differences between pretest and posttest assessments. Almost all teams conducted an introduction round when new team members joined. However, these introduction rounds were limited to presenting names and disciplines and did not comprise specific expertise, background and interests. In one of the teams, the chairperson introduced the team to the new team member, and provided the new member with background information on the composition and history of the team, and the team's rules and agreements. Additionally, some teams developed a 'face book' including professional and personal details of all team members plus a photo. Compared to the observations during the pretest, the team members did not seem to have become more able to ask each other specific questions at posttest.

\section{Participants' experiences?}

The interviews indicated that the chairpersons perceived getting to know each other as the most important aspect of IPT meetings. They mentioned that meeting each other physically at regular intervals helps them get to know each other personally, resulting in short communication lines. The team members also tended to contact each other more 
easily outside the team meetings. As an example, they perceived an increase in bilateral consultations.

'If you know each other, it is easier to contact each other outside the IPT meetings' (Practice Nurse, Chair of team 3)

Others mentioned that their team worked on getting to know each other by organizing yearly team excursions. Another participant perceived a closer partnership among team members of her team. However, one chairperson mentioned that her team members did not know each other that well, as the team was still in the initial phase of group development.

\section{Clear structure and organization}

\section{Level of implementation}

Compared to the pretest, the meetings observed in the posttest assessment appeared to be more structured and better organized. Organizational roles were clearly divided, teams were working according to a set agenda, and some of them appointed a permanent secretary (responsible for taking notes). Chairpersons were fulfilling their role by structuring, summarizing and managing time, which was in clear contrast with most pretest meetings, where content was presented ad hoc, and mainly included announcements. At posttest, we observed less redundant talk and discussion of irrelevant matters. Meetings appeared to be better focused, resulting in clearer agreements.

Participants appeared to find it difficult to use the various tools to structure the meeting. Some teams used the toolbox form to prepare the meeting and introduce patients, others used a tailored version, while some teams did not use the tools at all. Only in one team was the brochure (including information on the different tools) placed on the table.

\section{Participants' experiences?}

The chairpersons perceived improving the structure and organization of their meetings as highly relevant and felt they had improved most on this issue as result of taking part in the programme. the chairpersons described their new way of working as being more efficient. 
'I now increasingly come out of these meetings feeling yes, that was rather efficient (Family Physician, chair of team 4)

The chairpersons stated that preparation of the meeting and agenda setting ensured that team members knew beforehand what patients and topics would be discussed, offering them the opportunity to focus their preparation. The team members also perceived improved team meeting efficiency thanks to better agenda setting and division of tasks. It was especially the agenda setting that had made the distinction between announcements and cases to be discussed in detail clearer.

'I think the chairpersons now work in a more structured way. They clearly distinguish between, err, when someone want to bring something up, is this an announcement or is it discussing a case, right? And, err, well if it's just an announcement, it is quickly dismissed, and then, on we go.' (Care Process Supervisor, team member of team 3)

One team member commented that the structure could be improved further by adding a time component to the agenda. This respondent also questioned whether their team should include a large number of participants, and recommended that team members should be invited selectively, based on the agenda. Furthermore, one chair reported a negative experience in that she constantly had to send reminders to the other team members to submit patient cases in time. Moreover, the chairpersons stated that it is hard to fulfil both roles, chairperson and secretary. In this respect, the suggestion to appoint a permanent and separate secretary was positively commented on by the participants.

The participants' opinions diverged regarding the use of the tools to prepare and structure the meeting. The chairpersons valued the brochure as highly useful and feasible, but often just forgot to bring it to the meeting. Some team members perceived that the tools offered added value for the efficiency of the meetings, while others mentioned adverse effects of preparing the meeting by means of a time-consuming form. Some participants also experienced using the supporting tools as extra work, since it could not be integrated into their normal work routines. Other team members were not aware of the existence of some of the tools. Additionally, the chairpersons mentioned the negative impact of bureaucracy on their work routines, and warned against an overload of forms and protocols. 


\section{Patient-centredness}

\section{Level of implementation}

Compared to the findings at pretest, some practices appeared to have become more focused on the patient's perspective, by frequently asking: 'What do we know about the patient's needs?' We also observed that some teams paid special attention to the privacy of the patients discussed. They mentioned that the patients should be informed beforehand and asked for permission to present their cases during the IPT meeting. They also explicitly incorporated agreements on privacy in their working protocols. In none of the meetings did a patient or a representative take part. The tool to enhance patientcentredness (the six-step plan) was only occasionally used as intended. In most of the cases discussed, the goals of the patient (step 2) and the analysis of the situation, including aspects of self-management (step 3) were not explicitly mentioned. Only in exceptional cases did the teams use the placemat presenting a description of the sixstep plan. For some of the cases discussed, the team suggested to present the options to the patient in order to enhance shared decision making. However, in other cases the team decided upon actions without the patient's direct approval.

\section{Participants' experiences?}

After implementation, participants reported to have become more aware of the patient's perspective and to have developed increased awareness of the rationale of their contribution. Some stated that they had become more aware of privacy issues regarding sharing patient information.

'I now probably, perhaps still not enough, but certainly more than before, think more about what the patients themselves want. What their wishes are, or their goals, and I notice that we still often talk from a medical perspective, what we think is good for people, but the alertness and the fact that people have preferences, that I now think about that more often. And that feels very good.' (Family Physician, chair of team 5)

However, chairpersons experienced a lack of patient and family involvement before, during and after team meetings. They expressed that, for instance, in the case of care avoiders, it is often difficult to explore a patient's goals and get their permission to present the patient during an IPT meeting. Participants reported that the professional perspective often dominates especially in those cases. Regarding the tools, chairpersons mentioned that the form used to present patient cases was easy to use, and indicated 
that using the form made team members more aware of their contributions. However, team members often wanted to present and discuss patients ad hoc, leaving less time to fill in the form. Since using the form, some members had detected a decrease in the number of patients being presented during their meetings. In order to avoid the form becoming a threshold to presenting patients, some teams adjusted the form and applied it less strictly.

'No, we didn't use the actual form, but used a number of items from it, which we regard as essential for us.' (Family Physician, chair of team 1 )

Some of the team members experienced the six-step plan as useful and as offering added value. Others regarded the six-step plan as too extensive and they mentioned lacking the time to go through all six steps. Some mentioned that they did not follow all steps as intended and explained that they still had to get used to the new way of working.

'The disadvantage is that it takes more time. It has, has to be filled in beforehand, you need to think about it beforehand, right? You can't just come to an IPT meeting unprepared." (Practice Nurse, team member of team 4)

'I try to think about it, to focus on the client, but sometimes it, it just disappears, as you allow yourself to get carried away by the content of the questions discussed by the care providers.' (District Nurse, chair of team 6)

\section{Feedback and team reflexivity}

\section{Level of implementation}

Three of the six teams observed at posttest reflected on their functioning. One of the teams put reflection on the agenda. All team members were given the opportunity to provide input and express their thoughts. Regarding team climate, we observed a pleasant atmosphere and informal working environment in all teams, allowing reflection and enabling team members to give each other feedback. Chairpersons rarely attempted to ask in-depth questions. Consequently, reflection remained superficial, with personal opinions and experiences not explored in depth. 


\section{Participants' experiences?}

Most chairpersons acknowledged the added value of team reflection in relation to team development. One team member mentioned a positive experience regarding reflection on the application of the form.

'Yeah, that's the main thing. Not just thinking this is it, but to keep searching to see, well, this is where we stand, what can we improve?' (Family Physician, chair of team 4)

However, most chairpersons mentioned that reflection did not occur often enough, which was confirmed by other team members. One team member stated that initiating reflection is the chairpersons' job, and that he did not feel responsible for initiating reflection and improving team functioning.

'A sense of responsibility also has to do with a sense of binding, of engagement. You see, we just sit there once a month. And if you miss a meeting, it's once in two months.' (District Nurse, team member of team 2)

One chairperson stated that reflection was intended to be part of the any other business round at the end of the meeting, but in practice this round was used for other contentrelated matters. Others perceived reflection on team functioning as difficult due to the continuously changing team composition. Some chairpersons perceived added value of reflection on problem situations. Moreover, the chairpersons reported that if reflection was needed, it should be initiated spontaneously during the meeting itself and not be scheduled at fixed reflection moments. Lastly, the participants perceived an open and safe team climate, with plenty of room for reflection.

\section{Chairing meetings and guiding team development}

\section{Level of implementation}

Our observations showed that most chairs at posttest were more explicitly structuring the meetings and guiding their team. Compared to pretest, chairs summarized and paraphrased more often at posttest. We also observed a growth in leadership skills. Some chairs were noticeably inspiring and involving other team members to take part in the discussion, by recognizing and appreciating their contributions. Most were contributing to a positive atmosphere and healthy working environment, by acting as a host. 


\section{Participants' experiences?}

Most chairpersons enjoyed developing their skills to guide the team. They felt that attending the programme had enabled them to structure the meetings and guide team development. Some mentioned that their role had changed into 'the team's driving force'. In addition, the chairpersons mentioned that they had become more aware of group processes and specific behaviours, and better able to observe processes. Conversely, team members did not perceive huge changes in the role and position of their chairpersons. Some reported to have noticed that their team's chairperson was still experimenting. Other team members mentioned to have become more confident, empowered and active and more willing to express their opinions, since they had more practical tools.

'Taking part in this programme gave us a boost to continue conducting IPT meetings.' (Family Physician, chair of team 3)

Some team members mentioned the positive effect of the natural interplay between the chairperson and the co-chair. However, chairs also experienced that chairing meetings and guiding the team takes a lot of time, and is not always an easy task. A team member remarked that in their team two chairpersons were alternating with each other, and experienced this as rather confusing.

"I wasn't really aware that chairing the meetings would be such a different task for me. I just thought, well, I'll just do it. Well, and it wasn't like that. You don't just do it without effort.' (Physical therapist, chair of team 6)

None of the participating chairs reported finding it difficult to deal with irritations or annoying situations, although one team member perceived the dominance of one of the family physicians (not the chairperson) as a barrier to collaboration. One chair mentioned struggling with the large team size. Another chair mentioned that as a chairperson you constantly have to adjust to who is attending the meeting, questioning whether the team could be really considered a team given its continuously changing composition.

'Actually, I wonder whether you could call this a team at all, since there's a constant change of the people attending. Although they represent the disciplines we expect at that moment, it's never the same team. There are always different people, which means different perspectives.'(Practice Nurse, chair of team 2) 


\section{Programme's potential impact on team climate, efficiency and patient- centredness}

Table 8.3 offers an overview of the response rates and numbers of questionnaires collected, for each team. The main results for each section of the questionnaire are presented in Table 8.4. An overview of the scores on the individual questions per practice can be found in Appendix 8.4. Table 8.4 shows that pretest scores differed between the teams. Table 8.4 shows a small increase between pretest and posttest for all domains. The largest increase was found in the domain of 'Task Style', relating to team climate and including questions on team reflexivity. Differences between teams were small. However, as becomes clear from Table 8.4, team 1 had the largest number of highest scores at both pretest and posttest. Team 6 had the lowest scores on most parts of the questionnaire. At the level of individual items, the highest absolute increase, 0.71 (pretest=5.07 and posttest=5.78), was found for question 45: 'The way we work during team meetings can be considered efficient'.

Table 8.4 Mean scores of the questionnaire per team.

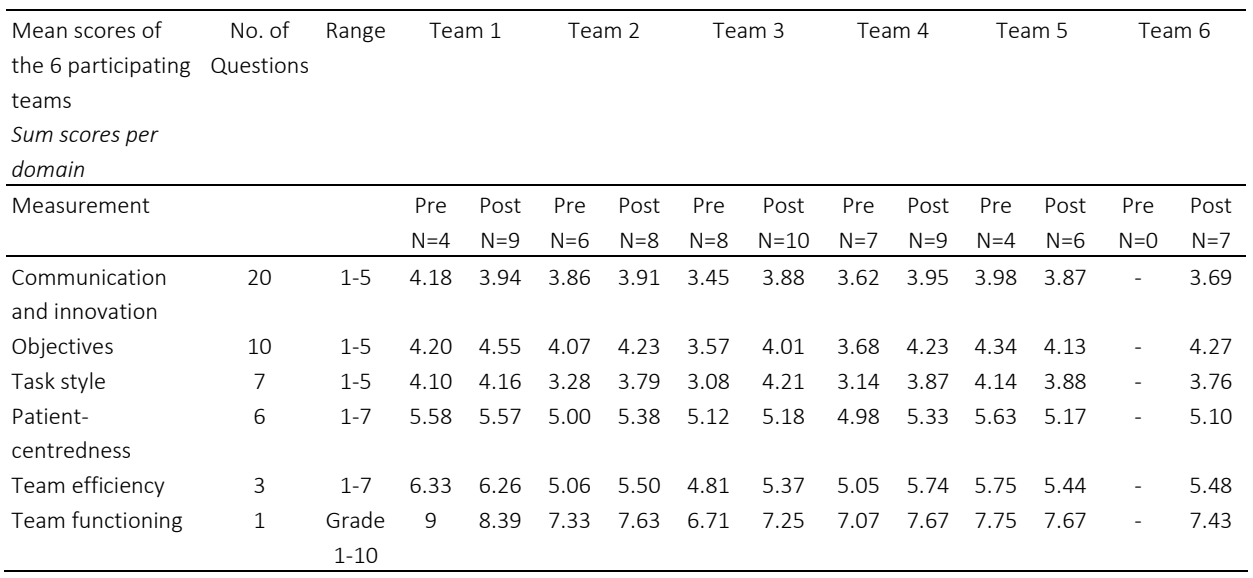

\section{Discussion}

This process evaluation has yielded insights into the suitability and potential impact of a programme intended to improve the functioning of interprofessional team (IPT) meetings in primary care, focusing on five main objectives for improvement: (1) knowing each other personally, (2) clear structure and organization, (3) patient-centredness, (4) feedback and team reflexivity, and (5) chairing meetings and guiding team 
development. The findings contribute to a good understanding of the programme's usefulness and offer suggestions to optimize the programme.

In general, our findings showed that the programme was suitable and well appreciated. The programme resulted in improved structure and organization of the meetings. Most progress was made on efficiency, by improved preparation, agenda setting, time use, and increased focus. Moreover, the programme resulted in greater awareness of the value of the patient perspective and the team processes. However, apart from increased awareness, no great impact was seen in the observations on patient-centredness in terms of explicitly exploring patient goals. There seems to be a discrepancy between what professionals do and what they think they do regarding patient-centredness. These findings appear similar to those of our previous study during the needs assessment, which also showed discrepancies between observations and interviews regarding efficiency and patient-centredness. ${ }^{4}$ In some teams, the number of patients discussed during the meetings had decreased. Participants explained that the new approach challenges the team members to carefully consider the patient's goals and their level of complexity beforehand, resulting in more consciousness regarding patients discussed. Others stated that the decrease was caused by the threshold formed by the obligation to prepare the meeting according to a structured form, and the extra time this takes. The tools we provided to enhance patient-centredness may be too complex or timeconsuming for some team members. Simplified tools, tailored to the needs of the team, seem desirable.

Within our programme, the chairpersons were positioned as key figures, who were intended to operate as role models and change agents, enabling the team to improve its own functioning. The chairpersons were trained and facilitated to organize and structure meetings, and enhance patient-centredness by showing effective leadership and using the tools. They were trained to adapt their style of leadership (directive, convincing, participatory, or delegating) to the specific team context and the phase of the group development process, which is known as situational leadership. ${ }^{22}$ Different leadership styles were observed, however, most chairpersons actually adopted a more directive style of leadership. Further, it is known that seniority of grade is associated with a higher quality of leadership behaviour. ${ }^{23}$ This view could be reasonable, since the findings of our questionnaire show high scores for team 1, which was chaired by two physicians.

Although programme components and materials were perceived as valuable, some chairs experienced difficulties in implementing their new role, and did not feel able to guide their team through development. Chairpersons of the less stable teams reported being confronted with a continuously changing team composition and frequent absence of core team members. Given this changing team composition, it appears questionable whether all interprofessional primary care teams can be considered teams, or whether it 
would be better to regard some of them as networks. ${ }^{24}$ In this respect, Lingard talks about distributed teams composed of members from various organizations who may not know each other and have restricted opportunities to develop shared values compared to acute care teams. ${ }^{25}$

The dynamic composition of some teams also hampered their ability to reflect upon and adjust team functioning. However, there are more reasons why team reflection was not conducted as intended. Some chairpersons experienced problems initiating reflection moments, or did not perceive any added value. As a possible strategy to enhance reflexivity, participants mentioned the value of an external facilitator who, compared to the chairperson, would as an outsider be better able to identify and comment on problem points. In this respect, participants also suggested to expand the on-the-job learning activities in which the entire team is coached. Other studies have also shown that supporting change by means of reflection is more effective when IPT meetings are mediated by a skilled facilitator, e.g. a researcher/consultant who is familiar with the specific team context. ${ }^{26,27}$ Transformational leadership, characterized by a leader who inspires and motivates other team members regarding their vision, goals and action plans, is also positively related to team reflection. ${ }^{28,29}$ Adopting principles of this approach to leadership in our programme can therefore be a suitable strategy to stimulate team reflexivity and adapting to a rapidly changing environment. ${ }^{28,29}$

It is likely that increasing patient-centredness and integrating new ways of working into existing work processes requires time and behavioural change among the participating professionals. According to Bandura's learning theory, behaviour change is rooted in social systems, in which behaviour is learned from the environment through a process of observational learning. ${ }^{30}$ Since people tend to follow good examples, the chairs in our programme could act as role models and change agents.

Lastly, interprofessional primary care teams differ in context, in terms of setting, composition, organization, and phase of development. Our findings did indeed appear to vary under the influence of the professional and organizational contexts of the teams. Harris and colleagues also found differences in the impact of programmes to enhance interprofessional teamwork, due to contextual differences. ${ }^{10}$ Even more than anticipated, the findings of our evaluation indicate that both content and form of the programme should be flexible in use, adapted to the team context, and tailored to its specific needs. Other studies have found similar results. ${ }^{11,12,31}$ Conducting an intake procedure at the start of the programme, including a thorough assessment (including needs assessment and observation), could offer insights into these specific team contexts and needs. Outcomes of this intake procedure can then be used to shape and tailor the content and form of the programme. 


\section{Strengths and limitations}

We used a systematic approach to design and conduct our process evaluation, using the Medical Research Council (MRC) Guide. ${ }^{14}$ Our use of different forms of data collection (observations, interviews, focus groups and questionnaires) helped to clarify the complex pathways and contextual factors. Some of the interviews with chairpersons included both chairperson and co-chair. Interviewing them together may have led to less forthright answers. However, the interviewees appeared to elaborate on each other's answers, resulting in additional viewpoints. Our findings show some discrepancies between the experiences of chairpersons and those of the other team members. This can be explained by the fact that the chairpersons had all practiced with the various tools we offered, while some of the team members were not even aware of the existence of some of the tools.

The fact that the input for this process evaluation was a systematic needs assessment in which the programme had been developed in close collaboration with all stakeholders (using an action research approach), can be regarded as strength of our study. Nevertheless, this does not remove the need for a thorough process evaluation when a programme is implemented in daily practice.

During the needs assessment observation and interview guides had already been evaluated, which can also be regarded as a strength of our study [4-6]. The observations were conducted by two independent researchers, as recommended by Moore et al. ${ }^{14}$

The researcher (JVD) who observed the meetings and interviewed participants also functioned as trainer/coach. Ideally, according to the MRC guide, researchers should not engage in continuous quality improvement activities, because this may compromise the external validity of the evaluation. However, in our case the researcher acted as a passive observer, and did not intervene or feed findings back during or after the team meeting, minimizing the effects of this possible limitation. ${ }^{32}$

Although only a limited number of teams and members were included and were selected by convenience sampling, the teams varied considerably regarding composition and organization which reflects the situation in primary care. The average score for team functioning at baseline was relatively high for some of the teams, which may imply that we included mainly well-functioning teams. However, the observations at baseline showed that all teams required some improvement. Given the average frequency of meetings and the time needed to change behaviour, the follow-up of the teams can be regarded as relatively short.

To end, due to the process evaluation character of this study, the differences between the teams, and the low number of respondents, the quantitative data were only analysed descriptively. As a consequence of this design, we were not able to evaluate 
the effect of the programme, but have only offered some insights into its potential impact.

\section{Conclusion}

Overall, the programme improves both the structure and organization of interprofessional primary care team meetings. The programme also contributed to increased awareness of patient-centredness and group processes among the participants. It is likely that increasing team reflexivity and patient-centredness, and integrating new ways of working in existing work processes, will require time among the participating professionals. Furthermore, to be more effective, the programme should be even more context-specific and flexible in use than anticipated, and asks for an intake procedure at the start, and support and coaching by an external facilitator at the workplace. Given the perceived added value of the peer feedback and on-the-job coaching of the entire team, it appears worthwhile to improve these components of the programme. 


\section{References}

1. Pullon $\mathrm{S}$, et al. Observation of interprofessional collaboration in primary care practice: A multiple case study. J Interprof Care. 2016;30(6):787-94.

2. Zwarenstein M, Goldman J, Reeves S. Interprofessional collaboration: effects of practice-based interventions on professional practice and healthcare outcomes. Cochrane Database Syst Rev. 2009(3): CD000072.

3. Bookey-Bassett S, et al. Understanding interprofessional collaboration in the context of chronic disease management for older adults living in communities: a concept analysis. J Adv Nurs. 2017;73(1):71-84.

4. van Dongen JJJ, et al. Interprofessional primary care team meetings: a qualitative approach comparing observations with personal opinions. Fam Pract. 2017;34(1):98-106.

5. van Dongen JJJ, et al. Successful participation of patients in interprofessional team meetings: A qualitative study. Health Expect. 2016.

6. van Dongen JJJ, et al. Interprofessional collaboration regarding patients' care plans in primary care: a focus group study into influential factors. BMC Fam Pract. 2016;17:58.

7. van Dongen JJJ, et al. "They Are Talking About Me, but Not with Me": A Focus Group Study to Explore the Patient Perspective on Interprofessional Team Meetings in Primary Care. Patient. 2017.

8. van Dongen, J.J.J., et al., Developing interprofessional care plans in chronic care: a scoping review. BMC Fam Pract. 2016;17(1):137.

9. van Dongen JJJ, et al. Development of a customizable programme for improving interprofessional team meetings. An action research approach. Manuscript submitted for publication. 2017.

10. Harris MF, et al. Interprofessional teamwork innovations for primary health care practices and practitioners: evidence from a comparison of reform in three countries. J Multidiscip Healthc. 2016;9: 35-46.

11. O'Leary KJ, et al. Interdisciplinary teamwork in hospitals: a review and practical recommendations for improvement. J Hosp Med. 2012;7(1):48-54.

12. Buljac-Samardzic, M., et al., Interventions to improve team effectiveness: a systematic review. Health Policy. 2010;94(3):183-95.

13. Reeves $\mathrm{S}$, et al. A scoping review to improve conceptual clarity of interprofessional interventions. J Interprof Care. 2011;25(3):167-74.

14. Moore GF, et al. Process evaluation of complex interventions: Medical Research Council guidance. BMJ. 2015;350:h1258.

15. Nelson EC, et al. Microsystems in health care: Part 1. Learning from high-performing front-line clinical units. Jt Comm J Qual Improv. 2002;28(9):472-93.

16. Mills PD, Weeks WB. Characteristics of successful quality improvement teams: lessons from five collaborative projects in the VHA. Jt Comm J Qual Saf. 2004;30(3):152-62.

17. Ouwens $\mathrm{M}$, et al. The Team Climate Inventory: application in hospital teams and methodological considerations. Qual Saf Health Care. 2008;17(4):275-80.

18. Schroder C, et al. Development and pilot testing of the collaborative practice assessment tool. J Interprof Care. 2011;25(3):189-95.

19. Hsieh HF, Shannon SE. Three approaches to qualitative content analysis. Qual Health Res. 2005;15(9): 1277-88.

20. Mortelmans D. Kwalitatieve analyse met Nvivo (Qualitative analysis with Nvivo). 2011, Leeuwen: Acco Uitgeverij.

21. O'Cathain A, Murphy E, Nicholl J. Three techniques for integrating data in mixed methods studies. BMJ. 2010;341:c4587.

22. Remmerswaal J. Group Dynamics: an introduction. 2015, Amsterdam: Uitgeverij boom/nelissen.

23. Wylie DA, Gallagher HL. Transformational leadership behaviors in allied health professions. I Allied Health. 2009;38(2):65-73.

24. Kane RA. The interprofessional team as a small group. Soc Work Health Care. 1975;1(1):19-32.

25. Lingard $L$, et al. Pulling together and pulling apart: influences of convergence and divergence on distributed healthcare teams. Adv Health Sci Educ Theory Pract. 2017. 
26. Liberati EG, Gorli M, Scaratti G. Invisible walls within multidisciplinary teams: Disciplinary boundaries and their effects on integrated care. Soc Sci Med. 2016;150:31-9.

27. Cheater FM, et al. Can a facilitated programme promote effective multidisciplinary audit in secondary care teams? An exploratory trial. International Journal of Nursing Studies. 2005;42(7):779-91.

28. Firestone DT. A Study of Leadership Behaviors among Chairpersons in Allied Health Programs. Journal of Allied Health. 2010;39(1):34-42.

29. Schippers $M C$, et al. The role of transformational leadership in enhancing team reflexivity. Human Relations. 2008;61(11):1593-616.

30. Bandura A. Social foundations of thought and action: A social cognitive theory 1986, New Jersey: Prentice-Hall, Inc.

31. Korner $\mathrm{M}$, et al. Interprofessional teamwork and team interventions in chronic care: A systematic review. J Interprof Care. 2016;30(1):15-28.

32. Jorgensen DL. Participant observation. 1989: Wiley Online Library. 
Appendix 8.1

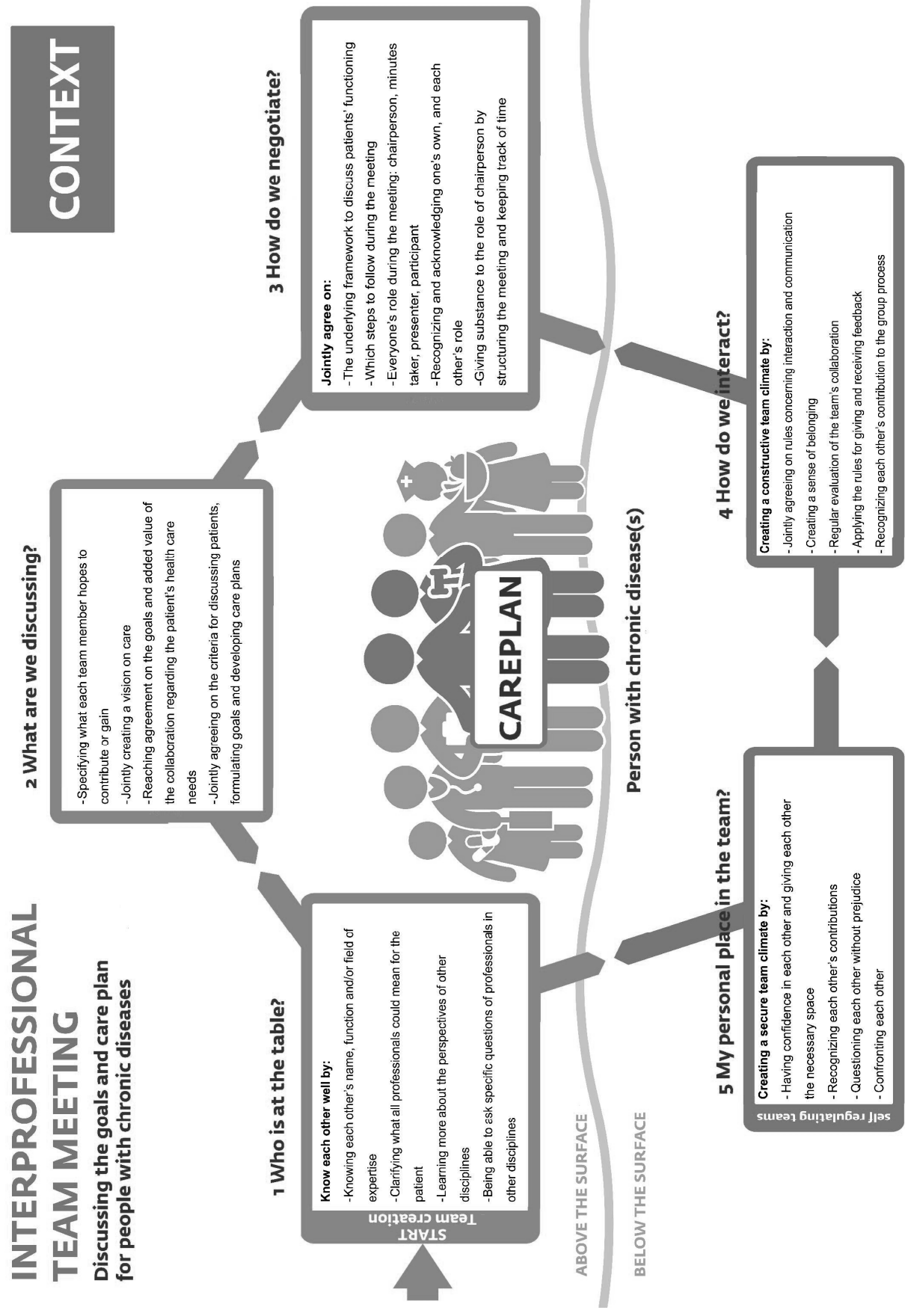




\section{Appendix 8.2}

\section{Observation guide}

\begin{tabular}{|c|c|c|}
\hline $\begin{array}{l}\text { Observation } \\
\text { list } \\
\text { Overall }\end{array}$ & $\begin{array}{l}\text { Is the programme (core component / tool) being } \\
\text { applied, and if so, which parts? } \\
\text { How (and to what extent) are the different } \\
\text { components and tools of the programme being } \\
\text { applied? }\end{array}$ & $\begin{array}{l}\text { Manageability and feasibility } \\
\text { What do you notice about the feasibility of } \\
\text { the programme? } \\
\text { Bottlenecks } \\
\text { What are the evident bottlenecks? } \\
\text { Contextual factors } \\
\text { Which visible contextual factors are } \\
\text { influencing the application of the } \\
\text { programme? } \\
\text { Added value } \\
\text { What can you say about the added value } \\
\text { provided by the programme? }\end{array}$ \\
\hline $\begin{array}{l}\text { Knowing } \\
\text { each other }\end{array}$ & $\begin{array}{l}\text { Team members know each other (No one has to be } \\
\text { introduced, no new faces) }\end{array}$ & \\
\hline $\begin{array}{l}\text { Rules for the } \\
\text { meeting }\end{array}$ & $\begin{array}{l}\text { Everyone visibly adheres to the agreements and } \\
\text { rules for the meeting } \\
\text { Team members stick to the organizational } \\
\text { agreements }\end{array}$ & \\
\hline Roles & $\begin{array}{l}\text { Chairperson } \\
\text { Has prepared the meeting } \\
\text { Structures the meeting } \\
\text { Ensures adherence to the rules of the meeting } \\
\text { Follows the six-step plan } \\
\text { Summarizes } \\
\text { Keeps track of time } \\
\text { Guides reflection } \\
\text { Points out tensions } \\
\text { Clearly announces closing the meeting and plans } \\
\text { next meeting } \\
\text { Secretary } \\
\text { Takes care of the reporting (preparing minutes) } \\
\text { Checks regularly whether minutes correspond to } \\
\text { what has been agreed on during discussion } \\
\text { Where appropriate, refers to previous minutes }\end{array}$ & \\
\hline $\begin{array}{l}\text { Inter- } \\
\text { professional } \\
\text { meeting } \\
\text { structure }\end{array}$ & $\begin{array}{l}\text { Preparation } \\
\text { Clear agenda } \\
\text { Information about patients is provided before the } \\
\text { meeting } \\
\text { Meeting } \\
\text { Opening } \\
\text { Discussion of each patient } \\
\text { Closing } \\
\text { Aftercare } \\
\text { Reporting } \\
\text { Agreements regarding feedback to patient } \\
\text { Agenda and agreements for next meeting } \\
\end{array}$ & \\
\hline
\end{tabular}




\begin{tabular}{|l|l|l|}
\hline $\begin{array}{l}\text { Interaction } \\
\text { and team } \\
\text { climate }\end{array}$ & $\begin{array}{l}\text { Team members give each other feedback } \\
\text { On content } \\
\text { On procedure } \\
\text { On interaction }\end{array}$ & \\
& $\begin{array}{l}\text { Any comments about the team climate and } \\
\text { atmosphere? } \\
\text { Are there any visible irritations? } \\
\text { Any comments about the way the team talks about } \\
\text { patients? }\end{array}$ & \\
\hline $\begin{array}{l}\text { Reflection } \\
\text { tool }\end{array}$ & $\begin{array}{l}\text { At which level does the team reflect? } \\
\text { Is there any input from participants? } \\
\text { Are specific learning objectives defined? } \\
\text { Does the team refer back to previous agreements } \\
\text { and learning objectives? }\end{array}$ & \\
\hline
\end{tabular}




\section{Appendix 8.3}

\section{Interview guide}

- Introduction

o Introduction of the interviewer

o Consent for audio recording

- Explanation of participants' rights

o Aim of the interview: The aim is to explore personal experiences (both barriers and facilitators) regarding usability and added value of the programme

- Procedure, duration etc.

o Emphasizing that all information is relevant

\section{Introduction}

In the past year, your practice took part in a programme to improve interprofessional team functioning. You as the chairperson attended various training activities relating to structuring and organizing meetings and enhancing patient-centredness. Activities comprised two training sessions, peer feedback sessions and on-the-job coaching. During these activities you learned about the use of various supporting tools and then experimented with them in practice.

\section{Subquestions}

- Can you give an example?

- Can you explain in detail what you mean by...?

- Why do you perceive ... as a relevant factor/barrier/facilitator?

\section{Main questions}

Questions concern perceived use, handling, added value and corresponding facilitators and barriers to the programme.

1. How did you feel about applying the lessons learned during the training activities in practice? How did you feel about applying the new methodology and supporting tools?
a. Why did you use (or not use) the components of the programme/ tools?
b. What about their usability?
c. What barriers did you encounter in applying the new methodology and tools?
d. What is the added value of the different components of the programme / tools?

2. What did the programme and new approach bring to the team?
a. Could you explain this? Why is that an added value?

3. How satisfied are you with the new approach / methodology?

a. Why? Could you explain this? Could you give an example? 
4. How would you describe your role in the team? How did this role develop in the recent period?

a. To what extent did your role in the team change compared to before you took part in the programme?

b. If applicable, could you tell me something about your personal growth. What changed? What did you learn? What would you like to learn?

c. To what extent did the training and coaching facilitate you in this development?

d. What supported or hampered you in acquiring the knowledge?

e. In your opinion, what aspects were missing from the training and coaching?

f. Could you mention components that we have to keep in the training? And could you mention aspects that could be removed?

5. What did the programme bring you as a person?
a. Could you explain this?
b. What did you learn?
c. For what skills/competences did you develop more confidence?
d. What new insights did the programme offer you?
e. What are you still struggling with?

6. Is there something else you want to share regarding the programme and the various training activities?

\section{Summary}

Interviewer gives a summary.

- Did I forget any relevant information in this summary? 


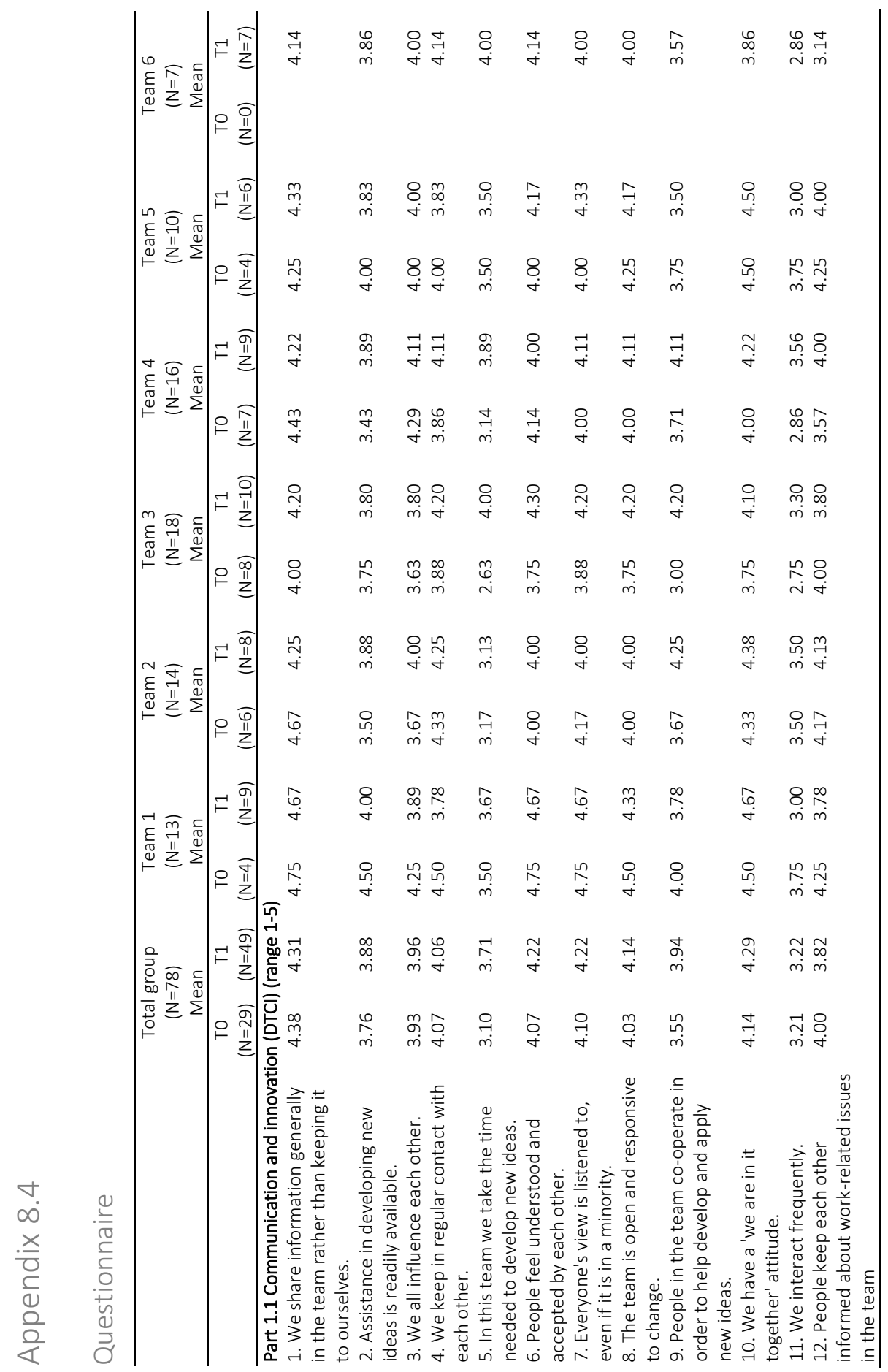




\begin{tabular}{|c|c|c|c|c|c|c|c|c|c|c|c|}
\hline$\stackrel{\vec{m}}{\stackrel{\vec{m}}{m}}$ & 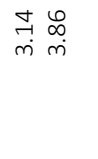 & $\underset{\hat{m}}{\vec{r}}$ & $\underset{+}{\stackrel{\leftrightarrow}{+}}$ & $\begin{array}{l}\vec{r} \\
\dot{m}\end{array}$ & $\begin{array}{l}\infty \\
\infty \\
\dot{m}\end{array}$ & $\stackrel{n}{n}$ & 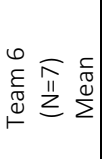 & 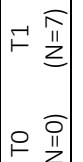 & $\stackrel{\hat{n}}{+}$ & 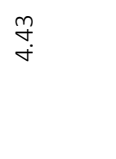 & 辇 \\
\hline $\begin{array}{l}\hat{b} \\
\dot{m}\end{array}$ & $\begin{array}{l}\stackrel{\circ}{\leftrightarrow} \underset{m}{\infty} \\
m \\
m\end{array}$ & $\begin{array}{l}\infty \\
\infty \\
m\end{array}$ & $\begin{array}{l}\vec{f} \\
\stackrel{f}{+}\end{array}$ & $\begin{array}{l}\stackrel{8}{+} \\
\dot{+}\end{array}$ & $\stackrel{\vec{f}}{\stackrel{f}{+}}$ & $\begin{array}{l}\stackrel{8}{m} \\
\dot{m}\end{array}$ & 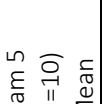 & 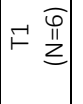 & $\stackrel{\stackrel{f}{\vec{r}}}{\stackrel{+}{*}}$ & $\underset{\stackrel{+}{\circ}}{\stackrel{8}{ }}$ & $\stackrel{m}{m}$ \\
\hline $\begin{array}{l}\stackrel{n}{n} \\
\dot{m}\end{array}$ & 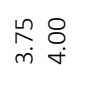 & $\underset{+}{\stackrel{\leftrightarrow}{+}}$ & $\stackrel{\stackrel{n}{\sim}}{\sim}$ & $\begin{array}{l}\stackrel{n}{\stackrel{n}{m}} \\
\dot{m}\end{array}$ & $\begin{array}{l}\stackrel{n}{\stackrel{n}{m}} \\
\dot{m}\end{array}$ & $\stackrel{\stackrel{n}{\sim}}{+}$ & & $\circ \begin{array}{ll}\stackrel{f}{I I} \\
\underline{1}\end{array}$ & 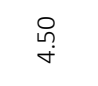 & $\underset{+}{\stackrel{8}{+}}$ & 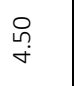 \\
\hline $\begin{array}{l}\infty \\
\stackrel{\infty}{\infty} \\
\end{array}$ & $\stackrel{\infty}{\stackrel{\infty}{m}} \underset{m}{\stackrel{\infty}{m}}$ & $\stackrel{\vec{F}}{\vec{f}}$ & $\stackrel{m}{m}$ & $\underset{+}{\stackrel{8}{+}}$ & $\stackrel{\vec{r}}{\stackrel{-}{+}}$ & $\stackrel{\hat{\sigma}}{i}$ & 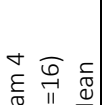 & 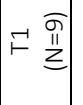 & 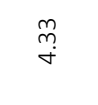 & 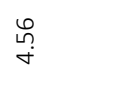 & $\begin{array}{l}\stackrel{\mathscr{n}}{\sim} \\
\stackrel{+}{*}\end{array}$ \\
\hline 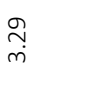 & $\begin{array}{l}\underset{\sim}{\mathcal{H}} \underset{\infty}{\infty} \\
\dot{m}\end{array}$ & $\underset{\text { N }}{\text { r }}$ & $\underset{\sim}{\stackrel{\sim}{*}}$ & $\stackrel{m}{\stackrel{m}{m}}$ & $\stackrel{\vec{\lambda}}{m}$ & $\underset{\stackrel{H}{\sim}}{\stackrel{J}{*}}$ & & $\circ \begin{array}{ll}\stackrel{\pi}{I} \\
\qquad\end{array}$ & $\stackrel{\hat{n}}{\mathrm{n}}$ & $\begin{array}{l}\hat{\omega} \\
\dot{m}\end{array}$ & $\begin{array}{l}m \\
\infty \\
m\end{array}$ \\
\hline $\begin{array}{l}\infty \\
\stackrel{\infty}{m} \\
\end{array}$ & $\begin{array}{l}\stackrel{\circ}{\circ} \\
\dot{m}\end{array}$ & $\begin{array}{l}\stackrel{8}{0} \\
\dot{m}\end{array}$ & $\stackrel{\circ}{\stackrel{\leftrightarrow}{+}}$ & 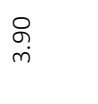 & $\begin{array}{l}\stackrel{8}{+} \\
\dot{+}\end{array}$ & $\begin{array}{l}\stackrel{0}{0} \\
i\end{array}$ & 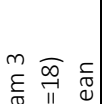 & 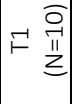 & $\begin{array}{l}\stackrel{\circ}{n} \\
\text { r }\end{array}$ & $\begin{array}{l}\stackrel{8}{\mathrm{~m}} \\
\text {. }\end{array}$ & $\begin{array}{l}\stackrel{P}{न} \\
\stackrel{+}{+}\end{array}$ \\
\hline$\stackrel{m}{\underset{m}{m}}$ & $\stackrel{\infty}{m} \underset{m}{\stackrel{n}{\stackrel{n}{m}}}$ & $\stackrel{m}{m}$ & $\underset{+}{\stackrel{8}{+}}$ & $\stackrel{m}{m}$ & $\stackrel{\infty}{m}$ & 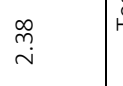 & & 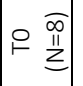 & $\stackrel{\stackrel{ }{n}}{\text { m }}$ & 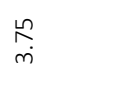 & $\begin{array}{l}\tilde{n} \\
\ddot{m}\end{array}$ \\
\hline in & $\begin{array}{ll}\infty & \stackrel{m}{\infty} \\
\stackrel{\infty}{r} & \stackrel{+}{+}\end{array}$ & $\stackrel{\substack{n \\
m}}{m}$ & $\underset{+}{\stackrel{\leftrightarrow}{+}}$ & $\begin{array}{l}\stackrel{8}{+} \\
\dot{+}\end{array}$ & $\begin{array}{l}\infty \\
\infty \\
m \\
\dot{m}\end{array}$ & $\stackrel{\infty}{m}$ & 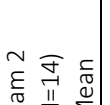 & 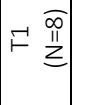 & $\stackrel{\infty}{m} \underset{\sim}{\sim}$ & 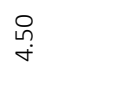 & 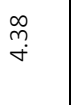 \\
\hline $\begin{array}{l}m \\
\infty \\
\dot{m}\end{array}$ & 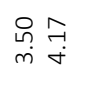 & $\begin{array}{l}\hat{\omega} \\
\dot{m}\end{array}$ & $\begin{array}{l}\stackrel{8}{\circ} \\
\stackrel{+}{ }\end{array}$ & 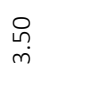 & $\underset{+}{\stackrel{F}{+}}$ & $\stackrel{m}{m}$ & & 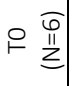 & 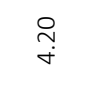 & $\underset{\stackrel{\overbrace{}}{\sim}}{\stackrel{f}{*}}$ & $\underset{\sim}{\stackrel{\sim}{\sim}}$ \\
\hline $\begin{array}{l}\stackrel{\infty}{\infty} \\
\stackrel{m}{n}\end{array}$ & $\begin{array}{l}\hat{b} \underset{\infty}{\infty} \\
\dot{m}\end{array}$ & $\begin{array}{l}\stackrel{\circ}{\infty} \\
\text { m. }\end{array}$ & 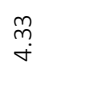 & $\begin{array}{l}\stackrel{\leftrightarrow}{\infty} \\
\text { n் }\end{array}$ & $\begin{array}{l}\stackrel{\infty}{\infty} \\
\text { m. }\end{array}$ & $\stackrel{\text { ᄂn }}{\sim}$ & 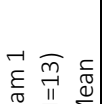 & 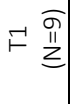 & $\stackrel{\infty}{\stackrel{\infty}{+}}$ & $\stackrel{\infty}{\stackrel{\infty}{\sim}}$ & $\begin{array}{l}\stackrel{\mathscr{Q}}{\infty} \\
\dot{+}\end{array}$ \\
\hline $\begin{array}{l}\stackrel{\circ}{n} \\
\text { m }\end{array}$ & 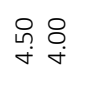 & $\underset{+}{\stackrel{8}{+}}$ & 号 & $\stackrel{\stackrel{n}{\sim}}{\stackrel{\sigma}{*}}$ & $\stackrel{\stackrel{\sim}{\sim}}{+}$ & 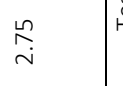 & & 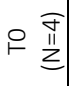 & 草 & 号 & 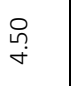 \\
\hline $\begin{array}{l}\hat{6} \\
\dot{m}\end{array}$ & $\begin{array}{l}\overrightarrow{6} \text {. \& } \\
\dot{m} \text { m }\end{array}$ & $\begin{array}{l}\stackrel{\sim}{\infty} \\
\tilde{m}\end{array}$ & $\begin{array}{l}\stackrel{\bullet}{+} \\
\stackrel{+}{*}\end{array}$ & $\begin{array}{c}\tilde{N} \\
\text { ñ }\end{array}$ & $\begin{array}{l}\infty \\
\stackrel{\infty}{m}\end{array}$ & $\stackrel{\infty}{\stackrel{\infty}{i}}$ & 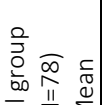 & $\vdash \begin{array}{c}\frac{\sigma}{f} \\
\underline{11} \\
\Sigma\end{array}$ & $\stackrel{\stackrel{n}{m}}{\stackrel{+}{*}}$ & $\underset{\substack{m \\
\dot{\sigma}}}{ }$ & $\stackrel{f}{f}$ \\
\hline$\stackrel{\substack{f \\
m}}{m}$ & 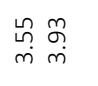 & $\stackrel{\sim}{n}$ & $\underset{+}{\stackrel{J}{+}}$ & $\stackrel{\tilde{N}}{m}$ & 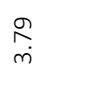 & $\stackrel{\infty}{\infty}$ & & 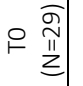 & $\stackrel{n}{\stackrel{n}{n}}$ & $\begin{array}{l}\mathscr{L} \\
\text { m }\end{array}$ & $\begin{array}{l}\dot{+} \\
\stackrel{+}{ }\end{array}$ \\
\hline 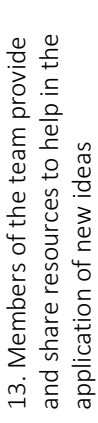 & 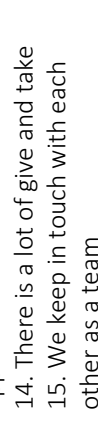 & 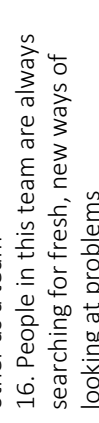 & 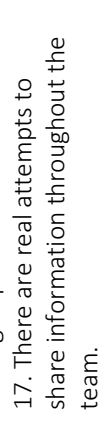 & 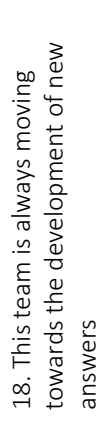 & 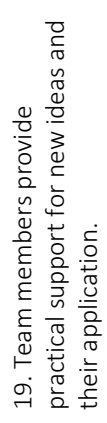 & 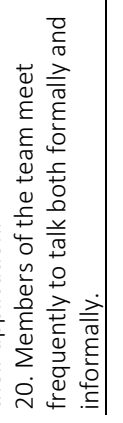 & & & 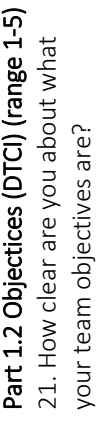 & 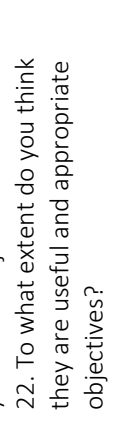 & 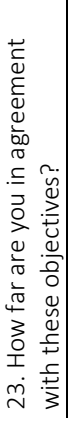 \\
\hline
\end{tabular}




\begin{tabular}{|c|c|c|c|c|c|c|c|c|c|c|}
\hline$\stackrel{\vec{f}}{\stackrel{\leftrightarrow}{+}}$ & $\stackrel{\vec{f}}{\stackrel{f}{*}}$ & $\begin{array}{l}\infty \\
\infty \\
m \\
m\end{array}$ & 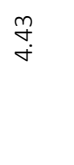 & $\stackrel{m}{\stackrel{m}{+}}$ & $\stackrel{\stackrel{\sim}{\sim}}{\underset{+}{+}}$ & $\underset{+}{\stackrel{8}{+}}$ & $\stackrel{\vec{J}}{\stackrel{+}{+}}$ & 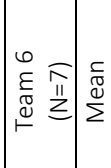 & {$\left[\begin{array}{ll}\vdash & \frac{\pi}{3} \\
\vdots & 0 \\
0 & 0\end{array}\right.$} & $\stackrel{\stackrel{+}{\sim}}{+}$ \\
\hline$\stackrel{m}{m} \underset{\sim}{\sim}$ & $\underset{+}{\stackrel{8}{+}}$ & $\begin{array}{c}\infty \\
\infty \\
m \\
m\end{array}$ & $\underset{+}{\stackrel{8}{+}}$ & $\stackrel{\vec{f}}{\vec{f}}$ & $\stackrel{\text { }}{+}$ & $\underset{+}{\stackrel{8}{+}}$ & $\underset{+}{\stackrel{8}{+}}$ & 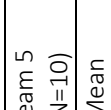 & 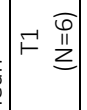 & $\stackrel{m}{m}$ \\
\hline 隼 & 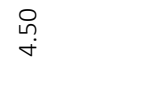 & $\begin{array}{l}\stackrel{n}{\stackrel{n}{m}} \\
\dot{m}\end{array}$ & 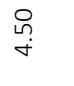 & 栥 & 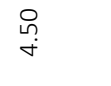 & $\stackrel{\stackrel{\sim}{N}}{+}$ & $\stackrel{\stackrel{\sim}{\sim}}{\sim}$ & & $\vdash \begin{array}{ll}\stackrel{f}{z} \\
\underline{3}\end{array}$ & $\stackrel{\stackrel{n}{\stackrel{f}{r}}}{\stackrel{f}{r}}$ \\
\hline & 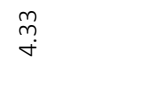 & $\begin{array}{l}\stackrel{\mathscr{L}}{n} \\
m\end{array}$ & $\underset{f}{\stackrel{J}{*}}$ & 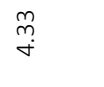 & 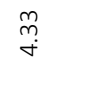 & $\stackrel{\vec{F}}{\vec{r}}$ & $\begin{array}{l}\infty \\
\infty \\
m\end{array}$ & 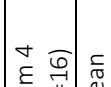 & 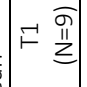 & $\stackrel{m}{m}$ \\
\hline $\begin{array}{l}\infty \\
\infty \\
m \\
m\end{array}$ & $\begin{array}{l}\hat{b} \\
\dot{n}\end{array}$ & $\begin{array}{l}\infty \\
\infty \\
m\end{array}$ & $\begin{array}{l}\infty \\
\infty \\
m\end{array}$ & $\begin{array}{l}\hat{b} \\
\dot{m}\end{array}$ & $\begin{array}{l}\hat{6} \\
\dot{n}\end{array}$ & $\begin{array}{l}\hat{b} \\
\dot{m}\end{array}$ & 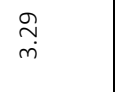 & & $\circ \begin{array}{ll}\pi & \pi \\
z\end{array}$ & $\begin{array}{l}\stackrel{8}{+} \\
\dot{+}\end{array}$ \\
\hline $\begin{array}{l}\infty \\
\stackrel{\infty}{m} \\
m\end{array}$ & $\begin{array}{l}\stackrel{8}{0} \\
\text { ri }\end{array}$ & $\stackrel{\text { ণ }}{+}$ & $\underset{+}{\stackrel{8}{+}}$ & $\underset{\sim}{\stackrel{\sim}{+}}$ & $\stackrel{\text { Pे }}{\stackrel{+}{+}}$ & $\underset{+}{\stackrel{\leftrightarrow}{+}}$ & 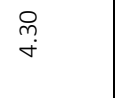 & $\underset{\varepsilon}{m} \underset{\sim}{\infty} \underset{\sigma}{\infty}$ & 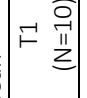 & 号 \\
\hline nn & $\begin{array}{l}\tilde{n} \\
\dot{m}\end{array}$ & 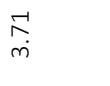 & $\begin{array}{l}\infty \\
\stackrel{\infty}{m} \\
m\end{array}$ & $\begin{array}{l}\infty \\
\stackrel{\infty}{m} \\
m\end{array}$ & $\begin{array}{l}\infty \\
\infty \\
m\end{array}$ & $\begin{array}{l}\ddot{n} \\
\ddot{n}\end{array}$ & $\stackrel{i}{\hat{m}}$ & & 交 & $\begin{array}{l}8 \\
\dot{+}\end{array}$ \\
\hline 隽 & $\stackrel{\stackrel{\sim}{\sim}}{\sim}$ & $\begin{array}{l}\stackrel{n}{\stackrel{n}{m}} \\
\dot{n}\end{array}$ & $\stackrel{\substack{m \\
\sim}}{+}$ & 号 & $\stackrel{\infty}{m}$ & 㿽 & 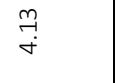 & $=\frac{1}{0}$ & $\mapsto \begin{array}{cc}\overline{0} \\
\underline{z}\end{array}$ & $\stackrel{\substack{m \\
\sim}}{+}$ \\
\hline 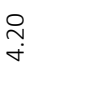 & $\begin{array}{l}\stackrel{8}{+} \\
\dot{+}\end{array}$ & $\begin{array}{l}\stackrel{8}{\circ} \\
\dot{+}\end{array}$ & $\begin{array}{l}8 \\
\dot{+}\end{array}$ & $\stackrel{\stackrel{\sim}{+}}{+}$ & $\stackrel{\curvearrowright}{\stackrel{\leftarrow}{+}}$ & $\underset{+}{\stackrel{8}{+}}$ & $\stackrel{8}{\dot{m}}$ & & 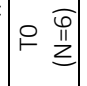 & $\underset{+}{\stackrel{8}{+}}$ \\
\hline 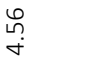 & $\stackrel{\leftrightarrow}{\leftrightarrow n}$ & $\stackrel{m}{m}$ & 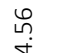 & $\underset{+}{\stackrel{\forall}{*}}$ & $\stackrel{\leftrightarrow}{\leftrightarrow}$ & $\stackrel{\leftrightarrow}{\leftrightarrow}$ & $\stackrel{8}{\circ}$ & & $\begin{array}{ll}-1 & \overline{1} \\
\square & 11\end{array}$ & $\underset{+}{\forall}$ \\
\hline $\begin{array}{l}8 \\
\dot{+}\end{array}$ & $\stackrel{\stackrel{\sim}{\sim}}{+}$ & $\underset{+}{\stackrel{\leftrightarrow}{+}}$ & $\stackrel{\stackrel{\sim}{+}}{\stackrel{+}{*}}$ & $\stackrel{\stackrel{\sim}{+}}{\sim}$ & $\stackrel{\stackrel{\sim}{\sim}}{\sim}$ & $\begin{array}{l}\stackrel{8}{\not} \\
\dot{+}\end{array}$ & 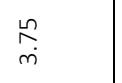 & & $\circ \stackrel{f}{\stackrel{f}{I}}$ & 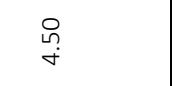 \\
\hline 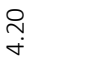 & $\stackrel{\vec{f}}{\stackrel{+}{+}}$ & $\begin{array}{l}\text { Jे } \\
\text { r }\end{array}$ & $\stackrel{\vec{m}}{\dot{\sim}}$ & $\stackrel{\stackrel{n}{m}}{\sim}$ & $\stackrel{\vec{m}}{\dot{\sigma}}$ & $\begin{array}{l}\stackrel{+}{\sigma} \\
\dot{\sigma}\end{array}$ & $\begin{array}{l}\infty \\
\stackrel{+}{+}\end{array}$ & & 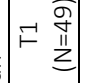 & 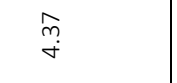 \\
\hline $\begin{array}{l}\mathscr{8} \\
\stackrel{m}{m}\end{array}$ & $\stackrel{n}{\stackrel{n}{m}}$ & $\begin{array}{l}\stackrel{\sim}{\infty} \\
\stackrel{m}{m}\end{array}$ & $\begin{array}{l}\dot{O} \\
\dot{+}\end{array}$ & $\underset{+}{\stackrel{+}{+}}$ & \begin{tabular}{l}
\multirow{+}{*}{} \\
$\dot{+}$
\end{tabular} & $\begin{array}{l}\stackrel{\infty}{\infty} \\
\stackrel{n}{n}\end{array}$ & $\underset{\dot{m}}{\hat{n}}$ & $\underline{0} \leq \mid z$ & $\vdash \begin{array}{ll}\frac{\pi}{3} \\
\underline{3}\end{array}$ & $\stackrel{\infty}{\stackrel{\sim}{\sim}}$ \\
\hline 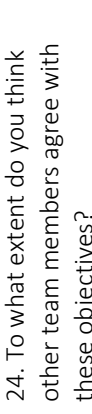 & 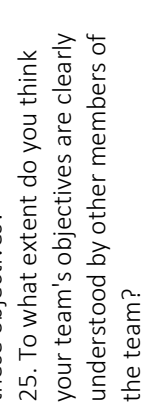 & 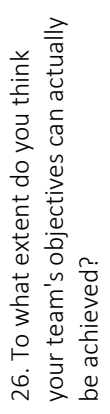 & 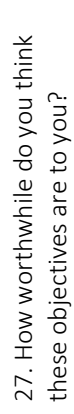 & 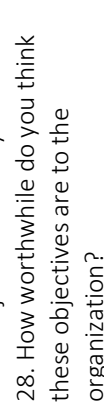 & 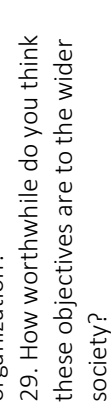 & 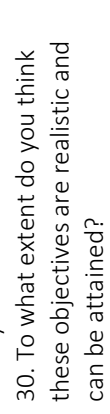 & 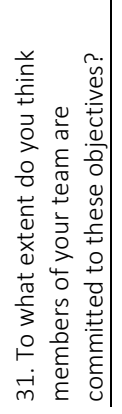 & & & 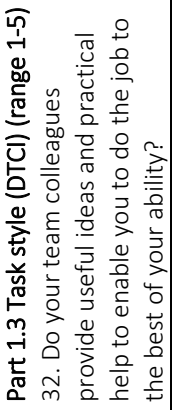 \\
\hline
\end{tabular}




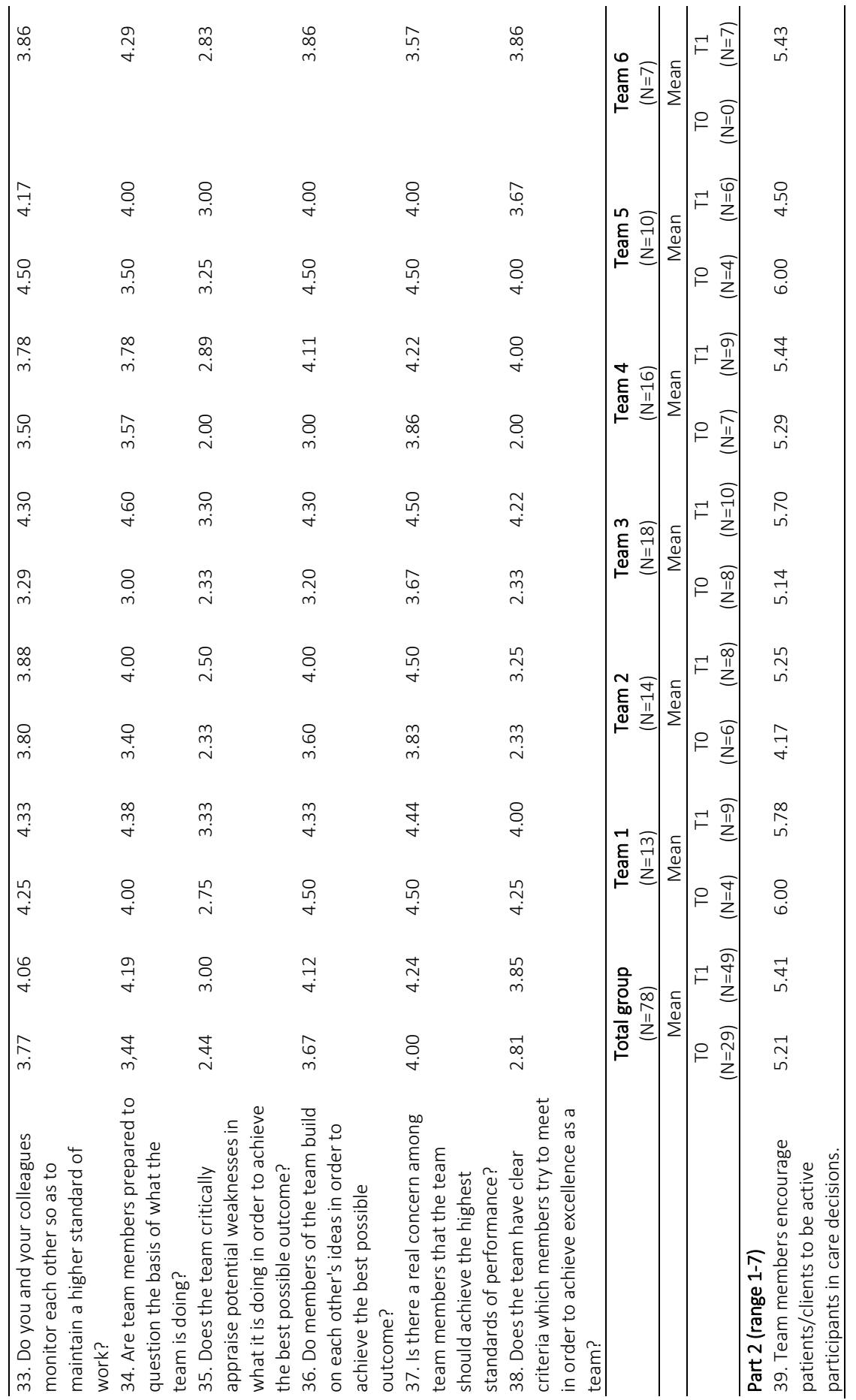




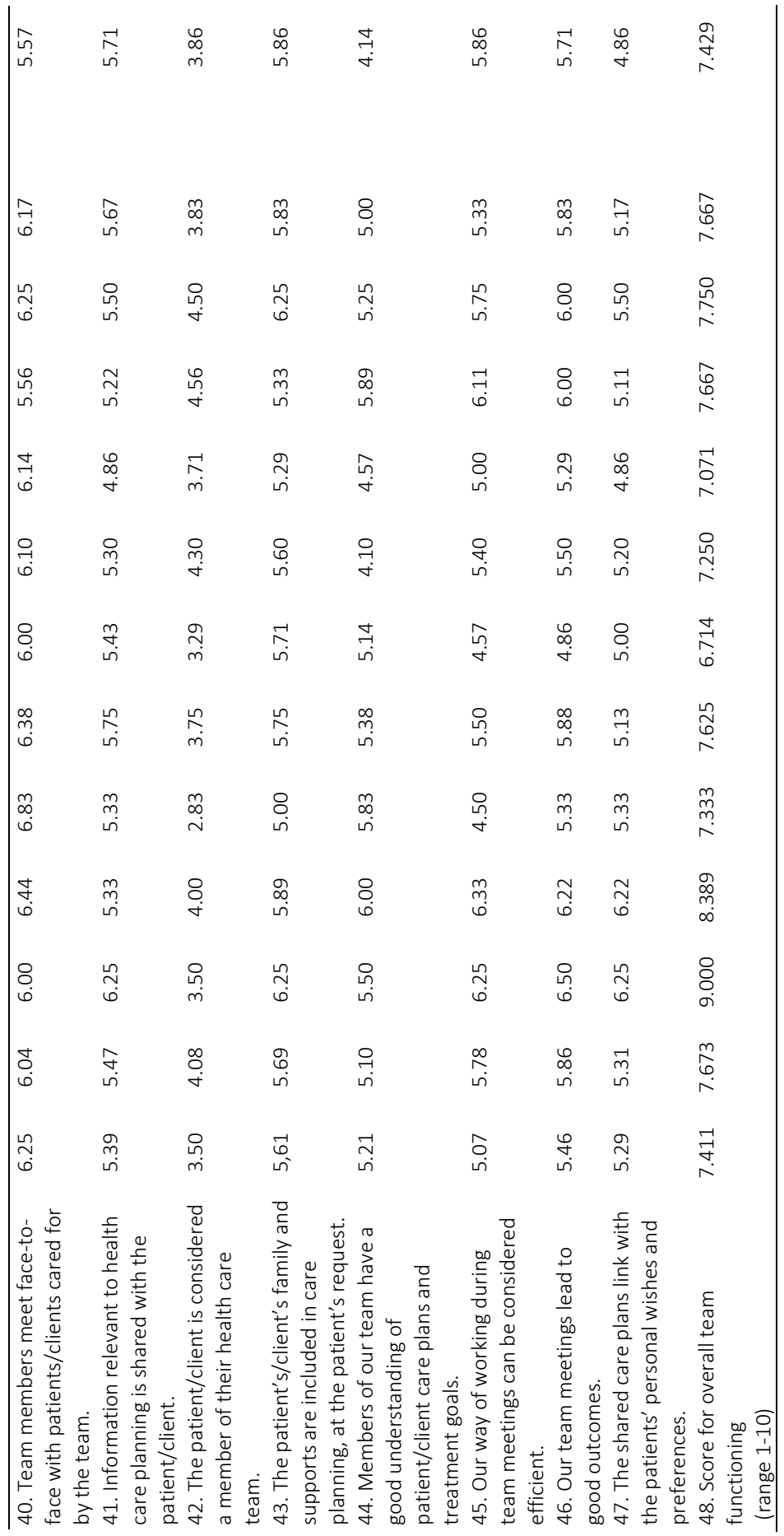




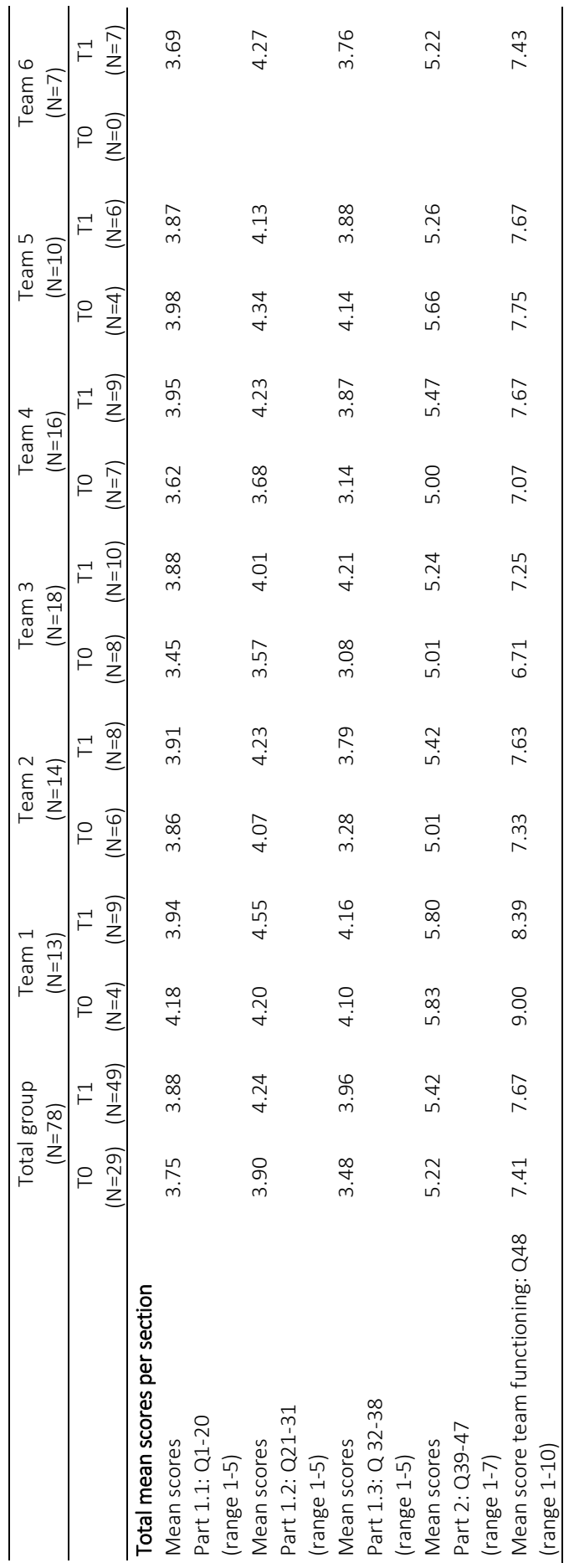




\section{Chapter}

Sustainable interprofessional teamwork needs a teamfriendly healthcare system: Experiences from a collaborative Dutch programme

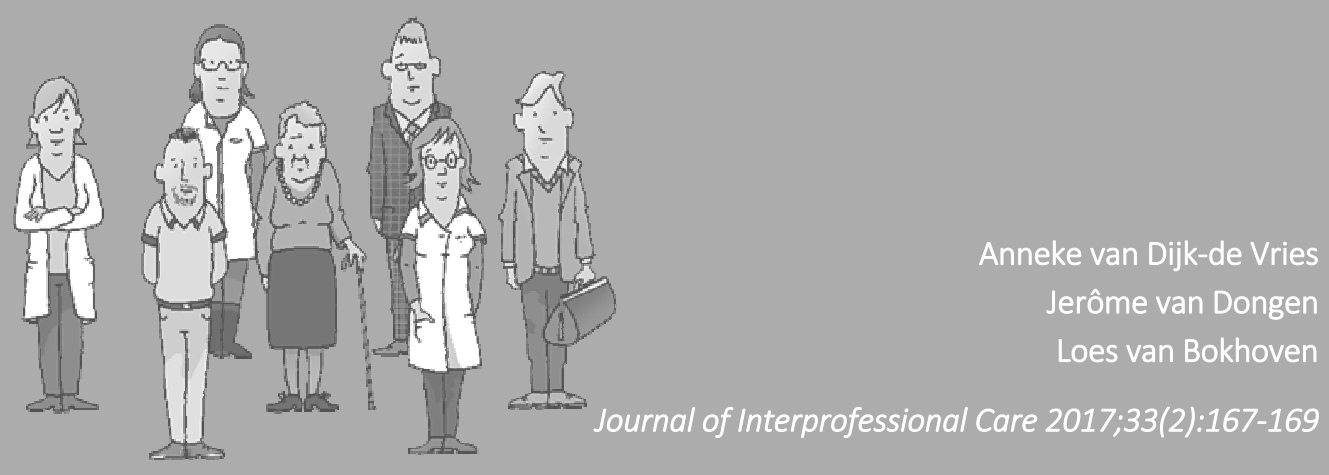




\section{Abstract}

The significance of effective interprofessional teamwork to improve the quality of care has been widely recognised. Effective interprofessional teamwork calls on good collaboration between professionals and patients, coordination between professionals, and the development of teamwork over time. Effective development of teams also requires support from the wider organisational context. In a Dutch village, healthcare professionals work closely together, and mutual consultations as well as interprofessional meetings take place on a regular basis. The network was created as a precondition for sustainable interprofessional teamwork in elderly care. However, several external barriers were experienced regarding the supportive structure and cooperative attitude of the healthcare insurer and municipality. The aim of the article is to examine these experience-based issues regarding internal organisation, perspective, and definition of effective teamwork. Complicating factors refer to finding the right key figures, and the different perspectives on team development and team effectiveness. Our conclusion is that the organisation of healthcare insurance companies needs to implement fundamental changes to facilitate an interprofessional care approach. Furthermore, municipalities should work on their vision of the needs and benefits of a fruitful collaboration with interprofessional healthcare teams. The challenge for healthcare teams is to learn to speak the language of external partners. To support the development of interprofessional teams, external parties need to recognise and trust in a shared aim to provide quality of care in an efficient and effective way. 


\section{Introduction}

Demographic trends refer to a proportionate rise of the ageing population with larger numbers of patients with chronic, complex needs. ${ }^{1,2}$ Most of their care is delivered in the primary care setting by health professionals from a range of disciplines. The goals of chronic care management are generally not to cure, but to enhance patients' daily functioning, and quality of life. This calls for effective interactions between patients and healthcare professionals, but also for professionals who work together in an integrated and interdependent manner. Four layers of interprofessional collaborative practice can be distinguished (see Figure 9.1). Layer 1 refers to the interactions between a patient and healthcare professional. In layer 2, professionals from various disciplines communicate and coordinate on the care around one patient. This takes place in informal ways and by means of formal structures like planned interprofessional team meetings, in which interprofessional care plans are formulated. Research suggests that interprofessional teamwork contributes to staff satisfaction, quality of care and control of costs through a reduction of duplication and gaps in service provision. ${ }^{3}$ Several facilitators and barriers regarding team structures and team processes have been identified. ${ }^{3,4}$ Besides, interventions are developed to foster interprofessional teamwork. ${ }^{5}$ However, as interprofessional teams are not fixed entities and group dynamics and team composition develop over time, it is not clear whether these interventions can be implemented in a sustainable way. Research has shown that a shared vision and mission, participation of team members, an emphasis on quality, and support for innovation and change are related to overall team effectiveness and quality of team working. ${ }^{3,4}$ Layer 3 of interprofessional collaborative practice refers to this longitudinal process of team development, which requires a deeper level of collaboration than in layer 2.

As studies show the need for supportive systems to maintain the collaborative practice of interprofessional teams, ${ }^{6}$ the interaction between a team and external partners is considered to be a fourth layer of collaborative practice.

In 2013, a funding programme of the Dutch government provided support to set up a sustainable interprofessional network in the care for frail elderly in Elsloo, a village with 8,000 inhabitants in the Netherlands. See text box 1 for more information about this network. The funding programme was aimed to learn about facilitators of and barriers to the sustainable implementation of interprofessional teamwork in the primary care setting. A systematic evaluation of the project provided insight into factors related to all four levels of collaboration. The aim of this article is to use the experiences to examine 
the fourth level, in order to illustrate the need for a team-friendly healthcare system that supports sustainable interprofessional teamwork in daily practice.

Text box $9.1 \quad$ The interprofessional network in the Dutch village Elsloo

Local setting

Elsloo is a village with 8,000 inhabitants, located within a larger municipality, in the south of the Netherlands. In the village, the number of elderly people, aged 75 or more, are supposed to double in the next 20 years up to approximately 1,300 people (18\%). In 2013, a new health center was built that included primary care facilities as well as a nursing home and care apartments. This was a momentum to realise a mutual approach in the care for the older people in the community. The professionals got funding from a programme of the Dutch government aimed at sustainable organisation of multidisciplinary care in the community. The project included:

- Development of an integrated care process, including structural team meetings

- Arrangement of an administratively, legally and financially sustainable network organisation

- Regular input from patients' expertise

- Providing opportunities for other professionals in prevention, care, and welfare, working in the community to join the network

The organisational structure was aimed at the effectiveness and sustainability of the team. To foster the interprofessional bond, the professionals in the network not only meet each other to discuss patients' care plans, but also collaborate in projects to improve their joint quality of care. Furthermore, they meet each other during informal network meetings.

Dutch context

Since 2015, municipalities have been responsible for all social support and assistance, while health insurance companies have become responsible for the purchasing policy of all medical and paramedical care and nursing care. The healthcare system reform is aimed at keeping people as self-supported as possible (Kroneman, 2015). ${ }^{7}$

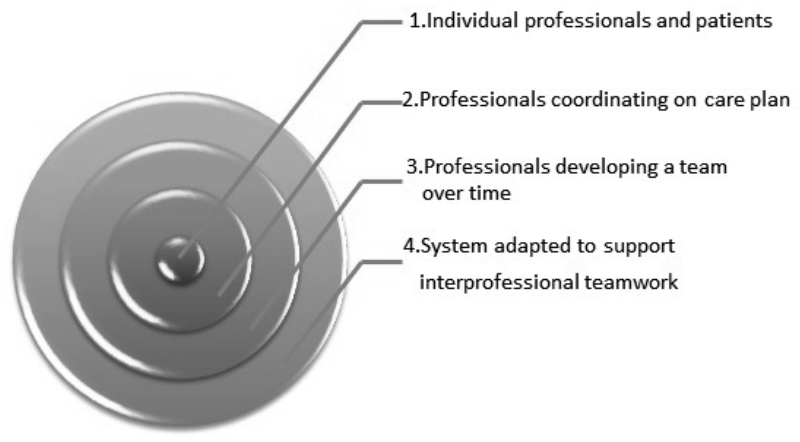

Figure 9.1 Layers of interprofessional collaboration. 


\section{Process}

Our experience-based examination of the external challenges in setting up sustainable interprofessional collaboration focused on fundamental differences in internal organisation, perspective, and definition of effective teamwork, between the healthcare team, healthcare insurer and municipality. The examination is based on a business case analysis of the network, three conversations with the dominant health insurance company in the region, several interaction moments between network representatives and civil servants from the municipality, and on our evaluation report of the network development project.

\section{Outcomes}

First, we found that it was complex to find the right key persons within the healthcare insurance company and municipality. Dutch healthcare insurers are internally organised according to the type of care (i.e. medical care, paramedical care, and nursing home care). Moreover, persons that are responsible for innovation are not in charge of contracting care. These organisational structures appeared to be not supportive for interprofessional care arrangements that go beyond traditional boundaries. For example, reimbursement of team meetings for family physicians is provided, whilst paramedics are expected to attend these regular meetings without a financial reward. For each discipline, a different contact person took the decision about arrangements. Interprofessional care arrangements were not available. Within the municipality, it was also hard to find the right persons, especially during times of elections and health reforms. Personnel changes, interim workers and differences in contact persons' power of decision resulted in collaboration on an ad-hoc basis without long-term planning. Plans are made in the first year of an alderman's four-year term, and policy effects must be visible in the fourth year. In this political domain, the development of sustainable juridical procedures to collaborate with health professionals in the elderly care is not a priority.

On the other hand, this also requires new competencies from health professionals, to be able to speak the language of the external partners. It requires time to learn the specific communication skills. We learnt that being present at informal meetings and to get informed about the political agenda are crucial in learning these skills.

A next complicating factor is the preferred level of stimulating improvement of care. With regard to innovation, the primary focus of our healthcare team is on the perceived needs in the local communities. Health care insurers and municipalities are more likely 
to benefit from innovation at a broader scale. For example, we suggested that minor surgical procedures, for which patients in the nursing home had to be referred to the hospital, could be done by the family physicians nearby. However, the financial structure of the health care insurer has not been arranged for this kind of local initiatives. At the side of the municipality, we noticed fear to show favour to an individual health care team over other professionals working within the municipality. Collaboration with health care teams may also conflict with their perceived need to remain in charge regarding procedures and decisions.

The third challenge in the collaborative practice between interprofessional health care teams and external partners referred to the perspective on the added value of effective teamwork. From the perspective of healthcare professionals, interprofessional teamwork has to contribute to the quality of care in an efficient and satisfying way. The dominant focus of our health care insurer is on cost minimisation. Our health care team was asked for indicators that provide insight into the cost-effectiveness of our interprofessional team. Together with external experts, we searched for indicators like a decrease of emergency admissions to the hospital. We concluded that team costeffectiveness cannot be measured by simple indicators. The heterogeneous patient population, the small scale and the need for longitudinal data were barriers in getting insight into the cost-effectiveness of our interprofessional network. With regard to the municipalities, their vision on effective teamwork in the health and welfare domain was still under development. Both their expertise and data on patients' needs for collaborative care in the medical and social domains appeared to be lacking. Partly due to healthcare reforms, the energy of the municipalities has been spent on internal procedures and decisions.

\section{Discussion}

Although a large body of literature exists about determinants of an effective team, most of the issues that were experienced in organising sustainable interprofessional collaborative practice had not been related to the development of the team itself, ${ }^{8}$ but to the connection between a team and its external environment. Chances for the development and innovation of the interprofessional team were not optimally enforced by the health care insurer and municipality, both key players in the Dutch healthcare system. This article was aimed to provide an experience-based examination of these issues.

The experiences underline that leaders of interprofessional healthcare teams not only have to make a range of decisions and negotiations within the team, but also encounter 
economic, social and political issues in building a collaborative relationship with external partners. ${ }^{9}$ They highlighted that health professionals have to learn to communicate with external partners in an effective way.

Furthermore, the development of interprofessional teams over time requires long-term planning, interprofessional care arrangements and innovation. Teams get stronger when they get the opportunities for innovative initiatives. ${ }^{6}$ However, the priorities of external partners lay in broad, regional projects rather than in local initiatives. Moreover, team effectiveness outcomes cannot easily be measured. All these factors are barriers to the sustainability of interprofessional team development processes.

\section{Conclusion}

Interprofessional teamwork in care for patients with complex needs is not only a challenge for healthcare professionals, striving for effective coordination and communication. The development of sustainable interprofessional teams also requires a team-friendly healthcare system. To make steps forward in realising sustainable interprofessional care, fundamental changes are needed in the internal organisation of healthcare insurance companies and municipalities. Insurance companies should remove interprofessional barriers inside their organisations, to reflect their vision on integral care. Also, promoting interprofessional teamwork requires support for initiatives at the community level. Municipalities need to develop a vision about the needs of inhabitants and the benefits of collaboration with the healthcare professionals in their area, and to translate their vision into policy. Members of interprofessional healthcare teams need to learn to speak the language of the external partners more. It seems useless to keep searching for simple indicators of effective team care. In our opinion, it is a shared challenge to define outcome measures that are useful for all stakeholders to evaluate the needs and results regarding effective teamwork. The implication is that health care teams, insurers and municipalities together need to make long-term plans that focus on local communities. It calls for integrated care arrangements that are based on needs of the people in that specific area. This care should be evaluated with a focus on the extent of care that has been realised rather than on measuring effectiveness indicators. 


\section{References}

1. Robustill S, Corsini V, Marcu M, Vasileva K, Marchetti E. EU Employment and Social Situation, Quarterly Review. Special Supplement on Demographic Trends. Luxembourg: : European Union. 2013.

2. Van Campen, C. Frail older persons in the Netherlands. The Hague: The Netherlands Institute for Social Research (SCP). 2011.

3. Xyrichis A, Lowton K. (2008). What fosters or prevents interprofessional teamworking in primary and community care? A literature review. Int J Nurs Stud 2008;45(1):140-153.

4. Poulton $\mathrm{BC}$, West MA. The determinants of effectiveness in primary health care teams. J Interprof Care 1999;13(1):7-18.

5 Korner M, Butof S, Muller C, Zimmermann L, Becker S, Bengel J. Interprofessional teamwork and team interventions in chronic care: A systematic review. J Interprof Care 2016;30:15-28.

6. Cashman S, Reidy P, Cody K, Lemay C. Developing and measuring progress toward collaborative, integrated, interdisciplinary health care teams. J Interprof Care 2004;18(2):183-196.

7. Kroneman M. 2015. Health Systems in Transition (HiT) profile of Netherlands. The Health Systems and Policy Monitor. Retrieved 30/01/2016, from http://www.hspm.org/countries/netherlands25062012/ livinghit.aspx?Section=6.8\%20Long\%20term\%20care\&Type=Section

8. San Martin-Rodriguez L, Beaulieu MD, D'Amour D, Ferrada-Videla M. The determinants of successful collaboration: a review of theoretical and empirical studies. J Interprof Care 2005;19 Suppl 1: 132-147.

9. Reeves S, Macmillan K, Van Soeren M. Leadership of interprofessional health and social care teams: a socio-historical analysis. J Nurs Manag 2010;18(3):258-264. 


\section{Chapter 10}

General discussion

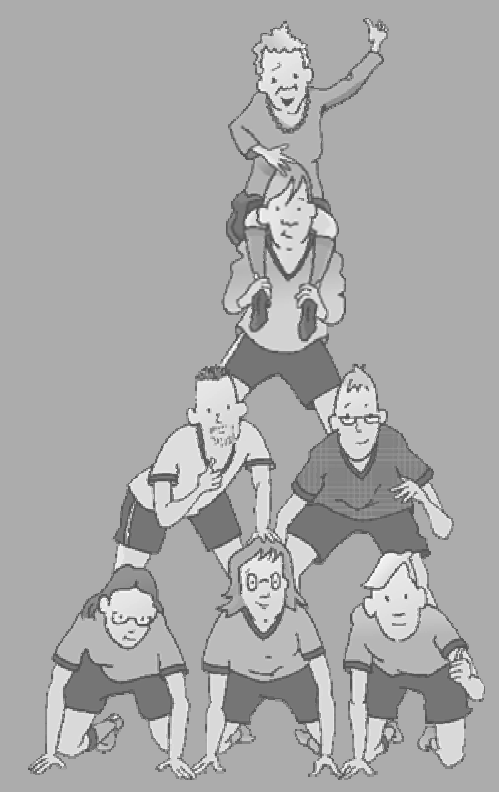





\section{Introduction}

Primary care professionals are confronted with the increasing complexity of patients' care demands, including both biomedical and psychosocial aspects. Interprofessional collaboration is needed to coordinate care and meet the needs of people with complex care demands. It involves periodic team meetings including professionals from a diversity of disciplines with the aim of sharing knowledge and eventually developing interprofessional patient-centred care plans focusing on patients' goals. However, conducting efficient and patient-centred interprofessional team meetings seems to be challenging. The aim of the research project described in this thesis was therefore to explore key elements of a programme to support professionals in improving their interprofessional collaboration for the development of patient-centred care plans in primary care. We started by exploring the field of interprofessional collaboration by conducting an in-depth problem analysis based on existing literature and current practice (phase 1). The findings of this explorative phase were used to define objectives for improvement, prioritise them, and use them as input for developing a programme to improve current practice (phase 2). The programme was developed using an action research approach, characterised by co-creation with all stakeholders. Lastly, the programme's suitability for use in daily practice and the added value it offered were evaluated (phase 3). In these three phases the following research questions were addressed:

Phase 1: Exploring current practice

1. What is known in the scientific literature about developing interprofessional shared care plans?

2. What factors influence the development of interprofessional shared care plans?

3. How are interprofessional team meetings currently conducted in Dutch primary care, and what are the participants' experiences?

4. How do patients and professionals experience patient participation in interprofessional team meetings?

5. What is the patients' perspective on interprofessional team meetings in primary care?

Phase 2: Developing a programme to improve current practice

6. What are the key elements of a programme to improve interprofessional team meetings in primary care? 
Phase 3: Evaluation of the programme

7. What are the critical factors determining the suitability and potential impact of a programme to improve the functioning of interprofessional team meetings?

8. What are the contextual facilitators of and barriers to a sustainable implementation of interprofessional teamwork in a primary care setting?

The following sections describe the main findings for each phase, followed by some general methodological considerations about this research project. The main findings are discussed, as well as the lessons learnt. Finally, a summary of recommendations for practice and research is provided.

\section{Main findings}

\section{Phase 1: Exploring current practice}

Current practice was explored by means of a scoping review and various qualitative studies (chapters 2-6). Findings showed that the development of patient-centred care plans can be regarded as the result of an underlying process of interprofessional collaboration. This process is influenced by many interrelated factors that can be divided into five key categories: (1) patient-related, (2) professional-related, (3) interpersonal, (4) organisational, and (5) external factors. Consequently, improving the interprofessional collaboration for care plan development calls for an integrated approach embracing all categories of factors. In practice, interprofessional collaboration often happens through periodic team meetings, including professionals from various disciplines. Patients only exceptionally take part. Observations of team meetings showed variation among meetings in terms of composition, form, content, and procedures. Most took place in a pleasant atmosphere, but could be considered more or less chaotic, unstructured, and lacked a team coordinator or leader. Remarkably, team members appeared to know each other only superficially. Meetings were mostly conducted from a professional rather than a patient perspective. Only occasionally were patient goals and preferences introduced. Nevertheless, during the interviews, most participants expressed favourable opinions and experiences regarding the efficiency and patientcentredness of their team meetings. In the focus group with patients, they emphasised the right of patients or their representatives to take part or be represented in interprofessional team meetings if they so desire. They expect health care professionals to put the patient at the centre and to follow a structured, holistic approach to address their needs. Apparently, meetings could benefit from improvements in structure and 
organisation, patient-centredness, and leadership by chairpersons. Given the discrepancy between our observations and interviews, it appeared useful to improve team members' awareness of the actual team functioning. A recurring topic in all studies presented in chapters 2-6 was the important role of the chairperson as leader of the team in securing the patient perspective, organising and coordinating interprofessional collaboration, and guiding team development.

\section{Phase 2: Developing a programme to improve current practice}

Based on the knowledge collected in phase one of this thesis, a list of topics for improvement was compiled. This list was prioritised by a development team during a consensus meeting, resulting in five main objectives for improvement, as presented in Figure 10.1.
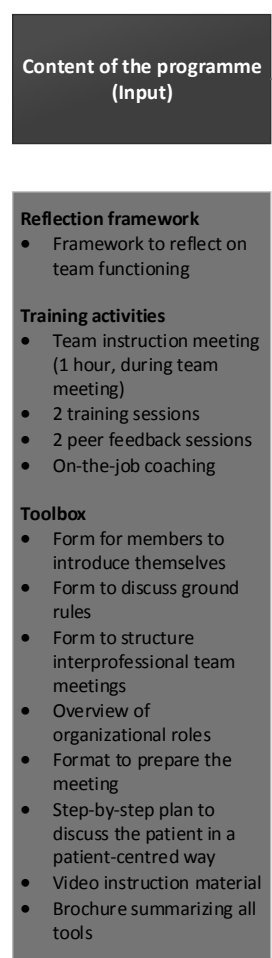

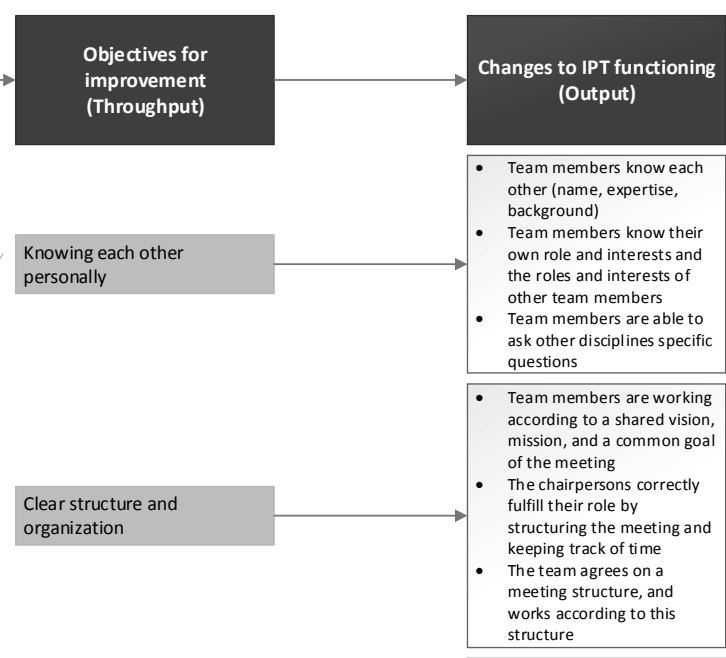
guiding team guiding team by paying attention to: 
The objectives for improvement were used as input for the development of the draft programme, which was used and evaluated iteratively by three primary care teams, in an action research approach. The findings of this developmental phase emphasise the essential role of the team's chairperson, who, in addition to technically structuring meetings, should act as a change agent guiding team development. The backbone of the final programme is a framework that can be used by teams to reflect on their team functioning. We also developed various training activities, including explanation of theory, role-play, peer feedback and on-the-job coaching. These training activities, intended for the chairperson and a co-chair, focused on organising and structuring meetings, guiding team development, and enhancing patient-centredness. A toolbox including various supporting tools was developed, to help achieve the objectives for improvement.

\section{Phase 3: Evaluation of the programme}

The process evaluation showed that on the whole, the programme was appreciated by participants. The greatest progress after participation was perceived in the structure and organisation of the meetings. Participating chairpersons perceived increased awareness of patient-centredness and team processes. They valued the training activities, particularly the peer feedback and on-the-job coaching. Findings regarding the potential impact of the programme showed a small increase between pretest and posttest for all domains tested (team climate, patient-centredness, and efficiency). The programme can thus be considered a suitable approach for improving team functioning. However, enhancing patient-centredness requires long-term behavioural change and additional on-the-job coaching and training. Moreover, the programme should be tailored to the specific team context and learning objectives. Lastly, our examination of external challenges, presented in chapter 9, showed that achieving long-term and sustainable interprofessional teamwork requires a teamwork-friendly healthcare system. Teams require support from the wider organisational context and should also learn to speak the language of external partners. Furthermore, healthcare insurance companies need to implement fundamental organisational changes to facilitate an interprofessional care approach. 


\section{Methodological considerations}

This section addresses the general methodological issues, relating to the qualitative design, participating teams, trustworthiness, and measuring the quality of interprofessional collaboration.

\section{A qualitative design}

A combination of a scoping review and several (mainly) qualitative studies (using observations, interviews and focus groups) was used to answer the research questions used to explore the current practice, and the development and evaluation of our programme. A qualitative approach was chosen since we intended to achieve an indepth understanding of 'the way' in which interprofessional team meetings in primary care are actually conducted, as well as both patients' and health care professionals' opinions. Qualitative designs generally generate rich data and can lead to a thorough understanding of different perspectives. ${ }^{1}$ The methodology we developed was based on the basic assumptions of naturalistic inquiry. In this approach, phenomena are studied in their natural context. ${ }^{2}$ Observations and semi-structured interviews were used to explore and produce a naturalistic description of current practice, and to develop, test, and evaluate the programme. For practical reasons, the individual interviews in phases 1 and 2 of this thesis were rather short (15 minutes), which might have caused us to miss some in-depth findings. However, we included many perspectives by interviewing a range of professionals from different professional backgrounds. For practical reasons, a group of researchers attended the meetings, in order to be able to interview as many team members immediately afterwards. The team meetings we observed would have been more natural without the presence of researchers, e.g. using only video recordings. Nevertheless, by physically attending and observing the meeting, the researchers were able to ask more specific questions during the interviews afterwards. Moreover, the approach combining observations with interviews provided us with the opportunity to detect blind spots that team members were not aware of. By observing teams in different practices, and interviewing professionals from various disciplines and different practices about different patients, we were able to create a broad view on the functioning of the interprofessional team meetings. Combining data from literature, observations, interviews, and focus groups, known as methodological triangulation, helped us explore additional perspectives and enhanced the credibility of the findings.

We used an action research design to develop the improvement programme, as this approach is known to be useful for improving conditions and practices in various health care environments. ${ }^{3}$ The rationale for using action research was that we wanted to 
develop a programme in an iterative process, by learning through action and reflection, and ensuring the involvement of intended users. ${ }^{3,4}$ In action research, it is usually the professionals who initiate the development process and the researchers who support it ${ }^{5}$. Ideally, the health care professionals should take responsibility for achieving change, and regard themselves as researchers. ${ }^{6}$ Both researchers and professionals should interact and communicate with each other frequently, share ideas, and together refine current practice. In our study, however, the researchers took up a more active and dominant role in both development and research, compared to the participating professionals. The researchers adopted a dominant role because problem awareness among professionals was initially limited, and limited time was available for the development of the programme. Therefore, one could question whether the moderate degree of co-creation in our approach fits the principles of sound action research. Nonetheless, involvement of the participants was achieved by leaving the actual decisions on both content and form of the programme to the three participating primary care teams, in collaboration with a development team (including health care professionals, researchers, and developers), which made the findings more likely to be implemented in practice. ${ }^{7}$

Given the complexity of the primary care environment, the diversity of stakeholders involved, the multitude of influencing factors, and the lack of available evidence, a thorough, in-depth exploration was required. Due to our predominantly qualitative approach to needs assessment and development of the programme, which took more time than anticipated, we were not able to conduct any experimental studies. As a consequence, we were not able to present findings on effects. Instead, we decided to conduct a thorough process evaluation, which provided us with more information about the context in which the programme had been implemented. Moreover, by conducting a process evaluation, we gained insight into the actual experiences of participants regarding the programme's suitability, usefulness, and added value, enabling us to improve the programme further. The Council for Public Health and Society (Raad voor de Volksgezondheid in Dutch) also recommends adopting context-based approaches in which specific contexts are explored before new practices are implemented. ${ }^{8}$ Others have therefore recommended conducting a thorough process evaluation when developing complex interventions, before investing in an effectiveness study. ${ }^{9}$ Although it is also important to investigate the impact of interventions to improve the interprofessional collaborative practice, only a few studies are available offering high quality evidence on interventions to improve team effectiveness. ${ }^{10}$ Moreover, according to Tsakitzidis (2016), it seems important that interprofessional collaboration is clearly described and implemented over a long enough period, until effects on patient-related outcomes become measurable. ${ }^{11}$ Hence, we intend to conduct an effect study in a later phase. 


\section{Participating teams}

The studies primarily concentrated on the Dutch primary care setting. Observations and interviews took place in various health care centres and primary care practices. Participating primary care teams were recruited and selected by means of purposive and pragmatic sampling, using the researchers' network. We studied teams that had already been conducting interprofessional team meetings. Since the teams participated voluntarily, it is possible that we may have only selected early adopters and better functioning teams, which may not be representative of average primary care teams. As a consequence, we may have missed the perspectives and experiences of mainstream teams, which could be a potential source of bias. Inexperienced teams are probably confronted with other obstacles than experienced teams, and experiences relating to the application and suitability of tools and materials could also be different. However, the participating teams were very diverse in terms of their phase of development, composition, and approach, and the findings showed that for most teams there was much room for improvement. To enhance the transferability of our results, purposive sampling was used to include the perspectives of various disciplines, with the aim of interviewing a representative sample of the various disciplines in each team. Nevertheless, our findings cannot be simply transferred to teams in other settings outside primary care, for instance an oncology hospital setting. In such a setting, complex diagnostic and therapeutic discussions take place in permanent teams with complex therapeutic protocols and a high level of technology.

\section{Trustworthiness}

By conducting observations and interviews and using the naturalistic inquiry approach, we have tried to remain close to what actually happens in practice, thereby minimising the risk of incomplete, or unreliable answers. Nonetheless, we cannot ignore the risk of participants' comments being based on theory or social desirability, instead of personal experiences or beliefs. During the focus group with experts, we encountered participants who often referred to theory instead of their personal experiences. ${ }^{12}$ However, we used methodological triangulation and collected data from professionals and patients, to try and overcome the risk of only including theory-based findings. ${ }^{13}$ Other actions that were taken to enhance the trustworthiness of our findings are: double coding of data, using field notes and written comments, and conducting member checks.

A possible source of bias that may have occurred during both our action research and the process evaluation could be interference by the researcher who provided the training activities. Although, the trainer adopted a leading role during training activities, the researcher might have introduced his own expertise to achieve the desired results. 
The researcher fulfilled multiple roles: researcher, developer, and trainer/coach. These various roles might be problematic, as on the one hand the researcher must critically evaluate and study the programme, while on the other hand also having an important share in developing and providing the programme. However, we tried to sensitise ourselves to this by periodic self-reflection on potential researcher biases and roleblurring by the researcher and in the research team. We feel that we have, to the best of our knowledge and intentions, minimised optimistic bias. In addition, by being present and involved in the various training activities, the researcher was able to collect additional information on participants' experiences regarding suitability.

\section{Measuring the quality of interprofessional collaboration in primary care teams}

No validated measurement instrument was available that met our requirements and covered aspects of all five change objectives (leadership, knowing each other, structure and organisation, patient-centredness, and reflexivity). However, elements of two validated and reliable instruments seemed useful. The domains of the Dutch Team Climate Inventory $(\mathrm{TCl}),{ }^{14}$ measuring team climate as an important characteristic of successful teams, ${ }^{15,16}$ were combined with domains of the Collaborative Practice Assessment Tool (CPAT). ${ }^{17}$ The latter assesses levels of collaborative practice and includes domains relating to both patient-centredness and efficiency. We therefore compiled a questionnaire including different domains from the $\mathrm{TCl}$ and the CPAT to measure the functioning of interprofessional primary care teams, and to examine the programme's potential impact on team climate and patient-centredness during the process evaluation. Without access to anything better, this seemed the best option at the time of the study.

The field of science which is concerned with measuring the quality of interprofessional team-based primary care appears to be still in its early stages. ${ }^{18}$ Most existing questionnaires primarily focus on measuring the functioning of teams consisting of members who collaborate frequently. However, as Vyt (2017) mentions, measuring the quality of such a team is different from measuring that of a group or network consisting of participants who work together infrequently. ${ }^{19}$ Currently, a range of instruments are being developed to measure team functioning, focusing on different aspects. Vyt developed a tool to monitor the quality of ad hoc meetings which enables researchers to identify aspects that could be improved, ${ }^{19}$ and the Windesheim University of Applied Sciences has developed a similar (digital) instrument, named the collaboration thermometer. ${ }^{20}$ Such instruments offer promising opportunities for researchers and 
practitioners to assess team performance, but additional work is needed to adapt and validate these instruments for primary care settings.

\section{Lessons learnt}

This thesis provides new insights into the interprofessional collaborative practice for the development of patient-centred care plans in primary care, especially as regards conducting interprofessional team meetings. What major lessons and consequently recommendations for practice and research can be drawn from the findings reported on in this thesis? And how can we reach a situation in which professionals from a diversity of disciplines and the patient system work together to deal with the complexity of chronic care? The next paragraphs reflect on differences between primary care teams, on team reflexivity, and on the challenging task of leadership, and then highlight the potential of interprofessional learning during team meetings. They then go on to discuss the difficulty of adopting a patient-centred approach, and professionals' considerations in balancing between professional and patient perspectives. Lastly, the complexity of decision making in current primary care is highlighted, and a plea is made for implementing the programme in a flexible way, tailored to each team's specific context and development needs.

\section{Should we speak of interprofessional primary care teams or networks?}

Findings from this project showed that interprofessional primary care teams differ in their purpose, processes, composition and formation, and phase of development. Some teams share a long-standing history, consist of a permanent core group, and can be considered teams. A team is defined as a small number of people with complementary skills who are committed to a common purpose, set of performance goals, and approach, for which they hold themselves mutually accountable. ${ }^{21}$ In teams, the members are interdependently committed to each other in order to achieve a shared goal. Experts have stated a preference for smaller teams comprising five or six members, ${ }^{22}$ offering enough space to express conflicting views. ${ }^{23}$

Other primary care teams rather resemble networks. Care networks can be regarded as loose forms of organisation, broader in scope than teams, and can be defined as frequently recurring ad hoc interactions between professionals from various organisations. ${ }^{24,25}$ One of the characteristics of a network is that people join and leave continuously. ${ }^{24}$ Moreover, networks often spontaneously develop in complex situations where coordination is lacking. Since the members of networks serve different 
organisations, the individuals who take part often have to refer back to higher management within their own organisation before they can commit themselves to the network's shared decisions and actions, which may result in an increased risk of collaborative inertia at network level. ${ }^{26}$

An average primary care team comprises 10 members of various disciplines, and can in most cases be considered dynamic, since its composition changes continuously. Teams differ and appear to be positioned on a continuum from teams whose composition remains unchanged for longer periods of time to looser forms of networks. Lingard (2017) describes these dynamic teams as distributed teams composed of members from various organisations who may not know each other and have restricted opportunities to develop shared values, compared to permanent teams. ${ }^{27}$

The various studies reported on in this thesis included several dynamic teams, and it was especially the continuously varying composition which hampered the implementation of our programme. Some teams were not able to develop because they remained in an orientation phase in which they did not move beyond getting to knowing each other and discussing procedures. Therefore, as a first step it is worthwhile to explore the type of collaboration or partnership in teams before implementing an improvement programme, after which interventions and improvement actions suited to the specific type of collaboration can be developed and implemented.

Nonetheless, regardless of the type of collaboration, our findings showed that professionals, but also participating patients, seem to appreciate structured and wellprepared meetings. ${ }^{12,28-30}$ Getting to know each other personally, exploring each other's backgrounds and competences, and shared commitment to team objectives, division of roles, procedures, and interaction, ${ }^{31}$ can be considered the first necessary steps towards further development. ${ }^{12,30-34}$

\section{Team reflexivity}

Since every primary care team has its specific features, reflexivity - the extent to which teams reflect upon their functioning - can be considered the basis for improvement in all teams. ${ }^{35,36}$ Team reflexivity has been described by West (1996) as 'the extent to which group members overtly reflect upon the group's objectives, strategies, and processes and adapt them to current or anticipated circumstances' ${ }^{37}$ Reflexivity is positively associated with team effectiveness. ${ }^{37,38}$ Moreover, especially for teams in a demanding environment, like primary care teams, team reflexivity is known to be an important predictor of innovation. ${ }^{39,40}$ Findings in this thesis showed that team reflexivity is not embedded in the current practice of most teams. Primary care teams are primarily content-oriented and are apparently not used to reflecting on the process of working 
together and on the underlying group processes. Some participants said they found it difficult, while others did not perceive any added value of shared reflection. The tendency and ability to reflect appears to vary across individuals. ${ }^{41}$ The continuously changing team composition also complicates reflection. ${ }^{42}$

A literature review on reflection and reflexive practice found that the following factors are positively associated with successful reflexive practice: a facilitating context, a safe atmosphere, peer support, and time to reflect. ${ }^{41}$ In addition, the behaviour of the leader seems to have an encouraging or inhibiting effect on reflection. ${ }^{41}$ It is known that a leader who inspires and motivates other team members regarding their visions, goals and action plans, has a positive effect on team reflexivity. ${ }^{43,44} \mathrm{~A}$ possible strategy to enhance ongoing reflexivity for continuous team development is to initiate it through regularly scheduled reflection moments. ${ }^{34}$ Furthermore, creating a safe atmosphere, and a climate of learning in which team members can reflect openly and critically, fosters reflection. ${ }^{40,45}$ It might be helpful especially for novice teams if reflection is mediated by an external facilitator who is able to detect blind spots, offer feedback, and comment on problem points in an unprejudiced manner. ${ }^{46-48}$ Such an external facilitator should preferably show the benefits of reflection and eventually teach the team how to reflect independently. The results of a self-assessment tool, like Windesheim's collaboration thermometer, could also function as eye-opener and provide valuable input to encourage team reflexivity. ${ }^{20}$

\section{Appropriate leadership}

Throughout all the studies included in this thesis, the leadership role turned out to be important for the functioning of interprofessional team meetings. Since interprofessional primary care teams are rather dynamic groups, their degree of selforganisation is often limited. Within this dynamic type of collaboration, the leader can be considered the constant factor. Hence, the quality of the meetings may depend to a large extent on the preparation and coordinating skills of the person leading the team and organising the meetings. Leadership is defined as any conscious act of influence on the behaviour of others, and comprises a combination of goal-oriented and interpersonal skills. ${ }^{49}$ Literature on interprofessional team meetings also shows the importance of having an effective leader. ${ }^{50-54}$ Furthermore, leader coaching has a positive effect on the team members' satisfaction with the team, and contributes to a positive team climate. ${ }^{55}$

The chairpersons in our programme were positioned as key figures, who were intended to operate as role models and change agents, enabling the team to improve its own functioning. For each team, a chairperson and co-chair were trained, coached, and 
facilitated to organise and structure meetings, and enhance patient-centredness by showing effective leadership, initiating reflection, and using supporting tools. Chairpersons were trained to adapt their style of leadership to the group's current circumstances and phase of development, known as situational leadership. ${ }^{56}$ Given the dynamic composition and large size of most teams, a more directive style of leadership appeared to be preferable. Directive leadership is characterised by a leader who initiates ideas and tasks, sets out a clear course, and is able to make decisions and empower the other team members to collaborate. ${ }^{52,57}$ Our process evaluation showed that most chairpersons were able to improve both the structure and organisation of the interprofessional primary care team meetings. ${ }^{42}$ Most progress was made on efficiency, by improved preparation, agenda setting, time use, and increased focus. Less progress was observed regarding patient-centredness, which requires behavioural changes of team members, and regarding team reflexivity.

Clearly, being able to effectively chair meetings and guide a continuously changing team, often comprising a large group of members, is a demanding task for the chairperson. ${ }^{22}$ Therefore, it is important to carefully select the appropriate person for this challenging job. Within the programme, teams were asked to delegate two chairpersons. The actual decision in selecting the chairpersons was made by the teams themselves. No formal selection criteria were applied. One study suggested the leader and chairperson should be selected based on seniority of grade, ${ }^{58}$ while another proposed to choose the leader, not on the basis of professional affiliation, but based on specific competences and skills needed to guide group processes. ${ }^{22}$ In fact, a possible combination of chairperson and co-chair could be an interplay between seniority of grade and specific competences, for example, a family physician (highest in decision making hierarchy) and a practice nurse.

In our studies, we may have relied too much on the teams' chairpersons. The duration of the programme and training activities may have been too limited in order to prepare chairpersons for this demanding task. Follow-up activities like additional on-the-job (team) coaching and peer feedback sessions could be helpful. In addition to training the teams' chairpersons, the other team members also expressed a need for training in collaborative skills, since most professionals have not been trained to work in interprofessional teams. ${ }^{42,59}$ Expanding the programme with team coaching activities presented by an external coach may offer opportunities to create a 'fresh' view on team functioning, subsequently resulting in a wider range of ideas to support team development. ${ }^{60,61}$ It is particularly in the case of implementing complex innovations that guidance by an expert is perceived to be helpful in making meaningful changes. ${ }^{61}$ However, to obtain an efficient and sustainable situation, these coaching activities should in the long term be transferred to the chairperson, who as an insider knows most about the teams' specific context (history, organisation, systems, members). Currently, 
specific competences required for leadership and coaching activities have been incorporated in various competency frameworks for medical education, such as CanMEDS. ${ }^{62}$ This may support future health care professionals and prepare them for this challenging task.

\section{The potential of interprofessional learning for undergraduates during team meetings}

According to the competence model by Hugh Barr (1998), every health care professional should have acquired three categories of competences, namely: common, complementary, and collaborative competences [63]. Common competences are those expected of all health care professionals, such as efficiently organising one's own work. Complementary competences are those specifically related to a single profession, distinguishing one profession from another. Collaborative competences are those needed to be able to collaborate with colleagues from the same profession, patients, informal caregivers, and professionals from other disciplines. During their undergraduate education, most of today's professionals were primarily trained to acquire common and complementary competences, but did not receive explicit training in the collaborative competences needed to be able to work in interprofessional teams. ${ }^{59}$ Therefore, it might be useful to provide future professionals with specific training in these collaborative skills. ${ }^{64}$ The Centre for the Advancement of Interprofessional Education (CAIPE) explains that this kind of education, known as 'Interprofessional education' occurs when two or more professionals learn with, from and about each other, in order to improve collaboration and the quality of care. ${ }^{65}$ Moreover, it can be perceived as a social undertaking informed by theories of group interaction and social learning. ${ }^{66}$

Shared, interprofessional learning appears to work best in small groups, using real-life problems to stimulate learning through experience and reflection. ${ }^{67,68}$ Research also shows that students trained in interprofessional teams are more likely to develop the collaborative skills and attitudes needed for effective teamwork with professionals from other disciplines. ${ }^{69,70}$ Interprofessional team meetings involve many of the collaborative key competences identified by the European Interprofessional Practice and Education Network (EIPEN). ${ }^{71}$ In this respect, interprofessional team meetings (if conducted properly) can be considered appropriate situations for encouraging interprofessional learning. ${ }^{53}$ However, implementing interprofessional education is a complex process influenced by various factors. ${ }^{72}$ Until now, most interprofessional educational programmes appear to be formal, structured, and offered in simulated settings [69]. More opportunities need to be created for trainee health care professionals to learn together in interprofessional team-based settings, at an early stage of their education. 
More, it would appear interesting to expand and study interprofessional team-based learning activities at the workplace. ${ }^{73,74}$

\section{Balancing between perspectives}

The findings reported in this thesis showed that chronically ill patients appreciate having a voice in their own care process and feeling part of the team. ${ }^{29}$ Patients seem to prefer a patient-centred approach, and mention communication and partnership as crucial aspects of patient-centredness. ${ }^{75}$ The literature shows that almost all patients prefer to be offered choices and to be asked their opinion during care planning, although not all patients prefer the same level of participation. ${ }^{76,77}$ Patients also value having the opportunity to take part or be represented in team meetings. ${ }^{28,29}$ However, the findings in this thesis show that in Dutch primary care it is not routine practice for patients to take part in interprofessional team meetings, ${ }^{28,30}$ and not all patients are able and willing to take part in such meetings. ${ }^{28,29}$ Professionals also sometimes strongly prefer a meeting without the patients or family members being present. A tailored approach to patient involvement before, during, and after team meetings is preferable.

Appropriate patient involvement requires that professionals are able to adapt their approach (including language use, preparation, and explanation) and the extent of patient participation based on patients' abilities and preferences. Instead of a standardised evidence-based practice approach, a context-based approach in which health care professionals adapt their practice to the specific patient's preferences and context seems desirable. ${ }^{8}$ For future research it seems useful to further explore the extent to which patients are actually willing and able to participate before, during, and after team meetings. In this respect it would be interesting to examine what active participation involves for a patient, what information a patient needs to be prepared for a meeting, and how they can be sufficiently informed to make an informed choice to participate or not.

Adopting a patient-centred approach to the provision of health care, focusing on the patient as a whole in the context of his or her entire life, appears to be a key principle for most governments and care organisations. ${ }^{78-80}$ These organisations focus on supporting patients' self-management abilities and enabling them to live independently and take part in society. Active participation, and using patients' own strengths, resources, and personal networks, are important for health care systems to remain accessible to everyone. $^{81}$ In this perspective, health care should focus on patients' individual demands, expressed in goals in various domains. Improved integration of the physical, mental, and social aspects of care seems essential for the provision of patient-centred care. $^{82}$ 
The programme developed as part of this project contributed to an increased awareness of patient-centredness among professionals, but apart from this increased awareness, no great impact on patient-centredness was seen in our observations, in terms of explicitly exploring patient goals. In this respect, the studies included in this thesis showed that the patient perspective was not always central, and professionals were not always working in accordance with the patients' personal goals. Sometimes professionals were not aware of their dominating professional perspective. In other situations, the professionals appeared to be balancing between the patient perspective and the professional perspective. The degree of patient-centredness in health care delivery and patient involvement seems strongly influenced by systemic factors such as legal frameworks or financial restrictions, as well as professionals' personal characteristics such as values, standards, religion, and ethics. ${ }^{83,84}$ In addition, financial restrictions, often expressed as lack of time, limit professionals in conducting an in-depth exploration of patients' personal goals. In the case of care avoiders, for example, it is often a challenge to enter into a dialogue and explore the patient's goals. In such cases professionals deviate consciously from the patient perspective, and determine care planning based on the principles of professionalism or good counsellorship. Another example is the case where it is the patient's personal preference to stay at home as long as possible, whereas from a professional perspective the team recommends moving the patient to a nursing facility. In these situations, the professional's approach is perhaps most closely related to the deliberative model of professional-patient interaction as described by Emanuel and colleagues. ${ }^{85}$ In this deliberative model, the professional persuades the patient of the most desirable values and dialogues on what course of action would be best. ${ }^{85}$ A recently published report by the Netherlands Scientific Council For Government Policy (WRR) highlights the contrast between what is expected of patients and what they are actually capable of. ${ }^{86}$ A considerable number of patients appear to lack the ability to self-manage their lives, particularly in stressful situations. According to the report, this category of patients is not by definition restricted to the vulnerable, but may also be found among more highly educated people with a good social position. ${ }^{86}$ The WRR concluded that not all people have the same desire to develop the non-cognitive abilities (self-control, belief, temperament) that are needed to self-manage their lives. Forcing patient-centredness, only relying on patient goals, and pursuing self-management in all situations would therefore not always be an appropriate approach.

Increased awareness of patient-centredness can be perceived as a first step towards actually improving professionals' practical behaviour in this respect. Factors which contribute to the intention to change one's behaviour include attitude towards the behaviour, subjective norm, and perception of behavioural control. ${ }^{87}$ According to the theory of planned behaviour as proposed by Icek Ajzen, intention is the immediate 
antecedent of behaviour and is itself a function of attitude. However, in addition to the right attitude and mindset, professionals also need to develop skills enabling them to communicate in a patient-centred way. ${ }^{81}$ In the context of interprofessional teams, strong leadership that influences the subjective norm towards patient-centredness is desirable to facilitate change towards a patient-centred practice. ${ }^{84}$ In future research, it appears useful to explore strategies enabling behavioural change among professionals regarding patient-centredness.

\section{A complex environment requiring a tailored approach}

The findings of the various studies reported on in this thesis appear to vary under the influence of multiple contexts. Next to the patients' and professionals' own contexts, the teams also differed in their organisational context, including organisational support and the presence of facilities (e.g. availability of a communication tool, meeting room, secretarial support). ${ }^{12,28,30,42,88,89}$ Other contextual aspects that can be assumed to have their own impact include funding, the legislation, and regulations, such as the rules and regulations set by insurance companies. For example, in the Dutch primary care setting, attending interprofessional team meetings is only financially remunerated for family physicians (and not for the allied health care staff)), which affects the collaboration.

The literature also shows that culture, policies, and organisational contexts (e.g. laws, regulations, and funding) affect the ability of teams to collaborate effectively. ${ }^{69,90-92}$ Apparently, effective primary health care teams require not only competent professionals but also support from organisational systems and protocols to work with shared patients. ${ }^{93}$ Teams should be aware of these contextual factors and the influence of external relations, i.e. with other healthcare teams, insurance companies and municipal authorities. We assume that all efforts spent on improving interprofessional team functioning are useless if the team is not aware of, and does not learn how to deal with, those contextual factors. ${ }^{88}$

Our findings showed that the various contextual factors influenced the suitability and feasibility of the different programme components. ${ }^{42}$ As a consequence, some of the participants experienced components of the programme and supporting tools as too complex or time-consuming. ${ }^{88}$ However, it was certainly not our intention to increase the workload of those involved, but to make processes more efficient. The findings of our action research were used to adjust both form and content of the draft programme. Training was expanded with an additional peer feedback session and on-the-job coaching, tools were simplified, and a flexible approach towards implementation was adopted. As a result, teams were able to implement the programme (including training activities and tools) in a flexible way, to fit with existing procedures and working 
methods. This approach to implementing innovations in complex environments is in line with the recommendation by the Council for Public Health and Society to adopt contextbased approaches in which specific contexts are explored before new practices are implemented [8]. In order to tailor the programme to the specific context, type of collaboration, phase of group development, and learning objectives of a team, assessment (including an intake interview, self-assessment tool, and observation) should be embedded from the start.

\section{Summary of recommendations}

Based on the above discussion of the main findings of this thesis and the methodological considerations, this section summarises recommendations for future practice and research.

\section{Recommendations for practice}

For interprofessional primary care teams it is recommended to:

- be aware that interprofessional collaboration is influenced by several factors, which can be divided into patient-related, professional-related, interpersonal, organisational, and external factors;

- not only pay attention to the content of the meetings, but also to the procedure, interaction, and underlying processes regarding interprofessional collaboration;

- appoint a leader who is not only competent in chairing meetings but also in guiding the team through its development;

- consider the support of an external coach, depending on the team's learning needs, and the leader's competences;

- continuously invest in getting to know each other personally and exploring each other's backgrounds, competences, and contexts;

- $\quad$ strive for shared commitment to team objectives, division of roles, procedures, and interaction;

- $\quad$ explore patients' individual goals, needs, concerns and preferences, and adopt a tailored approach towards patient-centredness, including patient involvement before, during, and after team meetings;

- incorporate in the meetings a cycle of team reflection on content, procedure, and interaction levels, leading to the formulation of learning objectives; 
- tailor an improvement programme to the specific team context, type of collaboration, phase of group development, and learning objectives, based on an assessment of the team's learning needs;

- take into account that effective interprofessional team functioning develops over time, and needs continuing attention.

\section{Recommendations for research}

Based on the different research themes that emerged from the findings presented in this thesis, it is recommended to:

- explore how patient participation (before, during, and after interprofessional team meetings) can be tailored to patients' preferences and capabilities;

- explore strategies to enable professionals to make the step from increased awareness to actual behavioural change regarding patient-centredness;

- evaluate the effects of programmes to improve collaborative practice after sustainable consolidation;

- study and further develop interprofessional team-based learning activities for undergraduate students;

- develop a feasible instrument for the assessment of the type of collaboration and the learning needs concerning interprofessional collaboration, to enable teams to identify points for improvement. 


\section{References}

1. Kuper A, Reeves S, Levinson W. An introduction to reading and appraising qualitative research. BMJ, 2008; 337(7666):404-7.

2. Lincoln YS, Guba EG. Naturalistic Inquiry. 1985, Newburry Park: SAGE.

3. Koshy E, Koshy V, Waterman H. Action Research in Healthcare. 2011: SAGE publications Ltd. 200.

4. Reason P, Bradbury H. Handbook of action research: Participative inquiry and practice. 2001: Sage.

5. Migchelbrink F. De kern van participatief actieonderzoek. 2016, Amsterdam: SWP.

6. McNiff J. You and your action research project. 2016: Routledge.

7. Karim K. Assessing the strengths and weaknesses of action research. Nurs Stand 2001;15(26):33-5.

8. The Council for Public Health and Society, No evidence without context. About the illusion of evidence-based practice in healthcare. 2017, The Council for Public Health and Society (Raad voor Volksgezondheid en Samenleving, RVS): The Hague.

9. Moore GF, et al. Process evaluation of complex interventions: Medical Research Council guidance. BMJ 2015;350:h1258.

10. Buljac-Samardzic $M$, et al. Interventions to improve team effectiveness: a systematic review. Health Policy 2010;94(3):183-95.

11. Tsakitzidis $\mathrm{G}$, et al. Outcome Indicators on Interprofessional Collaboration Interventions for Elderly. Int J Integr Care 2016;16(2):5.

12. van Dongen JJ, et al. Interprofessional collaboration regarding patients' care plans in primary care: a focus group study into influential factors. BMC Fam Pract 2016;17:58.

13. Mathison S. Why triangulate? Educational researcher 1988;17(2):13-7.

14. Ouwens $\mathrm{M}$, et al. The Team Climate Inventory: application in hospital teams and methodological considerations. Qual Saf Health Care 2008;17(4):275-80.

15. Nelson EC, et al. Microsystems in health care: Part 1. Learning from high-performing front-line clinical units. Jt Comm J Qual Improv 2002;28(9):472-93.

16. Mills PD, Weeks WB. Characteristics of successful quality improvement teams: lessons from five collaborative projects in the VHA. Jt Comm J Qual Saf 2004;30(3):152-62.

17. Schroder C, et al. Development and pilot testing of the collaborative practice assessment tool. J Interprof Care 2011;25(3):189-95.

18. Shoemaker SJ, et al. A review of instruments to measure interprofessional team-based primary care. J Interprof Care 2016;30(4):423-32.

19. Vyt A. Development and validation of a questionnaire to self-assess the quality of interprofessional team meetings in primary and community healthcare. J Interprof Care 2017;31(2):140-6.

20. Windesheim. Samenwerkingsthermometer. 2017; Available from: https://www.windesheim.nl/ onderzoek/onderzoeksthemas/gezondheid-en-welzijn/innoveren-met-ouderen/onderzoeksprojecten/ professioneel-samenwerken-in-de-wijk/.

21. Katzenbach JR, Smith DK. The discipline of teams. Harv Bus Rev 1993;71(2):111-20.

22. Kane RA. The interprofessional team as a small group. Soc Work Health Care 1975;1(1):19-32.

23. Luszki MB. Interdisciplinary team research: Methods and problems. Vol. 3. 1958: National Training Laboratories New York.

24. Ferlie E, Montgomery K, Pedersen AR. The Oxford Handbook of Health Care Management. 2016, Oxford: Oxford University Press. 554.

25. Toiviainen $\mathrm{H}$, Kira M. From struggles to resource gains in interprofessional service networks: Key findings from a multiple case study. Journal of Interprofessional Care 2017:1-8.

26. Thomson AM, Perry JL, Miller TK. Conceptualizing and measuring collaboration. Journal of Public Administration Research and Theory 2007;19(1):23-56.

27. Lingard $L$, et al. Pulling together and pulling apart: influences of convergence and divergence on distributed healthcare teams. Adv Health Sci Educ Theory Pract 2017.

28. van Dongen JJ, et al. Successful participation of patients in interprofessional team meetings: A qualitative study. Health Expect 2016.

29. van Dongen JJ, et al. "They Are Talking About Me, but Not with Me": A Focus Group Study to Explore the Patient Perspective on Interprofessional Team Meetings in Primary Care. Patient 2017. 
30. van Dongen JJ, et al. Interprofessional primary care team meetings: a qualitative approach comparing observations with personal opinions. Fam Pract 2017;34(1):98-106.

31. Legare, F., et al., Interprofessionalism and shared decision-making in primary care: a stepwise approach towards a new model. J Interprof Care 2011;25(1):18-25.

32. Poulton BC, West MA. The determinants of effectiveness in primary health care teams. Journal of Interprofessional Care 1999;13(1):7-18.

33. Xyrichis A, Lowton $\mathrm{K}$. What fosters or prevents interprofessional teamworking in primary and community care? A literature review. Int J Nurs Stud, 2008. 45(1): p. 140-53.

34. Mulvale G, Embrett M, Razavi SD. 'Gearing Up' to improve interprofessional collaboration in primary care: a systematic review and conceptual framework. BMC Fam Pract 2016;17:83.

35. Widmer PS, Schippers MC, West MA. Recent developments in reflexivity research: A review. Psychology of Everyday Activity 2009;2(2):2-11.

36. Nic a Bháird C, et al. Multidisciplinary team meetings in community mental health: a systematic review of their functions. Mental Health Review Journal 2016;21(2):119-40.

37. West M. Reflexivity and work group effectiveness: A conceptual integration. 1996: John Wiley \& Sons, Ltd., Chichester.

38. Schmutz JB, Eppich WJ. Promoting Learning and Patient Care Through Shared Reflection: A Conceptual Framework for Team Reflexivity in Health Care. Acad Med 2017.

39. Schippers MC, West MA, Dawson JF. Team reflexivity and innovation: The moderating role of team context. Journal of Management 2015;41(3):769-88.

40. Shaw EK, et al. How team-based reflection affects quality improvement implementation: A qualitative study. Qual Manag Health Care 2012;21(2):104.

41. Mann K, Gordon J, MacLeod A. Reflection and reflective practice in health professions education: a systematic review. Adv Health Sci Educ 2009;14(4):595.

42. van Dongen JJJ, et al. Suitability of a programme for improving interprofessional primary care team meetings. Manuscript submitted for publication, 2017.

43. Firestone DT. A Study of Leadership Behaviors among Chairpersons in Allied Health Programs. J Allied Health 2010;39(1):34-42.

44. Schippers $M C$, et al. The role of transformational leadership in enhancing team reflexivity. Human Relations 2008;61(11):1593-616.

45. Konradt U, et al. Reflexivity in Teams: A Review and New Perspectives. J Psychol 2016;150(2):153-74.

46. Cheater FM, et al. Can a facilitated programme promote effective multidisciplinary audit in secondary care teams? An exploratory trial. Int J Nurs Stud 2005;42(7):779-91.

47. Liberati EG, Gorli M, Scaratti G. Invisible walls within multidisciplinary teams: Disciplinary boundaries and their effects on integrated care. Soc Sci Med 2016;150:31-9.

48. Gabelica $C$, et al. The effect of team feedback and guided reflexivity on team performance change. Learning and Instruction 2014;34:86-96.

49. Bass BM. Leadership, psychology, and organizational behavior. Harper \& Row en de plaats California, 1960.

50. van Drielen E, et al. [Beter multidisciplinair overleg past bij betere zorg]. Ned Tijdschr Geneeskd 2012;156(45):A4856.

51. Kennedy $\mathrm{N}$, et al. Primary care team working in Ireland: a qualitative exploration of team members' experiences in a new primary care service. Health Soc Care Community 2015;23(4):362-70.

52. Harris MF, et al. Interprofessional teamwork innovations for primary health care practices and practitioners: evidence from a comparison of reform in three countries. J Multidiscip Healthc 2016;9: 35-46.

53. Nisbet G, Dunn S, Lincoln M. Interprofessional team meetings: Opportunities for informal interprofessional learning. J Interprof Care 2015;29(5):426-32.

54. Reeves S, Macmillan K, van Soeren M. Leadership of interprofessional health and social care teams: a socio-historical analysis. J Nurs Manag 2010;18(3):258-64.

55. Dimas ID, Renato Lourenco P, Rebelo $T$. The effects on team emotions and team effectiveness of coaching in interprofessional health and social care teams. J Interprof Care 2016;30(4):416-22.

56. Remmerswaal J. Group Dynamics: an introduction. 2015, Amsterdam: Uitgeverij bNoom/nNelissen. 
57. Bodenheimer T, et al. The 10 building blocks of high-performing primary care. Ann Fam Med 2014;12(2): 166-71.

58. Wylie DA, Gallagher HL. Transformational leadership behaviors in allied health professions. J Allied Health 2009;38(2):65-73.

59. Boult C, Wieland GD. Comprehensive primary care for older patients with multiple chronic conditions: "Nobody rushes you through". JAMA 2010;304(17):1936-43.

60. Godfrey MM, et al. Coaching interprofessional health care improvement teams: the coachee, the coach and the leader perspectives. J Nurs Manag 2014;22(4):452-64.

61. Grumbach K, Bainbridge E, Bodenheimer T. Facilitating improvement in primary care: the promise of practice coaching. Issue Brief (Commonw Fund) 2012;15(1):14.

62. Frank, J.R. and D. Danoff, The CanMEDS initiative: implementing an outcomes-based framework of physician competencies. Medical Teacher 2007;29(7):642-7.

63. Barr H. Competent to collaborate: towards a competency-based model for interprofessional education. Journal of Interprofessional Care 1998;12(2):181-7.

64. van Vliet K, Grotendorst A, Roodbol P. Anders kijken, anders leren, anders doen, in Grensoverstijgend leren en opleiden in zorg en welzijn in het digitale tijdperk. 2016, Zorginstituut Nederland (De Commissie Innovatie Zorgberoepen \& Opleidingen): Diemen.

65. CAIPE, Interprofessional education in pre-registration courses, in A CAIPE Guide for Commissioners and Regulators of Education. 2012, Caipe United Kingdom: Fareham.

66. Freeth D, et al. Effective Interprofessional Education: Development, Delivery and Evaluation. Promoting Partnership for Health, ed. H. Barr. 2005, Oxford, UK: Blackwell Publishing Ltd.

67. Parsell G, Bligh J. Interprofessional learning. Postgrad Med J 1998;74(868):89-95.

68. Nasir J, et al. Case-based interprofessional learning for undergraduate healthcare professionals in the clinical setting. J Interprof Care 2017;31(1):125-8.

69. Reeves $\mathrm{S}$, et al. A BEME systematic review of the effects of interprofessional education: BEME Guide No. 39. Medical Teacher 2016;38(7):656-68.

70. Rossler KL, et al. Effective Learning of Interprofessional Teamwork. Nurse Educ 2017;42(2):67-71.

71. Vyt A. Exploring quality assurance for interprofessional education in health and social care. 2009, Antwerpen: Garant.

72. de Vries-Erich J, et al. Identifying facilitators and barriers for implementation of interprofessional education: Perspectives from medical educators in the Netherlands. J Interprof Care 2017;31(2):170-4.

73. Brewer ML, Flavell HL, Jordon J. Interprofessional team-based placements: The importance of space, place, and facilitation. J Interprof Care 2017:1-9.

74. Wong AKC, et al. The effect of interprofessional team-based learning among nursing students: A quasiexperimental study. Nurse Education Today 2017;53:13-8.

75. Little $P$, et al. Preferences of patients for patient centred approach to consultation in primary care: observational study. BMJ 2001;322(7284):468.

76. Levinson $W$, et al. Not all patients want to participate in decision making. A national study of public preferences. J Gen Intern Med 2005;20(6):531-5.

77. Murray E, et al. Clinical decision-making: Patients' preferences and experiences. Patient Educ Couns 2007;65(2):189-96.

78. Kitson A, et al. What are the core elements of patient-centred care? A narrative review and synthesis of the literature from health policy, medicine and nursing. J Adv Nurs 2013;69(1):4-15.

79. Olsson LE, et al. Efficacy of person-centred care as an intervention in controlled trials-a systematic review. J Clin Nurs 2013;22(3-4):456-65.

80. Starfield B. Is patient-centered care the same as person-focused care? The Permanente Journal 2011; 15(2):63.

81. Royal College of General Practitioners, An Inquiry into Patient Centred Care in the 21st Century. Implications for general practice and primary care. 2014, Royal College of General Practitioners: London.

82. Peek CJ. Integrating care for persons, not only diseases. J Clin Psychol Med Settings 2009;16(1):13-20.

83. Hawkes N. Seeing things from the patients' view: what will it take? BMJ 2015;350:g7757.

84. Moore L, et al. Barriers and facilitators to the implementation of person-centred care in different healthcare contexts. Scand J Caring Sci 2016.

85. Emanuel EJ, Emanuel LL. Four models of the physician-patient relationship. JAMA 1992;267(16):2221-6. 
86. WRR. Weten is nog geen doen. Een realistisch perspectief op redzaamheid. 2017, De Wetenschappelijke Raad voor het Regeringsbeleid (The Netherlands Scientific Council For Government Policy): Den Haag.

87. Van Lange PAM, Kruglanski AW, Higgins ET. The Handbook of Theories of Social Psychology. Vol. 1. 2011: SAGE Publications Ltd.

88. van Dijk-de Vries A, van Dongen JJ, van Bokhoven MA. Sustainable interprofessional teamwork needs a team-friendly healthcare system: Experiences from a collaborative Dutch programme. J Interprof Care 2017;31(2):167-9.

89. van Dongen JJJ, et al. Development of a customizable programme for improving interprofessional team meetings. An action research approach. Manuscript submitted for publication, 2017.

90. Pullon S, McKinlay E, Dew K. Primary health care in New Zealand: the impact of organisational factors on teamwork. Br J Gen Pract 2009;59(560):191-7.

91. Ries NM. Law matters: How the legal context in Canada influences interprofessional collaboration. 2017, Taylor \& Francis.

92. Hall P. Interprofessional teamwork: Professional cultures as barriers. J Interprof Care, 2005;19(sup1): 188-96.

93. Sargeant J, Loney E, Murphy G. Effective interprofessional teams: "contact is not enough" to build a team. J Contin Educ Health Prof 2008;28(4):228-34. 
Summary 



\section{Summary}

Chapter 1 starts with an introduction of the subject of this thesis: interprofessional collaboration in primary care teams. The introduction begins by reflecting on the increasing complexity of care for chronic patients. In addition to physical and mental challenges, chronically ill patients are increasingly confronted with problems in their social situation. The chapter then defines the primary care setting (the setting for the research discussed in this thesis). There is a need for a patient-centred approach, focusing on the patient's goals and acquiring a complete understanding of a patient's situation, preferences, and individual needs. Important aspects include patient participation and involvement, self-management, and goal setting. Interprofessional collaboration is a strategy to enhance patient-centredness, by coordinating care and developing shared care plans. However, implementing efficient, patient-centred, interprofessional collaboration is perceived as complex and is influenced by many interrelated factors. Therefore, the aim of the research reported on in this thesis was to explore the key factors for improving primary care professionals' interprofessional collaboration in the development of patient-centred care plans. This thesis reports on three phases, including eight studies, starting by exploring the field of interprofessional collaboration and an in-depth problem analysis of current practice (phase 1), followed by a process to develop a programme to improve interprofessional team meetings, characterised by co-creation with intended users (phase 2), and finally an evaluation of the resulting programme (phase 3 ). The research questions for each phase are:

\section{Phase 1}

1. What is known in the scientific literature about developing interprofessional shared care plans?

2. What factors influence the development of interprofessional shared care plans?

3. How are interprofessional team meetings currently conducted in Dutch primary care, and what are the participants' experiences?

4. How do patients and professionals experience patient participation in interprofessional team meetings?

5. What is the patients' perspective on interprofessional team meetings in primary care?

\section{Phase 2}

6. What are the key elements of a programme to improve interprofessional team meetings in primary care? 


\section{Phase 3}

7. What are the critical factors determining the suitability and potential impact of a programme to improve the functioning of interprofessional team meetings?

8. What are the contextual facilitators of and barriers to a sustainable implementation of interprofessional teamwork in a primary care setting?

Chapter 2 describes the findings of a scoping review. This literature review surveys the scientific literature on developing shared care plans. A systematic database search resulted in 45 articles being included, 5 of which were empirical studies concentrating purely on care plans. Findings were synthesised using directed content analysis. The review revealed three themes. The first theme was the format of the shared care plan, with the following elements: patient's current state, goals and concerns, actions and interventions, and evaluation. The second theme concerned the development of shared care plans. Factors influencing this process can be categorised as interpersonal, organisational and patient-related factors. The third theme covered tools, whose main function is to support professionals in sharing patient information without personal contacts. Such tools involve documentation of and communication about patient information. We concluded that care plan development is not an independent concept, but should be seen as the result of an underlying process of interprofessional collaboration between team members, including the patients. To integrate the patients' perspectives into the care plans, their needs and values need careful consideration. Moreover, the review indicates a need for new empirical studies examining the development and use of shared care plans and evaluating their effects.

Chapter 3 describes an in-depth exploration of the factors influencing the process of interprofessional collaboration. As the previous chapter showed, the process of interprofessional collaboration for care plan development is influenced by a number of interrelated factors. Hence, we decided to explore these factors in greater depth, by conducting a qualitative focus group study, with healthcare professionals, patient representatives and experts in the field of interprofessional collaboration. In four groups participants discussed viewpoints, barriers, and facilitators regarding interprofessional collaboration for care plan development. The data were analysed by means of inductive content analysis. The resulting factors can be divided into 5 key categories: (1) patientrelated factors: active role, self-management, goals and wishes, membership of the team; (2) professional-related factors: individual competences, domain thinking, motivation; (3) interpersonal factors: language differences, knowing each other, trust and respect, and motivation; (4) organisational factors: structure, composition, time, 
shared vision, leadership, and administrative support; and (5) external factors: education, culture, hierarchy, domain thinking, law and regulations, funding, technology and ICT. Apparently, improving interprofessional collaboration for care plan development calls for an integrated approach including patient- and professional-related factors, as well as interpersonal, organisational, and external factors. Moreover, the leader of the team seems to play a key role in keeping the patient perspective in mind, organising and coordinating interprofessional collaboration, and guiding the team through development.

Chapter 4 describes our second qualitative study to explore the process of interprofessional collaboration in primary care team meetings. Current practice was observed and compared with team members' personal opinions, explored by interviewing them individually immediately after the observed team meeting. Eight interprofessional team meetings in different primary care practices were observed. Experiences and personal opinions were explored in 60 individual semi-structured interviews with the participating health care professionals, from different disciplines. The data were analysed by means of content analysis. Most participants expressed favourable opinions about their team meetings. However, observations showed that team meetings were more or less chaotic, unstructured, and lacked a team coordinator or leader. This study showed a discrepancy between the findings from observations and interviews. From the interviews, four main themes were extracted: (1) team structure and composition, (2) patient-centredness, (3) interaction, and (4) attitude and motivation. Based on the observations and interviews, we concluded that interprofessional team meetings could benefit from improvements in structure, patientcentredness, and leadership by the chairpersons. Moreover, given the discrepancy between observations and interviews, it appeared useful to improve team members' awareness of aspects that could be improved before training them in dealing with specific challenges.

Observations from the study presented in chapter 4 showed that patient participation during interprofessional collaboration occurred only occasionally. Therefore Chapter 5 describes a qualitative study to examine how health care professionals and patients who are used to patient participation in their interprofessional team meetings experience and organise patient participation in these meetings. This study included observations of eight different team meetings in various settings (both institutional and noninstitutional) and interviews with professionals, patients, and informal caregivers. Professionals and patients were asked about their experiences with patient participation immediately after the team meetings. Results from both observations and interviews 
were analysed using content analysis. The findings show a variety of influencing factors, which can be divided into five categories: (1) meeting structure and task distribution, (2) group composition, (3) relationship between professionals and patients or relatives, (4) patients' characteristics, and (5) purpose of the meeting. The study concluded that patient participation in team meetings was appreciated by both professionals and patients. A tailored approach to patient involvement in team meetings is preferable. When considering the presence of patients in team meetings, attention should be given to patients' willingness and ability to participate, and the necessary information shared between patient and health care team before the meeting. Participating patients seem to appreciate support and preparation for the meeting.

As regards patient-centeredness, it is useful to actively include the patients' perspective. Therefore the research described in Chapter 6 explored the patients' perspectives regarding interprofessional team meetings in primary care by means of a qualitative study with a focus group design. Two focus group meetings took place, for which the same patients were invited. The participants, seven chronically ill patients with experience of interprofessional collaboration were recruited through the regional patient association. Participants discussed viewpoints, expectations, and concerns regarding interprofessional team meetings in two rounds, using a focus group protocol and selected video-taped vignettes of team meetings. The first meeting focused on conceptualisation and identification of the themes related to interprofessional team meetings that are important to patients. The second meeting aimed to gain more indepth knowledge and understanding of the priorities. Discussions were audio-taped and transcribed verbatim, and analysed by means of content analysis. Findings were divided into six key categories, capturing the factors that patients found important regarding interprofessional team meetings: (1) putting the patient at the centre, (2) opportunities for patients to participate, (3) appropriate team composition, (4) structured approach, (5) respectful communication, and (6) informing the patient about meeting outcomes. They also emphasised the right of patients or their representatives to take part in interprofessional team meetings.

The findings from the studies presented in chapters 2-6 were used as input for the next study, described in Chapter 7, which aimed to develop a programme to improve the efficiency and patient-centredness of interprofessional team meetings (phase 2 of the project). This chapter describes the development and final content of the programme, which was developed using an action research approach characterised by co-creation with intended users. A first draft of the programme was developed, and iteratively used and evaluated by three primary care teams. Data were collected by means of 
observations, interviews, and a focus group, and analysed using directed content analysis. The final programme comprises a framework to reflect on team functioning, and training activities supplemented by a toolbox. Training includes an information meeting for all team members, and two day parts training, peer feedback sessions, and on-the-job coaching intended for the chairperson and co-chair. Training activities are directed at organising and structuring meetings, guiding the team through development, and enhancing patient-centredness. Findings of this study emphasised the essential role of the team's chairperson, who, in addition to technically structuring meetings, should act as a change agent guiding team development. Moreover, findings showed that the programme should be customisable to each individual team's context and participants' learning objectives. The study also concluded that becoming acquainted with new structures can be considered a growth process, in which teams have to find their way, with the chairperson serving as a change agent.

Chapter 8 describes the study in which the perceived suitability and potential impact of the programme were evaluated (phase 3 of the project). A prospective process evaluation was conducted, using a mixed-methods approach. Six primary care interprofessional teams participated. Data collection included observations of team meetings, semi-structured interviews with team chairpersons, a focus group meeting, and a questionnaire for all team members. Qualitative data were analysed using directed content analysis and quantitative data using descriptive statistics. Results of our evaluation showed that, on the whole, the programme was appreciated. Most progress was perceived regarding structure and organisation. Chairs perceived increased awareness of patient-centredness and team processes. They perceived the training activities as useful and instructive, and valued peer feedback and on-the-job coaching as the most effective strategies. Findings from the questionnaire showed a tendency in the intended direction for all variables. We concluded that the programme can be considered a suitable approach for improving team functioning, although enhancing patient-centredness requires additional training/practice and on-the-job coaching. Lastly, the programme should be context-specific, flexible in use, and preferably delivered and mediated by an external facilitator at the workplace.

In addition to the process evaluation, Chapter 9 describes a case study examining contextual facilitators of and barriers to a sustainable implementation of teamwork. Effective development of teams requires support from the wider organisational context. In a Dutch village, healthcare professionals work closely together, and mutual consultations as well as interprofessional meetings take place on a regular basis. The network was created as a precondition for sustainable interprofessional teamwork in 
care for the elderly. However, several external barriers were encountered regarding the supportive structure and cooperative attitude of the healthcare insurer and the municipal authorities. Complicating factors included finding the right key figures, and the different perspectives on team development and team effectiveness. We concluded that healthcare insurance companies need to implement changes in their internal organisation to facilitate an interprofessional care approach. Furthermore, municipal authorities should work on their views about the needs and benefits of a fruitful collaboration with interprofessional healthcare teams. The challenge for healthcare teams is to learn to speak the language of external partners. To support the development of interprofessional teams, external parties need to recognise and put their trust in a shared aim to provide quality of care in an efficient and effective way.

Chapter 10 presents the general discussion of this thesis. This final chapter starts with an overview of the main findings in each phase of the project, and then discusses some general methodological considerations regarding the qualitative study design, participating teams, trustworthiness, and measurement of the quality of interprofessional collaboration in primary care teams. It then discusses the main findings and lessons learnt in the light of existing literature. This discussion chapter reflects on the differences between primary care teams and their dynamic composition. However, regardless of the type of collaboration, all teams should invest in knowing each other, implement a repetitive cycle of reflection, and strive for commitment to procedures and interaction. It is also important to appoint a competent leader, able to cope with this challenging task. The chapter then highlights the potential of interprofessional learning by undergraduate students during team meetings, and recommends further exploration and expansion of team-based learning activities. This is followed by a discussion of the difficulty of adopting a patient-centred approach. Professionals have to strike a balance between professional and patient perspectives. Both professionals and patients have their preferences regarding the level of patient participation before, during, and after team meetings. It seems worthwhile to explore how these two perspectives and levels of participation can be tailored to patients' preferences and capabilities. We also recommend to study strategies to enable behavioural change among professionals regarding patient-centredness. Lastly, the chapter highlights the complexity current primary care is confronted with. A plea is made for implementing the programme in a flexible way, tailored to a team's specific context and development needs, optionally supported by an external coach. A feasible self-assessment tool should be developed to detect blind spots and guide the team towards learning objectives. The chapter ends with a summary of recommendations for future practice and research. 
Samenvatting 



\section{Samenvatting}

Hoofdstuk 1 begint met een introductie op het onderwerp van dit proefschrift: interprofessioneel samenwerken in eerstelijns teams. Allereerst reflecteren we op het belang van interprofessioneel samenwerken, bij de toenemende complexe chronische zorg. Patiënten met een of meerdere chronische aandoeningen hebben naast lichamelijke en geestelijke klachten ook problemen in het dagelijks leven. Vervolgens beschrijven we de eerstelijns setting, de onderzoekssetting van dit proefschrift. Verder geven we uitleg over het belang van een patiëntgerichte aanpak waarin wordt gefocust op de gehele patiënt en waarbij een zo compleet mogelijk beeld wordt gecreëerd van zijn of haar situatie, voorkeuren en individuele behoeftes. De begrippen 'patiënt participatie en betrokkenheid', 'zelfmanagement' en het proces van 'doelen stellen' worden uitgelegd. Hierna wordt interprofessioneel samenwerken beschreven als strategie om door middel van coördinatie van zorg en het samen opstellen van zorgplannen patiëntgerichtheid te bevorderen. In de praktijk blijkt efficiënte en patiëntgerichte interprofessionele samenwerking vaak lastig, doordat deze wordt beïnvloed door diverse met elkaar samenhangende factoren. Het doel van het onderzoek zoals beschreven in dit proefschrift is dan ook om de belangrijkste factoren te achterhalen die van invloed zijn op het verbeteren van interprofessionele samenwerking, tussen eerstelijns professionals, zoals huisartsen, fysiotherapeuten, ergotherapeuten, logopedisten en praktijkondersteuners, rondom het samen opstellen van zorgplannen. Dit proefschrift kent drie fases waarin in totaal acht studies zijn opgenomen. Fase 1 bestaat uit een probleemanalyse van de huidige werkwijze. In fase 2 wordt vervolgens op basis van de bevindingen uit fase 1 een programma ontwikkeld met als doel het interprofessioneel teamoverleg te verbeteren. Dit gebeurt op systematische wijze en in co-creatie met gebruikers waaronder professionals en patiënt(vertegenwoordigers). Tot slot worden de bruikbaarheid en toepasbaarheid van het programma in fase 3 geëvalueerd. De onderzoeksvragen per fase zijn:

\section{Fase 1}

1. Wat is er in de wetenschappelijke literatuur bekend over het samen opstellen van zorgplannen?

2. Welke factoren beïnvloeden het gezamenlijk opstellen van interprofessionele zorgplannen?

3. Hoe wordt interprofessioneel teamoverleg op dit moment vormgegeven in de eerste lijn en hoe ervaren teamleden deze huidige werkwijze? 
4. Hoe ervaren patiënten en professionals patiëntparticipatie tijdens interprofessioneel teamoverleg?

5. Wat is het patiëntperspectief op interprofessionele teambesprekingen in de eerste lijn?

\section{Fase 2}

6. Wat zijn de belangrijkste elementen van een programma gericht op het verbeteren van interprofessioneel teamoverleg in de eerste lijn?

\section{Fase 3}

7. Hoe zijn de toepasbaarheid en mogelijke impact van een programma ter verbetering van het functioneren van interprofessionele teambesprekingen?

8. Welke contextuele factoren bevorderen of belemmeren een duurzame implementatie van de interprofessionele samenwerking in de eerste lijn?

Hoofdstuk 2 beschrijft de bevindingen van een scoping review. Dit literatuuronderzoek brengt de wetenschappelijke literatuur met betrekking tot het opstellen van gezamenlijke zorgplannen in kaart. Het systematisch doorzoeken van verschillende databases resulteerde tot de inclusie van 45 artikelen. Vijf van deze artikelen betroffen empirisch onderzoek specifiek gericht op het opstellen van zorgplannen, de overige onderzoeken beschreven elementen van het zorgplan. Bevindingen van alle artikelen werden geanalyseerd volgens de principes van deductieve inhoudsanalyse. Het onderzoek onthulde drie thema's. Het eerste thema betreft de onderdelen van het gezamenlijk zorgplan: 'de huidige situatie van de patiënt', 'doelen en belangen', 'acties en interventies' en 'evaluatie'. Het tweede thema betreft de ontwikkeling van het gezamenlijke zorgplan. Factoren die van invloed zijn op dit proces kunnen worden gecategoriseerd als interpersoonlijk, organisatorisch en patiënt-gerelateerd. Het derde thema omhelst hulpmiddelen die kunnen worden gebruikt om professionals te ondersteunen bij het (op afstand) delen van patiënt gerelateerde informatie. We concludeerden dat het ontwikkelen van zorgplannen geen op zichzelf staand concept is, maar het resultaat van een onderliggend proces van interprofessioneel samenwerken tussen teamleden en de patiënt. Om het patiëntperspectief te kunnen integreren in het zorgplan, moet aandacht worden besteed aan de behoeftes en waarden van de patiënt. Tot slot tonen de bevindingen van deze review aan dat er behoefte is aan nieuw empirisch onderzoek gericht op de ontwikkeling, de toepassing en evaluatie van gezamenlijke zorgplannen. 
Hoofdstuk 3 beschrijft een onderzoek naar de factoren die van invloed zijn op het proces van interprofessioneel samenwerken. Zoals blijkt uit het vorige hoofdstuk, wordt het proces van interprofessioneel samenwerken rondom het opstellen van zorgplannen beïnvloed door een groot aantal met elkaar samenhangende factoren. Om meer inzicht te krijgen in deze factoren, hebben we een kwalitatief onderzoek met focusgroep interviews uitgevoerd. Deelnemers aan de focusgroepen waren professionals van diverse disciplines, patiëntvertegenwoordigers en experts op het gebied van interprofessioneel samenwerken. In vier focusgroepen discussieerden de deelnemers over hun perspectieven op interprofessioneel samenwerken rondom de ontwikkeling van zorgplannen en de verschillende belemmerende en bevorderende factoren daarbij. De data werden geanalyseerd volgens de principes van inductieve inhoudsanalyse. De factoren konden worden onderverdeeld in vijf (hoofd) categorieën: (1) patiënt gerelateerde factoren: een actieve rol, zelfmanagement, doelen en wensen, deelname aan het team; (2) professional gerelateerde factoren: individuele competenties, domein denken, motivatie; (3) interpersoonlijke factoren: diversiteit in taal, elkaar kennen, vertrouwen en respect, motivatie; (4) organisatorische factoren: structuur, samenstelling, tijd, gedeelde visie, leiderschap, administratieve ondersteuning; en (5) externe factoren: opleiding, cultuur, hiërarchie, domein denken, wet- en regelgeving, financiering, technologie en ICT. Blijkbaar vraagt het verbeteren van de interprofessionele samenwerking rondom het samen opstellen van zorgplannen om een integrale aanpak waarin zowel patiëntfactoren, als professional gerelateerde, interpersoonlijke, organisatorische en externe factoren worden meegenomen. Bovendien vinden de deelnemers dat de leider van het team een belangrijke rol speelt in het bewaken van het patiënt perspectief, het organiseren en coördineren van de interprofessionele samenwerking en het begeleiden van het team door ontwikkeling.

Hoofdstuk 4 beschrijft een tweede kwalitatieve studie, gericht op het in kaart brengen van het proces van interprofessioneel samenwerken tijdens eerstelijns teamoverleg. Om een beeld te krijgen van de huidige manier van werken, werden acht interprofessionele teamoverleggen in verschillende eerstelijns praktijken geobserveerd. Om de persoonlijke ervaringen en meningen van de deelnemers aan dit overleg te verzamelen werden direct na afloop individuele interviews afgenomen. In totaal vonden 60 semigestructureerde interviews met teamleden van diverse disciplines plaats. Data werden geanalyseerd met een inhoudsanalyse. Het merendeel van de deelnemers bleek positief te zijn over het functioneren van hun teamoverleg. Echter, de observaties tonen aan dat het teamoverleg in de meeste gevallen min of meer ongestructureerd verliep en een teamcoördinator of voorzitter vaak ontbrak. Er is dus een discrepantie tussen de bevindingen van de observaties en de interviews. Uit de analyse van de interviews 
kwamen vier thema's: (1) de structuur en samenstelling van het team, (2) patiëntgerichtheid, (3) interactie tussen de teamleden, en (4) attitude en motivatie. Naar aanleiding van de bevindingen van de observaties en interviews kan worden geconcludeerd dat interprofessioneel teamoverleg baat zouden kunnen hebben bij verbeteringen in structuur, patiëntgerichtheid en leiderschap door de voorzitter. Verder lijkt het, gezien de discrepantie tussen de observaties en interviews, waardevol om bewustwording van de verbeterpunten bij de teamleden te creëren, alvorens ze te trainen in teamoverleg.

Uit de observaties beschreven in hoofdstuk 4 blijkt dat patiënten in de meeste gevallen niet deelnemen aan eerstelijns teamoverleg. Daarom beschrijft Hoofdstuk 5 een kwalitatief onderzoek naar de manier waarop teamoverleg met patiënten erbij wordt georganiseerd. Vanuit het perspectief van zowel professional als patiënt worden de ervaringen van de deelnemers met deelname van patiënten aan het teamoverleg geïnventariseerd. In deze studie werden acht verschillende teamoverleggen waarbij patiënten aanwezig waren in diverse settings zowel intra- als extramuraal geobserveerd. Verder vonden direct na afloop van het teamoverleg interviews plaats met zowel professionals, patiënten als mantelzorgers. Inhoudsanalyse werd gebruikt om zowel de observaties als de interviews te analyseren. Dit leverde vijf categorieën op: (1) overlegstructuur en taakverdeling, (2) groepssamenstelling, (3) de relatie tussen professionals, patiënten en familieleden, (4) eigenschappen van de patiënt en (5) het doel van het overleg. We concluderen dat de deelname van patiënten aan de overleggen door zowel professionals als patiënten wordt gewaardeerd. Verder blijkt een maatwerk aanpak voor het betrekken van patiënten in teamoverleg gewenst. Bij de overweging om patiënten deel te laten nemen aan interprofessioneel teamoverleg zijn de bereidheid en mogelijkheden van de patiënt om te kunnen participeren en het delen van belangrijke informatie met de patiënt vooraf van belang. Deelnemende patiënten geven aan adequate ondersteuning bij en voorbereiding van het overleg te waarderen.

In het kader van patiëntgerichtheid is het goed om patiënten actief te betrekken. De kwalitatieve studie beschreven in Hoofdstuk 6 richt zich dan ook op het exploreren van het patiëntperspectief met betrekking tot interprofessioneel teamoverleg in de eerste lijn. Hiertoe werden twee focus groep bijeenkomsten met dezelfde groep deelnemers georganiseerd. Deelnemers, die allen een chronische ziekte hebben en ervaring met interprofessionele samenwerking, werden geworven door de regionale, onafhankelijke patiënten federatie. In twee rondes deelden de deelnemers aan de hand van videobeelden van interprofessioneel teamoverleg hun meningen, verwachtingen en zorgen. De eerste bijeenkomst was gericht op het identificeren van thema's die vanuit 
het perspectief van de deelnemers belangrijk werden bevonden in relatie tot interprofessioneel teamoverleg. De tweede bijeenkomst had als doel verdieping aan te brengen en de verschillende thema's te prioriteren. Beide bijeenkomsten werden opgenomen met een voice recorder, letterlijk getranscribeerd en vervolgens geanalyseerd met inhoudsanalyse. De thema's kunnen worden onderverdeeld in zes categorieën: (1) de patiënt centraal, (2) de mogelijkheid om als patiënt te participeren, (3) de juiste teamsamenstelling, (4) een gestructureerde aanpak, (5) respectvolle communicatie en (6) de patiënt informeren over de uitkomsten van het overleg. Er kan worden geconcludeerd dat de deelnemers aan dit onderzoek de mogelijkheid voor patiënten om deel te nemen aan interprofessioneel teamoverleg waarderen. Hiertoe benadrukken ze het recht van patiënten of hun vertegenwoordigers om deel te kunnen nemen aan interprofessioneel teamoverleg.

De bevindingen van de voorgaande studies, beschreven in de hoofdstukken 2 tot en met 6 vormen de input voor de volgende studie, beschreven in Hoofdstuk 7. Deze studie had als doel een programma te ontwikkelen waarmee de efficiëntie en de patiëntgerichtheid van interprofessioneel teamoverleg zou kunnen worden verbeterd (fase 2 van het project). Het programma werd ontwikkeld volgens de principes van actieonderzoek waarbij co-creatie met de uiteindelijke gebruikers centraal stond. Een eerste concept van het programma werd ontwikkeld en vervolgens in een iteratief proces getest en geëvalueerd door drie eerstelijns teams. Data werden verzameld middels observaties, interviews en een focus groep interview en geanalyseerd volgens de principes van deductieve inhoudsanalyse. Het uiteindelijke programma omvat een raamwerk dat kan worden gebruikt voor reflectie op het team functioneren, diverse trainingsactiviteiten en een toolbox. De training bestaat uit een informatiebijeenkomst voor het hele team en twee dagdelen training, twee intervisiebijeenkomsten en coaching on the job voor de voorzitter en vicevoorzitter van het team. De trainingsactiviteiten zijn gericht op het organiseren en structureren van bijeenkomsten, het begeleiden van het team en het bevorderen van de patiëntgerichtheid. De bevindingen van deze studie bevestigen de essentiële rol van de voorzitter van het team. In aanvulling op het technisch structureren van bijeenkomsten heeft de voorzitter een belangrijke rol als change agent in het begeleiden van het team bij ontwikkeling. Verder tonen de bevindingen dat het programma zou moeten worden aangepast aan de context van het team en leerdoelen van de deelnemers. Naar aanleiding van de bevindingen van deze studie concluderen we dat het aanpassen aan nieuwe structuren kan worden gezien als een groeiproces waarin teams hun weg moeten vinden. 
Hoofdstuk 8 beschrijft het onderzoek waarin de ervaren toepasbaarheid en potentiële impact van het programma werden geëvalueerd (fase 3 van het project). Hiertoe werd een prospectieve procesevaluatie met verschillende dataverzamelingsmethoden toegepast. Zes interprofessionele eerstelijns teams namen deel aan deze studie. Data werden verzameld door observaties van teamoverleg, semigestructureerde interviews met de voorzitters van de teams, een focusgroep bijeenkomst en een vragenlijst die werd uitgezet onder alle teamleden. De kwalitatieve data werden geanalyseerd volgens deductieve inhoudsanalyse. Voor de analyse van de kwantitatieve data werd beschrijvende statistiek toegepast. De resultaten van de evaluatie laten zien dat het programma in zijn geheel positief wordt gewaardeerd. De grootste vooruitgang werd ervaren in structuur en organisatie. Verder ervaren de voorzitters meer bewustwording rondom patiëntgerichtheid en groepsprocessen. Ze zien de trainingsactiviteiten als nuttig en leerzaam en waarderen vooral de intervisie onderdelen en coaching on the job als effectieve onderdelen. De bevindingen van de vragenlijst laten een lichte verandering in de gewenste richting zien op alle variabelen. We concluderen dat het programma toepasbaar is en geschikt is voor verbetering van team functioneren. Echter, het vergroten van de patiëntgerichtheid vereist aanvullende oefening en coaching on the job. Tot slot, om het meeste rendement uit het programma te halen is aanpassing aan de context van het team en flexibele inzetbaarheid van het programma gewenst. Bij voorkeur wordt het programma aangeboden op de werkvloer, begeleid door een externe facilitator.

In aanvulling op de procesevaluatie beschrijft Hoofdstuk 9 een casestudie gericht op het in kaart brengen van contextuele factoren (zowel bevorderende en belemmerende) die van invloed zijn op de duurzame implementatie van teamwerk. Effectieve doorontwikkeling van teams vraagt om ondersteuning vanuit een brede organisatorische context. Deze casestudie richt zich op een dorp in Nederland waar een netwerk van zorgprofessionals nauw met elkaar samenwerkt en er regelmatig interprofessionele consultaties en teamoverleg plaatsvinden. Het netwerk werd samengesteld als voorwaarde voor de realisatie van een duurzame interprofessionele samenwerking in de ouderenzorg. Het liep echter tegen een aantal externe barrières aan, dat betrekking had op de ondersteunende structuur en houding van de zorgverzekeraar en gemeente. Ook waren het vinden van de juiste contactpersonen en de uiteenlopende perspectieven op teamontwikkeling en effectiviteit ingewikkelde factoren. We concluderen dat zorgverzekeraars aandacht zouden moeten besteden aan hun interne bedrijfsvoering om interprofessionele samenwerking te kunnen faciliteren. Verder zouden gemeenten moeten nadenken over de wijze waarop ze een vruchtbare samenwerking zouden kunnen aangaan met interprofessionele zorgteams. De uitdaging voor zorgteams of 
netwerken is gelegen in het leren spreken van de taal van externe partners. Om de ontwikkeling van interprofessionele teams te bevorderen, zouden externe partijen vertrouwen moeten hebben in het gezamenlijk doel om kwalitatief goede zorg te bieden op een zo efficiënt en effectief mogelijke manier.

In Hoofdstuk 10 is de algemene discussie van dit proefschrift beschreven. Dit laatste hoofdstuk start met een overzicht van de belangrijkste bevindingen per fase van dit project. Vervolgens wordt er gereflecteerd op de methodologische afwegingen, waaronder het design van de studies, de deelnemende teams, betrouwbaarheid van het onderzoek en het meten van de kwaliteit van interprofessionele samenwerking in eerstelijns teams. Hierna worden de belangrijkste bevindingen en de getrokken lessen uit dit proefschrift naast de bestaande literatuur gelegd. Er wordt gereflecteerd op de verschillen tussen eerstelijns teams en hun dynamische samenstelling. Ongeacht het type samenwerkingsverband, lijkt het voor alle teams goed om te investeren in het elkaar leren kennen, het implementeren van een terugkerende reflectiecyclus en het streven naar overeenstemming over de te volgen procedure en manier van communiceren. Verder is het van belang een competente leider te benoemen die in staat is om te gaan met de uitdagende taak het team te begeleiden. Ook de mogelijkheid voor interprofessioneel leren tijdens teamoverleg bij bachelor studenten komt aan bod. Hiertoe wordt een aanbeveling gedaan voor het verder onderzoeken en uitbreiden van team gerelateerde leeractiviteiten. Hierna vindt reflectie op de moeilijkheid van het aannemen van een patiëntgerichte benadering plaats. Hierin balanceren professionals tussen het professionele en patiënt perspectief. Zowel professionals als patiënten hebben hun voorkeuren met betrekking tot de mate van patiëntparticipatie voorafgaand aan, tijdens en na teamoverleg. Het lijkt waardevol om verder onderzoek te doen naar de manier waarop de mate van participatie kan worden aangepast aan de voorkeuren en mogelijkheden van de patiënt. Met betrekking tot patiëntgerichtheid wordt aanbevolen verder onderzoek te doen naar mogelijke strategieën die gedragsverandering bij professionals mogelijk maken. Tot slot geeft dit hoofdstuk inzicht in de complexiteit waarmee de huidige eerstelijns zorg te maken heeft. Flexibele implementatie van het programma en aanpassing aan de specifieke context en ontwikkelbehoefte van het team, desgewenst ondersteund door een externe coach zouden duurzame implementatie van het programma kunnen bevorderen. Om de blinde vlekken en ontwikkelpunten van het team te detecteren en vervolgens richting te geven aan een ontwikkeltraject, is er behoefte aan een zelfevaluatie instrument. Het hoofdstuk eindigt met een samenvatting van de aanbevelingen voor de praktijk en verder onderzoek. 

Valorisation 



\section{Valorisation}

This valorisation chapter describes the societal value of our findings. Besides the scientific value of the findings described in this thesis, they also have societal value. To become valuable, the outcomes of the research presented in this thesis have to be communicated not only within the scientific community, but also to the general public and to daily practice. This process of value creation from knowledge by making it suitable for and available to a broader public is known as 'valorisation'. This valorisation chapter reflects on the relevance and innovativeness of the findings described in this thesis. It also discusses how the knowledge gained in this research project can be translated to the various target groups such as patients and health care professionals. Lastly, it outlines new activities and further dissemination.

\section{Relevance}

Dealing with the increasingly complex care demands of patients with (multiple) chronic conditions, care requires interprofessional collaboration by professionals of various disciplines, and the patient. Within the primary care setting, interprofessional collaboration often occurs in periodic team meetings. However, professionals appear to struggle to conduct efficient and patient-centred team meetings. Supporting such team meetings can improve the collaboration and communication among health care professionals and patients, which should eventually lead to the delivery of efficient coordinated and patient-centred care. We assume that efficient and patient-centred team meetings contribute to good quality of care, staff satisfaction and patients' selfmanagement. ${ }^{1,2}$ The findings presented in this thesis are relevant in this respect, since they outline a programme that assists interprofessional teams in reflecting on their functioning, eventually making them capable of improving the efficiency and patientcentredness of their meetings. Training chairpersons of interprofessional team meetings to become leaders and change agents for team development seems to be a promising and efficient approach. A sufficiently trained chairperson is equipped to guide a team's development. Efficient collaboration will enable professionals from different disciplines to learn about each other, allowing them to consult each other more specifically. Improving patient-centredness and coordination of care might also overcome unnecessary use of care, decrease the number of errors, and conceivably reduce future health care costs. ${ }^{3,4}$ Although the initial programme was developed within the primary health care setting, its ingredients and basic ideas are also revealed within other settings, like hospital care and nursing homes. 


\section{Innovativeness}

Nowadays, the importance of interprofessional collaboration and a patient-centred approach, i.e. the why question, appears to be generally accepted. However, application in practice, i.e. the how question, remained often unclear so far. Findings reported in this thesis offer insights into possible strategies for conducting patient-centred interprofessional team meetings. Our programme comprises different training activities including a team instruction meeting, peer feedback sessions, and on-the-job coaching. Moreover, the programme includes a toolbox with various practical tools to support organizing and structuring patient-centred team meetings. These tools are customizable and flexible in use. Improving team functioning by training and facilitating the teams' chairpersons to become change agents can be regarded as the programme's 'unique selling point'. Given the precondition of developing a programme for improving team functioning that requires a minimal time investment, we primarily directed our efforts at the chairpersons. As a change agent, the chairperson is trained to guide the team through development, and ensure patient-centredness before, during and after the interprofessional team meetings. Moreover, by conducting a thorough needs assessment (including intake interview, observation, and self-assessment), we aimed to deliver a programme adapted to a team's specific context and needs.

Our programme also aimed to fit in with the modern approach to health and functioning, in which health is defined as the ability to adapt and to self-manage, in the face of social, physical and emotional challenges. ${ }^{5}$ In contrast to the traditional definition by the World Health Organisation (WHO), this new concept is more holistic, including multiple domains. During the training course, we aim to encourage the participants to look at patients from a broader perspective, to be sensitive to patients' preferences and personal goals, and to avoid adopting a professional-centred and supply-driven approach. Within this perspective, participants were explicitly trained to explore patients' functioning from a broader perspective, supporting patients in expressing personal values and formulating goals. With the help of various tools, e.g. the format to prepare the meeting, we intended to guide teams to approach patients before, during and after interprofessional team meetings from a wider perspective, including, for instance, patient participation and social activities. These 'innovative' ideas regarding patient-centredness were incorporated as core values of the programme. Moreover, the fact that we actively involved patients in our research, and consulted them during both exploratory and development phase can be perceived innovative. 


\section{Target groups}

There are several target groups for whom the results of this thesis can be considered relevant.

\section{Patients}

Based on the findings of our qualitative studies, in which we focused on patient participation and incorporated the patient perspective, we conclude that patients appreciate receiving consistent and coordinated care, rather than fragmented care by a number of different health care professionals and organisations. Patients increasingly value being given a voice in their own care process and being involved in the decisionmaking process. Patient-centredness can be regarded as a core value of our programme, in which patients' personal goals and needs are the point of departure during interprofessional team meetings. Actually exploring and introducing patients' personal preferences, and offering them (based on their preferences and capabilities) the opportunity to take part in interprofessional team meetings, should increase their selfmanagement abilities and give them more of a say in their care process. However, it is neither always needed, nor preferred by patients to take part. As part of our programme, a central contact person or case manager was assigned to each patient. This contact person prepares the meeting by consulting the patient and exploring his or her goals. The contact person also introduces the patients' goals and perspective during the meeting, and informs the patient about the outcomes of the meeting afterwards, which is valued by patients.

\section{Health care professionals}

Our studies showed that professionals experienced problems in conducting efficient and effective, patient-centred interprofessional team meetings in primary care practices. Our observations showed that these meetings often lacked a clear structure and a team coordinator or leader. Moreover, various factors appeared to influence the process of interprofessional collaboration. Our programme aimed to provide the interprofessional teams with the support they needed to reflect on their own functioning, with the aim of improving team functioning.

In general, taking part in our programme was well appreciated by the professionals. They reported that the programme had resulted in improved structure and organisation of their meetings. According to them, the greatest progress was made in terms of efficiency, through improved preparation, agenda setting, time use and greater focus. Furthermore, the professionals perceived increased awareness of patient-centredness 
and team processes. Achieving actual behaviour change among professionals regarding patient-centredness appears to be challenging.

Based on the findings, we concluded that both social care and health care professionals from various disciplines may benefit from improved interprofessional collaboration. On the one hand, better coordination and communication of care eases their workload, while on the other, collaboration and consultation with colleagues leads to increased knowledge and insights. Furthermore, interprofessional collaboration seems to increase the professionals' job satisfaction. ${ }^{6}$

\section{Students and lecturers}

In order to be able to collaborate in practice, students have to develop collaborative competences, ${ }^{7}$ which can be acquired during interprofessional education. ${ }^{8}$ In order to enable future health care professionals to develop these competences, Zuyd University of Applied Sciences, and Maastricht University are increasingly paying attention to interprofessional education. In several activities during their studies, the students are being acquainted with aspects of interprofessional collaboration. The collaborative competences are subdivided on the basis of their complexity, and incorporated into the curricula of various study programmes. Shared interprofessional learning appears to work best in small groups, using real-life problems. ${ }^{9,10}$ Findings from the research reported on in this thesis are used to shape the content of the interprofessional training. An example is the module entitled 'Interprofessional team meetings' in which all medical students from Maastricht University rotating in extramural care, and students from Zuyd University studying allied health subjects like speech therapy, occupational therapy, physical therapy, art therapy and nursing take part in a simulated interprofessional team meeting in which they discuss real patients. At each of these meetings, five real life care plans of patients encountered by the five medical students during their internship, are introduced, and discussed with five allied health students. Preliminary evaluations of this activity show that both students and supervisors positively experienced taking part. They mentioned to learn a lot about each other's discipline and especially valued working with real life, authentic cases.

In order to support lectures for the challenging task of guiding students in interprofessional activities, we recently developed and conducted a masterclass. During this masterclass we prepare lecturers to become facilitators for interprofessional education by providing them with practical tools they can use in their lessons and interprofessional activities. 


\section{Health insurance companies}

The findings reported in this thesis underline the importance of interprofessional collaboration and show the role played by external organisations like insurance companies. Health insurers acknowledge the importance of interprofessional collaboration in team meetings. They can play a significant role in encouraging interprofessional collaboration by including it as a precondition for reimbursement in the negations on purchasing care. Currently, reimbursement for participation in interprofessional team meetings is only provided for family physicians, while allied health professionals are expected to attend interprofessional team meetings without any financial reward.

Health care insurance companies therefore should pay attention to their internal organisation and remove interprofessional barriers in order to create a supportive structure and cooperative attitude, enabling an interprofessional care approach. Moreover, insurance companies primarily focus on initiatives that show quantified effects or generate cost savings. Although it is hard to assess the cost-effectives of interprofessional team meetings, we assume that if efficiently conducted, patientcentred interprofessional team meetings will eventually contribute to efficient use of time, and reducing health care costs.

\section{Regional care groups}

Our programme was developed and implemented through action research comprising a process of co-creation with various health care professionals from different primary care practices. In the Netherlands, most of these practices are connected to regional coordinating care groups, some of which acted as partners in recruiting participating practices. These care groups are responsible for providing continuing education mainly to the participating family doctors and practice nurses. Most care groups feel the need to work on interprofessional collaboration, and some have already incorporated a refresher course or training activity on creating awareness of interprofessional collaboration in the activities they offer, based on our programme.

\section{Researchers}

The findings presented in this thesis contribute to the body of scientific knowledge about the process of interprofessional collaboration for care plan development. In addition, the findings offer insights into the challenges as well as the advantages of the different methodologies used in our practice-based research. It appears valuable to conduct a thorough problem analysis, and develop an improvement programme following an iterative process characterized by co-creation with intended users. 
Moreover, various useful themes for future research have emerged from our findings. Conducting the research for this thesis also contributed to the research collaboration between Zuyd University and Maastricht University, resulting in follow-up activities.

Moreover, interprofessional collaboration is also needed in research projects in which researchers from different disciplines, departments or institutions take part. Ingredients of our programme could also be useful for improving the functioning of interprofessional research teams.

\section{Activities and further dissemination}

Given the currently available knowledge and expertise, and the increasing number of questions from people engaged in interprofessional collaboration, it appears valuable for Zuyd University in alliance with Maastricht University to develop a centre of excellence in interprofessional collaboration. This centre of excellence could act as a joint organisation conducting research, disseminating knowledge, and providing support and training in the field of interprofessional care. Together with Zuyd Professional (the commercial division of Zuyd University), we will examine the possibilities for further dissemination in practice. The programme described in this thesis will be disseminated and implemented in various primary care practices through the regional care groups. By means of national and international presentations and articles, we will attempt to raise our profile in other geographic regions and care settings. At the moment several professionals and organisations also from other settings than primary care, nationally as well as internationally, are interested in acquiring our programme and the various tools. Therefore, we intend to examine the programme's suitability and applicability in other settings, like hospitals, community centres and nursing homes, by conducting qualitative needs assessments. At two nursing homes of the Zuyderland organisation, we recently conducted a pilot project aimed at initiating and developing interprofessional team meetings. Based on a thorough needs assessment (including intake interview, observation, and self-assessment), the content of our programme, including training activities and supporting tools, has been adapted to fit the specific nursing home context.

We are also exploring the field outside our geographic region. For example, we recently started to collaborate with the local interdisciplinary network in the Belgian city of Ghent. The findings reported in this thesis will also be applied in the curricula of various undergraduate programmes. Interprofessional collaboration and the development of collaborative competences will become mandatory within the curricula of various educational programmes. An example is that of the interprofessional team meetings 
described above, in which students from various disciplines and types of education take part. To further disseminate our research findings and teach students, a textbook highlighting the various aspects of interprofessional collaboration and education will be written. Dissemination will also be achieved by supporting the development of learning environments in different practices. These environments, known as communities of practice, offer opportunities for both students and professional workers to learn about, from and with each other. ${ }^{11}$

The findings presented in this thesis will also be used as input for other research projects, and will enhance further research collaboration between Zuyd University and Maastricht University. We will also explore possible collaboration with other universities working on interprofessional collaboration, like Windesheim University of Applied Sciences, HAN University of Applied Sciences, Fontys University of Applied Sciences, Radboudumc, and University of Antwerp.

The possibilities for innovative e-Health technology supporting interprofessional collaboration are expanding, ${ }^{12}$ so it seems interesting to explore suitable opportunities for the implementation and integration of e-Health technology to support interprofessional teams. And finally, the development of sustainable interprofessional teams needs a team-friendly healthcare system, including support from the wider organisational context. In order to achieve fundamental changes in the policy and approach of insurance companies regarding remuneration of interprofessional team meetings, they have to be convinced of the added value offered by such meetings. Therefore, follow up studies should examine the actual outcomes of efficient and patient-centred interprofessional team meetings.

As becomes clear, implementation and dissemination are in full swing. However, we have to be aware that we are still at the beginning, and realize that additional research in the field of interprofessional collaboration is needed. 


\section{References}

1. Rathert C, Wyrwich MD, Boren SA. Patient-centered care and outcomes: a systematic review of the literature. Med Care Res Rev. 2013;70(4):351-79.

2. Xyrichis A, Lowton $\mathrm{K}$. What fosters or prevents interprofessional teamworking in primary and community care? A literature review. Int J Nurs Stud. 2008;45(1):140-53.

3. Reeves $\mathrm{S}$, et al. Interprofessional collaboration to improve professional practice and healthcare outcomes. Cochrane Database Syst Rev. 2017;6:CD000072.

4. Stewart M, et al. The impact of patient-centered care on outcomes. J Fam Pract, 2000;49(9):796-804.

5. Huber M, et al. How should we define health? BMJ. 2011;343:d4163.

6. Korner $\mathrm{M}$, et al. Relationship of organizational culture, teamwork and job satisfaction in interprofessional teams. BMC Health Serv Res. 2015;15:243.

7. Barr H. Competent to collaborate: towards a competency-based model for interprofessional education. Journal of Interprofessional Care. 1998;12(2):181.

8. Frenk J, et al. Health professionals for a new century: transforming education to strengthen health systems in an interdependent world. Lancet. 2010;376(9756):1923-58.

9. Nasir J, et al. Case-based interprofessional learning for undergraduate healthcare professionals in the clinical setting. J Interprof Care. 2017;31(1):125-8.

10. Parsell G, Bligh J. Interprofessional learning. Postgrad Med J, 1998;74(868):89-95.

11. Wenger E. Communities of Practice and Social Learning Systems. Organization. 2000;7(2):225-46.

12. de Jong CC, et al. How Professionals Share an E-Care Plan for the Elderly in Primary Care: Evaluating the Use of an E-Communication Tool by Different Combinations of Professionals. J Med Internet Res. 2016;18(11):e304. 


\section{Dankwoord}





\section{Dankwoord}

Toen ik in mei 2012 solliciteerde op de functie van junior-onderzoeker en promovendus wist ik eigenlijk nog niet zo goed wat ik van een promotietraject zou kunnen verwachten. Nu 5 jaar later kan ik zeggen dat het een pittig maar leerzaam traject is waarin je de mogelijkheid krijgt je te verdiepen en jezelf te ontplooien. Ik ben dan ook dankbaar dat ik dit traject heb mogen doorlopen.

Dat interprofessionele samenwerking van belang is voor het kunnen bieden van afgestemde en persoonsgerichte zorg blijkt uit de resultaten van mijn proefschrift. Maar ook voor de totstandkoming van dit proefschrift bleek interprofessionele samenwerking van essentieel belang. Velen hebben hier een bijdrage aan geleverd. Een aantal mensen wil ik in het bijzonder bedanken.

Allereerst mijn (interprofessionele) promotieteam, bestaande uit de promotoren Sandra Beurskens (fysiotherapeut) en Trudy van der Weijden (arts), copromotoren Loes van Bokhoven (huisarts) en Ramon Daniëls (ergotherapeut), en collega-promovenda Stephanie Lenzen (ergotherapeut). De combinatie van disciplines, perspectieven en ervaringen, hebben ons tot een sterk team gemaakt. Zonder het goede teamwerk, jullie adequate begeleiding, enthousiasme en drive zou ik de eindstreep niet hebben behaald.

Sandra. Ik ben je heel dankbaar dat je me in 2012 hebt aangenomen en de kans hebt gegeven dit traject te doorlopen. Jouw enthousiasme heeft me telkens weer gestimuleerd. Je promoot me overal en weet me telkens weer in mijn kracht te zetten. Ik werk ontzettend graag voor en met je!

Trudy. Wat was het fijn om een ervaren iemand als jij aan boord te hebben. Je overziet het geheel en weet de juiste verbindingen te leggen. Je motiverende manier van coachen en feedback geven heb ik altijd erg gewaardeerd.

Loes. Wat een energie heb jij! Ik heb bewondering voor de manier waarop jij al je werkzaamheden combineert en ondanks je volle agenda altijd tijd voor me vrij wist te maken. Je kritische blik en perfectionisme heeft de kwaliteit van de verschillende studies en publicaties telkens weer een boost gegeven. Wanneer voor mij een artikel af was, kwam jij vaak toch nog met een aantal wezenlijke zaken. Ik heb veel van je geleerd, bedankt voor alles wat je voor me hebt gedaan! 
Ramon. Ik apprecieer je oprechte betrokkenheid en inzet voor kwetsbaren in de samenleving. Je hebt me geleerd bewust te zijn van het patiëntperspectief. Je verfrissende blik, en innovatieve ideeën hebben vaak tot nieuw inzichten geleid. Complexe materie wist je door middel van het tekenen van een simpel schema of figuur altijd goed te verhelderen.

Stephie. Gezamenlijk zijn we in 2012 gestart als promovendus. Zeker in het begin van het traject hebben we intensief samengewerkt. We hebben samen onze weg gevonden in de wereld van het onderzoek. Samen hebben we onderzoeksprotocollen geschreven, cursussen gevolgd, en conferenties bezocht. Je was mijn maatje en sparringpartner. Samen met jou had ik het gevoel er niet alleen voor te staan. Bedankt voor je steun!

Naast de leden van mijn promotieteam, zijn er nog een aantal anderen die ik wil bedanken.

Wim. Ik ben erg blij dat Ramon je ergens in 2014 aan me heeft voorgesteld. Naast de inhoudelijke draai die je aan het project hebt gegeven met het invliegen van het IPG model en je expertise rondom groepsdynamica heb ik aan jou een fijne sparringpartner gehad. Je bent dan officieel op papier geen begeleider geweest, toch heb ik van jou de nodige waardevolle coaching en begeleiding ervaren. Ik ben blij dat je me als paranimf bij wil staan tijdens de verdediging. Zie deze rol ook als blijk van waardering voor wat je allemaal voor me hebt betekend.

Stephanie en Prisca en daarvoor ook Marja en Jacqueline. Met de meest uiteenlopende vragen heb ik bij jullie aangeklopt, jullie wisten me altijd goed op weg te helpen. Bedankt voor alle (praktische) steun. Wat zouden we als onderzoekers toch zonder jullie moeten!

Alle deelnemers aan de studies die zijn beschreven in dit proefschrift ben ik bijzonder dankbaar. Een diversiteit aan beroepskrachten, experts, ervaringsdeskundigen en patiënten heeft deelgenomen. In het bijzonder wil ik bedanken Inge Systermans, Lucienne Spaans, Wendy Bemelen en Marcel Schmitz voor hun waardevolle deelname aan het actieonderzoek en de ontwikkeling van het programma. Zonder de medewerking van al deze mensen zou er geen resultaat zijn geweest.

De leden van de klankbordgroep en ontwikkelgroep, dank voor jullie waardevolle inbreng en advies. 
Mijn kamergenoten Linda, Li-Juan, Kyra, Steffy, Darcy, Hester, Stephie, Esther, Ruth en Jolanda. Als enige man in het kippenhok heb ik me staande weten te houden. Op onze kamer heerst altijd een prettige en collegiale sfeer. ledereen helpt elkaar en er is altijd een luisterend oor. Dank voor jullie belangstelling.

Collega's van Zuyd Hogeschool, in het bijzonder de leden van het lectoraat Autonomie en Participatie van Chronisch Zieken, dank voor jullie interesse, steun en advies.

Pieter en Harrie van de AV dienst. Bedankt voor jullie audiovisuele ondersteuning en het ontwikkelen van de diverse (animatie) video's. Harrie, ik heb bewondering voor je creativiteit. Dank ook voor het ontwerpen van de kaft van mijn proefschrift.

Anita. In de laatste fase van mijn promotietraject heb ik meermaals een beroep op je mogen doen. Je hebt me veel praktische tips gegeven. Voor mij was jij in onderzoekstermen een echte 'best practice'.

Albine. Je hebt me ontzettend veel geleerd over kwalitatief onderzoek. Telkens wanneer ik vragen had over methodologie nam je de tijd om me van heldere uitleg te voorzien.

Hester. Op verschillende manieren heb jij een steentje bijgedragen aan mijn proefschrift. In het bijzonder bedankt voor je bijdrage aan de focusgroep studie met patiënten als beschreven in hoofdstuk 6 .

Herbert. Bedankt dat je me de mogelijkheid biedt ook inzichten te verzamelen rondom interprofessioneel samenwerken in de ziekenhuis setting.

De leden van de werkgroep interprofessioneel samenwerken Zuyd Professional: Hub, Rob, Ingrid, Giel, Marcel, Albine, Sandra, Claudy en Wim. Met jullie verken ik de mogelijkheden voor disseminatie van mijn onderzoeksbevindingen in de praktijk. Dank voor de inspirerende bijeenkomsten.

Collega's van de vakgroep huisartsgeneeskunde dank voor jullie belangstelling en collegialiteit. Ondanks het feit dat ik maar sporadisch aanwezig was in Maastricht heb ik me bij jullie altijd thuis gevoeld.

Ine. In het creëren van dat thuisgevoel had jij een groot aandeel! Bedankt voor al je steun en praktische hulp. 
Silvia. Als onderzoeksassistent heb je me op verschillende fronten ondersteund. We hebben tijdens de data-verzameling samen diverse teamoverleggen geobserveerd en professionals geïnterviewd. Verder heb je me enorm geholpen met de analyse van alle kwalitatieve data in Nvivo. Ik heb met heel veel plezier met je samengewerkt en vind het fijn hoe oprecht geïnteresseerd je altijd in me bent.

Anneke. Als eerste promovenda van Loes heb je de lat wel heel erg hoog gelegd. Voor mij ben je altijd het grote voorbeeld geweest. Je hebt me op diverse fronten geholpen en geadviseerd. We hebben samen overleggen geobserveerd, geanalyseerd en bijeenkomsten georganiseerd. In het bijzonder wil ik je bedanken voor het feit dat ik mee heb mogen werken aan een van je studies welke ik heb mogen includeren als hoofdstuk 9 van mijn proefschrift.

Wencke. Als onderdeel van je traineeship bij Zuyd heb je me ondersteund bij het uitvoeren van mijn literatuurstudie. Honderden artikelen heb je op titel en abstract gescreend. Ook bij het analyseren van de artikelen en vervolgens beschrijven van de resultaten heb je een waardevolle bijdrage geleverd.

Iris. Gedurende je WESP stage heb je onderzoek gedaan naar patiëntparticipatie tijdens interprofessioneel teamoverleg. Mede door jouw inzet hebben we waardevolle informatie over patiëntparticipatie weten te verzamelen.

Manon. Als werkstudent van Zuyd heb ik meerdere malen een beroep op je gedaan. Je hebt diverse interviews en focusgroepen met grote nauwkeurigheid getranscribeerd.

Maarten. Samen met jou heb ik de focusgroepen met patiënten georganiseerd. Ik waardeer je inzet en betrokkenheid voor het patiëntperspectief.

Esther. Als belangenbehartiger van de patiënt vanuit Huis voor de Zorg heb je op meerdere momenten een bijdrage geleverd aan mijn proefschrift. Je was lid van de klankbordgroep, hebt meegedaan aan een focusgroep en hebt meegewerkt aan de studie die beschreven is in hoofdstuk 6. Ik werk graag met je samen en waardeer je inzet voor mensen in een kwetsbare positie.

Clementine. Samen hebben we mijn onderzoeksbevindingen en -producten vertaald naar de setting van het verzorgingshuis. Het was erg leuk om samen met jou de pilot bij Zuyderland te mogen doen. 
Arie. Jij hebt me wegwijs gemaakt in de wet- en regelgeving rondom het delen van patiënt-gerelateerde informatie. Ik heb de samenwerking rondom het publiceren van ons artikel als bijzonder prettig en leerzaam ervaren.

Tiny. Bedankt voor de mooie lay-out van mijn proefschrift. De service die jij levert is super!

Jan. Dank voor het redigeren en corrigeren van de Engelse taal van mijn artikelen. Ik waardeer je snelle, vakkundige en adequate aanpak.

Jeroen. Vanuit je rol als implementatiemanager bij Egpo heb ik je leren kennen. Regelmatig hebben we overleg waarin we elkaar informeren en inspireren. Ik hoop in de toekomst onze samenwerking op deze manier te kunnen blijven voortzetten.

Jhoy. Hoewel je niet direct betrokken bent geweest bij mijn promotietraject, wil ik je hier toch noemen. Je bent een geweldige collega, ik leer veel van je en werk met veel plezier met je samen.

Mijn ex-collega's van de stafgroep LAB Maastricht UMC, in het bijzonder Daphne. Bedankt voor jullie interesse en de flexibiliteit en ruimte die jullie me destijds hebben geboden om het werken als productie controller in het ziekenhuis te kunnen combineren met mijn promotietraject.

De leden van de beoordelingscommissie Prof. Jean Muris, Prof. Diana Dolmans, Prof. Dirk Ruwaard, Dr. Carolien Smits, Prof. Paul van Royen, bedankt voor het beoordelen van mijn proefschrift. Prof. Mirjam Oude Egbrink en Dr. Mitchel van Eeden fijn dat jullie deel willen uitmaken van de promotiecommissie.

Mijn vrienden en (schoon)familie, te veel om allemaal apart te benoemen. Ik dank jullie voor de interesse die jullie in me tonen.

Michel. We zijn al heel wat jaren bevriend, hebben bij elkaar in de klas gezeten, samen gevoetbald, op vakantie geweest en heel wat biertjes gedronken. Twee jaar geleden was ik jouw paranimf, maar nu zijn de rollen omgedraaid. Fijn dat jij mijn paranimf wil zijn.

Mijn schoonfamilie. Guy en Marie-Jose, Lieke, Stan en Carol. Na een week hard werken kijk ik altijd uit naar de vrijdagavond waarop we gezellig samen zelfgemaakte frieten van Marie-Jose eten. Dank voor jullie interesse in mijn werk en voor de steun en hulp die jullie mij, Anne en Rim bieden. Geweldig hoe jullie altijd voor ons klaar staan! 
Mijn broertje en beste vriend Jules en zijn vrouw Lisa. Ondanks dat jullie in Amerika wonen en we elkaar niet zo vaak zien hebben we een ontzettend goede band. Jules, ik heb erg genoten van ons tripje naar Canada, waar ik het bezoek aan de Collaborating Across Borders conferentie heb kunnen combineren met een mini-roadtrip met jou.

Mijn lieve ouders Jack en Josée. Jullie hebben me van kleins af aan gestimuleerd mezelf te ontplooien. Jullie hebben me de faciliteiten en mogelijkheden geboden om te kunnen studeren en te worden wie ik nu ben. Voor moeilijkheden of lastige keuzes vond ik bij jullie altijd een luisterend oor en advies. Mede door jullie onvoorwaardelijke steun sta ik nu hier.

Lieve Anne, al ruim 6 jaar ben je mijn vriendin. Je staat altijd voor me klaar, bent erg zorgzaam en zorgt voor een goede thuisbasis. Jij helpt me te relativeren en zorgt ervoor dat ik een goede balans tussen privé en werk weet te vinden. Je motiveert en geeft me zelfvertrouwen. Met jou aan mijn zijde sta ik sterk! Samen en met veel hulp van familie en vrienden hebben we ons droomhuis kunnen (ver)bouwen. Een prachtig huis waar jij vervolgens ons thuis van hebt gemaakt. Maar...ons leven werd nóg completer en mooier dan het al was met de geboorte van Rim.

Allerliefste Rim. Vrolijk mannetje. Elke dag met jou is een feestje. Ik ben trots dat ik je pappa mag zijn!

...in mei staat ons gezinnetje weer een promotie te wachten...

Rim zal dan zijn kleine broertje of zusje verwachten! 
About the author 



\section{About the author}

Jerôme van Dongen was born on 7 December 1986 in the Dutch town of Geleen. He grew up in Meerssen, where he lived with his younger brother Jules and parents Jack and Josée. In 2005 he graduated from secondary school (Atheneum), at the Stella Maris College in Meerssen. He studied health sciences at Maastricht University and graduated as a Master of Health Policy Economics and Management, with a thesis about anticipating demand and supply at the outpatient clinic of the St. Elisabeth Hospital in Tilburg.

After graduation in 2009, he started working as a production controller at Maastricht University Medical Centre, where he worked for seven years. In 2012, he

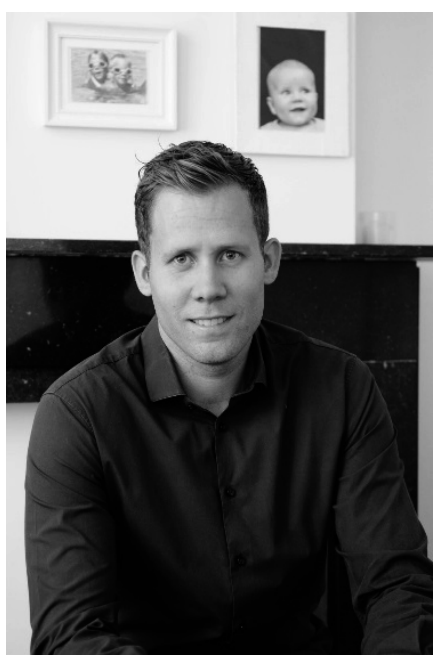
started working at Zuyd University of Applied Sciences as a junior researcher on a PhD research project that resulted in this thesis. This is a collaborative project of the Research Centre on Autonomy and Participation of Persons with a Chronic Illness of Zuyd University and the Department of Family Medicine, CAPHRI School, at Maastricht University.

During the PhD project he continued working as a production controller at Maastricht University Medical Centre, until 2016, when he started working on a second research project, named 'Optimal social support of citizens'. In the context of this project he is studying the implementation and working procedures of the new Dutch social support act.

Currently, his work involves a combination of research and lecturing at the Research Centre for Community Care at Zuyd University, and the Department of Family Medicine at Maastricht University. The focus of his work is on the dissemination of the findings of his thesis. The topics he is interested in include interprofessional collaboration and education, team functioning, community care and the social support act.

Jerôme lives in Meerssen, the Netherlands, together with his girlfriend Anne Pinckaers and their son Rim. 
List of publications, presentations and workshops 


\section{List of publications, presentations and workshops}

\section{International peer-reviewed publications}

- van Dongen JJ, Lenzen S, van Bokhoven MA, Daniëls R, van der Weijden T, Beurskens A. Interprofessional collaboration regarding patients' care plans in primary care: a focus group study into influential factors. BMC Family Practice. 2016. 17:58

- van Dongen JJ, van Bokhoven MA, Daniëls R, van der Weijden T, Emonts WWGP, Beurskens A. Developing interprofessional care plans in chronic care: a scoping review. BMC Family Practice. 2016

- Lenzen S, van Dongen JJ, Bokhoven MA, Daniëls R, van der Weijden T, Beurskens A. What does it take to set goals for self-management in primary care? A qualitative study. Family practice. 2016

- van Dongen JJ, van Bokhoven MA, Daniëls R, Lenzen S, van der Weijden T, Beurskens A. Interprofessional primary care team meetings: a qualitative approach comparing observations with personal opinions. Family Practice. 2017. 34(1), 98-106

- van Dongen JJ, Habets I, Beurskens A, van Bokhoven MA. Successful participation of patients in interprofessional team meetings: A qualitative study. Health Expectations. 2016

- $\quad$ van Dijk A, van Dongen JJ, van Bokhoven MA. Sustainable interprofessional teamwork needs a team-friendly healthcare system. Journal of Interprofessional Care. 2017. 31(2): 167-169

- $\quad$ van Dongen JJ, de Wit M, Smeets H, Stoffers E, van Bokhoven MA, Daniëls R. "They Are Talking About Me, but Not with Me": A Focus Group Study to Explore the Patient Perspective on Interprofessional Team Meetings in Primary Care. The Patient. 2017

- van Dongen JJ, van Bokhoven MA, Goossens WNM, Daniëls R, van der Weijden T, Beurskens A. Development of a customizable programme for improving interprofessional team meetings. An action research approach. International Journal of Integrated Care. (Under review)

- van Dongen JJ, van Bokhoven MA, Goossens WNM, Daniëls R, van der Weijden T, Beurskens A. Suitability of a programme for improving interprofessional primary care team meetings. Journal of Interprofessional Care. (Submitted)

\section{National publications}

- $\quad$ van Dongen J, van Bokhoven L. Vergeet de voorzitter niet! Tijdschrift voor verpleegkundig experts. 2015. 5: 19-20 
- Cobben C, van Dongen J, van Bokhoven L, Daniëls R. Best practices interprofessionele samenwerking. Tijdschrift voor praktijk ondersteuning. 2016. 1: 611

- van Dongen J, de Jong A, van Bokhoven L. Patiëntinformatie delen: Wat mag wel, wat niet? Tijdschrift voor verpleegkundig experts. 2017. 1: 48-51

- $\quad$ van Dongen J, de Jong A, van Bokhoven L. Interprofessioneel teamoverleg: Wat mag wel en niet rond het delen van patiënt informatie? Op één lijn. 2017. 1: 36-39

- $\quad$ van Dongen J, Dassen J. Drie pijlers van vraagverheldering. WMO Magazine. 2017. 5(2): 11-13

- Dassen J, van Dongen J. Wie is de eigenaar van de oplossing?. WMO Magazine. 2017. 6(3): 18-21

- $\quad$ van Dongen J, Dassen J. Monitoring: Essentieel in ondersteuning burger. WMO Magazine. 2017. 9(4): 18-21

- van Dongen J, Cobben C, van Bokhoven L, Daniëls R. Best practices interprofessionele samenwerking. Boekbijdrage in: Innovatieve teams en interprofessionalisering. Uitgeverij Coutinho. In progress.

- $\quad$ Post G, Edelbroek H, Mijnders, M. Interdisciplinary Learning Activities. Boekbijdrage door Smeets H, van Dongen J, Lierop M, Janssen M, Moser, A. Amsterdam University Press. In progress.

\section{Oral presentations}

- Current practice, factors, and barriers of interprofessional collaboration concerning tailored goal setting. EACH Conference, Amsterdam. September 2014.

- Interprofessionele zelfmanagement ondersteuning in de eerste lijn. Onderzoeksmeeting, Leuven. Juni 2015.

- $\quad$ Samenwerking en communicatie. Symposium geriatrie netwerk westelijke mijnstreek, Sittard. November 2015.

- Efficiënt en effectief interprofessioneel teamoverleg. Mini symposium Egpo, Roosmalen. December 2015.

- $\quad$ IPOS module interprofessioneel teamoverleg. NFU symposium, Utrecht. Juni 2016.

- Interprofessioneel samenwerken. Nascholingsbijeenkomst ZIO, Maastricht. September 2016

- Interprofessional team meeting. National Interdisciplinary Education Conference, Amsterdam. Februari 2017.

- Interprofessioneel samenwerken. Opening Zorginnovatiewinkel, Maastricht. Maart 2017. 
- Improving collaboration in interprofessional primary care teams. CARE4 Conference, Antwerpen. Februari 2017.

- Interprofessioneel teamoverleg in de eerstelijn. NHG-Wetenschapsdag, Utrecht. Juni 2017.

- Leren interprofessioneel samenwerken tijdens teamoverleg. NHG-Wetenschapsdag, Utrecht. Juni 2017.

- Quickscan interprofessionele samenwerking. IPOS-dag Zuyd, Heerlen. Juni 2017.

- Development of a customizable programme for improving interprofessional team meetings: An action research approach. EIPEN Conference, Laussanne (Zwitserland). September 2017.

- They are talking about me, but not with me: Patient perspective on interprofessional team meetings in primary care. EIPEN Conference, Laussanne (Zwitserland). September 2017.

- The chairperson as change agent. Developing and evaluating a programme for improving interprofessional team meetings in primary care. Collaborating Across Borders Conference (CAB), Banff (Canada). Oktober 2017.

\section{Poster presentations}

- Interprofessional collaboration concerning tailored goal setting. CAPHRI research day, Maastricht. December 2015.

- Improving collaboration in interprofesisonal team meetings. ICCH Conference, Heidelberg. September 2016.

\section{Workshops}

- Samenwerken rondom de doelen van de cliënt. Ergotherapie congres, Utrecht. November 2013.

- Interprofessional collaboration concerning tailored goal setting. EIPEN Conference, Nijmegen. Augustus 2015.

- Interprofessioneel samenwerken. Symposium academische werkplaats ouderenzorg Zuid-Limburg, Sittard. September 2016.

- Interprofessionele samenwerking boven en onder de waterspiegel. Mini-symposium Zorginnovatiewinkel, Maastricht. Maart 2017. 
